\title{
water
}

\section{Flood Risk \\ Governance for \\ More Resilience}

Edited by

Piotr Matczak and Dries L. T. Hegger Printed Edition of the Special Issue Published in Water 
Flood Risk Governance for More Resilience 



\section{Flood Risk Governance for More Resilience}

Editors

Piotr Matczak

Dries L. T. Hegger 


\section{Editors}

Piotr Matczak

Adam Mickiewicz University

Poland
Dries L. T. Hegger

Utrecht University

The Netherlands

\section{Editorial Office}

MDPI

St. Alban-Anlage 66

4052 Basel, Switzerland

This is a reprint of articles from the Special Issue published online in the open access journal Water (ISSN 2073-4441) (available at: https://www.mdpi.com/journal/water/special_issues/Flood_Risk_ Governance_Resilience).

For citation purposes, cite each article independently as indicated on the article page online and as indicated below:

LastName, A.A.; LastName, B.B.; LastName, C.C. Article Title. Journal Name Year, Article Number, Page Range.

ISBN 978-3-03943-196-0 (Hbk)

ISBN 978-3-03943-197-7 (PDF)

Cover image courtesy of Adam Choryński.

(C) 2020 by the authors. Articles in this book are Open Access and distributed under the Creative Commons Attribution (CC BY) license, which allows users to download, copy and build upon published articles, as long as the author and publisher are properly credited, which ensures maximum dissemination and a wider impact of our publications.

The book as a whole is distributed by MDPI under the terms and conditions of the Creative Commons license CC BY-NC-ND. 


\section{Contents}

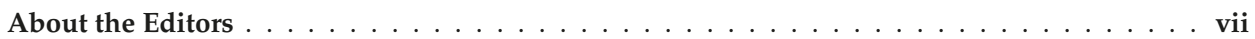

Preface to "Flood Risk Governance for More Resilience" $\ldots \ldots \ldots \ldots \ldots$. . . . . . ix

Piotr Matczak and Dries L. T. Hegger

Flood Risk Governance for More Resilience-Reviewing the Special Issue's Contribution to

Existing Insights

Reprinted from: Water 2020, 12, 2122, doi:10.3390/w12082122 _ . . . . . . . . . . . . . 1

Astrid Molenveld and Arwin van Buuren

Flood Risk and Resilience in the Netherlands: In Search of an Adaptive Governance Approach

Reprinted from: Water 2019, 11, 2563, doi:10.3390/w11122563 . . . . . . . . . . . . 13

Jacomien den Boer, Carel Dieperink and Farhad Mukhtarov

Social Learning in Multilevel Flood Risk Governance: Lessons from the Dutch Room for the

River Program

Reprinted from: Water 2019, 11, 2032, doi:10.3390/w11102032 _ . . . . . . . . . . . 33

Silvana Ilgen, Frans Sengers and Arjan Wardekker

City-To-City Learning for Urban Resilience: The Case of Water Squares in Rotterdam and Mexico City

Reprinted from: Water 2019, 11,983, doi:10.3390/w11050983 . . . . . . . . . . . . . 51

Romy C. Brockhoff, Steven H.A. Koop and Karin A.W. Snel

Pluvial Flooding in Utrecht: On Its Way to a Flood-Proof City

Reprinted from: Water 2019, 11, 1501, doi:10.3390/w11071501 . . . . . . . . . . . . . 73

Ralf Nordbeck, Lukas Löschner, Melani Pelaez Jara and Michael Pregernig

Exploring Science-Policy Interactions in a Technical Policy Field: Climate Change and Flood Risk Management in Austria, Southern Germany, and Switzerland

Reprinted from: Water 2019, 11, 1675, doi:10.3390/w11081675

Md Ruknul Ferdous, Anna Wesselink, Luigia Brandimarte, Kymo Slager,

Margreet Zwarteveen and Giuliano Di Baldassarre

The Costs of Living with Floods in the Jamuna Floodplain in Bangladesh

Reprinted from: Water 2019, 11, 1238, doi:10.3390/w11061238 . . . . . . . . . . . . . . 117

Flavia Simona Cosoveanu, Jean-Marie Buijs, Marloes Bakker and Teun Terpstra

Adaptive Capacities for Diversified Flood Risk Management Strategies: Learning from

Pilot Projects

Reprinted from: Water 2019, 11, 2643, doi:10.3390/w11122643.

Sungju Han and Christian Kuhlicke

Reducing Hydro-Meteorological Risk by Nature-Based Solutions: What Do We Know about People's Perceptions?

Reprinted from: Water 2019, 11, 2599, doi:10.3390/w11122599 _ . . . . . . . . . . . . 161

\section{Mathilde Gralepois}

What Can We Learn from Planning Instruments in Flood Prevention? Comparative Illustration to Highlight the Challenges of Governance in Europe

Reprinted from: Water 2020, 12, 1841, doi:10.3390/w12061841 _ . . . . . . . . . . . . 185 



\section{About the Editors}

Piotr Matczak Mickiewicz University in Poznan (Poland). He publishes on flood risk governance, adaptation to climate change, ecosystem services, crisis management and sustainable development. He is a member of The Commission of Climatology, Water Resources, and Air Quality Protection of the Poznan Branch of the Polish Academy of Sciences. He has been engaged in several EU and Polish National Science Centre funded research projects as principal investigator and coordinator of work packages.

Dries L. T. Hegger is an Assistant Professor in Regional Water and Climate Governance at UU's Copernicus Institute of Sustainable Development. He studies modes of environmental governance and their relationship with resilient and sustainable urban development. He has been involved in several national and international projects on flood risk governance (EU-FP7 STAR-FLOOD; JPI-CLIMATE TRANS-ADAPT), on knowledge co-creation in regional climate adaptation (Dutch National Research Program Knowledge for Climate), on relationships between water companies and consumers (funded by Dutch drinking water companies) and on innovation in wastewater management systems in a Western context (nationally funded). All his past projects have involved extensive stakeholder engagement, leading to an equally extensive network of national and international governmental, business and civil society organizations. 



\section{Preface to "Flood Risk Governance for More Resilience"}

Resistance-based strategies for flood risk management (FRM), which are based on controlling floods via structural infrastructure, laws and regulations, have been increasingly challenged in the last 20 years. Instead of seeking to build 'fail-safe' systems that remove the threat and try to minimize societal and economic losses, new approaches are being developed that are considered 'safe-to-fail'. These approaches embrace uncertainty and put emphasis on adaptation instead of control. Such resilience-based approaches address the need to absorb water and recover from floods, and focus on the potential of societal systems to transform in response to stressors. There is emerging evidence that a diversification of flood risk management strategies contributes to more flood resilience. The idea is that a roster of strategies is applied: addressing flood risk prevention through pro-active spatial planning, flood defence, flood mitigation, flood preparation and flood recovery. Recent research efforts have significantly contributed to knowledge on the mechanisms through which a diversification and alignment of strategies may take place in different contexts. Different sub-themes have attracted attention. Firstly, the role of citizens and stakeholders in FRM has been investigated in terms of public participation, collaboration, co-production, communication and perception of flood risk, amongst other topics. Secondly, FRM policies have been analysed, investigating their structures, assumptions and limitations. In addition, the application of policies as well as their feasibility and performance have been scrutinized. Thirdly, there are studies on particular FRM measures and tools, dealing with their applicability to policies and decision making. A cross-cutting issue in this area of research is the role of governance. FRM has become an increasingly reflexive policy domain. Initially, FRM relied on top-down decisions, but these have become much more embedded in a dense network of relations, with stakeholders holding various powers, resources and competences. These present-day developments lead to several emerging questions about the role of governance in FRM: How do we integrate traditional resistance-based measures with non-structural approaches? How would cooperative natural-social sciences research advance the role of governance in building flood resilience? How do we (re)conceptualize resilience to capture the governance and the resistance aspects of FRM? How could social experimentation approaches transform FRM? How do we frame FRM to identify win-win situations where environmental (e.g., biodiversity conservation) and social (e.g., equality) aims are integrated? The ten papers collected in this book look critically at flood risk governance, unpack the issues discussed above and identify important new research areas. Case studies have been derived from Europe, America and Asia in order to produce novel theoretical and methodological insights enriching our understanding of new approaches to flood risk governance.

Piotr Matczak, Dries L. T. Hegger 



\title{
Editorial \\ Flood Risk Governance for More Resilience-Reviewing the Special Issue's Contribution to Existing Insights
}

\author{
Piotr Matczak ${ }^{1, *}$ and Dries L. T. Hegger ${ }^{2}$ \\ 1 Faculty of Sociology, Adam Mickiewicz University, 60-568 Poznan, Poland \\ 2 Copernicus Institute of Sustainable Development, Utrecht University, 3584 CB Utrecht, The Netherlands; \\ d.l.t.hegger@uu.nl \\ * Correspondence: matczak@amu.edu.pl
}

Received: 25 June 2020; Accepted: 23 July 2020; Published: 26 July 2020

\begin{abstract}
There is lively scholarly and societal debate on the need to diversify flood risk management strategies to contribute to more flood resilience. The latter requires dedicated governance strategies related to which relevant insights are currently emerging. However, more systematic theoretical and empirical insights on how to specify and implement governance strategies are still urgently needed. The Special Issue 'Flood Risk Governance for More Resilience' has brought together nine contributions by renowned flood risk governance scholars that together help to unpack lessons about these governance strategies. This Special Issue's editorial introduces the debate on flood risk governance for more resilience and presents the key findings of the individual contributions to the Special Issue. We show that flood risk governance arrangements in specific regions in the Netherlands, Germany, Switzerland, Bangladesh, France, and Mexico are gradually evolving. A common denominator is that more horizontal forms of governance are under development in which a more diverse array of public and private actors-including citizens, as well as different sectors, is becoming involved. Efforts are underway to establish connectivity between actors, levels, and sectors, both through regional and international exchanges. While lessons on how to do the former successfully are emerging, we notice that these should still be unpacked more fully. Moreover, there is still a need to establish a more open and inclusive societal debate on societal preferences regarding flood risk protection in which all actors with a stake in flood risk governance processes and outcomes can participate.
\end{abstract}

Keywords: flood risk governance; resilience; adaptation; learning; science-policy interactions; interdisciplinarity

\section{Introduction: Debate on Resilient Flood Risk Governance}

Flood risks have been increasing worldwide in the last decades. As a result, fundamental and long-lasting assumptions in our understanding of how to deal with floods are being questioned [1-3]. A basic tenet of water managers used to be that physical conditions are relatively stable. However, climate change induces changes in the very nature of these physical conditions [4]. Second, ongoing urbanization exacerbates flood risks in many regions, mostly in deltas [5]. Third, it is increasingly argued that flood risk management cannot be organized solely in a top-down fashion, with national governments, in particular their offices of Public Works, in a leading position [6]. Recent insights show that the long-held belief in our capacity to control natural processes and the wish to adopt managerial reactions have missed the point. Fourth, in accordance with the more general transformation in functioning of public administrations, starting with the participatory revolution in the 1970s, new actors and social groups aspired to have a voice in flood management. On top of all this, since the 1980s, market-based logics have been introduced to the formerly state-controlled water sector. These four 
factors challenge the predict-and-control approach that was dominant in flood risk management until recently.

The notion of flood risk governance (FRG) was coined in this respect, depicting a new organizational approach [6], which addresses the turn from flood defense to flood risk management $[7,8]$ and the growing role of previously disregarded stakeholders. Bergsma [3] treats FRG as a distinctly different form of dealing with floods as compared with the welfare state model that forms the backbone of more traditional approaches. First of all, the models differ in terms of the values they rely on. The welfare state model assumes that a centralized actor takes care of the public interest and collects resources to achieve this aim. A basic principle of this model is that flood managers should provide security defined as, ideally, absolute protection. Contrary to the welfare state model, the FRG value system implies that a wide array of public and private actors, including the ones at the local level, becomes involved in FRG. Such diversification of the actor base is expected to allow for cost sharing and more efficient information exchange. Additionally, and more widely debated, the FRG model accepts that not all floods can always be prevented and there will be inevitable losses. The task is to manage these losses by minimizing them in order to make them acceptable. In this respect, Kundzewicz et al. [9] write about the need to move from a 'fail-safe' system to a system that is 'safe-to-fail'.

The involvement of multiple actors, levels, and sectors in FRG implies that multiple types of solutions, but also potentially competing interests, are brought to the table. This makes governance systems more network-like, as opposed to a top-down management setting based on a deterministic view of nature and social life. We witness the effects of this in practice. On the policy level, the discussions on available flood risk management options have started to become more open for stakeholders willing to participate. More often than not, skilled and professionally trained hydrologists have started to be one of the involved groups instead of the ultimate solution provider. As part of this overall shift towards more multi-actor and decentralized governance, as observed in several countries [10], the need for participatory processes has been institutionalized in legal systems. Mandatory stakeholder consultation on implementation, as laid down within the EU Water Framework Directive, is a case in point. Participatory processes in a European context also received a boost through the Aarhus Convention that establishes rights of the public to access environmental information, public participation and justice (https://ec.europa.eu/environment/aarhus/).

Within the flood risk governance debate, new concepts were incorporated. Notably, the notion of resilience has been translated from the field of ecology in which it emerged. In the past years, the resilience notion has been specified for the floods domain, systematically unpacked and translated into governance strategies $[5,10,11]$. A core tenet of thinking in terms of flood resilience is to search for integrated flood risk management approaches that comprise multiple probability and consequence-reducing strategies. These strategies need to be adjusted to local conditions [5,8,10]. A diversity of strategies is key to advancing flood resilience [11]. The discussion on flood risk governance for more resilience requires input from different perspectives and is therefore inherently multi-disciplinary [8]. Besides hydrological and technical sciences, perspectives of public administration, law, human geography, ecology, amongst others also have the potential to contribute to advancements of more resilient governance settings.

The Special Issue 'Flood Risk Governance for More Resilience' aims to build on the emerging insights referred to above. Apart from the editorial, it includes nine papers from diverse geographical contexts that adopt a diversity of multi-disciplinary perspectives. The current paper provides an overview of the Special Issue and reflects on its contribution to the existing state of the art. In order to do so, section two first provides a rough sketch of current knowledge on flood risk governance for more resilience by discussing some recent well-informed contributions to the debate. This leads to the identification of relevant insights, but also apparent knowledge gaps regarding the aforementioned roles of citizens and stakeholders, FRM policies and measures, and tools. Section three presents the key findings of each of the nine papers in the Special Issue. In section four, we wrap up by reflecting on the 
papers' joint contribution to the identified knowledge gap and present a revised research agenda for studies into resilient flood risk governance.

\section{State of the Art: Knowledge Gaps and Proposed Future Directions in FRG Literature}

\subsection{Knowledge Gaps in FRG Literature}

A growing literature has explored the application and specification of the resilience concept to the floods domain. In 2018, Morrison et al. [12] assessed the last decade of scholarship in this field and from this distilled five key avenues for further inquiry:

1. Stakeholder engagement is an often-explored topic. The role of citizens and stakeholders and methods of citizen and stakeholder involvement in FRM have been investigated in terms of public participation, collaboration, co-production, communication between groups, networks, relations between stakeholders and governmental agencies, and perceptions of flood risk, amongst other themes [13-16].

2. Flood risk management policies and their changes have been analyzed in terms of their assumptions, consequences, and alternatives. This critical literature relies on particular cases or explores possibilities for shallow modifications of FRG policies or more profound paradigmatic change.

3. FRG policies have been analyzed in terms of their implementation, feasibility, performance, investigating their structures, assumptions, and limitations.

4. A significant body of literature focuses on tools for modeling and predicting the direct and indirect effects of flood risk. A large part of this research lies within the natural and engineering sciences.

5. There is an emerging body of literature on governance frameworks. This body of literature analyses integrative organizational, conceptual, and research environments enabling or hampering FRG practices [5].

While Morrison et al. focused on scholarship pertaining to governance for more resilience, McClymont et al. [8] centered more on the dependent variable of what resilience entails and what it is that should be made more resilient. They differentiate between three conceptualizations of flood resilience employed by scholars: engineering resilience, systems resilience, and complex adaptive systems resilience. The authors observe that seldom are all three frameworks taken into account in the analyses, with only $15 \%$ of papers covering all three frameworks. In addition, the authors found that studies are restricted in terms of the precise topics they include as elements of resilience. For example, they observe that at larger spatial scales, resilience is often used interchangeably with resistance, a concept with a different normative starting point. Another case in point is that in terms of flood risk management strategies, studies often focus on flood recovery.

According to McClymont et al. [8], a key knowledge gap is the actual and necessary division of responsibilities between actors. They notice a shift in responsibilities from state protection to individual responsibility [3]. They argue, though, that this shift is highly geographically and institutionally situated. Processes leading to or hampering resilience can be strikingly different in the well-developed countries and in the Global South. In addition, across contexts, top-down and bottom-up approaches in building resilience need to be combined in a multi-level governance framework. The authors note that the aforementioned issues are being experimented with in practice, but we still lack systematic insights on how to allocate responsibilities.

The contributions by Morrison et al. [12] and McClymont et al. [8] provide an overview of important knowledge gaps and challenges for research. Morrison et al. emphasize that more specific insights are needed to enhance connectivity in several respects in order to address (institutional) fragmentation: (1) They point at the need to better connect natural and social science-based contributions. Now they are often separated, amongst other reasons because they are fueled by different flows of research funding. (2) They observe that knowledge-action networks need to be strengthened to improve the 
science-policy interface in flood risk governance. (3) They point out the need to establish connectivity between professionals and stakeholders and see a lack of tools to address this social dimension of flooding. (4) They point out the need to integrate insights arising from governance research and governance models external to the floods domain into flood risk management literature.

Morrison et al. [12] acknowledge that some progress has been made in relation to the aforementioned knowledge gaps. They show that studies on modeling tools and on stakeholder engagement and public participation have been getting increasing attention. In addition, notable advances have been made regarding the translation of governance-related knowledge to the floods domain. Nevertheless, more progress is still to be made and, in particular, the operationalization of flood resilience requires more research, as also argued by McClymont et al. [8].

\subsection{Proposed Future Directions in FRG Policy and Practice}

While engaging with the aforementioned debate on flood risk governance for more resilience, Driessen et al. [5] proposed six governance strategies for improving flood resilience in the face of climate change. These have been identified based on comparative empirical research in a European context; hence, these lessons have been empirically validated to some extent, albeit mostly for Europe.

1. Pursue a context-sensitive diversification of strategies: it has been shown that relying on a roster of strategies is conducive to flood resilience, but not all strategies are equally feasible and desirable in all contexts [10].

2. Establish connectivity: flood risk management strategies should be linked together and aligned, not stay isolated. Involvement of different sectors (water management/spatial planning/disaster management) is needed [12].

3. Involve a wide array of public and private actors: flood risk governance, especially the implementation of strategies other than flood defense, requires increased involvement of private actors including residents, businesses, and NGOs.

4. Issue adequate rules and regulations: rules and regulations that provide legal certainty and respect the rule of law, but at the same time, allow for future flexibility are needed.

5. Ensure that a diversity of financial and non-financial resources is present. In terms of finances, partnership funding, as has been thoroughly assessed in a UK context, is a noteworthy development [17]. In terms of non-monetary resources, the development of tailor-made climate services that may help translate science into action is a prominent recent development [18].

6. Initiate open and inclusive societal debate. This is expected to lead to the adoption of certain normative principles as the outcome of a political discussion.

These strategies have some degree of generalizability as they have been validated in different contexts in Europe while their validity in other contexts is plausible. To the best of our knowledge, these strategies constitute the most encompassing overview of necessary improvements in flood risk governance literature and practice. Therefore, the current paper uses these strategies to organize the key findings of the Special Issue.

\section{Logic and Outline of the Special Issue}

In this Special Issue, nine papers deal with various aspects of 'Flood Risk Governance for More Resilience'. Eight papers cover a variety of cases in different countries while one paper is a review paper. Section 3.1 first discusses the key findings of each of the nine papers in the Special Issue in turn. Next, Section 3.2 links these key findings to the six aforementioned governance strategies for improving flood resilience and discusses the contribution of each paper to these strategies. 


\subsection{A Summary of Papers of the Special Issue}

3.1.1. Flood Risk and Resilience in the Netherlands: In Search of an Adaptive Governance Approach

Astrid Molenveld and Arwin van Buuren [19] have analyzed the discursive shift towards more resilience-based approaches in the Netherlands that took place at the end of the 2000s as well as its implications for flood risk governance practice. At that time, the multilayered safety concept (MLS) was coined and started to be discussed. MLS is a policy concept designed for adaptive flood risk management in the Netherlands. The authors took an innovative conceptual approach by using Elinor Ostrom's Institutional Analysis and Design (IAD) framework to analyze this shift. Relying on her polycentric and adaptive governance framework, they were able to point out a concrete timing of the shift, as they compared the FRG approaches before and after the year 2008. The multi-layered safety approach was introduced as a part of the Dutch Delta Program. It aimed to produce more adaptive FRG as it involved a more polycentric and loosely structured institutional regime. This new regime was to be more inclusive and it was to stem from collaboration of wide set of stakeholders. The 'multilayered safety' policy was intended to be loose but in practice it was found to be fairly tight, i.e., a system where rules strictly determine adaptation action. Authors attribute this relative failure to the fact that dealing with floods has deliberately been presented as a 'tame' problem for decades, which means that existing solutions turned into an institutionalized and hard to change routine. As the authors conclude, 'adopting a more adaptive and polycentric approach necessitates 'untaming' the issue of flood safety'. Issues that have been taken for granted need to be put on the table for discussion in an open debate.

3.1.2. Social Learning in Multilevel Flood Risk Governance: Lessons from the Dutch 'Room for the River Program'

Learning and accumulation of knowledge among actors is widely acknowledged [20] as crucial for water and flood risk governance in particular. Jacomien den Boer, Carel Dieperink and Farhad Mukharov [21] looked at factors influencing learning processes. The authors analyze the example of the Dutch 'Room for the River Program' to identify enabling conditions for social learning in multi-level flood risk governance arrangements. They integrated concepts present in FRG: adaptive co-management, sustainable land and water management, and integrated flood risk management, concluding that all these concepts assume that social learning is a multi-level and multi-stakeholder governance challenge. Thus, cooperation occurs between different sectors, including those of water management, spatial planning, and disaster management. Cross-sectoral cooperation is arguably challenging in itself. It appears even more difficult though, if multilevel cooperation is involved. The study differentiates between four types of factors influencing a cooperation and learning process: attributes of engaged individuals; collaborative arena factors (e.g., mutual trust, communication); organizational factors (e.g., cooperation structures, knowledge sources); and external factors (e.g., crisis events, administrative procedures). Examination of the Dutch Room for the River Program showed that a strong personal commitment to learning and mutual inter-personal trust in working groups were key conditions for successful social learning. External factors played a less significant role.

3.1.3. City-To-City Learning for Urban Resilience: The Case of Water Squares in Rotterdam and Mexico City

Similarly to den Boer et al. [21], Silvana Ilgen, Frans Sengers and Arjan Wardekker [22] have studied city-to-city learning for urban resilience. They assessed the on the ground implementation of water squares in Rotterdam and Mexico City and therewith provided important insights about the functioning of knowledge-action networks (in Morrison et al.'s terms [12]). A key finding of the paper is that city-to-city learning took place within identifiable phases: exploration and marketing (phase 1), building pipelines (phase 2), translation and adoption (phase 3), and internalization and reflection (phase 4). The authors point out that it was critical in a first phase to analyze one's own 
systems, strengths, and weaknesses, rather than performing an outward-looking search for knowledge or mentees. Next, cities reframed their own narratives to match those of their counterparts as a way to create a mutual understanding of each other's developments. A process of policy and knowledge exchange could take place because of that. However, strong leadership turned out to be necessary to make sure that the acquired knowledge was implemented and retained. Fourth and finally, the authors stress that 'by internalizing such lessons, cities might strengthen not only their own resilience, but also enhance future exchanges with other cities'.

\subsubsection{Pluvial Flooding in Utrecht: On Its Way to a Flood-Proof City}

Citizen engagement is recognized as an important issue in order to make progress in flood risk governance and hence a recognized study area in flood risk governance analyses. Romy Brockhoff, Steven Koop, and Karin Snel [23] have assessed the topic in the case of pluvial flooding in Utrecht. They assessed to what extent the necessary governance capacities to make the city prepared for pluvial flooding have been developed within the city. The authors depart from the viewpoint that pluvial flooding can be addressed by a single actor that is in the lead, such as the municipality, and indicate that addressing pluvial flooding requires the involvement and engagement of a diverse set of actors, including citizens. Applying the governance capacity framework to the city of Utrecht, the authors found that most governance capacities needed to address pluvial flooding have been relatively well-developed: 'collaboration between public authorities is advanced, sufficient financial resources are available, and smart monitoring that enables high levels of evaluation and learning.' Citizen awareness and engagement is, however, in need of further development. The authors recommend developing financial incentives that invite citizens to take measures to address pluvial flooding on their own properties and advise to further develop arrangements for active citizen engagement. The authors argue that these recommendations are valid for other urbanized areas that will face increased problems with pluvial flooding.

3.1.5. Exploring Science-Policy Interactions in a Technical Policy Field: Climate Change and Flood Risk Management in Austria, Southern Germany, and Switzerland

Science is an important factor in FRG. Scientific evidence and expertise deliver solutions and justification for FRG policies and management. Ralf Nordbeck, Lukas Loeschner, Melani Pelaez Jara and Michael Pregernig [24] in their paper on science-policy interactions in the field of flood risk governance analyzed three Alpine regions, in Switzerland, South Germany, and Austria. They assess science-policy interactions from three perspectives: (i) dynamics of knowledge creation; (ii) institutionalization of the science-policy interface; and (iii) pathways of influence of expertise on policy development. The authors found increasing influence of climate change on flood risk governance in the selected regions. Policies to address climate change were supported by evidence-based arguments. The influence of experts was significant; however, it was mediated by national factors. This social embeddedness of expertise was heavily mediated by the 'political climate'. Scientists had to adjust their knowledge to have their expertise recognized. Notably, in South Germany, the high political profile of the climate change issue inclined scientists to recommend climate change as a significant factor despite a very uncertain scientific basis.

\subsubsection{The Costs of Living with Floods in the Jamuna Floodplain in Bangladesh}

Ruknul Ferdous, Anna Wesselink, Luigia Brandimarte, Kymo Slager, Margreet Zvarteveen, and Giuliano di Baldassarre [25] assessed how residents of the Jamuna floodplain in Bangladesh responded to flood events. Flood resilience literature often stresses that external shocks can induce learning and therewith facilitate adaptation and transformation, ultimately leading to a more resilient state [26]. A study by Ferdous et al. [25] challenges this assumption. They found that Bangladeshi people do develop strategies to cope with floods, such as relocation, temporary evacuation, change in cropping patterns, and supplementing their income from migrating household members. While these 
strategies facilitate short-term coping and reduce the negative impact of floods on their livelihoods, they do not prevent impoverishment. The authors conclude that the inhabitants of the Jamuna floodplain do not achieve successful adaptation and that gradually their situation worsens.

3.1.7. Adaptive Capacities for Diversified Flood Risk Management Strategies: Learning from Pilot Projects

The development of diversified flood risk governance is a process that requires both a vision and capacities. Flavia Simona Cosoveanu, Jean-Marie Buijs, Marloes Bakker, and Teun Terpstra [27] focus on adaptive capacities observed in the implementation of two pilot projects: 'Alblasserwaard-Vijfheerenlanden' (The Netherlands) and the 'Wesermarsch' (Germany). The projects aimed at enhancement of the integration of mitigation and preparedness measures. The authors looked for capacities that were missing, employed, and developed throughout the implementation, via the lens of the Adaptive Capacity Wheel that identifies 22 adaptation capacities instrumental in organizational adaptation, and the Triple Loop Learning approach, that measures the depth of learning in an organization. The study found three capacities particularly important to diversify the current form of Flood Risk Management: the capacity to develop a greater variety of solutions, continuous access to information about diversified FRMS, and collaborative leadership. The authors furthermore found that, in both cases, mostly shallow as opposed to deep learning took place. The study suggests that changing FRG to make it more diversified faces organizational hurdles, as in any organizational change. Thus, any process of updating FRG requires taking into account and anticipating a certain level of organizational resistance.

3.1.8. Reducing Hydro-Meteorological Risk by Nature-Based Solutions: What Do We Know about People's Perceptions?

The recently developed concept of Nature Based Solutions (NBS) points at the possibility of developing approaches 'to sustainably reduce hydro-meteorological risks, providing co-benefits for both ecosystems and affected people'. This way, such approaches are supported by nature, and are cost-effective and conducive to resilience. Sungju Han and Christian Kuhlicke [28] reviewed factors shaping people's perceptions of NBS as a means to reduce hydro-meteorological risks, including floods. The authors identified the following six core topics within which perceptions of NBS were discussed: (1) valuation of the co-benefits; (2) evaluation of risk reduction efficacy; (3) stakeholder participation; (4) socio-economic and location-specific conditions; (5) environmental attitude, and (6) uncertainty. The authors noted ambiguous and even contradictory results of the studies and propose a conceptual model for future research. The model comprises socio-economic-demographic conditions, operational knowledge, trust, threat appraisal, environmental attitudes, and direct interaction with NBS.

3.1.9. What Can We Learn from Planning Instruments in Flood Prevention? Comparative Illustration to Highlight the Challenges of Governance in Europe

Planning is crucial for flood governance. Mathilde Gralepois, in her paper [29], examines flood prevention planning instruments in three European countries: England, France, and the Netherlands. Maps were shown to be a vital and powerful tool in flood governance, in accordance with the Flood Directive requirements. Maps were not only geographical representations of territories, but-more importantly - a part of legal zoning, excluding certain types of land use. However, as socio-technical objects, flood maps are negotiated by actors engaged in their preparation and application. Gralepois claims that this process laid bare tensions that hamper a potentially beneficial role of planning in flood risk governance. Firstly, local spatial planning often conflicts with flood prevention policies implemented by national authorities. Local bodies often have more precise data and expertise and challenge the strict approach of the central administrations. In England, local planning authorities often disregard the non-mandatory recommendations of the central authorities, in order to continue local development. The situation in France is a manifestation of local authorities' pursuit to extend 
their autonomy. In the Netherlands, the situation is more balanced. The Water Impact Assessment is a mandatory procedural instrument to ensure that local plans fit the national criteria, but it is non-binding. Secondly, there is tension in professional culture between planning and prevention, which results in different preferences concerning instruments. The flood management administration prefers instruments referring to hydraulic models. Within the planning domain, allocation of land for different purposes and local development is the main concern. As a result, establishing a platform allowing debate and reconciliation of interests and expertise could contribute to balancing flood prevention and development needs. In France the Flood Risk Prevention Plan, and in the Netherlands, the Water Impact Assessment can play such a role.

\subsection{Contribution of the Special Issue to the Discussion about Governance Strategies for Improving Flood Resilience}

\subsubsection{Context-Sensitive Diversification of Strategies}

Several papers in the Special Issue contributed insights to the governance strategy of achieving a context-sensitive diversification of strategies. Molenveld and Van Buuren [19] illustrated the challenges of discussing and implementing such a diversification in the Netherlands, a country that had relied on predict-and-control approaches and flood defense for decades. They showed that several path-dependency mechanisms may have a tendency to reduce the scope of the debate on diversification of flood risk management strategies and may water down its implementation in practice. In the words of the authors, multi-layered safety was introduced at a time in which flood risk governance was a 'tame' issue, while the issue would have needed 'untaming' first. Regarding context-sensitivity, Ilgen et al. [22] identified an interesting mechanism. They showed that city-to-city learning processes can induce processes of international inter-city comparison, in which actors analyze their own systems and deliberately reframe their own narratives. Gralepois [29] showed that the difference in professional culture between planning and prevention hinders flexibility in applying instruments. In addition, in centralized flood risk governance, actors tend to favor the application of standardized instruments. However, the tension between the need for coordination and the necessity to take local interests into account needs to be acknowledged and addressed. In line with this claim, Cosoveanu et al. [27] showed that pilot projects can provide learning experiences for achieving diversified flood risk management. However, it remains challenging to achieve forms of second order learning that invite actors to reconsider dominant approaches and assumptions. There is a tendency to return to business as usual since higher order learning may lead to resistance. The papers together focus mainly on the policy side of FRG. In particular, factors hampering and enhancing the diversification of flood risk governance strategies have been revealed.

\subsubsection{Involvement of Different Sectors in Flood Risk Management Strategies}

Ilgen et al. [22] concur with the need to involve a wide range of sectors. They point at mechanisms that can enhance city-to-city learning. They show that what is first needed is to enhance connectivity within and knowledge of their own water governance system. This is a prerequisite to engage in city-to-city learning. In addition, den Boer et al. [21] unpack this key governance strategy. They claim that flood risk management strategies should be linked together and aligned, not stay isolated. Involvement of different sectors (water management/spatial planning/disaster management) is needed. Den Boer et al. argue, on the one hand, that social learning requires multi-sector and multi-level cooperation. On the other hand, they presuppose that integration between different sectors requires and to some extent enables social learning. Gralepois [29] underlines difficulties in cooperation between planners and flood prevention specialists. Examination of the Dutch Room for the River Program showed that a strong personal commitment to learning and mutual inter-personal trust in working groups were key conditions for successful social learning. External factors played a less significant role. This lesson also recurs in the paper by Brockhoff et al. [23]. They show that pluvial flooding requires 
the engagement of a diverse set of actors from different sectors and reveal the challenges related to their involvement. These papers explore the topic of stakeholder engagement in FRG. Barriers in engagement of sectors have been indicated as well as difficulties related to an engagement process. The need for learning is articulated in particular.

\subsubsection{Involvement of Private Actors Including Residents, Businesses, and NGOs}

Iligen et al. [22] note the need to involve private actors in building urban resilience. In addition, Molenveld and Van Buuren [19] have seen increased involvement of other types of actors in flood risk governance. They note, though, that it is difficult to involve these private actors in a Dutch context. Often, newly entering actors are still public rather than private ones. Broadening the actor base-referred to by the authors as achieving more polycentricity as well as becoming more adaptive and less static-is not something that can be achieved overnight. The authors show that in the Dutch case this requires a re-politicization or, in the terms of the authors, an un-taming of a tame problem. Brockhoff et al. [23] claim that pluvial flooding requires the engagement of citizens. Amongst all resources, the substantive contribution that citizens can offer to address pluvial flooding is most in need of improvement. Han and Kuhlicke [28] contributed to the theme of actor involvement by studying a specific response to flood risks: nature-based solutions. They highlighted several relevant elements that co-determine the perception of different types of actors of these nature-based solutions as described in the previous sub-section. These papers contribute to the research gap concerning stakeholder engagement and the reshuffle of responsibilities, from the state to private actors and residents. The studies note both pulling and blocking factors in this respect. The studies suggest that engagement of private actors can be a postulate difficult to achieve due to institutional, economic, and social reasons.

\subsubsection{Rules and Regulations}

Gralepois' paper [29] focuses on instruments applied in flood risk governance in England, France, and the Netherlands. In all three countries, legal instruments dominate. Moreover, the hierarchical legal structure leaves limited space for diversification of policy instruments. Rules and regulations are implicitly discussed in the papers of the Special Issue, although Molenveld and Van Buuren [19] touch upon this issue when they point at a 'loose' vs. a 'tight' implementation of the multi-layered safety policy, which alludes to the fact that existing rules and regulations in some cases may have a tendency to reinforce stability and path dependency. These papers contribute to the research gap concerning flood risk management policies. The dominant role of legal instruments and their stabilizing character are noted.

\subsubsection{Financial and Non-Financial Resources}

Ferdous et al. [25] point out the fact that dealing with flooding in a Bangladeshi context can also lead to a vicious circle where coping strategies cannot prevent negative long-term outcomes such as impoverishment. In terms of strategy number five: the resource base (in particular: human capital, but also livelihood resources) is steadily declining, which undermines communities' resilience.

Nordbeck et al. [24] shed light on specific resources for improving flood resilience in the face of climate change. They point to the importance of science-policy interfaces and their role in making flood risk governance climate-sensitive. They show how climate-related information is used in Switzerland, South-Germany, and Austria. The mechanisms through which this information was used differed in the three countries, but in all cases reliance on experts and on evidence-based information was high. The paper shows, however, that the extent to and ways in which scientists' expertise was recognized depended on the political climate in the different countries. Brockhoff et al. [23] in their paper write, amongst other resources, about the substantive contribution that citizens can offer to address pluvial flooding. This resource is said to be most in need of cultivation. Cosoveanu et al. [27] in their assessment of adaptive capacities for diversified flood risk management in two case studies 
found that three types of capacities are particularly important: the capacity to develop a greater variety of solutions, continuous access to information about diversified FRMS, and collaborative leadership. The issue of resources dealt with in the papers refers to the division of responsibility between state and non-state actors and flood risk governance policies in general. The studies reveal that significant resources can be found in the state, and in the private sector, the use of the private sector resources is conditional. Moreover, the resources are vulnerable.

\subsubsection{Open and Inclusive Societal Debate}

The paper by Molenveld and Van Buuren [19] is the only paper that explicitly addresses the need for an open and inclusive societal debate. The forms of re-politicization or un-taming pleaded for by the authors can be seen as a specific way to implement governance strategy number six of Driessen et al. [5]: to achieve an open and inclusive societal debate that leads to the adoption of certain normative principles as the outcome of a political discussion. While the other papers do not address this last governance strategy explicitly, they all implicitly hint at it. Recurring issues in all contributions are that different types of actors are becoming and have to become involved in flood risk governance; that these may have different viewpoints and often vested interests; that institutional change is necessary, and that there are various mechanisms that make institutions relatively inert to change. This is a setting in which, arguably, the need to put un-debated issues up to deliberation again becomes increasingly important. Moreover, the paper by Ferdous et al. [25] strongly points to the potential detrimental and/or distributive effects that a resilience discourse may have, in addition to several positive effects. This shows all the more how important it is that flood risk governance is debated by diverse societal actors.

\section{Concluding Remarks and Suggestions for Future Research}

The nine contributions to the Special Issue 'Flood Risk Governance for More Resilience' together have advanced the state of the art in scholarship on flood risk governance. At the same time, they have also laid bare the limitations that this literature still has. A dominant message that can be derived from the papers is that more horizontal forms of governance are being developed in which a more diverse array of public and private actors, including citizens as well as a diverse array of sectors is becoming involved. Efforts are underway to establish connectivity between actors, levels, and sectors, both through regional and international exchanges. The diversity of lessons provided by the papers in the current Special Issue signals the even larger diversity existing in empirical reality. Despite recent progress, including in this Special Issue, it is safe to say that the empirical knowledge base regarding governance strategies for achieving flood resilience still needs to be significantly expanded, whereby different aspects of the six governance strategies for more resilience should be further unpacked. We also note that there is still a need to expand the geographical scope.

Secondly, although the papers demonstrate engagement of various actors within FRG, analyses of the mechanisms through which participation is taking place and the underlying power relations remain a bit shallow. It seems that actor participation often takes place through mechanisms close to cooptation, but these mechanisms are not yet systematically unpacked. In particular, within and between actor conflicts are hardly explored. It is an open question whether these issues of power in participation are missing because they would add too much complexity to research, or that conflicts are "suppressed" in FRG and do not appear as an issue. In any case, it seems unlikely that FRG is always a non-zero-sum game with winners only. Exploration of this aspect is an area for future studies.

A third key message, one closely related to the second, is that the scope of normative debates on what flood resilience entails and who should be resilient to what is still too limited in scope, both in literature and in practice. The Special Issue reconfirms the finding of Driessen et al. [5] that normative debates are often absent or not accessible to all actors with a stake in flood risk governance processes and outcomes. Further lessons on how to improve this practice need to be drawn. 
An element in scholarly literature that is relevant here is that insights from the natural and social sciences are often still separated. While flood perception is addressed in FRG studies, most literature adopts a 'realist' approach to the environment. We endorse the suggestion by Birkholz et al. [30] to add more constructivist studies that try to unpack how flood risks and flood risk management approaches are understood, interpreted, framed, and given meaning and how this influences the terms of the debate, including the substantive outcomes for different types of stakeholders in terms of dynamics in power relations and in terms of actual flood protection. Another aspect of the uneasy relation between the social and the natural sciences that appears in the papers is a weak reference to the concepts worked out in the water management literature. For instance, the concept of Integrated Water Resource Management necessitates looking at the processes using the river basin scale as a unit of analysis. This is hardly done in the studies.

The Special Issue combines the notion of flood risk governance with the notion of resilience. The papers discuss several factors enhancing resilience: necessity of learning [22,27]; organizational capacities [22,27]; the role of changes in narratives [22]; infrastructural individual/communal capacities [25]; the role of citizens' engagement [23]; citizen awareness and engagement [23]; "taming" of new policies [19]; problem solving capacities [23]; knowledge/expertise production and application [24]; personal commitment to learning and mutual interpersonal trust [21]. Whether the analyzed influence of particular factors is idiosyncratic or representative of more general patterns is an issue to be corroborated. Notably, the claim by Ferdous et al. [25] that presence of diverse strategies does not automatically imply resilience is deserving of further research.

The papers of this Special Issue rely mostly on case studies. They offer in-depth insights into the process and organization of flood risk governance. A problem with case study research is its limited external validity. In terms of the need for cumulative research, some sort of meta-language would need to be used by researchers to make findings comparable. The key themes of Section 3.2 may provide a first exploration towards such a meta-language.

We encourage scholars and practitioners from diverse scientific perspectives to contribute further to these debates.

Author Contributions: Conceptualization, P.M. and D.L.T.H.; methodology, P.M. and D.L.T.H.; formal analysis, P.M. and D.L.T.H.; writing—original draft preparation, P.M. and D.L.T.H.; writing—review and editing, P.M. and D.L.T.H. All authors have read and agreed to the published version of the manuscript.

Funding: This research received no external funding.

Conflicts of Interest: The authors declare no conflict of interest.

\section{References}

1. Dahm, R. Flood resilience a must for delta cities. Nature 2014, 516, 329. [CrossRef] [PubMed]

2. Tullos, D. Opinion: How to achieve better flood-risk governance in the United States. Proc. Natl. Acad. Sci. USA 2018, 115, 3731-3734. [CrossRef] [PubMed]

3. Bergsma, E. The development of flood risk management in the United States. Environ. Sci. Policy 2019, 101, 32-37. [CrossRef]

4. Milly, P.C.D.; Betancourt, J.; Falkenmark, M.; Hirsch, R.M.; Kundzewicz, Z.W.; Lettenmaier, D.P.; Stouffer, R.J. Stationarity Is Dead: Whither Water Management? Science. 2008, 319, 573-574. [CrossRef]

5. Driessen, P.; Hegger, D.; Kundzewicz, Z.; van Rijswick, H.; Crabbé, A.; Larrue, C.; Matczak, P.; Pettersson, M.; Priest, S.; Suykens, C.; et al. Governance Strategies for Improving Flood Resilience in the Face of Climate Change. Water 2018, 10, 1595. [CrossRef]

6. Heintz, M.D.; Hagemeier-Klose, M.; Wagner, K. Towards a Risk Governance Culture in Flood Policy—Findings from the Implementation of the "Floods Directive" in Germany. Water 2012, 4, 135-156. [CrossRef]

7. Butler, C.; Pidgeon, N. From 'Flood Defence' to 'Flood Risk Management': Exploring Governance, Responsibility, and Blame. Environ. Plan. C Gov. Policy 2011, 29, 533-547. [CrossRef]

8. McClymont, K.; Morrison, D.; Beevers, L.; Carmen, E. Flood resilience: A systematic review. J. Environ. Plan. Manag. 2019, 1-26. [CrossRef] 
9. Kundzewicz, Z.W.; Hegger, D.L.T.; Matczak, P.; Driessen, P.P.J. Opinion: Flood-risk reduction: Structural measures and diverse strategies. Proc. Natl. Acad. Sci. USA 2018, 115, 12321-12325. [CrossRef]

10. Hegger, D.L.T.; Driessen, P.P.J.; Wiering, M.; van Rijswick, H.F.M.W.; Kundzewicz, Z.W.; Matczak, P.; Crabbé, A.; Raadgever, G.T.; Bakker, M.H.N.; Priest, S.J.; et al. Toward more flood resilience: Is a diversification of flood risk management strategies the way forward? Ecol. Soc. 2016, 21, 52. [CrossRef]

11. Aerts, J.C.J.H.; Botzen, W.; Van Der Veen, A.; Krywkow, J.; Werners, S. Dealing with Uncertainty in Flood Management Research, part of Special Feature on New Methods for Adaptive Water Management Dealing with Uncertainty in Flood Management Through Diversification. Ecol. Soc. 2008, 13, 17.

12. Morrison, A.; Westbrook, C.J.; Noble, B.F. A review of the flood risk management governance and resilience literature. J. Flood Risk Manag. 2018, 11, 291-304. [CrossRef]

13. Bosher, L.; Dainty, A.; Carrillo, P.; Glass, J.; Price, A. Attaining improved resilience to floods: A proactive multi-stakeholder approach. Disaster Prev. Manag. Int. J. 2009, 18, 9-22. [CrossRef]

14. Mees, H.; Alexander, M.; Gralepois, M.; Matczak, P.; Mees, H. Typologies of citizen co-production in flood risk governance. Environ. Sci. Policy 2018, 89, 330-339. [CrossRef]

15. Restemeyer, B.; Woltjer, J.; van den Brink, M. A strategy-based framework for assessing the flood resilience of cities-A Hamburg case study. Plan. Theory Pract. 2015, 16, 45-62. [CrossRef]

16. Uittenbroek, C.J.; Mees, H.L.P.; Hegger, D.L.T.; Driessen, P.P.J. The design of public participation: Who participates, when and how? Insights in climate adaptation planning from the Netherlands. J. Environ. Plan. Manag. 2019, 62, 2529-2547. [CrossRef]

17. Thaler, T.; Priest, S. Partnership funding in flood risk management: New localism debate and policy in England. Area 2014, 46, 418-425. [CrossRef]

18. Lourenço, T.C.; Swart, R.; Goosen, H.; Street, R. The rise of demand-driven climate services. Nat. Clim. Chang. 2016, 6, 13-14. [CrossRef]

19. Molenveld, A.; van Buuren, A. Flood Risk and Resilience in the Netherlands: In Search of an Adaptive Governance Approach. Water 2019, 11, 2563. [CrossRef]

20. Pahl-Wostl, C.; Becker, G.; Knieper, C.; Sendzimir, J. How Multilevel Societal Learning Processes Facilitate Transformative Change: A Comparative Case Study Analysis on Flood Management. Ecol. Soc. 2013, 18, 58. [CrossRef]

21. den Boer, J.; Dieperink, C.; Mukhtarov, F. Social Learning in Multilevel Flood Risk Governance: Lessons from the Dutch Room for the River Program. Water 2019, 11, 2032. [CrossRef]

22. Ilgen, S.; Sengers, F.; Wardekker, A. City-To-City Learning for Urban Resilience: The Case of Water Squares in Rotterdam and Mexico City. Water 2019, 11, 983. [CrossRef]

23. Brockhoff; Koop; Snel Pluvial Flooding in Utrecht: On Its Way to a Flood-Proof City. Water 2019, 11, 1501. [CrossRef]

24. Nordbeck, R.; Löschner, L.; Pelaez Jara, M.; Pregernig, M. Exploring Science-Policy Interactions in a Technical Policy Field: Climate Change and Flood Risk Management in Austria, Southern Germany, and Switzerland. Water 2019, 11, 1675. [CrossRef]

25. Ferdous, M.R.; Wesselink, A.; Brandimarte, L.; Slager, K.; Zwarteveen, M.; Di Baldassarre, G. The Costs of Living with Floods in the Jamuna Floodplain in Bangladesh. Water 2019, 11, 1238. [CrossRef]

26. Folke, C.; Carpenter, S.R.; Walker, B.; Scheffer, M.; Chapin, T.; Rockström, J. Resilience thinking: Integrating resilience, adaptability and transformability. Ecol. Soc. 2010, 15, art20. [CrossRef]

27. Cosoveanu, F.S.; Buijs, J.-M.; Bakker, M.; Terpstra, T. Adaptive Capacities for Diversified Flood Risk Management Strategies: Learning from Pilot Projects. Water 2019, 11, 2643. [CrossRef]

28. Han, S.; Kuhlicke, C. Reducing Hydro-Meteorological Risk by Nature-Based Solutions: What Do We Know about People's Perceptions? Water 2019, 11, 2599. [CrossRef]

29. Gralepois, M. What Can We Learn from Planning Instruments in Flood Prevention? Comparative Illustration to Highlight the Challenges of Governance in Europe. Water 2020, 12, 1841. [CrossRef]

30. Birkholz, S.; Muro, M.; Jeffrey, P.; Smith, H.M. Rethinking the relationship between flood risk perception and flood management. Sci. Total Environ. 2014, 478, 12-20. [CrossRef]

(C) 2020 by the authors. Licensee MDPI, Basel, Switzerland. This article is an open access article distributed under the terms and conditions of the Creative Commons Attribution (CC BY) license (http://creativecommons.org/licenses/by/4.0/). 
Article

\title{
Flood Risk and Resilience in the Netherlands: In Search of an Adaptive Governance Approach
}

\author{
Astrid Molenveld ${ }^{1,2, *}$ and Arwin van Buuren ${ }^{1}$ \\ 1 Department of Public Administration and Sociology, Erasmus University Rotterdam, 3062 PA Rotterdam, \\ The Netherlands; vanbuuren@essb.eur.nl \\ 2 Research Group on Politics and Public Governance, University of Antwerp, 2000 Antwerp, Belgium \\ * Correspondence: molenveld@essb.eur.nl
}

Received: 30 August 2019; Accepted: 2 December 2019; Published: 5 December 2019

\begin{abstract}
In the Netherlands, dealing with the risk of flooding in the face of the current climate change requires a governance approach that is less based upon the long-standing tradition of prevention and protection, and more oriented toward ideas of resilience and adaptivity. Such an approach is assumed to be more resilient compared to static approaches and better equipped to deal with the indeterminate character of a problem like flood risk. This article presents the Dutch attempt to introduce a more polycentric and adaptive governance approach in flood management, called multilayered safety (MLS). We studied this approach via interviews and an extensive document study, and analyzed the institutions governing the issue using the Institutional Analysis and Development (IAD) framework of Elinor Ostrom. For years, the issue was in the hands of a small network of actors, mainly occupied by water experts and governed by a strong lead organization and permanent bodies. While introducing a new, more adaptive policy concept the government encountered both resistance and inability within the existing policy regime. This article shows that the issue of flood safety was successfully 'tamed' for decades. Adopting a more adaptive and polycentric approach necessitates 'untaming' the issue of flood safety.
\end{abstract}

Keywords: IAD framework; adaptive governance; multi-level safety; untaming

\section{Introduction}

The risk of flooding grows because of more extreme rainfall, sea-level rises, higher river water discharges, and more intense storms. Scholars are, therefore, heavily discussing the basic principles of the current approach of dealing with flood risk. For a long time, the Dutch approach to flood-risk management was mainly based upon the idea of prevention [1]. Over the last 10 centuries, a whole system of dikes and dams was developed in order to protect the Low Countries from flooding. This system was further refined following the major flooding of 1953, after which the world-famous delta works were realized, and a whole regime of legal flood-risk norms was established. To date, the Dutch system of protecting a highly flood-prone country against flooding is seen as an international hallmark of flood-risk management.

This system can be described as a 'domesticated or tamed' strategy [2]. In such a system, an ill-structured problem, such as water safety, is split up into manageable partial tasks [3] (p. 578), resulting in a lack of reflexivity, resilience, and inclusion of new and local experience and knowledge [2] (p. 11). Problem taming is aimed at reducing and controlling wicked problems, by scoping and delineating the problem in such a way that it fits the existing administrative expertise and policy responsibilities [3]. In other words, the existing organizational structure and body of knowledge define how a problem is dealt with. Roberts [4] adds to this the idea that in the case of taming, authority is transferred into the hands of a few selected actors, based upon their hierarchical position and with the authority to deal with the (strictly defined) issue. Roberts [4] wrote that these 'tame' systems 
are characterized by authoritative strategies based on preexisting organizational lines of functional specialization [3] (p. 578). Ostrom [5] and also Hardin [6] considered such strategies too narrow to be sustainable. Even agencies involved in water safety feel that taming strategies are undesirable and unsatisfactory, as they are relatively static, difficult to change, and not adaptive to new circumstances.

In the quest for suitable and adaptive governance approaches, we can learn a great deal from the work of Elinor Ostrom [7-9]. She demonstrated that adaptive and polycentric governance systems are able to cope more effectively with such issues [9]. In addition, Ostrom $[9,10]$ asserted that the theoretical support for the positive influence of polycentric and adaptive governance approaches is large (p. 284). She [11] argued that, if governance is adaptive, it will be able to resolve and grasp the issue in a sustainable way.

The Dutch debate on a new approach to flood safety closely resembles the search for a more polycentric governance system. The Dutch Delta Program introduced a new paradigm, called 'multilayered safety' (MLS), based upon a more inclusive scope and more integrative collaboration around flood-risk management. It differs quite significantly from the existing policy paradigm, focused upon flood protection, and is aimed at reorienting the flood management system toward a risk paradigm, in contrast to the dominant probability paradigm [12]. However, it turned out to be very complicated to implement this new approach because it necessitates 'untaming' of the issue of flood safety. Untaming means acknowledging the multifaceted character of the issue, as well as the complexity and controversy surrounding it, and trying to do justice to its wickedness. This approach is highly controversial because policymakers are insecure about the new strategy and scope of the 'reframed problem', and untaming is also very complicated on an institutional level. In this article, we aim to determine whether and to what extent introducing MLS can be seen as an attempt to develop a more polycentric and thus loosely structured institutional regime, as well as to explain its low level of success. In the following chapters, firstly, we address the way in which Ostrom [13] described governance arrangements: the institutional analysis and development (IAD) framework.

Elinor Ostrom et al. developed the IAD framework to assist researchers in studying action situations [8]. According to Ostrom [8], every policy situation has a few general building blocks that can be studied as an action situation, in which actors choose and alternate amongst strategies that lead to changes in the decision-making process [14]. These building blocks include (1) the participants, (2) their positions, (3) and their actions, as well as (4) their control over and (5) information about (6) the cost-benefit analyses and (7) outcomes ([8], (p. 189); [15], (p. 27)). Zooming in on such a specific action situation-such as the flood-safety issue-obviously means a simplification of the complexity inherent in an action situation. However, systematically approaching this action situation and the accompanying governance rules make the IAD framework fruitful when attempting to track changes over time while simultaneously keeping rich descriptions of the case. Understanding such action situations and the related changes is important in efforts to design new approaches $[8,16,17]$. We deliberately opted for this framework because it offers an extensive typology of (institutional) rules to describe concrete governance situations, but it also helps to distinguish between loose and tighter appearances of such rules. Other frameworks (e.g. [18,19]) mention governance elements as well; however, the IAD framework specifically focuses on the tightness of the rules and thus allows for comparison.

In the following paragraphs, we will first present the material and methods used to analyze the case. Thereafter, we discuss the Dutch case of MLS and study the institutional rules in the case. We end this article with analysis and conclusion.

\section{Materials and Methods}

To call climate change in the highly flood-prone Netherlands a complicated problem is quite an understatement. Not only is climate change a contested phenomenon but the strategy to tackle its consequences is also highly disputed within Dutch politics (cf. [12]). The exact consequences of climate change are uncertain, multifaceted, and related to each other in a nonlinear way [20]. There 
are thus no optimal solutions (i.e., solutions with definitive and objective answers). Climate change adaptation levies enormous costs and has broad consequences for landscape quality and similar issues (cf. [21,22], p. 9).

For a long time, flood safety was considered a technical issue that could be solved by means of technical expertise. There was a normative consensus in Dutch society and strong support for governmental action to safeguard the Netherlands against flooding, especially after the floods of 1953. With the help of a set of clear norms for flood safety, a whole system of dike maintenance, inspection, and enforcement was developed that functioned quite well. These norms were entirely based upon the "probability" of a flood: the dikes have to meet a certain standard that equals the probability of flooding of 1 in 1000, 3000, or 10,000 years (dependent upon population density and infrastructure development).

However, the consequences of climate change (more soil erosion, higher river water discharges, as well as sea-level rises) put this technical system under significant pressure [23]. It becomes increasingly difficult to implement the appropriate measures to meet the norms [23]. Moreover, it is recognized that meeting the norm does not mean that a flood cannot occur. Although the likelihood is low due to the impact of climate change, the risk of a flood increases. Sixty years after defining the legal norms, the consequences of a potential flood (and thus the risk) are much higher because investments in the infrastructure behind dikes (houses, companies, infrastructure, etc.) are enormous, and more people live in flood-prone areas. Thus, a potential flood will cause more casualties and economic losses. Hurricanes Katrina and Harvey were an important triggering event that fueled a discussion about the consequences of such a disaster [24].

At the same time, the normative consensus underlying the traditional 'protection' paradigm also eroded to some extent. Citizens increasingly question dike-enforcement projects. They object to the impact of dikes on their environment and the negative consequences for ecological, landscape, and cultural values. In various cases, (recurring) dike-enforcement operations have met fierce resistance from inhabitants who remained unconvinced of the necessity and asked for alternative solutions [25]. In the scientific community, the concern is growing that structural flood-protection measures have 'created flood disasters' [26]. The focus has gradually shifted from a 'protect-and-react' regime (managing the flood) which results in a 'safe development paradox' [27] by continuing the exposure of communities to the changing residual risk (the remaining chance that a disaster will occur), toward a regime in which the changing nature of the risk is managed proactively (managing the risk and strengthening resilience). Many authors have stressed that adapting to climate change for reasons of flood safety necessitates more resilient socio-ecological systems to deal with 'unexpected' shocks.

In the context of the Dutch Delta Program, several proposals have been developed to increase resilience and adaptiveness in the Dutch flood domain [28]. However, these attempts have only resulted in marginal changes in the dominant policy paradigm. In this article, we analyze these proposals with the help of the IAD framework of Ostrom $[5,8,13]$ to understand the efforts to realize a more adaptive and polycentric governance approach. The second author of this article extensively analyzed the single case study described in this article. He was involved in two important policy-advice trajectories regarding the revision of Dutch flood-risk management [15,29]. The Dutch Ministry of Infrastructure and Environment commissioned these trajectories to explore the possible governance approaches for implementing the new paradigm of MLS. Furthermore, he was the main evaluator of three pilots in which the new paradigm was tested [30]. The pilots were meant to explore both the physical and technical possibilities of MLS and the possibilities for an alternative governance approach to explore and implement such an alternative flood-risk strategy.

Given the research aim of this study, we opted for a qualitative approach that focuses on how involved actors interpret the change in policy paradigm, as well as how the governance arrangement and accompanying rules evolve. The more factual question about what really changed can be answered by analyzing policy documents and procedures to identify which elements of the Dutch flood management regime are described therein. To gain additional insights into how these changes were 
perceived, more than 50 key players were interviewed, and 10 focus groups with experts and officials were conducted. In addition, we analyzed contributions to the debate on flood-risk management reform and entries on diverse professional Internet forums. In the interviews, more than 30 experts, civil servants, and responsible authorities at national, regional, and local levels participated, and some respondents were interviewed twice. Furthermore, a survey was conducted, in which preferences regarding the new flood-risk regime were investigated [15]. In addition, the second author was actively engaged in the case as a participatory observer. He observed meetings among experts, practitioners, and officials who were discussing the issue of multilayered safety. Over 10 interactive meetings were attended between 2012 and 2015 to discuss the concept of MLS.

\subsection{The Institutional Analysis and Development (IAD) Framework}

Institutional rules consist of procedures and mechanisms that actors agree upon jointly (i.e., rules-in-use in the action situation) and influence how particular positions, actors, information, and actions are defined within the action situation [31]. These rules constitute the capacity 'to overcome dilemmas and create effective governance' (Blomquist, as quoted in [11]). In other words, the outcome of an action situation is based upon the extent of organized (or collective) action between independent organizations, in cooperation, to achieve a goal [8].

\subsubsection{Operationalizing the Rules-in-Use in Flood Safety}

While the IAD framework helps to sketch the action situation and then to study the institutional rules governing the situation, we still need a systematic way to compare how the rules change over time. In this article, we develop the rules-in-use-attached to specific times in the development of the approach to govern flood safety—of the IAD framework (see Figure 1 [8]) to make them suitable to study the case, as well as to compare the governance approach over time. We do not claim that we have found a way to study all types of governance approaches that exist, and we are well aware that this framework can be operationalized in many different ways. As Ostrom [13] concluded, an overall testable set of rules is not achievable, as there are too many rule configurations possible because governance approaches vary too much.

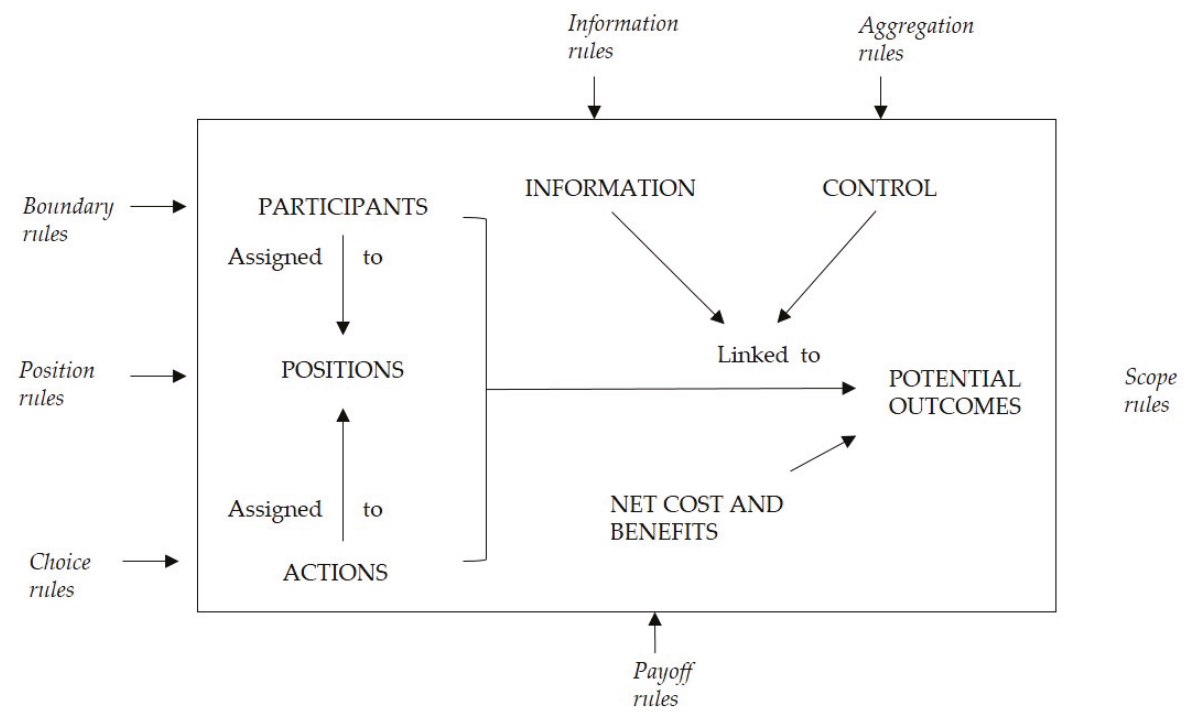

Figure 1. Institutional analysis and development framework [8]. 
In the end, how loose or tight the approach is, defines how stringently the governance approach presses organizations [32]. Many authors, including Elinor Ostrom herself, have made a distinction between tight, less tight, or lax rules [17,33].

In tight approaches, (self-established) authority is often the way to encourage organizations to follow-up on decisions and objectives [34] (i.e., superiors or lead organizations determine the actions of their subordinates). Tight approaches (or tightly coupled systems) are comparable with what Chisholm [34] called transitivity. A tight approach refers to a hierarchical chain of actors and assumes that, whenever an actor A takes a decision, actor B follows this decision. Translated to the action situation and the rule configuration, an action situation is tightly governed if institutional rules strictly determine how participants should adapt [31]. If rules are tight, participants have limited options, which leads to less uncertainty. Therefore, Roberts [4] called setting up a tight governance approach a 'taming strategy'. In such situations, power is in the hands of a few actors with authority, and it is much easier to predict outcomes compared to a situation in which rules are less strict [4,33]. It also has a downside. Elmore [35] argued that tight approaches could lead to more checks, norms, and formal decision points, which can create delays. Furthermore, many authors stress that such tight approaches can be met with reluctance or resistance by organizations because tight governance can diminish the autonomy of organizations ([8] (p. 284), [31,36]).

Loose approaches lie on the other end of the scale and are similar to self-organizational networks, in which autonomous - not guided by binding rules-participants discuss and contemplate issues [31]. Which actors are necessary at the table is determined based on the task at hand, not because of the organizational chart $[34,36]$. Roles and actions are continuously adjusted based on experience, and tasks are generally established by negotiation among the participants. A loose approach is almost like an 'adaptive device' ([35] p. 608). Participants have leeway in such approaches, which they can use to deal with conflicting or complex demands. However, not adapting, adhering, or exhibiting deviant behavior may lead to distrust [37]. In this way, a loose approach is almost like a self-reinforcing mechanism because the rules integrate and bind participants based on the issue, trust, and loyalty [31]. As such systems are flat-there is no one 'center of authority' - they may appear to be disordered ([34], (p. 54), [38]).

Both types have positive sides and challenges [31,39]. Besides the pitfalls per type, Benz [31] (p. 14) also wrote that, if the type of approach does not fit the organizational style, policy implementation and decision-making are both likely to end in an impasse. The tight approach resembles what Rittel and Webber called 'the systems approach of the first generation'. The second generation resembles a loose governance approach, based upon an open dialogue with participants, explorative argumentation, and an iterative search about the characteristics of the problem and a possible solution [21].

When researchers think of Elinor Ostrom and the IAD framework, studying common pool issues is what immediately comes to mind. Although the IAD framework is often used to analyze common-pool issues like forest, irrigation, or fisheries management, the framework is not restricted to studying common-pool resources. Elinor Ostrom [11] (p. 646) shows that the IAD framework is compatible with public goods as well [40]. Furthermore, the framework has been used by many other researchers focusing on flood risk e.g., [41,42]. The following paragraphs describe the elements of the IAD framework and the way we operationalize each element by using the four-point scale, leading to a rich and fine-grained method to score governance approaches on all their rules ranging from (1) tight rules to (4) loose rules.

\subsubsection{Boundary Rules}

The participants constitute the first element of the action situation [8]. In this article, organizations are considered to be the participants. Boundary rules describe how exclusive or open the collaboration is to participants, in the beginning, or along the way. These rules also indicate who can say something about 'the water issue': who is obliged to cooperate, which actors are excluded, and how participants can exit the action situation. Jordan and Schubert [43] described the boundary rules with three dimensions, including the number of participants, whether they are sectoral or trans-sectoral, and the stability. 
To operationalize this rule, two aspects were combined: the level of stability (based on $[43,44]$ ) and the diversity of participants (based on [45]). How open or closed the boundaries are can be described by the level of stability, which ranges from stable to unstable [43]. For the diversity of the participants, a distinction was made between vertical and horizontal linkages, in line with Bouckaert et al. [45]. One could think of vertical linkages between different hierarchical layers of organizations, as well as horizontal linkages between organizations of different policy sectors, portfolios, or different parts of the triple helix (universities, companies, and governments).

A tight participant constellation is highly institutionalized, formal, obliged, and restricted in terms of access to new participants. An open, ad hoc participant constellation, based on voluntary participation, is a loose arena. In loose approaches, the participant constellation is highly diverse, and the boundaries are open, fluent, and accessible to new participants. In tight approaches (see the left column in Table 1), the participant constellation is closed, and clusters' participants from one vertical hierarchy. The four institutionalization forms in Table 1 were borrowed from Van Waarden [44] and [43] combined with the vertical/horizontal linkages of Bouckaert et al. [45]. This dimension does not concern the centralization of power or the positions in the governance approach, it merely concerns the access and boundaries of the constellation.

\subsubsection{Positions Rules}

Secondly, next to the participant constellation, participants are, because of rules, agreements, and mandates, situated in different positions [8]. The actor's position in an action situation determines the extent of influence, as well as the bargaining and veto power, of a certain actor [46]. The operationalization of this dimension builds on the work of Provan and Kenis [47].

Positions may be, at one extreme, collectively structured (i.e., shared) by a separately created organization that deals with the administration, communication, and coordination tasks [47]. An action situation governed by a separately created administrative organization is the most highly structured and tightest form of governance. At the other extreme, positions may not be structured at all and thus participant governed, which is a very loose type of governance. In such a situation, members themselves govern their actions. Another example of loose governance occurs when the network (or collective body) acts as the basic entity where activities are governed, such as when a network functions as the collective structure in which consensus can be reached. Column 2 of this dimension describes a situation in which a single participant takes on the role of a lead organization [47].

\subsubsection{Choice Rules}

Choice rules determine the leeway a participant has, as described in the mission of the action arena, in terms of when the participant may, must (not), or should take action. Although Ostrom [8] employed the 'attributes, deontic, aim, conditions, or else' (ADICO) framework [48] as a systematic way to describe the rules-in-form [49], we used it to operationalize the leeway on the organization has. Ostrom distinguished between a rule, a norm, and a strategy (see also [49]). The ADICO grammar can help us determine if the objective is governed by a leading rule, a norm, or a strategy.

(1) Attributes: Who is addressed by the mission?

(2) Deontics: The prescriptive nature of a mission statement. If a deontic exists, we know that something is obliged, permitted, or forbidden.

(3) Aims: What is the aim of the actions in the mission statement?

(4) Conditions: Under what circumstances should the attribute do something (e.g., in which period, by which deadline, etc.)?

(5) Or else: The sanction if the participant does not follow the new demands. [49]

An objective containing each of the ADICO components is considered to be a rule. An objective containing the first four components (ADIC, i.e., those without sanction) is characterized as a norm. Objectives that only contain an attribute, aim, and condition (AIC) - and no sanction or 
prescription-are considered to be strategies [50]. If there is a tight and guiding rule, there is a strong degree of certainty [51] about what is expected of the participants. The loosest type of rule is a statement, which consists of an attribute (A) and an aim (I).

\subsubsection{Information Rules}

The fourth element of the IAD framework (see Table 1) is the information a participant has about how to reach the strategy and about the tasks of the other participants. This dimension does not stress the frequency or the amount of information, rather, it stresses the kind of information [8]. A situation in which a participant has a unique part of the information can lead to protection and 'bargaining', and it is the actor with the most information who has a dominant position [52]. In the situation of incomplete information and deficits, the strategies of the participants are 'messy' and uncoordinated [53]. Hood [54] distinguished between information that tightly and loosely presses organizations to adapt. Information is tight when responsibilities are ex-ante thoroughly described, involving the separation of 'coordination' and 'implementation' activities ([51], (p. 12); [52], (p. 34)). Another tight type also concerns an ex-ante described strategy and tasks, without this separation in 'coordination' and 'implementation' activities.

Information about the strategy and the tasks set during the process in the core group is looser. The group can agree on the strategy and tasks as a norm, but this can also be left to the participants themselves. In such situations, there is a rich exchange of information, with a lot of leeway for learning or adaptation [55]. Information, here, is seen as a collective asset. Participants of such loose types communicate on a personal, rather than formal, level with each other, which can result in more 'noise' and different conceptions of the task at hand [56]. Furthermore, participants who do not participate in the coordination process lack the information of those who do.

\subsubsection{Aggregation Rules}

The fifth element is the control that participants in the action situation have, how power is played out, how participants can affect the outcome, and how they reach final decisions [47]. Aggregation rules determine, for instance, whether a decision by a participant is needed to proceed to action and the implementation phase. In other words, aggregation rules can be symmetric (e.g., unanimity or voting schemes) or nonsymmetric (e.g., a leader takes a decision on behalf of the others, such as a chairman or lead organization) [8].

Compared to the position rules, which explain how the positions and the approach are structured, this dimension, 'aggregation rules', describes how participants come to decisions in the action situation. The literature tends to focus on three distinct forms, unicentric (tight), multicentric (having more than one authority), and pluricentric (loose) [57-59]. The role of the coordinator in a unicentric form is not to gain or to monopolize power but to perform roles that 'normal' participants are unable to perform: foreseeing threats, disasters, and deadlock, as well as undertaking long-term planning (Mulgan, 1997, as cited in [60]).

\subsubsection{Payoff Rules}

The cost-benefit analysis that the participant makes about the utility gained by either cooperation or defection is the sixth element of the IAD framework [8]. The 'payoff' can be either an extrinsic reward or sanction or an intrinsic valuation (e.g., joy, shame, or guilt [8]). In government organizations, the payoffs are highly institutionalized through accountability approaches. Accountability can influence policy coordination in different ways. Firstly, making organizations accountable places emphasis on goal formulation and achievement. Secondly, accountability systems can enable participants to comprehend the potential benefits of and pay attention to policy targets. Thirdly, accountability can aid in detecting and resolving overlaps and conflicts amongst policy objectives [61].

Fox [62] helped to operationalize this dimension by discussing two basic dimensions of accountability: 
- 'Soft face' accountability, peer review, the loosest type of accountability, implies dissemination and access to information (see 4 in Table 1). Answerability to specific coordination function means that organizations have the obligation to answer questions regarding their decisions and actions to a certain coordination function $[62,63]$.

- The 'hard face' form of accountability includes answerability plus the possibility of sanctions.

Types (2) and (3) in Table 1 are types of institutional answerability of the involved organizations to the coordinating actor: one type without an inspection, sanctions, or rewards, and the other type with these elements. The tightest form is what Fox [62] called the 'hard' accountability type: performance-based accountability to the coordinating actor with sanctions and the possibility to investigate actual institutional behavior.

\subsubsection{Scope Rules}

Lastly, the scope describes the range of possible outcomes that could be affected, and it specifies the ultimate goal that must be achieved [8]. How the scope is seen affects what is needed to reach the outcomes. These are the envisioned outcomes-not on the level of the participants but on the level of 'the collective'. The scope is, in the majority of instances, explicated in general mission statements.

According to Alter and Hage [64], the scope is the extent to which participants frame and see the mission they want to achieve in the action situation in a comprehensive way. On the one hand, this can be done broadly and holistically by seeing the problem and solution in a multidimensional and multidisciplinary way. First of all, 'multidimensional' means that the solution is the extent to which the problem and solution are seen 'holistically', for instance, that an area is a social, natural, geographical, and a political place. Secondly, 'multidisciplinary' means that the expertise of different professions is needed to understand the problem and find a solution. A broad framing leads to a wide-ranging assessment about which services, programs, and objectives should be met by the participants to target a particular problem. On the other hand, the problem and the solution can be seen more narrowly. A narrowly defined scope leads to objectives being unambiguous and more straightforward [64], as well as monodimensional and monodisciplinary goals and outcomes. In such a situation, it is clear who is responsible, who should take action, and how the goal must be achieved. Hence, monodimensional monodisciplinary goals and outcomes often explicitly link lead organizations to a problem, in which the organizations have a (self-established) authority over the action situation, and subsequently, the relations in the action situation are more tightly structured. Table 1 presents the various rules, using the IAD framework of Ostrom [8], and the different gradations between loose and tight versions of these rules. 


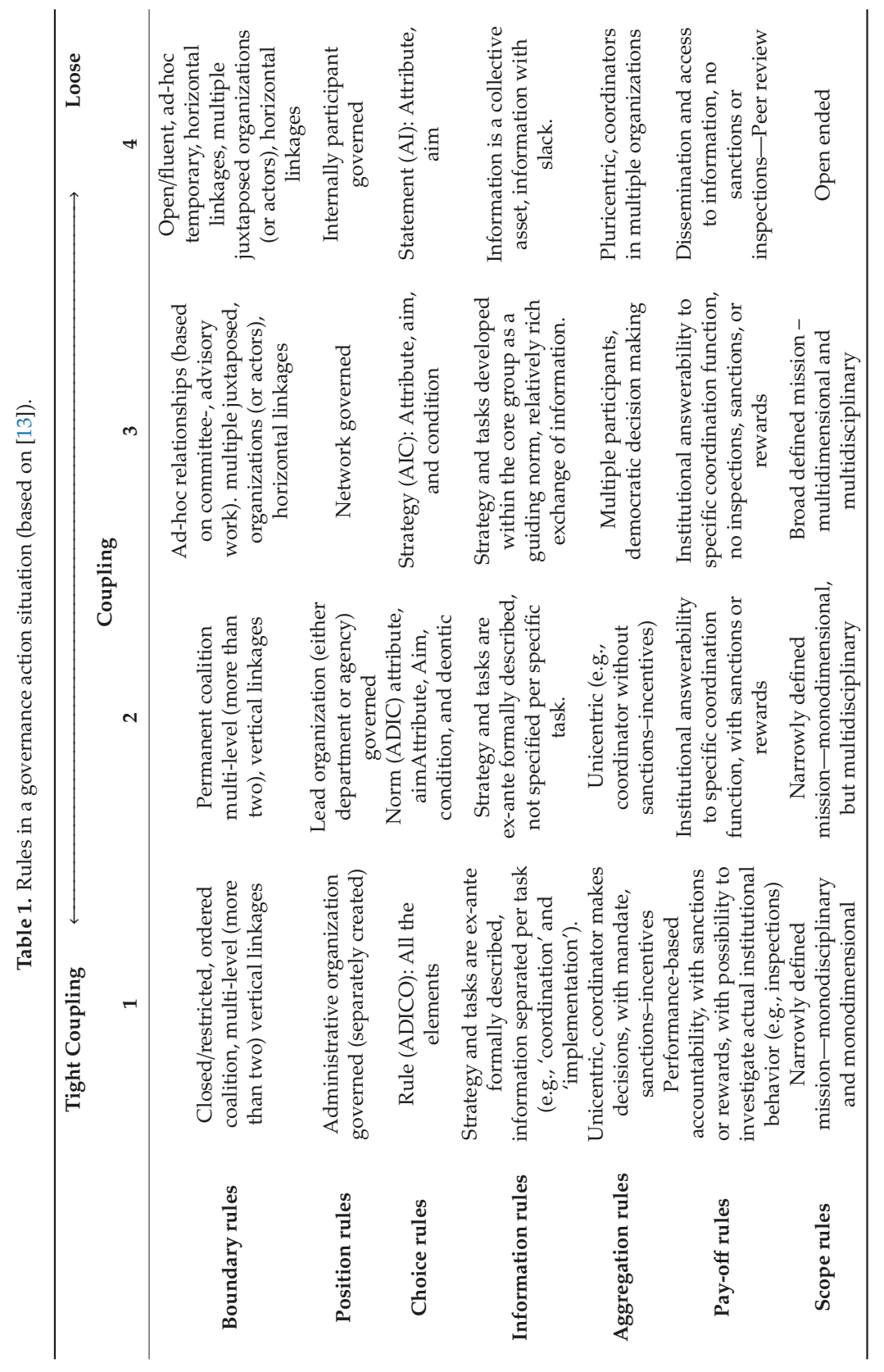




\section{Results}

When we try to deduce the rules that structure the action situation sketched above, it becomes clear that the governance approach governing flood safety until 2008 was rather tight (see Table 2 second column). For a long time, the governance regime regarding flood safety can be characterized as a highly tight governance approach that consists of a small coalition of interconnected actors with clear jurisdictions, which uses a highly formalized and detailed set of rules in order to realize a clear objective. Thus, there is a robust system of legal norms for flood protection. This system is embodied in a quite independent network of autonomous organizations responsible for implementing these norms. Within this network, there is a strong sectoral focus upon one dominant idea, namely prevention by means of protective measures.

This approach resembles the idea that flood management is a complicated, but technical, issue that can be dealt with in a well-structured way (a problem that can be 'tamed' [21]). The National Ministry of Infrastructure and Environment is responsible for flood management. The National Agency of Public Works and the regional water boards are responsible for implementing the norms. They focus their activities on the dikes, and only in very exceptional cases, a more spatial perspective is used to think about flood management strategies. The Room for the River program (2003-2016) can be seen as a first attempt to apply a more integrated focus by including aspects of discharge capacity and water levels in the decision to replace or to enforce the dikes along the main rivers [65]. When it comes to implementation (e.g. dike-enforcement projects or maintenance activities), other actors are informed or consulted, but they are not in a position to alter or to veto what has to be done in the eyes of the water authorities, the scope they use, or the alternatives they select. The maintenance of the flood defense system is based upon periodical inspection reports (every six years). In Table 2 (second column) we summarize the various rules that characterize the traditional approach of flood management.

\subsection{The Delta Program and the (Envisioned) Concept of Multilayered Safety (MLS)}

In 2008, a second Delta Commission was appointed to prepare advice about how the Netherlands could deal with the consequences of climate change. The report of the Veerman Committee stimulated the Dutch government to rethink the current methods of flood management. In 2009 the National Water Plan put the quest for another flood-risk policy on the national policy agenda and introduced the idea of MLS. The concept of MLS is based upon the idea that flood management has to become more risk-based and thus must have an open eye regarding the following question: What if a flood actually does happen? The concept grants a more prominent role to measures mitigating the impact of a possible flood by emphasizing the importance of risk management and planning strategies. It distinguishes amongst three layers of safety. The first layer includes dikes and other means to prevent flooding (the traditional approach of flood protection). The second layer consists of spatial measures that can help to reduce the impact of a flooding event. The third layer has to do with all sorts of activities regarding crisis and disaster management. Figure 2 presents this idea of MLS. 

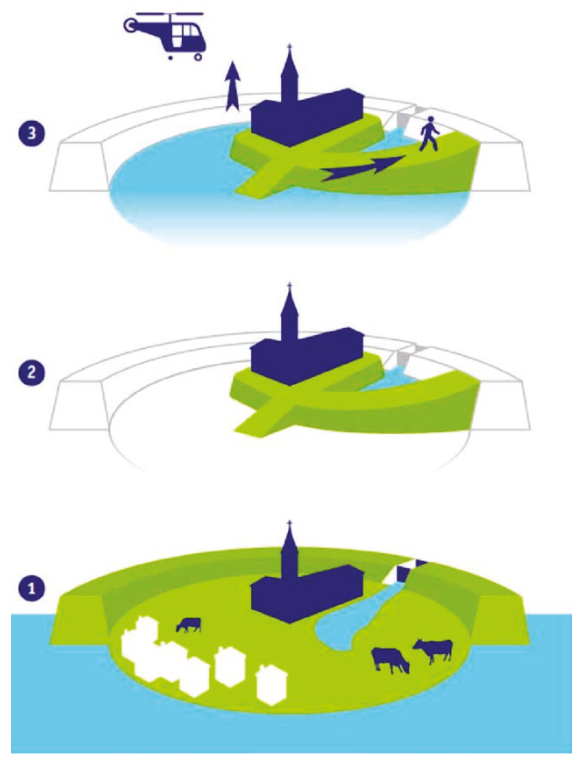

Figure 2. Multilayered safety (MLS). Source: Foundation for Applied Water Research Meerlaagsveiligheid (2014) Waterrobuust bouwen in stedelijk gebied, June 2014.

In 2010, the Dutch Cabinet appointed the national Delta Commissioner, and he started in 2011 by preparing the national Delta Program. The aim of this Delta Program was to develop a strategic policy plan for the long term that has to safeguard the Netherlands from the consequences of climate change related to floods, extreme rainfall, and droughts. One of the main characteristics of the Delta Program was its openness for other than traditional actors to get involved in drafting long-term policy strategies regarding flood risk management. This openness came with a more spatial perspective on flood management because regional and local authorities added their (spatial) agenda to the discussion about flood risk norms and ways to achieve these norms. Opening up the policy arena thus meant a more inclusive problem definition on flood risk and management.

In late 2014, the main results of the Delta Program were laid down in the so-called Delta Decisions. As van Buuren et al. [1] stated, two of the elements of multilayered safety were included. One Delta decision was devoted to the issue of 'land-use adaptation' or water-robust planning (to come to more risk-neutral spatial development on a voluntary basis), and the Delta Decision on 'flood-risk safety' incorporated the possibility of 'smart combinations'. The latter is aimed to provide the opportunity for exceptional situations in which dike enforcement can be replaced by a combination of measures in the first, second, and third layer: partial dike enforcement, measures in the spatial domain (compartmenting, waterproof development), and evacuation or risk reduction [1].

This Delta Program also laid the foundation for a new set of flood-risk norms in which the element of risk was much more emphasized than in the former norms. This new approach also resulted in a search for alternative governance approaches at the local and the regional levels to give meaning to this new philosophy and to enable a search for solutions at all three layers. In the six regional sub-programs of the Delta Program, the possibilities for MLS were explored. More specifically, the potentials of the concept were explored in three regional pilot projects to see whether it was possible to replace dike enforcements with a 'smart combination' of measures in all three layers [30].

The new policy paradigm, as proposed in the Dutch Delta Program, thus implies a couple of significant adjustments of the 'old' paradigm. These adjustments are at least threefold. First of all, the norms for flood-risk safety were adjusted in order to make them really "risk-based". The norms 
are now based upon two elements: the probability of a flood in relation to the expected impact of it in terms of economic losses and casualties. Secondly, by introducing the concept of MLS, the Delta Program ensures that flood-risk safety is no longer solely approached from the perspective of 'prevention'. It also draws attention to the so-called 'second layer', the spatial planning of an area, and the 'third layer', the possibilities for disaster and risk management. The Delta Program created the possibility to regionally explore the most suitable way of realizing the norm: an integrated package of measures of dike enforcement, spatial planning, and disaster management. Within the Delta Program, the importance of explorative searches at the local or regional level in order to find out which combination of measures fits best into the local context, the foreseen spatial developments, and the agendas of stakeholders was emphasized. This was framed as a joint responsibility of all regional actors.

The Delta Program also added the possibility of a 'smart combination'. Within a specific situation in which the norm necessitates dike enforcement, it became possible to exchange dike enforcement with a specific combination of measures in the first, second, and third layers. Such a combination should result in a lower norm for the dike and a formal commitment among the various responsible authorities to implement and maintain this combination of measures.

When we analyze the way in which the concept of MLS was used in the context of the Delta Program in the period between 2011 and 2014, we refer to the last column of Table 2, in which we sketch the various rules (in theory) the concept of MLS imply. In theory, the idea of MLS implies a fundamental shift toward a more loosely organized governance system. It implies that all actors that can possibly contribute to risk reduction at one of the three layers are welcome in a regional policy arena around a diked area (boundary rules: 4). It also presupposes that all these actors (e.g., the water boards, public safety regions, the municipalities, and other actors) internally develop a set of rules to set up a regional dialogue to discuss the way in which flood risk is dealt with (positions rules: 4). Regarding boundary rules, the idea of MLS can be seen as an open invitation to all actors within a certain region to bring in their ideas that could function as a building block at one of the three layers.

Developing a MLS strategy necessitates a regional dialogue in which all relevant stakeholders can contribute their ideas. It requires a very knowledge-intensive search in which an open and creative search can emerge toward innovative and integrative solutions. In various pilots, such a search was organized, and actors developed ideas about how to give meaning to this idea $[30,66,67]$.

\subsection{The Concept in Practice}

However, in practice (the third column of Table 2), it proved very difficult to implement the concept of MLS as originally envisioned (the fourth column of Table 2). The concept was translated in such a way that it was more or less compatible with the current institutional practice. In the final Delta Decisions, the first layer was said to safeguard a 'basic level of safety'. The new norms for the dikes have to ensure that the mortality rate due to flooding is 1 in 100,000 , thus $0.001 \%$. A strong bias in favor of legal norms regarding the dikes dominated the ultimate Delta Decisions: The idea of flood-risk management was entirely translated in a system of new norms for the dikes and thus not for the second or third layer (which were deemed too difficult to control). The more conservative community of national policymakers, civic engineers, and legal experts played an important role in this translation process. In the implementation phase, the policy arena was much more closed compared to the policy formulation stage. Regional and local actors were not in the position to defend or enforce the original concept. As a result, the idea of MLS was severely downsized because the norms for flood-risk safety are entirely focused upon the first layer, and all measures in the second and third layers are framed as complementary but not substitutive for the first layer. They seemed as 'nice to have' but not necessary. After the Delta Decisions were made, the new norms were implemented and translated by the water authorities in a strategy for planning the necessary measures to meet the norms in time. In this implementation process, many elements of the original concept (aimed at including the possible consequences of a flood- which depend upon the spatial characteristics of an area - in the calculation 
of the strength of the flood defense needed) were skipped in order to simplify the implementation challenge. At the moment, regional governance approaches around flood-risk management are less tight, but the focus remains on flood prevention by means of hard structures (the first layer).

Thus, although the new system enables the water authorities to opt for more tailor-made interventions to realize the norms, the actual resulting governance approach exhibits much more tight characteristics and thus a hybrid mix. Table 2 (column three) presents the various rules as they are currently in place regarding MLS. The current system of flood-risk management thus exhibits an interesting division between the strategic level (which is about programming measures) and the operational level (which is about implementing measures). At the strategic level, some regions invest in an intergovernmental dialogue between water authorities, provinces, and municipalities. The scope of such a dialogue differs in practice. In other regions, this dialogue is much less substantive and mainly used by the water authorities to present their intended measures regarding dike enforcement. Their plans are no longer only based on the technical specifications of the dike but also on the possible consequences of a dike breach. At the operational level, the water authorities organized a participation trajectory in order to fine-tune the way in which they implement dike enforcement. Within the domains of spatial planning and disaster management, other authorities (with different ambition levels) explore the possibilities for risk mitigation, but these trajectories are not entwined with the implementation efforts of the regional water boards. These attempts differ not only when it comes to how ambitious these are but also to what extent they are actually implemented. The latter mainly depends upon opportunities for coupling these types of measures to other spatial developments. 


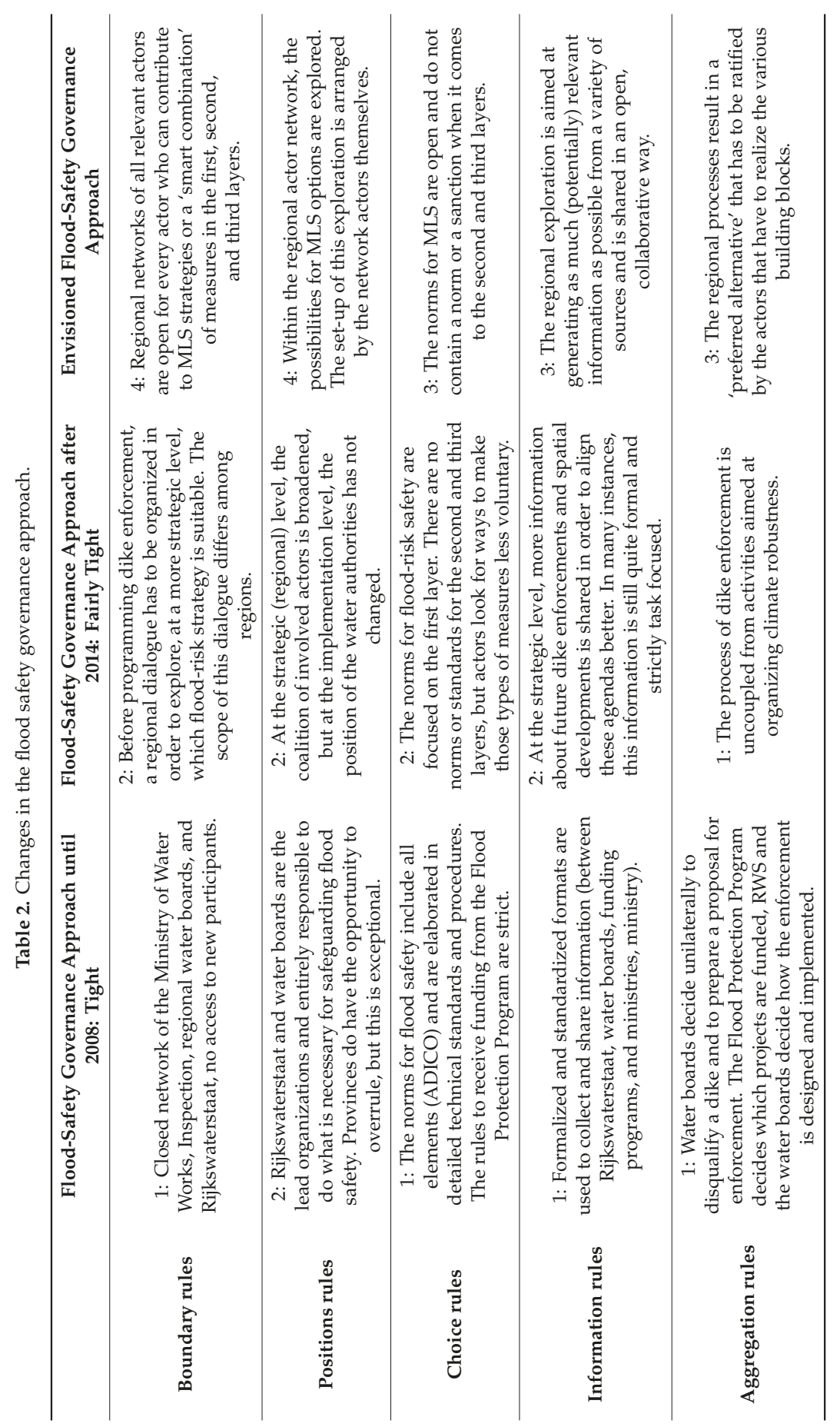




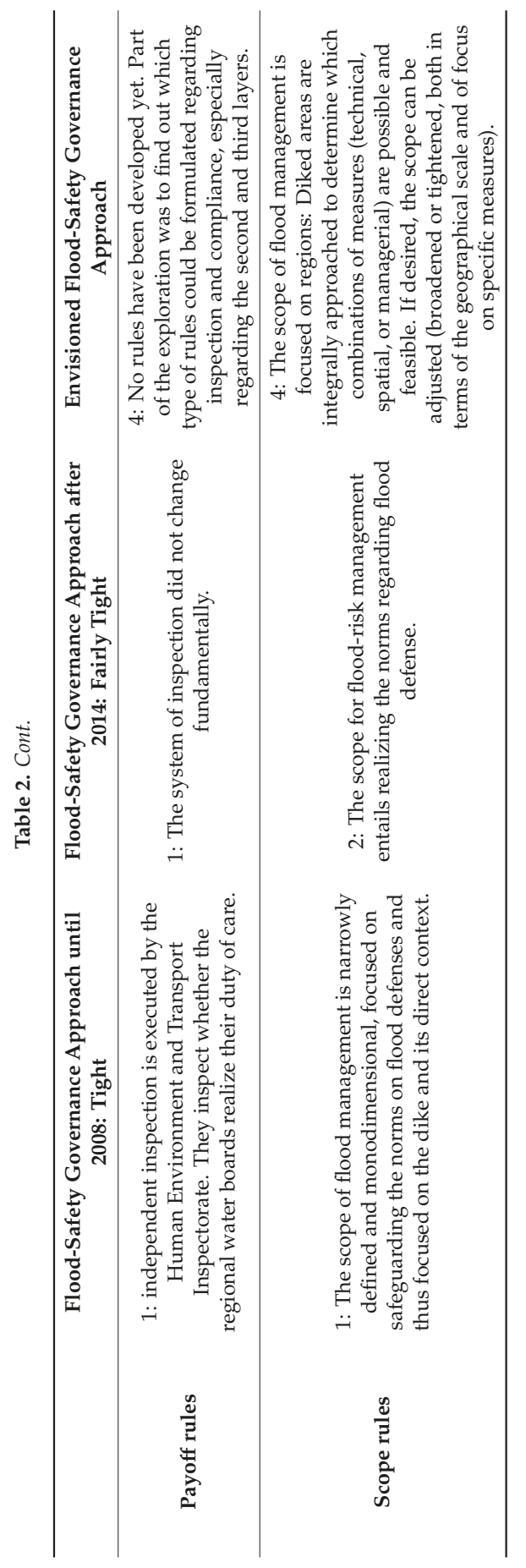




\section{Discussion}

Although the need for a more adaptive, integrated, and risk-oriented way of dealing with the issue of floods seems to be increasingly recognized, it remains very difficult to be freed from the classical idea of controlling floods by maintaining a system of dikes and dams only. The responsible actors in the Dutch flood-risk domain continue to tame the issue of flooding along three lines, which clearly reflect the taming strategies of Roberts [4].

Firstly, by relying on experts in one particular issue arena, the legal and regulative capacity remain in the hands of a few. The national government legally anchor new norms that are entirely translated into standards for dikes, and the very controversial idea of 'risk acceptance' is averted. As a result, all measures in the second and third layers are framed-by these actors who narrowly focus on flood safety as the one issue - as voluntary additions to the first layer, which is, in principle, sufficient to meet the norm. This is the second taming strategy of Roberts [4]. Thirdly, although a participative trajectory was organized, the original lead organizations decided on the strategy. By formally stating that a base level of safety is guaranteed by the first layer, the complexity of flood-risk management (in terms of scope, involved actors, available options, etc.) is reduced to the simplified question regarding the quality of flood defenses. This finding clearly supports the point of Daviter [3] that, via taming, problems are not dealt with in a holistic way but result in a solution that fits the functional specialization of a particular group of people. This taming strategy hinders reflexivity, as well as the inclusion of local experience and knowledge [2]. Certainly, the absence of a learning attitude can be explained by the rather strong path dependency that dominates this domain (cf. [1]) and the closed epistemic community that, for a long time, dominated the knowledge base of Dutch flood policies [68].

The introduction of the concept of MLS implies a search for more polycentric approaches in which the dominant position of the water authorities is reduced in favor of other actors who are responsible for planning and disaster management. Although the uncontrollable character of flood-risk safety is increasingly recognized, it is very difficult to acknowledge these unpredictable consequences in terms of how flood risk is dealt with. Given the risk-averse opinion of the public in the Netherlands, the strong normative consensus that the government is responsible for public safety, and the fact that people perceive themselves safe behind the dikes makes it nearly impossible to communicate that protection will never be perfect, that risks cannot be eliminated, and that it is important to think about more integrated strategies instead of focusing on the height and thickness of the dikes. Moreover, the consequences of a flood are, for most Dutch policymakers and citizens, too severe to accept. Therefore, it has proved to be highly controversial to untame the issue of flood-risk safety and to successfully implement MLS.

Two aspects make untaming very complicated. First of all, the current paradigm of flood-risk management by protection - essentially built on the simplifying idea that flood management is about protection-is seen as a very successful strategy that can be maintained even when the sea level rises by several meters [69]. With the help of tight rules, the choice menu for participants is limited, which leads to less uncertainty for those authorities responsible for maintaining flood-risk norms. Adopting MLS requires the courage to be open to a more ambiguous problem definition that necessitates mutual adjustment, exploratory strategies, and solutions that can only be realized with the help of all actors involved. Furthermore, the current governance approach is not only the simpler one; it is also a deeply embodied, path-dependent repertoire within the flood-risk domain [1]. There are strong self-reinforcing mechanisms in this domain. Not only high sunk costs (because of the existing infrastructure of flood defenses) but also learning and coordination effects make it difficult to leave the existing path [70]. The Dutch excel at flood protection, which causes a classical success trap [71].

\section{Conclusions}

In this article, we have developed a refined way to study governance approaches by distinguishing several dimensions, which together define and form tighter or looser approaches. The seven rules developed in this article, on the basis of the IAD framework [8], provide more insight into different 
elements of what can constitute a more polycentric and adaptive governance approach that can enhance resilient socio-ecological systems confronted with climate-related risks, and this approach proved to be a suitable analytical lens to study such issues. The seven rules give rich and in-depth insight into a complex governance arena. It has shown to be a holistic framework that can grasp the hybridity of governance arrangements and allows for comparison of approaches and over time.

By means of these rules, we have described the attempt to reinvent the governance of flood risk in the Netherlands. Following advice from the Dutch Delta Commission to reframe the issue, to re-configure the governance approach, and to have an open eye for new problem frameworks and solutions, an innovative policy concept was introduced: MLS. This concept, envisioned to enlarge the adaptivity of the Dutch flood-risk governance approach, was built on the idea that the core of the existing policy paradigm, focusing upon prevention, had to be exchanged for the idea of risk reduction, meaning that both the probability of a flood and its consequences are leverage points for measures. Policymakers saw MLS as a way to enlarge the scope of possibilities beyond the traditional focus on dike enforcement. Furthermore, it began a search for more polycentric and regional governance approaches, in which various actors can develop ideas or take measures that contribute to flood-risk reduction. In a couple of cases, this idea was piloted, and many interesting ideas were developed. However, the ultimate governance approach that resulted constitutes a much less adaptive and loose approach compared to the one envisioned.

The Dutch case of flood safety governance serves as a poignant example of an attempt to introduce an alternative governance approach based upon the idea of Ostrom to promote polycentricity and adaptivity in governance approaches. However, as demonstrated, this attempt also presupposes that previously successful taming strategies and paths have to be abandoned once a new approach is decided upon. Our case illustrates that untaming is not only highly controversial (because of the current frame that the government has to safeguard the people against flooding) but also institutionally very difficult due to the high institutional density and opacity of the current flood-risk domain. Taming strategies are firmly anchored in existing institutional practices. Therefore, the lead actors-the small group of established actors-demarcated and reframed the problem again as a tame issue to ensure safety by means of protective measures.

Presenting only one single case study from a rather particular domain (flood management) in a country with a strong tradition in this respect (the Netherlands), we must be cautious about drawing strong conclusions regarding the possibilities for untaming complex issues. The question becomes how we can successfully 'untame' different issues in different contexts in such a way that people dare to adopt the new kind of governance approaches that allow for exploration and deliberation. The answer to this question will differ amongst policy domains. Future research can focus on the untaming issue in other domains, to see whether this approach is attainable in other ways, by other actors and other approaches. However, from our case, we can conclude that acknowledging the power of path-dependency mechanisms and thinking about a strategy to mitigate them are indispensable steps for successfully untaming issues that (apparently) were successfully tamed for a long time.

Author Contributions: Conceptualization, A.M.; methodology, A.M.; software, not applicable; validation, A.M. and A.v.B.; formal analysis, A.M. and A.v.B.; investigation, A.v.B.; resources, A.M. and A.v.B.; data curation, A.v.B.; writing —original draft preparation, A.M. and A.v.B.; writing—review and editing, A.M. and A.v.B.; visualization, A.M.; supervision, A.M. and A.v.B.; project administration, A.M. and A.v.B.; funding acquisition, not applicable.

Funding: This research received no external funding.

Acknowledgments: The theoretical work in this article is based on the $\mathrm{PhD}$ project of Astrid Molenveld, which was part of the Policy Research Centre on Governmental Organisation in Flanders (SBOV III - 2012-2016), funded by the Flemish government. The operationalization, based on the IAD framework, was developed in the manuscript and further elaborated on in this article.

Conflicts of Interest: The authors declare no conflicts of interest. 


\section{References}

1. van Buuren, A.; Ellen, G.J.; Warner, J.F. Path-dependency and policy learning in the Dutch delta: Toward more resilient flood risk management in the Netherlands? Ecol. Soc. 2016, 21. [CrossRef]

2. Lach, D.; Rayner, S.; Ingram, H. Taming the waters: Strategies to domesticate the wicked problems of water resource management. Int. J. Water 2005, 3, 1-17. [CrossRef]

3. Daviter, F. Coping, taming or solving: Alternative approaches to the governance of wicked problems. Policy Stud. 2017, 38, 571-588. [CrossRef]

4. Roberts, N. Wicked problems and network approaches to resolution. Int. Public Manag. Rev. 2000, 1, 1-19.

5. Ostrom, E. Governing the Commons: The Evolution of Institutions for Collective Action; Cambridge University Press: Cambridge, UK, 1990.

6. Hardin, J.G. The tragedy of the commons. Science 1968, 162, 1243-1248. [CrossRef] [PubMed]

7. Ostrom, E.; Gardner, R.; Walker, J. Rules, Games, and Common-Pool Resources; University of Michigan Press: Ann Arbor, MI, USA, 1994.

8. Ostrom, E. Understanding Institutional Diversity; Princeton University Press: Princeton, NJ, USA, 2005.

9. Ostrom, E. Coping with tragedies of the commons. Annu. Rev. Polit. Sci. 1999, 2, 493-535. [CrossRef]

10. Ostrom, E.; Burger, J.; Field, C.B.; Norgaard, R.B.; Policansky, D. Revisiting the commons: Local lessons, global challenges. Science 1999, 284, 278-282. [CrossRef]

11. Ostrom, E. Beyond markets and states: Polycentric governance of complex economic systems. Am. Econ. Rev. 2010, 100, 641-672. [CrossRef]

12. Bekkers, V.; Van Buuren, A.; Edwards, A.; Fenger, M. Contested knowledge in Dutch climate change policy. Evid. Policy A J. Res. Debate Pract. 2017, 14, 571-587. [CrossRef]

13. Ostrom, E. The institutional analysis and development framework and the commons. Cornell Law Rev. 2010, 95, 807-815. [CrossRef]

14. Ostrom, E. Institutional rational choice: An assessment of the institutional analysis and development framework. In Theories of the Policy Process; Sabatier, P.A., Ed.; Westview Press: Boulder, CO, USA, 2007; pp. 21-64.

15. van Buuren, A.; Ellen, G.J. Multilevel Governance voor Meerlaagsveiligheid: Met Maatwerk Meters Maken; Erasmus Universiteit Rotterdam: Rotterdam, The Netherlands, 2013.

16. Ostrom, E. Multiorganizational arrangements and coordination: An application of institutional analysis. In Guidance, Control, and Evaluation in the Public Sector; Kaufmann, F.-X., Majone, G., Ostrom, V., Eds.; Walter de Gruyter: New York, USA, 1986; pp. 495-510.

17. Timmermans, A. Arenas as institutional sites for policymaking: Patterns and effects in comparative perspective. J. Comp. Policy Anal. 2001, 3, 311-337. [CrossRef]

18. Emerson, K.; Nabatchi, T.; Balogh, S. An integrative framework for collaborative governance. J. Public Adm. Res. Theory 2011, 22, 1-29. [CrossRef]

19. Ansell, C.; Gash, A. Collaborative governance in theory and practice. J. Public Adm. Res. Theory 2007, 18, 543-571. [CrossRef]

20. van Buuren, A.; Driessen, P.; Teisman, G.; van Rijswick, M. Toward legitimate governance strategies for climate adaptation in the Netherlands: Combining insights from a legal, planning, and network perspective. Reg. Environ. Chang. 2014, 14, 1021-1033. [CrossRef]

21. Rittel, W.J.; Webber, M.M. Dilemmas in a general theory of planning. Policy Sci. 1973, 4, 155-169. [CrossRef]

22. Bellamy, J. Adaptive governance: The challenge for regional natural resource management. In Federalism and Regionalism in Australia: New Approaches, New Institutions; Brown, A.J., Bellamy, J., Eds.; ANU E Press: Canberra, Australia, 2007; pp. 95-117.

23. Planbureau voor de Leefomgeving. Effecten van Klimaatverandering in Nederland; PBL Netherlands Environmental Assessment Agency: Den Haag, The Nederlands, 2012.

24. Vink, M.J.; Boezeman, D.; Dewulf, A.; Termeer, C.J.A.M. Changing climate, changing frames: Dutch water policy frame developments in the context of a rise and fall of attention to climate change. Environ. Sci. Policy 2013, 30, 90-101. [CrossRef]

25. van Buuren, A.; Edelenbos, J.; Klijn, E.-H. Gebiedsontwikkeling in Woelig Water: Over Water Governance Bewegend Tussen Adaptief Waterbeheer en Ruimtelijke Besluitvorming; Boom Lemma uitgevers: Den Haag, The Netherlands, 2010. 
26. Burton, I.; Kates, R.W.; White, G.F. The Environment as Hazard; Guilford Press: New York, NY, USA, 1993.

27. Burby, R.J. Hurricane Katrina and the paradoxes of government disaster policy: Bringing about wise governmental decisions for hazardous areas. Ann. Am. Acad. Pol. Soc. Sci. 2006, 604, 171-191. [CrossRef]

28. Vonk, M.; Bouwman, A.; van Dorland, R.; Eerens, H. Worldwide Climate Effects: Risks and Opportunities for the Netherlands; PBL Netherlands Environmental Assessment Agency: The Hague/Bilthoven, The Netherlands, 2015.

29. Ellen, G.J.; van Buuren, A. De Governance van Slimme Combinaties. Spelregels voor Samenwerking Rond Meerlaagse Vormen van Waterveiligheid; Deltares: Utrecht, The Netherlands, 2014.

30. van Buuren, A.; Ellen, G.J.; van Leeuwen, C.; Popering-Verkerk, J. Die Het Water Deert Die Het Water Keert: Overstromingsrisicobeheer als Maatschappelijke Gebiedsopgave. Opbrengsten en Lessen uit de Pilots Meerlaagsveiligheid; Erasmus Universiteit Rotterdam: Rotterdam, The Netherlands, 2015.

31. Benz, A. Governance in connected arenas: Political science analysis of coordination and control in complex rule systems. In New Forms of Governance in Research Organizations: Diciplinary Approaches, Interfaces and Integration; Jansen, D., Ed.; Springer: Dordrecht, The Netherlands, 2007; pp. 3-22.

32. Cameron, K.S. Organizational adaptation and higher education. J. High. Educ. 1984, 55, 122-144. [CrossRef]

33. Polski, M.M.; Ostrom, E. An Institutional Framework for Policy Analysis and Design; Workshop in Political Theory and Policy Analysis Working Paper W98-27: Bloomington, IN, USA, 2017.

34. Chisholm, D. Coordination without Hierarchy: Informal Structures in Multiorganizational Systems; University of California Press, Ltd.: Oxford, UK, 1992.

35. Elmore, R. Backward mapping: Implementation research and policy decisions. Polit. Sci. Q. 1979, 94, 601-616. [CrossRef]

36. Scott, W.R. Organizations, Natural, and Open Systems; Prentice Hall: Upper Saddle River, NJ, USA, 1992.

37. Jessop, B. The rise of governance and the risks of failure: The case of economic development. Int. Soc. Sci. J. 1998, 50, 29-45. [CrossRef]

38. Landau, M. On multiorganizational systems in public administration. J. Public Adm. Res. Theory 1991, 1, 5-18. [CrossRef]

39. Jessop, B. Governance, Governance Failure, and Meta-Governance; Policies, Governance and Innovation for Rural Areas, Universita Delaa Calabria, Arcavacata di Rende: Rende, Italy, 21-23 November 2003.

40. Ostrom, E. Background on the institutional analysis and development framework. Policy Stud. J. 2011, 39, 7-27. [CrossRef]

41. Van den Hurk, M.; Mastenbroek, E.; Meijerink, S. Water safety and spatial development: An institutional comparison between the United Kingdom and the Netherlands. Land Use Policy 2014, 36, 416-426. [CrossRef]

42. Roggero, M.; Bisaro, A.; Villamayor-Tomas, S. Institutions in the climate adaptation literature: A systematic literature review through the lens of the Institutional Analysis and Development framework. J. Inst. Econ. 2018, 14, 423-448. [CrossRef]

43. Jordan, G.; Schubert, K. A preliminary ordering of policy-network labels. Eur. J. Polit. Res. 1992, 21 , 7-27. [CrossRef]

44. Van Waarden, F. Dimensions and types of policy networks. Eur. J. Polit. Res. 1992, 21, 29-52. [CrossRef]

45. Bouckaert, G.; Peters, G.B.; Verhoest, K. The Coordination of Public Sector Organizations: Shifting Patterns of Public Management; Palgrave Macmillan: Rende, Hampshire, 2010.

46. Klijn, E.-H. Managing complexity: Achieving the impossible? Crit. Policy Stud. 2007, 1, 252-277. [CrossRef]

47. Provan, K.G.; Kenis, P. Modes of network governance: Structure, management, and effectiveness. J. Public Adm. Res. Theory 2007, 18, 229-252. [CrossRef]

48. Crawford, S.E.; Ostrom, E. A Grammar of institutions. Am. Polit. Sci. Rev. 1995, 89, 582-600. [CrossRef]

49. Siddiki, S.; Weible, C.; Basurto, X.; Calanni, J. Using the IAD's Institutional Grammar to Understand Policy Design: An Application to Colorado Aquaculture; Workshop in political theory and policy analysis working paper; Indiana Univ Bloom: Bloomington, IN, USA, 2009.

50. Siddiki, S.; Weible, C.M.; Basurto, X.; Calanni, J. Dissecting policy designs: An application of the institutional grammar tool. Policy Stud. J. 2011, 39, 79-103. [CrossRef]

51. Basurto, X.; Kingsley, G.; McQueen, K.; Smith, M.; Weible, C.M. A systematic approach to institutional analysis: Applying Crawford and Ostrom's Grammar. Polit. Res. Q 2010, 63, 523-537. [CrossRef]

52. Peters, G.B. Managing Horizontal Government: The Politics of Co-ordination; Canadian Centre for Management Development: Montreal, QC, Canada, 1998. [CrossRef] 
53. Ney, S. Messy Issues, Policy Conflict and the Differentiated Polity: Analysing Contemporary Policy Responses to Complex, Uncertain and Transversal Policy Problems. Ph.D. Thesis, University of Bergen, Bergen, Norway, 2006.

54. Hood, C. A public management for all seasons? Public Adm. 1991, 69, 3-19. [CrossRef]

55. Grant, R.W.; Keohane, R.O. Accountability and abuses of power in world politics. Am. Polit. Sci. Rev. 2005, 99, 29-43. [CrossRef]

56. Beekun, R.I.; Glick, W.H. Organization structure from a loose coupling perspective: A multidimensional approach. Decis. Sci. 2001, 32, 227-250. [CrossRef]

57. Lowndes, V.; Skelcher, C. The dynamics of multi-organizational partnerships: An analysis of changing modes of governance. Public Adm. 1998, 76, 313-333. [CrossRef]

58. Powell, W.W. Neither market nor hierarchy: Network forms of organization. In Research in Organizational Behavior; Slaw, B.M., Cummings, L.L., Eds.; JAI Press: Greenwich, UK, 1990; pp. 295-336.

59. Thompson, G.; Frances, J.; Levacic, R.; Mitchell, J. Markets, Hierarchies and Networks: The Coordination of Social Life; Sage Publications Limited: London, UK, 1991.

60. Parsons, W. From muddling through to muddling up: Evidence based policy making and the modernisation of British government. Public Policy Adm. 2002, 17, 43-60. [CrossRef]

61. Özerol, G.; Bressers, H.; Coenen, F. Irrigated agriculture and environmental sustainability: An alignment perspective. Environ. Sci. Policy 2012, 23, 57-67. [CrossRef]

62. Fox, J. The uncertain relationship between transparency and accountability. Dev. Pract. 2007, 17, 663-671. [CrossRef]

63. Schedler, A. Conceptualizing accountability. In The Self-Restraining State: Power and Accountability in New Democracies; Schedler, A., Diamond, L., Plattner, M.F., Eds.; Lynne Rienner Publishers, Inc.: Boulder, CO, USA, 1999; pp. 13-28.

64. Alter, C.; Hage, J. Organizations Working Together; Sage Publications: Thousand Oaks, VA, USA, 1993.

65. Zevenbergen, C.; Rijke, J.; van Herk, S.; Bloemen, P. Room for the river: A stepping stone in adaptive delta management. Int. J. Water Gov. 2015, 3, 121-140. [CrossRef]

66. Gersonius, B.; van Buuren, A.; Zethof, M.; Kelder, E. Resilient flood risk strategies: Institutional preconditions for implementation. Ecol. Soc. 2016, 21, 28. [CrossRef]

67. van Popering-Verkerk, J.; van Buuren, A. Developing collaborative capacity in pilot projects: Lessons from three Dutch flood risk management experiments. J. Clean. Prod. 2017, 169, 225-233. [CrossRef]

68. van Buuren, A.; Lawrence, J.; Potter, K.; Warner, J.F. Introducing adaptive flood risk management in England, New Zealand, and the Netherlands: The impact of administrative traditions. Rev. Policy Res. 2018, 35, 907-929. [CrossRef]

69. NRC. We Kunnen Meters Zeespiegelstijging Aan. Available online: https://www.nrc.nl/nieuws/2019/10/04/wekunnen-meters-zeespiegelstijging-aan-a3975698 (accessed on 6 October 2019).

70. Pierson, P. Increasing returns, path dependence, and the study of politics. Am. Polit. Sci. Rev. 2000, 94, 251-267. [CrossRef]

71. Gieske, H.; George, B.; van Meerkerk, I.; Buuren, A. Innovating and optimizing in public organizations: Does more become less? Public Manag. Rev. 2019, 1-23. [CrossRef]

(C) 2019 by the authors. Licensee MDPI, Basel, Switzerland. This article is an open access article distributed under the terms and conditions of the Creative Commons Attribution (CC BY) license (http://creativecommons.org/licenses/by/4.0/). 
Article

\title{
Social Learning in Multilevel Flood Risk Governance: Lessons from the Dutch Room for the River Program
}

\author{
Jacomien den Boer ${ }^{1}$, Carel Dieperink ${ }^{1, *}$ and Farhad Mukhtarov ${ }^{2,3}$ \\ 1 Copernicus Institute of Sustainable Development, Utrecht University, P.O. Box 80115, \\ 3508 TC Utrecht, The Netherlands; denboerjacomien@gmail.com \\ 2 International Institute of Social Studies (ISS), Erasmus University Rotterdam, Kortenaerkade 12, \\ 's-Gravenhage; 2518 AX The Hague, The Netherlands; mukhtarov@iss.nl \\ 3 Institute of Water Policy, Lee Kuan Yew School of Public Policy, National University of Singapore, \\ 469C Bukit Timah Road, \#02-03C, Singapore 259772, Singapore \\ * Correspondence: c.dieperink@uu.nl; Tel.: +31-30-253-2737
}

Received: 2 September 2019; Accepted: 25 September 2019; Published: 28 September 2019

\begin{abstract}
Although social learning is a key element of multilevel flood risk governance, it is hardly studied. This paper addresses this knowledge gap. The paper aims to identify enabling conditions for social learning in multilevel flood risks governance arrangements. We first conceptualize social learning and draw up a conceptual framework consisting of enabling conditions for social learning, using the literature on adaptive co-management, sustainable land and water management, and integrated flood risk management. Next, we apply this framework to analyze social learning in the context of the Dutch Room for the River program. Our interview results reveal that social learning about integrated flood protection measures took place at multiple levels. We found that a strong personal commitment to learning and mutual interpersonal trust in working groups are key conditions for successful social learning. Based on our analysis, we conclude with some recommendations for enhancing social learning processes in future flood protection programs.
\end{abstract}

Keywords: social learning; integrated flood risk management; Room for the River program; multilevel governance

\section{Introduction}

Population growth and increased socioeconomic activity in floodplains, combined with more recent effects of climate change, are important factors in the increase of flood risks [1,2]. A gradual shift is visible in flood management across a number of countries: from flood defense based on 'fighting against water' to flood risk management and 'living with water' [3,4]. This shift in flood protection measures over the last decades is known as integrated flood risk management (IFRM) and is increasingly adopted as the basis for a number of flood protection programs, e.g. in the Netherlands, the United Kingdom, and other countries [5-7]. Successful coexistence of the natural phenomenon of flooding and the human population depends largely on the organization of the governmental system and the decision-making process among mandated stakeholders. For IFRM, multiple actors at multiple policy levels need to collaboratively design and implement new flood risk management policies $[6,8]$. An integrated approach to flood risk governance includes both engineering solutions and spatial planning projects that are combined and aligned, such as spatial development, housing, economic activity, as well as governance solutions such as aligning funding from different policy domains and collaboration between multiple stakeholders [9-11]. IFRM can therefore, be seen as a multilevel and multistakeholder governance practice [12-14].

Growing scholarly interest in collaborative modes of governance stresses the complexity and uncertainty inherent to such institutional arrangements [14-18]. Collaborative arrangements are 
network structures where participating organizations depend on each other to achieve tasks that reach beyond their individual capacities [19]. Such interdependence requires the capacity for social learning for success and endurance of collaborative and multilevel arrangements. This realization has led to blossoming literature on social learning for collaborative institutions $[10,17,20-25]$. This literature discusses social learning in a natural resources management context. However, studies on social learning in the context of multilevel flood risk governance are rare, and we have not yet been confronted with studies that specify the conditions that enable social learning in flood risk governance.

This article deals with this gap in the literature by presenting a conceptual framework to study social learning in the context of flood risk governance arrangements, which is then applied in a case study. The case study concerns social learning in the Room for the River program, a multilevel flood risk management program in the Netherlands. The case involves multiple and diverse governmental actors, working collectively on flood risk management in the Netherlands.

Sections 2 and 3 reflect on the literature and conceptualize social learning for multilevel flood risk governance. For the conceptualization of social learning, we draw from literature on learning and organizational theories, which are related to the natural resources management domain. Suitable literature was found using Google Scholar and Scopus, by searching for different combinations of keywords like 'social learning', 'multi-level water governance', 'adaptive co-management', 'integrated flood risk management', 'learning process', 'collaborative learning' and 'multiple-loop learning'. In Section 4, the methods applied in the empirical part of the paper are explained. In Section 5, we present the results of the case study, leading to a discussion and conclusion in Section 6.

\section{Conceptualizing Social Learning: Three Debates}

Social learning is a key concept for adaptive co-management, multilevel governance, and integrated flood risk management (see e.g., $[10,13,15-18,20,21,26,27])$. Both complementary and overlapping definitions for social learning are found in these strands of literature. Social learning appears to be a highly debated concept in literature. Three debates can be distinguished, which concern the relation between individual and social learning (e.g., $[19,21,28]$, learning as an outcome or as a process $[15,25,29,30]$, and learning-levels and learning loops [6,31,32]).

A first important debate in the literature is the distinction between social learning as different from individual learning $[25,28,33]$. Scholars have maintained a distinction between individual learning and social learning $[14,19,21,34]$ in which the latter is based on deliberation and produces qualitatively different forms of decision-making as opposed to individual learning [35-37]. This line of research, for example, ventured to understand how individual learning may become social learning, as in the case of flood risk governance in the UK (e.g., [38]). As opposed to individual learning, the concept of social learning relates to notions of 'learning communities' and 'communities of practice' (e.g., [20]). These communities consist of people that share a common concern and pursue knowledge through regular interaction, based in practice [20]. It goes beyond individual learning (a football player improving his personal skills) or individuals learning together (football players who train their personal skills during team practice). Social learning here is understood to be a process of change at the group level [39] in which people learn from each other, which benefits the wider socioecological systems they operate in (e.g., river basins or community forests). For learning to be social, a change in understanding must occur at a larger scale, through social interaction [14,21]. Thomas and Allen [40] argue in a similar way for organizational learning, from which social learning is partially derived: 'while organizations learn through individual learning, organizational learning is not a cumulative result of individual learning. Rather, organizations learn when discoveries, evaluations, and insights by individuals are successfully embedded in the organization's mental models or cognitive systems and memories' (p. 125). To other scholars, however, collective learning may originate only when individual members of a collective learn and hence, is merely a sum of individual learning [41-43]. Heikkila and Gerlak [44] (p. 486), in turn, recognize the complexity of separating individual and collective learning in empirical settings and accept that learning may happen 'at multiple levels in collective settings, 
from individuals, to groups, organizations, and networks, and these levels are linked by dynamic social processes of producing and sharing knowledge' [44]. According to these scholars, the focus must be placed on the processes and products of learning rather than the relationship between the individual and collective learning, a view which is supported by Suskevics et al. [25].

Another area where a consensus is yet to emerge is in the debate on whether learning should be seen as a process or as an outcome $[21,25,29]$. Learning outcomes, or products, 'can include new shared ideas, strategies, or actions among the parties involved in the learning process' [19] (p. 4). Social learning outcomes are numerous (e.g., $[15,25,29,32])$. Among others, increased understanding of key issues, trust-building, acquisition of factual knowledge, and social skills are the results of social learning processes. The learning process, subsequently, is 'the set of actions that allow new information or knowledge to be acquired, processed and shared, and transferred across individuals within a group' [19] (p. 3). Mostert et al. [15] (p. 1,2) perceive social learning as a process within a specific context, which includes both a natural context (ecology, geography) and a social context (economy, culture, governance system). A learning process emerges when stakeholders realize they are interdependent in pursuing a goal or policy, which means that individual action will yield less or no result, and collaboration is thus necessary. The learning process can be initialized by the stakeholders or by an external party. According to Mostert et al. [15], the learning process involves 'the development of trust, joint problem definition, joint fact-finding, the development and assessment of different alternatives, joint decision-making, and joint planning for implementation' (p. 2). Process outcomes are, e.g., better relations, increased trust, and empowerment of stakeholders. They emphasize the participatory character of the process. Similarly, Bos et al. [30] define social learning as 'a collective process enabling change in a situation, as opposed to social learning as an outcome or 'emergent property' of a process to change a situation' (p. 399). The notion of social learning as a process points to 'actors developing shared meanings, values, and understanding through interaction, which provides the basis for joint future action' ([29,45] are quoted from [31]).

The third debate in the literature concerns the relative importance of various contextual factors in influencing the process and outcomes of social learning, which is a growing body of empirical literature that discusses case studies in individual and comparative settings. Medema et al. [32] and Pahl-Wostl [31] argue that learning processes are largely influenced by the governance system in which they are embedded. The governance structure includes 'the pertinent legal and organizational framework as well as the cultural and socioeconomic environment' [31] (p. 4). Social learning can be described as a multiscale process, hence learning can occur at multiple levels of agent interaction [31,32]. The macro-level is the level of the governance structure at societal level. The meso-level is at the level of actor networks, or organized stakeholder groups. The micro-level is at the level of collaboration processes between stakeholder representatives of flood protection authorities (i.e., actual meetings). According to Pahl-Wostl et al. [31], the multiparty collaboration processes are the 'nuclei' of the learning process (p. 5). When transferring this multiscale learning process to a geographical level, Huitema et al. [16] advocate a bioregional approach (i.e., at watershed level) for water governance, reflecting the micro-level of regional multi-party collaboration processes. With regard to conditions that explain learning processes, they will also pertain to the micro-level.

In this paper, we aim to contribute to these three debates by analyzing an empirical case in order to reveal what factors influence social learning in the context of multilevel flood risk governance.

\section{A Framework of Factors that Influence Social Learning}

To study learning in the setting of multilevel flood risk governance, we adopt the following definition for social learning (based on e.g., [15,17,18,20,21,23,27,46]:

Social learning is a process of change in understanding, that goes beyond the individual, at the micro-level of multi-party collaboration, aiming at collective action for integrated flood protection. 
By reviewing the abovementioned learning literature, we have found that most of the factors that will likely influence the learning process can be categorized into 4 categories-individual attributes, collaborative arena factors, organizational factors, and external context factors (see also [33]). Combined, these factors provide a framework that can be used to analyze learning processes (Figure 1).

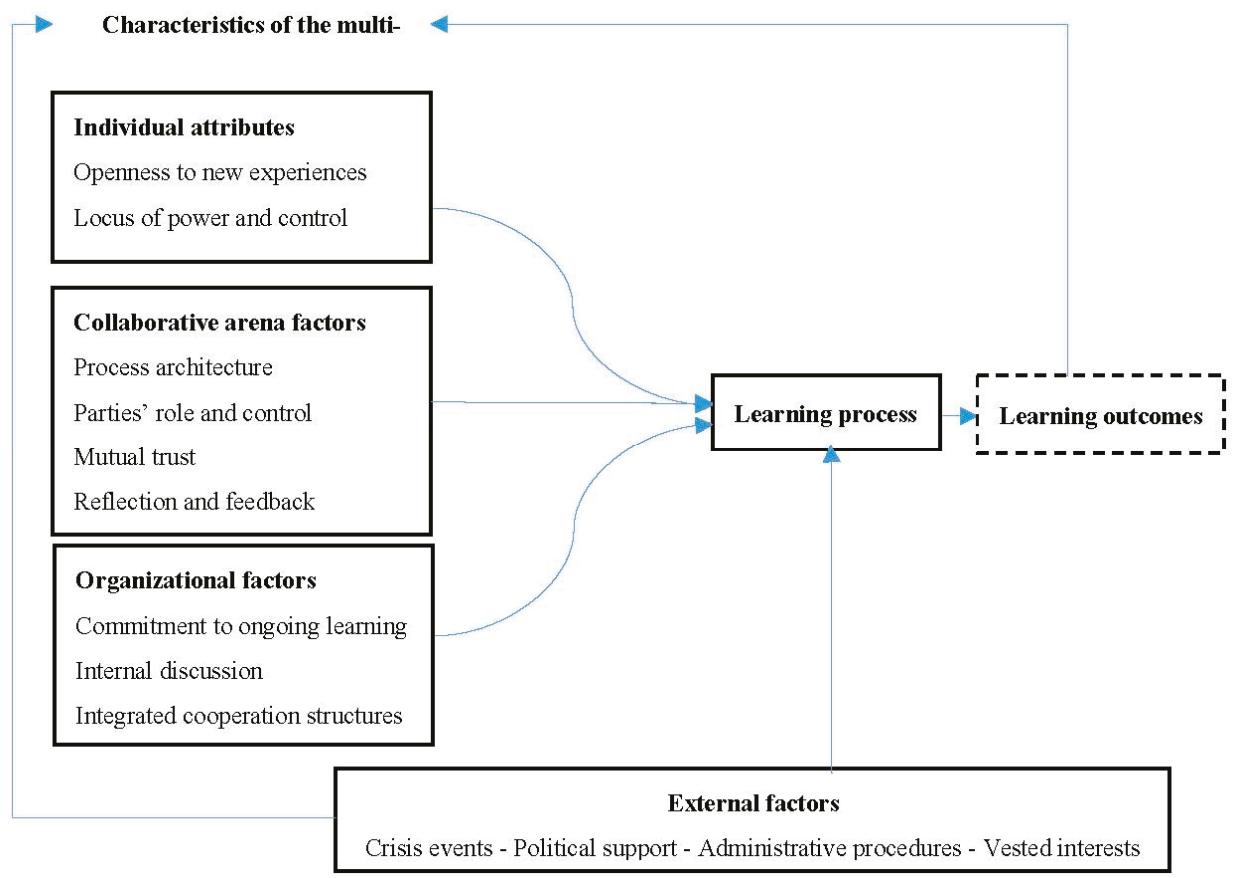

Figure 1. A framework for analyzing social learning.

\subsection{Individual Attributes}

Individual attributes (see Table 1) are described as the 'the micro-level factors relating to the reactions to change efforts by stakeholders and individuals involved in the learning process' or 'the psychological predispositions of the individuals experiencing change' [32] (p. 26); [47] (p. 107). Individuals and their characteristics form the basis through which learning is manifested [48]. First of all, a commitment to ongoing learning is an important characteristic of learning [49,50]. Individuals with personality traits like tolerance of ambiguity and openness to new experiences are better able to learn from experiences and are less eager to have a confirmation bias, i.e., searching for information that confirms their beliefs. The extent to which a person is flexible and open-minded is an important attribute for learning: when the individual has little resistance to changing the way things are done, he or she is more eager to learn from this situation [51-53]. Related to that is the capability for self-reflection, which is crucial for multiloop learning $[17,49,54-56]$ and the individual's perception and awareness of his own role and abilities to exercise control in certain situations, or locus of power and control $[51,57]$. Mostert et al. [15] stress that a legitimate process in which participants are willing to learn require high professional competence and motivation. Social skills, in the form of sticking to rules and principle of dialogue and interaction come into play when differing views and perceptions of parties may lead to conflict [15]. When participants address each other in a respectful manner, they are more likely to agree on core issues regarding the policy process, which improves learning. A factor that explains successful learning is previous experience with a multiparty approach [15]. A positive experience will make it more likely that participants are willing to learn from other participants. 
Table 1. Individual attributes influencing the social learning process.

\begin{tabular}{lll}
\hline \multicolumn{1}{c}{ Individual Attributes } & \multicolumn{1}{c}{ Description } & Authors \\
\hline Openness to new experiences & $\begin{array}{l}\text { Commitment to ongoing learning, capability for } \\
\text { self-reflection, flexible and open-minded attitude } \\
\text { to issues at hand, tolerance of ambiguity in policy } \\
\text { problems and solutions }\end{array}$ & {$[15,19,47,49-52,54,56,58]$} \\
\hline Locus of power and control & $\begin{array}{l}\text { Ability to control and influence one's } \\
\text { environment and hence feel engaged in policy } \\
\text { processes }\end{array}$ & {$[15,51,57]$} \\
\hline Social skills & $\begin{array}{l}\text { Ability to communicate, listen and express one's } \\
\text { opinion, and follow the rules of an open dialogue }\end{array}$ & {$[15,51]$} \\
\hline $\begin{array}{l}\text { Experience with multiparty } \\
\text { approaches }\end{array}$ & $\begin{array}{l}\text { Previous experience with multilevel governance } \\
\text { policy arenas }\end{array}$ & {$[15]$} \\
\hline
\end{tabular}

\subsection{Collaborative Arena Factors}

Collaborative arena factors (see Table 2) refer to the way the participatory process is organized and which actions and directions are taken during a policy planning and implementation phase. It is widely recognized that the structure of the institutional arrangement is an important explanatory factor in the occurrence or absence of social learning [19,34]. These factors determine if participants feel respected and heard [32]. Involving all relevant stakeholders in a participatory process for developing and implementing new policies is important [59]. With regard to collaboration, crucial factors in the participatory process are mutual trust, goodwill, and mutual understanding, as is acknowledged interdependency [58]. If lacking, learning is unlikely to occur as common understanding and goals will not be reached [60]. Openness and legitimacy of the participatory process through continuous feedback on the process (e.g., through distribution of meeting records, background documents, questionnaires) is important to create trust and goodwill [15,32]. The overall process architecture is an important condition in this respect. Frequent interaction among stakeholders is crucial for social learning [15]. Clear perspective and direction for feedback are crucial for multiloop learning, as the feedback navigates the process toward desired goals. It is also crucial that participants have clear expectations on the participatory process. A joint planning approach can facilitate this and also increase the transparency of the process, which in turn increases trust and goodwill [15,59]. Role and control of parties involved explaining what influence the role a party or representative has in the collaboration process and what the position of a party is relative to other parties. Related to that is having a neutral organizer or leader who facilitates and presides the participatory process so as to enable fair balancing of interests. This helps to build a democratic and enabling environment for learning processes, in which appropriate meeting formats and extended engagement (repeated and frequent interactions, field trips, bilateral contacts) facilitate trust, collective meaning, constructive conflict solving, that in turn help participants to create a sense of ownership and commitment toward the learning process [15,31,59]. Besides these rather intangible factors, available resources in the form of budget, time, and information are essential as well in order to facilitate a successful learning process. Feedback and reflection, provided there is a clear goal, create a loop in which participants can learn from their previous experiences, and consequently optimize the collaborative process. Framing and reframing of how a policy problem is perceived can open up individual perspectives, thereby creating win-win situations [61,62]. This results in improved mutual trust and better relations, factors previously marked as crucial for social learning. A final factor, communication, both internal (between members of the working groups) and external (to external parties or home organizations), is crucial for diffusion of information throughout the working group and to other organizations. 
Table 2. Collaborative arena factors influencing the social learning process.

\begin{tabular}{|c|c|c|}
\hline Collaborative Arena Factors & Description & Authors \\
\hline Process architecture & $\begin{array}{l}\text { Frequent interactions of working groups with appropriate } \\
\text { meeting formats, joint planning and a clear and shared } \\
\text { perspective, extended engagement, a transparent and } \\
\text { legitimate process for a democratic and enabling environment. }\end{array}$ & {$[15,17,54,55,58,59,61,63-66]$} \\
\hline $\begin{array}{l}\text { Role and control of parties } \\
\text { involved }\end{array}$ & $\begin{array}{l}\text { A neutral organizer or leader that includes all the relevant } \\
\text { stakeholders in the process. }\end{array}$ & {$[15]$} \\
\hline Reflection and feedback & $\begin{array}{l}\text { Continuous feedback on process and content, and framing and } \\
\text { reframing of issues and goals. }\end{array}$ & {$[15,58,66-72]$} \\
\hline Available resources & Knowledge, financial budget, time. & {$[15,55,58]$} \\
\hline
\end{tabular}

\subsection{Organizational Factors}

Organizational context factors (see Table 3) are preexisting forces in the governance system, which includes the internal context of the participants' home organization. Equality and balanced interests, or the lack thereof, as well as (a lack of) internal conflict on interests, are often mentioned as a prerequisite for social learning or frustrating learning [15], as equal treatment of and opportunities for participating and influencing the policy process will positively influence the learning process. Entering a long-term working relationship, thereby creating a horizontally and vertically integrated cooperation structure, brings the context of the participatory process and the home organization together $[15,32]$. It prevents contradictory decisions or recommendations in the internal context of an organization. Integration of knowledge and information sources through advanced information management is important in this respect. Bridging organizations, learning platforms facilitate institutional interplay, stimulate learning in the participatory process by providing connection between different scale and higher- and lower level organizations, thereby enabling the integration of knowledge $[16,59,70]$. According to Cash et al. [73], knowledge is stored and perceived differently at different levels, based on differing beliefs of what is credible and legitimate knowledge and the nature of the problem for which policy is developed and implemented. Cross-level linkages that allow access to validated information makes the information trustworthy and links the participants through the use of the information [74]. Organizational commitment to learning and overall involvement of parties in the process is an important condition for social learning. Continuity, facilitated by, e.g., transfer of information to other representatives of the same organization, fosters social learning [15]. This also creates a sense of belonging for the participants that feedback the process outcomes in their own organizations. Changing staff or participants during the participatory process hinders social learning, as knowledge and experience is lost. Consequently, being a reliable and consistent stakeholder in the policy formulation and implementation processes is important for a person's credibility and the extent to which other parties are willing to accept, e.g., new information [32]. 
Table 3. Organizational factors that influence the social learning process.

\begin{tabular}{lll}
\hline \multicolumn{1}{c}{ Organizational Factors } & \multicolumn{1}{c}{ Description } & \multicolumn{1}{c}{ Authors } \\
\hline Commitment to ongoing learning & $\begin{array}{l}\text { Internal commitment to learning as a way to improve } \\
\text { organizational practice. }\end{array}$ & {$[15,74]$} \\
\hline Internal discussion on interests & $\begin{array}{l}\text { Agreement on internal goals and interests, equality } \\
\text { and balanced interests. }\end{array}$ & {$[15,58]$} \\
\hline $\begin{array}{l}\text { Horizontally and vertically } \\
\text { integrated cooperation structures }\end{array}$ & $\begin{array}{l}\text { Institutional interplay in the internal context of the } \\
\text { organization, bridging organizations, integration and } \\
\text { synthesis of knowledge. }\end{array}$ & {$[17,46,58,59,70,74-78]$} \\
\hline $\begin{array}{l}\text { Integration of knowledge and } \\
\text { information sources }\end{array}$ & $\begin{array}{l}\text { Advanced information management and a sound } \\
\text { knowledge base for efficiency in policy development. }\end{array}$ & {$[58-60,79-84]$} \\
\hline Involvement of parties & $\begin{array}{l}\text { Reliability and consistency of partners, continuity of } \\
\text { staff in organizations. }\end{array}$ & {$[15,50,54]$} \\
\hline
\end{tabular}

\subsection{External Factors}

External context factors (see Table 4) are preexisting conditions and forces, but ones that are difficult to control by a specific governance regime [32]. Abrupt periods of change or crisis events (e.g., flooding or elections) are important drivers for change and hence for learning [15]. Such crises may turn out to be windows of opportunity for bringing about political support and supportive regulatory changes, which in turn can alter lengthy administrative procedures that hinder social learning [32]. Vested interests may hinder social learning, since existing regulatory frameworks are supported, allowing little room for lessons in social learning processes [15]. Existing laws and regulation also affect learning processes due to inflexible working processes that leave little room for change.

Table 4. External context factors influencing the social learning process.

\begin{tabular}{lll}
\hline \multicolumn{1}{c}{ External Factors } & \multicolumn{1}{c}{ Description } & \multicolumn{1}{c}{ Authors } \\
\hline Crisis event (calamity, elections) & $\begin{array}{l}\text { Events like floods or election can disrupt } \\
\text { collaborative processes. }\end{array}$ & {$[15,51,58,60,79,85]$} \\
\hline Political support & Supportive regulatory and political framework. & {$[15,51,55,60,79,85,86]$} \\
\hline Administrative procedures & Lengthy and complex procedures, e.g., permits. & {$[15]$} \\
\hline Existing laws and regulations & Path dependency, inflexible working processes. & {$[15]$} \\
\hline
\end{tabular}

\section{Methods: Case Characteristics and Data Collection}

The framework presented in the previous chapter is used for studying social learning in the context of multilevel flood risk governance. An eye-catching example of multilevel flood risk governance is the Dutch Room for the River (RftR) program. Aim of the program is to increase the buffering capacity of the Rhine river branches (Waal, IJssel and lower Rhine) in case of high water levels. This is done by creating more room for rivers and their branches through making more space for water by, e.g., dike relocation and the lowering of floodplains (Figure 2). By doing this, the Netherlands can deal with higher water levels $\left(16.000 \mathrm{~m}^{3} / \mathrm{s}\right.$ instead of from $\left.15.000 \mathrm{~m}^{3} / \mathrm{s}\right)$ that may enter the country at Lobith, where the river Rhine crosses the German-Dutch border [87]. 


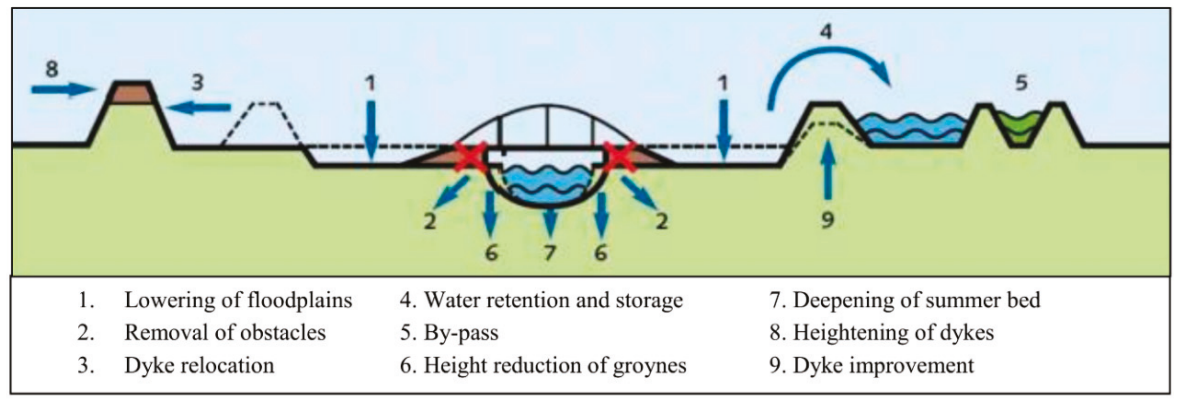

Figure 2. Measures applied to create more room for river in the Room for the River program. Adapted from [13].

The program consisted of 34 separate projects, with a total budget of $€ 2.3$ billion. It had a dual goal: both flood protection and spatial quality in the riverine area are increased, by means of, e.g., dike replacement and nature development. Hence, multiple disciplines and organizations are involved in designing and implementing the measures for making room for the river. It is exemplary for a multilevel governance program, as multiple actors, multiple disciplines, and multiple policy and decision-making levels are represented in the program both in the design and executive phase $[13,88]$. The program involved numerous formal and informal relationships among a group of organizations that agreed to achieve certain goals in a set period of time and a fixed budget. Nevertheless, competing demands and interests occurred.

RftR was initiated in 2000 and was finalized in mid-2017 [89]. From 2008/2009 until approximately 2012, the chosen projects were meticulously prepared by an extensive multilevel stakeholder collaboration process (including e.g., Rijkswaterstaat, provinces, water authorities, municipalities, citizens, societal organizations (e.g., nature conservation organizations, environmental groups)). Early involvement of politicians and non-governmental stakeholders was deemed crucial for establishing commitment and support [88]. The program had a long duration (2000-2017) which allowed for learning-by-doing [10], but it also requires an adaptive approach to deal with ongoing changes in both the internal and external context of the program, like changing stakeholder interests and configuration, socioeconomic developments (e.g., elections or economic crises), and new scientific findings [90]. Two government ministries (Ministry of Economic Affairs and the Ministry of Infrastructure and Environment, I\&E), together with eight water authorities, seven provinces, and thirty municipalities, were responsible for the execution of the projects in the program [91]. Fifteen out of 34 projects are executed by Rijkswaterstaat, the remaining 19 are executed mainly by water authorities, and some by provinces and municipalities.

In order to find out what learning has taken place during the Room for the River process, two rounds of in-depth, semi-structured, face-to-face interviews $(\mathrm{N}=16)$ were conducted with policy officers of governmental organizations involved in the RftR program (Rijkswaterstaat, Provinces, municipalities, water authorities). These governmental organizations were chosen since in the Netherlands they have the mandate and responsibility for flood risk management, as opposed to civil organizations or interest groups. The first round of interviews was instrumental in activating the respondents in recalling learning processes since they occurred over long periods of time. The second round of interviews (with the same interviewees) was based on a topic list that was adapted from the conceptual framework (Figure 1) including the possibility to add conditions that respondents felt were instrumental to social learning processes and were not mentioned in the initial framework. We assumed that respondents were able to clarify and distinguish the lessons learned and the different conditions that affected their learning processes. By asking follow-up questions during and after the interviews, we managed to get a better insight into the respondents' perceptions. 
Within the program, respondents were selected based on their involvement in either an administrative guidance group (ABG) or a licensing authority working group (AWBG) or both. The first was mainly involved in designing projects, whereas the latter is responsible for the permit procedures for, e.g., soil removal. These working groups were chosen as the platform for selecting respondents because the multilevel governance arrangement is institutionalized in these structures, i.e., all layers of governmental parties in the Dutch water sector are represented in these working groups. Represented are water authorities, Provinces, municipalities, Rijkswaterstaat RftR program directorate (PDR), and Rijkswaterstaat regional offices.

Supplementary to interviews, mid-term and end-term reviews commissioned by the PDR were used to gain insight into the overall RftR program and its performance on, e.g., timing and budget [92-95].

The interview results were transcribed, arranged, and coded using an excel table, which corresponded with the interview topic list: a list of learning outcomes and a list of enabling factors and how they influence learning.

\section{Results}

\subsection{Learning Outcomes}

The learning outcomes we found can be clustered in collective products [19], development of relations, and new shared interests, ideas, and strategies.

Examples of collective products are new strategies for, e.g., permit procedures, the introduction of life cycle costing in the design phase of the projects, strict record-keeping of complex decision-making procedures, and the creation of a bridging organization that facilitates knowledge exchange between projects. Besides, the use of Integrative Project Management (IPM) was introduced during the RftR program and later used in other, non-flood related projects as well. These IPM teams perform five very specific roles with corresponding responsibilities related to major infrastructural projects. The development of relations shows in the frequent so-called 'milestone celebrations', frequent face-to-face meetings, both official and in the field and flexible attitudes in formal operations (e.g., the occurrence of shared debates). Shared meaning shows in the parties' recognition and acknowledgment of one another's interests. At some point, parties were able to bring their own interests to the table, without denying other parties theirs. New strategies show in the early involvement of a broad range of stakeholders in the projects to allow for a joint project, that is broadly supported. Showing the added value of the project and choosing the right party to lead the project in its different phases is a learning outcome that has been instrumental in ensuring the progress of the projects.

\subsection{Learning Process}

The main findings from the interviews suggest that social learning in the Room for the River project is highly influenced by individual attributes and collaborative arena factors, and less by external context and organizational factors, as shown in Table 5.

\subsubsection{Individual Attributes}

Respondents confirmed that openness to new experiences, self-reflection, and flexibility add to a social learning process. Individuals that are open for new experiences are more likely to observe the lessons to be learned and are more willing to change. 'Learning is change' (interviewee 1), 'Every now and then you should take a little distance from your own work, and reflect on what's going well, what you should do different. That is the most important thing. [..] Because if you're not open for learning and change, you won't change' (1). Social skills or the ability to express yourself and formulate interests and arguments is paramount. This skill works in two ways: having the right social skills helps to formulate your own or organizations' point of view in the discussion, but also helps to recognize and formulate viewpoints from other parties or individuals in the collaboration process. It is seen by many as a precondition for collaboration and consequently for learning. 


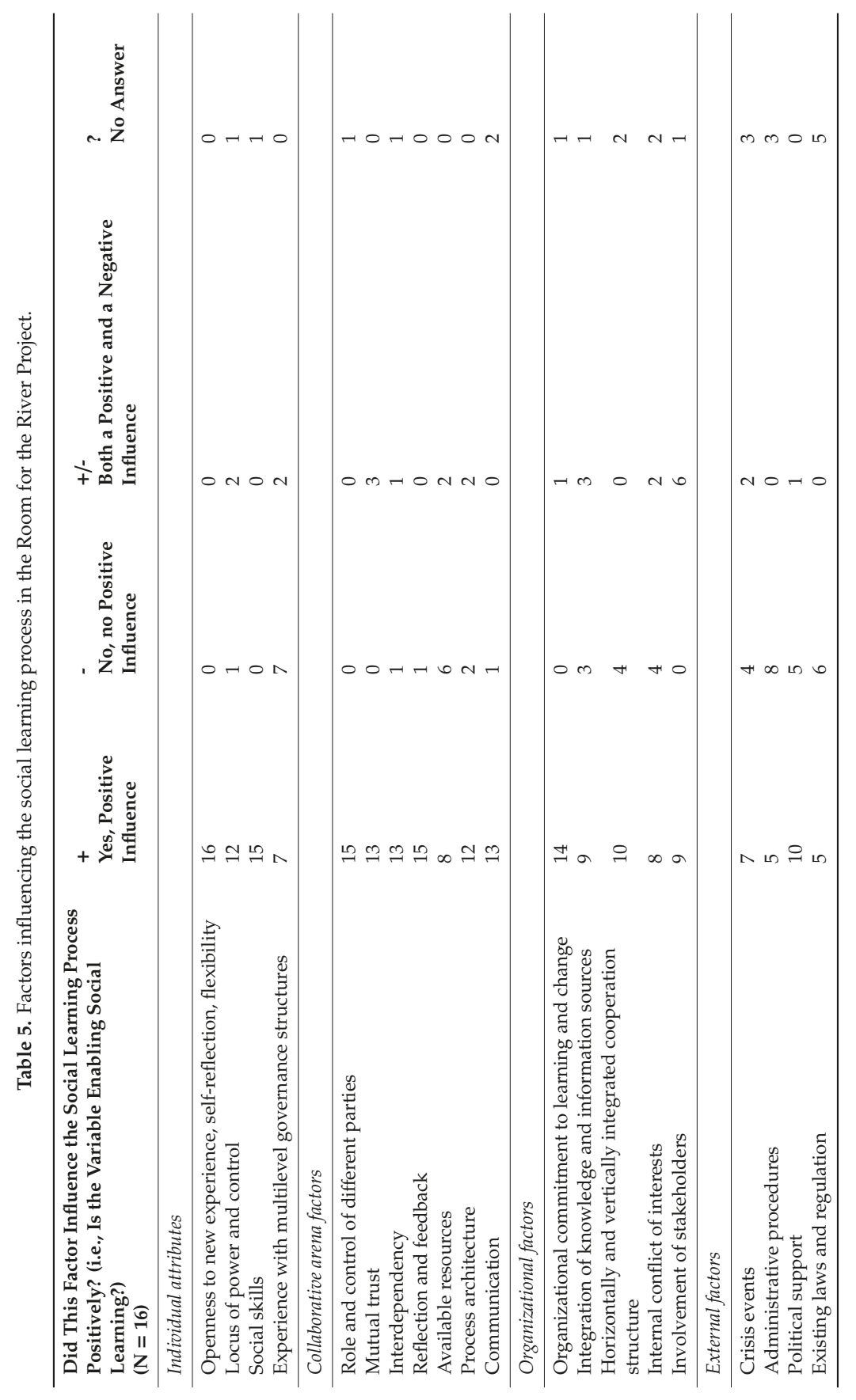




\subsubsection{Collaborative Arena Factors}

The role and control of different parties and reflection and feedback is seen by almost all respondents as a positive influence on the social learning process. Mutual trust and interdependency are also seen as preconditions for social learning, although some argue that trust is a precondition for collaboration but not necessarily for learning. Some even argue that a little distrust or suspicion has a positive influence on learning, 'because you learn most of someone who does things differently than you do' (interviewee 2). The opposite was also rhetorically addressed: 'Would you learn without trusting someone? I don't think so. So first of all you'll have to trust someone before you can learn anything. That is crucial. But trust is something you earn. And you earn trust by letting go of the details and checks. [... ] So giving trust in fact' (interviewee 3). The importance of trust is explained by most respondents by linking it to a safe environment for learning, in which people trust each other and share their issues. A safe learning environment through mutual trust is seen as a precondition for social learning by many respondents. The score for both a negative and a positive influence on learning is explained by learning when collaboration is not successful. As a respondent explained: 'Collaboration does not always have to be successful in order to learn, you can also learn when collaboration isn't working out. And you might even learn more from that, but not as a group. You'll learn as an individual, but as a group you won't, because everyone has withdrawn in his own island again' (interviewee 2). An additional condition that was mentioned in the interviews which influences the level of trust in a working group is stereotypical thinking. Due to parties having a certain image of each other, or ideas about each other's working processes, stereotypical thinking occurs, which negatively affects the collaboration process and consequently the level of trust in a working group. This is also related to previous experiences with other parties. When starting a new project with the same party, it frequently occurs that the participants start the project with a certain idea about the other parties, which frustrates an open start of the project and creates unrealistic or wrong expectations, which in turn affects the level of trust in a working group. Role and control of parties determine which position in the collaboration process you have, which also shapes the interdependency relation with the other parties. This relation determines what your attitude is toward other parties and delineates different tasks.

Reflection, feedback, and trust have a reciprocal relation, as trust is needed before individuals will give feedback and reflect on the collaborative process. Reflection is a joint activity in which the collaborative process so far or process outcome is reflected, whereas feedback is of a more personal nature, between individuals and their performance. Both yield the same results: explicit lessons to be learned to improve the collaborative process. For the other factors, results are mixed. The process architecture appears to be an important condition influencing social learning. The frequency of meetings, field trips, and extended engagement through bilateral contacts are helpful in formulating expectations and frameworks for the team to work with. It helps to delineate the process and creates the network in which the parties operate and the agreements on which the collaboration is based. Communication, both internal and external, is seen by many as part of the process architecture and a positive influence on social learning. Without communication in the working group, no information or feedback is fed back in the collaboration process, which would hamper social learning. Timing and what to communicate and what not were mentioned as well. Time was the only resource that was explicitly mentioned by respondents as a resource that influenced learning. Its effect is both positive and negative: getting time to do a task more than once to gain experience helps learning, but time pressure frustrates learning since there is only a little time for feedback and reflection.

\subsubsection{Organizational Context}

The internal context of an organization enables learning to such an extent that the organizations that are involved in the working groups need to have a commitment to learning in order for working group members to learn and for social learning to occur. Organizational commitment to learning allows representatives to deviate from the business as usual, which is beneficial for a social learning process: 'Regarding commitment to learning, I think that has been one of the major strengths of the Room 
for the River program. [ ... ] On all levels, this commitment was created' (interviewee 4). So, it is both a condition in the program and a result of the intensive collaboration processes throughout the program. Integration of knowledge and information sources is important in the context of sharing experiences, but less in sharing actual information and knowledge. The PDR would organize special training days for IPM-team members (e.g., technical manager, contract manager, location manager) to share their experiences and consequently learn from each other. The PDR also made sure that experts from the program office had cross-knowledge of all projects to prevent similar problems to occur and to transfer experiences and knowledge from one project to another. However, this points at sharing of experiences, and less to actual integration of information, which is therefore seen as less crucial. The negative score for this condition is explained by the fact that information and knowledge management was organized very well by the PDR, and there was a strong focus on facilitation of knowledge sharing to decentralized parties, so the necessity for parties to integrate their own information sources was small (see also [95] (p. 28)). Internal conflict on interests were deemed less important for social learning as they are mainly solved in the representatives' home organization, but aligning these different interests is a lesson in itself, although not a 'social lesson'. Involvement of stakeholders also contributes to learning in an ambiguous manner. Involvement of stakeholders was mainly seen as the continuity of staff and consistency in one's role and representation of the home organization. The influence of changing staff on social learning depends on the number of people that are replaced and their function; when too many people leave at once and from a specific team, the collective memory of the organization is affected, but a small change in staff every now and then results in new, fresh ideas that help to learn. It must be noted that this is also an indirect condition for social learning as this condition was researched for the internal context of an organization and not the multilevel governance structure.

\subsubsection{External Context}

Overall, external context conditions seem less important conditions for social learning compared to individual attributes and process factors. Political support is seen as both a positive influence and a negative influence on social learning; on one side, political support improves the collaborative process and creates space for a project to get going, whereas the lack of political support will create tension in the collaboration structure. A respondent formulated the role of political support like this: 'The lack of political support creates an even more urgent need to have a successful learning process I think. You are regarded more critically, which means the story you bring about the project needs to be really good. [ ...] when you just go with what the alderman says or wants, he'll like the ideas, and be more like 'we'll just do this', instead of 'why do we want this?', and 'is this really the best option?' (interviewee 5). It shows the need to be more critical of your own work, which helps to learn. On the other hand, political support for the outcome of a design process will create commitment in the working group, which may positively influence learning.

Crisis events do not directly contribute to social learning, but project-hiccups tend to bring project teams closer together, which in turn may positively influence collaboration and social learning. Administrative procedures do not directly influence social learning, except when they slow down the process to such an extent that the collaboration process suffers from a loss of trust, which frustrates social learning. The same goes for existing laws and regulations.

\section{Concluding Remarks}

This paper aimed to identify enabling conditions for social learning in multilevel flood risk governance. We found that most of the factors identified in the conceptual framework are relevant in a direct or indirect way to the learning processes in the RftR program. So, learning processes in multilevel flood risk governance are influenced by individual attributes, collaborative arena factors, organizational factor, and external factors. However, our case study results indicate that a hierarchy of conditions can be identified.

Individual attributes and collaborative arena factors can be labeled as key, whereas organizational factors and external factors are deemed supportive. Individual attributes of participants in IFRM 
projects seem to play a major role in the social learning process, as a participants' individual attributes ultimately determine the commitment to learning.

The relative importance of individual attributes and collaborative arena factors in the social learning process is also reflected in recent work of Bentley Brymer et al. [95], who state that a change in understanding (see [21]) is foremost an individual step that takes place in multiple dimensions of their understanding. On collaborative arena or process factors, they state that factors that trigger social learning are mostly inclusiveness, extended engagement, opportunities for information exchange, and opportunities for dialogue and interaction, which correspond closely with the factors in our framework. Studies on the Quebec water governance system [96] and the Bangladesh Adaptive Delta Management [97] show findings that also point at some kind of hierarchy in the conditions for social learning. Our findings on the importance of external factors is to some extent contradicted by Johannessen et al. [98], who state that transformations in water governance are often triggered by crises. This can be explained by their focus on multiple-loop learning and the outcomes of social learning, as opposed to a focus on the process of social learning.

However, more comparative future research on conditions for social learning in different contexts should point out the validity of this hypothesis (e.g., [99]). It would, for instance, be interesting to find out whether studying social learning in the context of the German Room for the River project results in the same findings. Moreover, future studies should also pay attention to political indecisiveness and distrust and other factors hampering social learning. Such studies could result in a more validated theory on social learning in multilevel flood risk governance. A very relevant topic to do further research on is how the level of centralization of the government system, as for instance addressed by Bonasia and Lucatello [100], affects social learning processes. In the Netherlands, the governmental system is very centralized (see e.g., [101]), which leads to a clear distinction of tasks and responsibilities, whereas in, e.g., Mexico, the governmental system is much more decentralized, which affects decision making in disaster risk management [100]. Further application in different socioeconomic contexts would further help refine the framework and judge its usefulness in understanding and facilitating learning processes in flood risk governance.

The framework drawn up in this paper is based on literature on natural resources management, adaptive co-management, and social learning. As another avenue for future research, the framework may be enriched by adding additional insights or governance conditions based on stakeholder theory [102], communities of practice [103], and network governance [104].

Social learning appeared to be a process that lacks a starting point as well as a finish line. Learning itself may emerge from both success and failure. It is a constant process of balancing stakes, sharing information, and the creation of mutual trust and collective memory. Learning itself is an intangible process that may happen without the learner fully aware of it, and is mostly identifiable in retrospect. So multilevel flood risk governance asks for the setup of learning organization or platforms in which reflection and openness to change are core qualities. More specifically, we conclude that in order to enhance the changes on successful learning, such a learning organization can try to mitigate influencing conditions. Process factors and internal context can be organized as such that individuals committed to learning are attracted and are willing to participate in a collaborative process. A program directorate can trigger social learning processes by designing specific learning workshops, in which mutual trust and reflection are addressed. Besides, a learning organization can contribute to learning processes by actively taking up a bridging function in the sharing of knowledge and experiences throughout the program. Learning from past experiences is of great importance for the development of future flood risk governance programs.

Author Contributions: Conceptualization, J.d.B., C.D., F.M.; Methodology, J.d.B., C.D., F.M.; Validation, C.D., F.M.; Formal Analysis, J.d.B.; Investigation, J.d.B.; Writing-Original Draft Preparation, J.d.B., C.D. F.M.; Writing-Review \& Editing, C.D, F.M.; Supervision, C.D.

Funding: This research received no external funding. 
Acknowledgments: The authors would like to greatly acknowledge Cor Beekmans for his contribution in creating the opportunity to carry out this research project at the Rijkswaterstaat Room for the River Program and his valuable feedback and in-depth discussions on the research outcomes. We also would like to thank the anonymous reviewers for their valuable feedback on the article.

Conflicts of Interest: The authors declare no conflict of interest.

\section{References}

1. Klijn, F.; Kreibich, H.; De Moel, H.; Penning-Rowsell, E. Adaptive flood risk management planning based on a comprehensive flood risk conceptualization. Mitig. Adap. Strateg. Glob. Chang. 2015, 20, 845-864. [CrossRef] [PubMed]

2. Pahl-Wostl, C.; Becker, G.; Knieper, C.; Sendzimir, J. How multilevel societal learning processes facilitate transformative change: A comparative case study analysis on flood management. Ecol. Soc. 2013, 18, 58. [CrossRef]

3. Zevenbergen, C.; Veerbeek, W.; Gersonius, B.; Van Herk, S. Challenges in urban flood management: Travelling across spatial and temporal scales. J. Flood Risk Manag. 2008, 1, 81-88. [CrossRef]

4. Baird, J.; Plummer, R.; Moore, M.L.; Brandes, O. Introducing resilience practice to watershed groups: What are the learning effects? Soc. Nat. Resour. 2016, 29, 1214-1229. [CrossRef]

5. Bubeck, P.; Kreibich, H.; Penning-Rowsell, E.C.; Botzen, W.J.W.; De Moel, H.; Klijn, F. Explaining differences in flood management approaches in Europe and in the USA-A comparative analysis. J. Flood Risk Manag. 2017, 10, 436-445. [CrossRef]

6. Van Herk, S. Delivering Integrated Flood Risk Management: Governance for Collaboration, Learning and Adaptation; CRC Press: Delft, The Netherlands, 2014.

7. Gaddis, E.; Grellier, J.; Grobicki, A.; Hay, R.; Mirumachi, N.; Mukhtarov, F.; Rast, W. Freshwater Policy. In Global Environment Outlook-GEO-6: Healthy Planet, Healthy People; UN Environment: Nairobi, Kenya, 2019.

8. Serra-Llobet, A.; Conrad, E.; Schaefer, K. Governing for integrated water and flood risk management: Comparing top-down and bottom-up approaches in Spain and California. Water 2016, 8, 445. [CrossRef]

9. $\quad$ Evans, E.P.; Ashley, R.; Hall, J.W.; Penning-Rowsell, E.C.; Saul, A.; Sayers, P.B.; Watkinson, A. Foresight Flood and Coastal Defence Project: Scientific Summary: Volume I, Future Risks and their Drivers; Office of Science and Technology: London, UK, 2004; p. 366.

10. Van Herk, S.; Rijke, J.; Zevenbergen, C.; Ashley, R. Understanding the transition to integrated flood risk management in the Netherlands. Environ. Innov. Soc. Trans. 2015, 15, 84-100. [CrossRef]

11. Mukhtarov, F. The Hegemony of Integrated Water Resources Management: A study of Policy Translation in England, Turkey and Kazakhstan. Ph.D. Thesis, Central European University, Budapest, Hungary, 2009.

12. Van Herk, S.; Rijke, J.; Zevenbergen, C.; Ashley, R. Governance of integrated flood risk management to deliver large scale investment programmes: Delivery focused social learning in the Netherlands. In Proceedings of the Floodrisk 2012 -2nd European Conference on Flood Risk Management, Rotterdam, The Netherlands, 20-22 November 2012.

13. Rijke, J.; van Herk, S.; Zevenbergen, C.; Ashley, R. Room for the River: Delivering Integrated River Basin Management in the Netherlands. Int. J. River Basin Manag. 2012, 10, 369-382. [CrossRef]

14. Schusler, T.M.; Decker, D.J.; Pfeffer, M.J. Social learning for collaborative natural resource management. Soc. Nat. Resour. 2003, 14, 309-326. [CrossRef]

15. Mostert, E.; Pahl-Wostl, C.; Rees, Y.; Searle, B.; Tàbara, D.; Tippett, J. Social learning in European river-basin management: Barriers and fostering mechanisms from 10 river basins. Ecol. Soc. 2007, 12, 19. [CrossRef]

16. Huitema, D.; Mostert, E.; Egas, W.; Moellenkamp, S.; Pahl-Wostl, C.; Yalcin, R. Adaptive water governance: Assessing the institutional prescriptions of adaptive (co-) management from a governance perspective and defining a research agenda. Ecol. Soc. 2009, 14, 26. [CrossRef]

17. Pahl-Wostl, C. A conceptual framework for analysing adaptive capacity and multi-level learning processes in resource governance regimes. Glob. Environ. Chang. 2009, 19, 354-365. [CrossRef]

18. Van Herk, S.; Zevenbergen, C.; Rijke, J.; Ashley, R. Collaborative research to support transition towards integrating flood risk management in urban development. J. Flood Risk Manag. 2011, 4, 306-317. [CrossRef]

19. Gerlak, A.K.; Heikkila, T. Building a theory of learning in collaboratives: Evidence from the Everglades Restoration Program. J. Public Adm. Res. Theory 2011, 21, 619-644. [CrossRef] 
20. Armitage, D.; Marschke, M.; Plummer, R. Adaptive co-management and the paradox of learning. Glob. Environ. Chang. 2008, 18, 86-98. [CrossRef]

21. Reed, M.; Evely, A.C.; Cundill, G.; Fazey, I.R.A.; Glass, J.; Laing, A.; Newig, J.; Parrish, B.; Prell, C.; Raymond, C.; et al. What is social learning? Ecol. Soc. 2010, 15, r1. [CrossRef]

22. Crona, B.I.; Parker, J.N. Learning in support of governance: Theories, methods, and a framework to assess how bridging organizations contribute to adaptive resource governance. Ecol. Soc. 2012, 17. [CrossRef]

23. Cundill, G.; Rodela, R. A review of assertions about the processes and outcomes of social learning in natural resource management. J. Environ. Manag. 2012, 113, 7-14. [CrossRef]

24. Ison, R.L.; Collins, K.B.; Wallis, P.J. Institutionalising social learning: Towards systemic and adaptive governance. Environ. Sci. Policy 2015, 53, 105-117. [CrossRef]

25. Suškevičs, M.; Hahn, T.; Rodela, R.; Macura, B.; Pahl-Wostl, C. Learning for social-ecological change: A qualitative review of outcomes across empirical literature in natural resource management. J. Environ. Plan. Manag. 2018, 61, 1085-1112. [CrossRef]

26. Mukhtarov, F.G. Intellectual history and current status of Integrated Water Resources Management: A global perspective. In Adaptive and Integrated Water Management; Springer: Berlin, Germany, 2008; pp. 167-185.

27. Berkes, F. Evolution of co-management: Role of knowledge generation, bridging organizations and social learning. J. Environ. Manag. 2009, 90, 1692-1702. [CrossRef] [PubMed]

28. Freeman, R. Learning in public policy. Oxf. Handb. Public Policy 2006. [CrossRef]

29. Muro, M.; Jeffrey, P. A critical review of the theory and application of social learning in participatory natural resource management processes. J. Environ. Plan. Manag. 2008, 51, 325-344. [CrossRef]

30. Bos, J.J.; Brown, R.R.; Farrelly, M.A. A design framework for creating social learning situations. Glob. Environ. Chang. 2013, 23, 398-412. [CrossRef]

31. Pahl-Wostl, C.; Craps, M.; Dewulf, A.; Mostert, E.; Tabara, D.; Taillieu, T. Social learning and water resources management. Ecol. Soc. 2007, 12, 5. [CrossRef]

32. Medema, W.; Light, S.; Adamowski, J. Integrating adaptive learning into adaptive water resources management. Environ. Eng. Manag. J. 2014, 13, 1801-1816.

33. Cangelosi, V.E.; Dill, W.R. Organizational learning: Observations toward a theory. Adm. Sci. Q. 1965, 10, 175-203. [CrossRef]

34. Newig, J.; Günther, D.; Pahl-Wostl, C. Synapses in the network: Learning in governance networks in the context of environmental management. Ecol. Soc. 2010, 15, 24. [CrossRef]

35. Cook, S.D.; Yanow, D. Culture and organizational learning. J. Manag. Inq. 1993, 2, 373-390. [CrossRef]

36. Knight, L. Network learning: Exploring learning by interorganizational networks. Hum. Relat. 2002, 55, 427-454. [CrossRef]

37. Senge, P. The Art and Practice of the Learning Organization; Currency Doubleday: New York, NY, USA, 1990; pp. 126-138.

38. Benson, D.; Lorenzoni, I.; Cook, H. Evaluating social learning in England flood risk management: An 'individual-community interaction' perspective. Environ. Sci. Policy 2016, 55, 326-334. [CrossRef]

39. Argyris, C.; Schön, D.A. Organizational Learning III; Addison Wesley: Boston, MA, USA, 2006.

40. Thomas, K.; Allen, S. The learning organization: A meta-analysis of themes in literature. Learn. Organ. 2006, 13, 123-139. [CrossRef]

41. March, J.G.; Olsen, J.P. The uncertainty of the past: Organizational learning under ambiguity. Eur. J. Polit. Res. 1975, 3, 147-171. [CrossRef]

42. Simon, H.A. Bounded rationality and organizational learning. Organ. Sci. 1991, 2, 125-134. [CrossRef]

43. Wenger, E. Communities of practice: Learning as a social system. Syst. Think. 1998, 9, 2-3. [CrossRef]

44. Heikkila, T.; Gerlak, A.K. Building a conceptual approach to collective learning: Lessons for public policy scholars. Policy Stud. J. 2013, 41, 484-512. [CrossRef]

45. Pahl-Wostl, C.; Sendzimir, J.; Jeffrey, P.; Aerts, J.C.J.H.; Berkamp, G.; Cross, K. Managing change toward adaptive water management through social learning. Ecol. Soc. 2007, 12, 30. [CrossRef]

46. Huntjens, P.; Pahl-Wostl, C.; Rihoux, B.; Schlüter, M.; Flachner, Z.; Neto, S.; Koskova, R.; Dickens, C.; Nabide Kiti, I. Adaptive water management and policy learning in a changing climate: A formal comparative analysis of eight water management regimes in Europe, Africa and Asia. Environ. Policy Gov. 2011, 21, 145-163. [CrossRef] 
47. Judge, T.A.; Thoresen, C.J.; Pucik, V.; Welbourne, T.M. Managerial coping with organizational change: A dispositional perspective. J. Appl. Psychol. 1999, 84, 107. [CrossRef]

48. Walker, J.H.; Armenakis, A.A.; Bernerth, J.B. Factors influencing organizational change efforts: An integrative investigation of change content, context, process and individual differences. J. Organ. Chang. Manag. 2007, 20, 761-773. [CrossRef]

49. Wanberg, C.R.; Banas, J.T. Predictors and outcomes of openness to changes in a reorganizing workplace. J. Appl. Psychol. 2000, 85, 132-142. [CrossRef] [PubMed]

50. Hofstede, G. The business of international business is culture. Int. Bus. Rev. 1994, 3, 1-14. [CrossRef]

51. Lankford, B.A.; Merrey, D.; Cour, J.; Hepworth, N. From Integrated to Expedient: An Adaptive Framework for River Basin Management in Developing Countries; International Water management Institute: Colombo, Sri Lanka, 2007.

52. Gasteyer, S.; Flora, C.B. Measuring ppm with tennis shoes: Science and locally meaningful indicators of environmental quality. Soc. Nat. Res. 2000, 13, 589-597.

53. Kusel, J.; Williams, L.; Danks, C.; Perttu, J.; Wills, L.; Keith, D.; LP Group. A Report on All-Party Monitoring and Lessons Learned from the Pilot Projects. Forest Community Research and The Pacific West. National Community Forestry Center; Technical Report No. 101-2000; Forest Community Research: Taylorsville, CA, USA.

54. Sol, J.; Beers, P.J.; Wals, A.E. Social learning in regional innovation networks: Trust, commitment and reframing as emergent properties of interaction. J. Clean. Prod. 2013, 49, 35-43. [CrossRef]

55. Pressman, J.L.; Wildavsky, A.B. Implementation: How Great Expectations in Washington are Dashed in Oakland: Or, Why It's Amazing that Federal Programs Work at All, This Being a Saga of the Economic Development Administration as Told by Two Sympathetic Observers Who Seek to Build Morals on a Foundation of Ruined Hopes; University of California Press: Berkeley, CA, USA, 1984.

56. Webster, J. Culture's influence: Towards understanding stakeholder interactions in rural water, sanitation and hygiene promotion projects. Ph.D. Thesis, Cranfield University, Cranfield, UK, 2007.

57. Rotter, J.B. Generalized expectancies for internal versus external control of reinforcement. Psychol. Monogr. Gen. Appl. 1966, 80, 1. [CrossRef]

58. Verbeeten, T. Wijs met de Waddenzee. Ph.D. Thesis, University of Utrecht, Utrecht, The Netherlands, 1999.

59. Muro, M.; Jeffrey, P. Time to talk? How the structure of dialog processes shapes stakeholder learning in participatory water resources management. Ecol. Soc. 2012, 17. [CrossRef]

60. Medema, W. Integrated water resources management and adaptive management: Shaping science and practice. PhD Thesis, Cranfield University, Cranfield, UK, 2008.

61. Dewulf, A.; Craps, M.; Bouwen, R.; Taillieu, T.; Pahl-Wostl, C. Integrated management of natural resources: Dealing with ambiguous issues, multiple actors and diverging frames. Water Sci. Technol. 2005, 52, 115-124. [CrossRef] [PubMed]

62. Van Buuren, A. Knowledge for governance, governance of knowledge: Inclusive knowledge management in collaborative governance processes. Int. Public Manag. J. 2009, 12, 208-235. [CrossRef]

63. McGinnis, M.D. Polycentric Games and Institutions: Readings from the Workshop in Political Theory and Policy Analysis; University of Michigan Press: Ann Arbor, MI, USA, 2000.

64. Geels, F.W.; Green, K. General introduction: Systems innovation and transitions to sustainability. In System Innovation and the Transition to Sustainability: Theory, Evidence and Policy; Elzen, B., Geels, F.W., Green, K., Eds.; Edward Elgar Publishing: Cheltenham, UK, 2004.

65. Keen, M.; Mahanty, S. Collaborative learning: bridging Scales and Interests, In Social learning in Environmental Management: Towards a Sustainable Future; Dyball, R., Keen, M., Eds.; Routledge: London, UK, 2012; pp. $20-38$.

66. Dyball, R.; Brown, V.; Keen, M. Towards sustainability: Five strands of social learning. In Social Learning Towards a Sustainable World; Principles, Perspectives, and Praxis; Wals, A.E.J., Ed.; Wageningen Academic Publishers: Wageningen, The Netherlands, 2007; pp. 181-195.

67. Staw, B.M.; Ross, J. Stability in the midst of change: A dispositional approach to job attitudes. J. Appl. Psychol. 1985, 70, 469. [CrossRef]

68. Bohm, D. On Dialogue; Routledge: Abingdon, UK, 2004.

69. Alvesson, M.; Sköldberg, K. Reflexive Methodology: New Vistas for Qualitative Research; Sage: Thousand Oaks, CA, USA, 2000.

70. Folke, C.; Hahn, T.; Olsson, P.; Norberg, J. Adaptive governance of social-ecological systems. Annu. Rev. Environ. Resour. 2005, 30, 441-473. [CrossRef] 
71. Keen, M.; Mahanty, S. Learning in sustainable natural resource management: Challenges and opportunities in the Pacific. Soc. Nat. Resour. 2006, 19, 497-513. [CrossRef]

72. Fernandez-Gimenez, M.; Ballard, H.; Sturtevant, V. Adaptive management and social learning in collaborative and community-based monitoring: A study of five community-based forestry organizations in the western USA. Ecol. Soc. 2008, 13, 4. [CrossRef]

73. Cash, D.W.; Adger, W.N.; Berkes, F.; Garden, P.; Lebel, L.; Olsson, P.; Pritchard, L.; Young, O. Scale and cross-scale dynamics: Governance and information in a multilevel world. Ecol. Soc. 2006, 11, 8. [CrossRef]

74. Keen, M.; Bruck, T.; Dyball, R. Social learning: A new approach to environmental management. In Social Learning in Environmental Management: Towards a Sustainable Future; Keen, M., Brown, V., Dyball, R., Eds.; Earthscan: London UK, 2005; pp. 3-21.

75. Berman, P.; McLaughlin, M.W. Federal Programs Supporting Educational Change: Vol. VIII, Implementing and Sustaining Innovations; Rand Corporation: Santa Monica, CA, USA, 1978.

76. Weick, K.E. Small wins: Redefining the scale of social problems. Am. Psychol. 1984, 39, 40. [CrossRef]

77. Measham, T. Combining people, place and learning. In Social Learning in Environmental Management: Towards a Sustainable Future; Keen, M., Brown, V.A., Dyball, R., Eds.; Routledge: Abingdon, UK, 2005.

78. Johannessen, Å.; Hahn, T. Social learning towards a more adaptive paradigm? Reducing flood risk in Kristianstad municipality, Sweden. Glob. Environ. Chang. 2013, 23, 372-381. [CrossRef]

79. Somach, S.L. Closing the Policy-Practice Gap in Water Resources Planning. J. Contemp. Water Res. Educ. 1993, 90, 5 .

80. Ostrom, E. Vulnerability and polycentric governance systems. IHDP Update 2001, 3, 1-4.

81. Adger, W.N.; Arnell, N.W.; Tompkins, E.L. Successful adaptation to climate change across scales. Glob. Environ. Chang. 2005, 15, 77-86. [CrossRef]

82. Pahl-Wostl, C. The importance of social learning in restoring the multifunctionality of rivers and floodplains. Ecol. Soc. 2006, 11, 10. [CrossRef]

83. Young, O. Designing environmental governance systems: The diagnostic method. In Proceedings of the Keynote at IDGEC Synthesis Conference, Bali, Indonesia, 6-9 December 2006; pp. 9-11.

84. Ostrom, E. Developing a method for analyzing institutional change. In Assessing the Evolution and Impact of Alternative Institutional Structures; Batie, S.M.N., Ed.; Routledge: Abingdon, UK, 2008.

85. Olsson, P.; Gunderson, L.; Carpenter, S.; Ryan, P.; Lebel, L.; Folke, C.; Holling, C.S. Shooting the rapids: Navigating transitions to adaptive governance of social-ecological systems. Ecol. Soc. 2006, 11, 18. [CrossRef]

86. Wurbs, R.A. Dissemination of generalized water resources models in the United States. Water Int. 1998, 23, 190-198. [CrossRef]

87. Programmadirectie Ruimte voor de Rivier. Planologische Kernbeslissing Ruimte voor de Rivier; Vastgesteld besluit: Utrecht, The Netherlands, 2006.

88. Herk, S.; van Rijke, J.; Zevenbergen, C.; Ashley, R.; Besseling, B. Adaptive co-management and network learning in the Room for the River programme. J. Environ. Plan. Manag. 2015, 58, 554-575. [CrossRef]

89. Programmadirectie Ruimte voor de Rivier. 31e Voortgangsrapportage Ruimte voor de Rivier, Verslagperiode 1 Juli-31 December 2017. Utrecht/Den Haag. 2018. Available online: https:/www.rijksoverheid.nl/documenten/ rapporten/2018/04/03/31e-voortgangsrapportage-ruimte-voor-de-rivier (accessed on 17 August 2018).

90. Hertogh, M.J.C.M.; Baker, S.; Staal-Ong, P.L.; Westerveld, E. Managing Large Infrastructure Projects: Research on Best Practices and Lessons Learnt in Large Infrastructure Projects in Europe; AT Osborne BV: Hilversum, The Netherlands, 2008.

91. Programmadirectie Ruimte voor de Rivier. 28e Voortgangsrapportage Ruimte voor de Rivier, Verslagperiode 1 Januari-30 Juni 2016. Utrecht/Den Haag. 2016. Available online: https://www.europa-nu.nl/id/vk7bkdpd1kz4/ agenda/28e_voortgangsrapportage_ruimte_voor_de (accessed on 8 August 2016).

92. Andersson Elffers Felix. 3/4 Evaluatie Ruimte voor de Rivier. Utrecht, The Netherlands. 2013. Available online: https://www.aef.nl/ruimte-voor-de-rivier-4602157c-36c7-443e-960e-e158e7aa63a1 (accessed on 8 August 2016).

93. Ten Heuvelhof, E.; Bruijn, H.; de Wal, M.; de Kort, M.; Vliet, M.; van Noordink, M.; Böhm, B. Procesevaluatie totstandkoming PKB Ruimte voor de Rivier; Berenschot: Utrecht, The Netherlands, 2007.

94. Twist, M.; van Heuvelhof, E.; ten Kort, M.; Olde Wolbers, M.; Berg, C.; van den Bressers, N. Tussenevaluatie PKB Ruimte voor de Rivier; Berenschot: Utrecht, The Netherlands, 2011.

95. Bentley Brymer, A.L.; Wulfhorst, J.D.; Brunson, M.W. Analyzing stakeholders' workshop dialogue for evidence of social learning. Ecol. Soc. 2018, 23. [CrossRef] 
96. Medema, W.; Adamowski, J.; Orr, C.J.; Wals, A.; Milot, N. Towards sustainable water governance: Examining water governance issues in Québec through the lens of multi-loop social learning. Can. Water Resour. J. 2015, 40, 373-391. [CrossRef]

97. Mutahara, M.; Warner, J.F.; Wals, A.E.; Khan, M.S.A.; Wester, P. Social learning for adaptive delta management: Tidal River Management in the Bangladesh Delta. Int. J. Water Resour. Dev. 2018, 34, 923-943. [CrossRef]

98. Johannessen, Å.; Gerger Swartling, Å.; Wamsler, C.; Andersson, K.; Arran, J.T.; Hernández Vivas, D.I.; Stenström, T.A. Transforming urban water governance through social (triple-loop) learning. Environ. Policy Gov. 2019, 29, 144-154. [CrossRef]

99. Armitage, D.; Dzyundzyak, A.; Baird, J.; Bodin, Ö.; Plummer, R.; Schultz, L. An Approach to Assess Learning Conditions, Effects and Outcomes in Environmental Governance. Environ. Policy Gov. 2018, 28, 3-14. [CrossRef]

100. Bonasia, R.; Lucatello, S. Linking Flood Susceptibility Mapping and Governance in Mexico for Flood Mitigation: A Participatory Approach Model. Atmosphere 2019, 10, 424. [CrossRef]

101. Wiering, M.; Kaufmann, M.; Mees, H.; Schellenberger, T.; Ganzevoort, W.; Hegger, D.L.T.; Larrue, C.; Matczak, P. Varieties of flood risk governance in Europe: How do countries respond to driving forces and what explains institutional change? Glob. Environ. Chang. 2017, 44, 15-26. [CrossRef]

102. Friedman, A.L.; Miles, S. Stakeholders: Theory and Practice; Oxford University Press: Oxford, UK, 2006.

103. Wenger, E. Communities of practice and social learning systems: The career of a concept. In Social Learning Systems and Communities of Practice; Springer: Berlin, Germany, 2010; pp. 179-198.

104. Sørensen, E.; Torfing, J. Introduction governance network research: Towards a second generation. In Theories of Democratic Network Governance; Palgrave Macmillan: London, UK, 2007; pp. 1-21.

(C) 2019 by the authors. Licensee MDPI, Basel, Switzerland. This article is an open access article distributed under the terms and conditions of the Creative Commons Attribution (CC BY) license (http://creativecommons.org/licenses/by/4.0/). 


\title{
City-To-City Learning for Urban Resilience: The Case of Water Squares in Rotterdam and Mexico City
}

\author{
Silvana Ilgen ${ }^{1}$, Frans Sengers ${ }^{1,2}$ and Arjan Wardekker ${ }^{1,3, *}$ \\ 1 Copernicus Institute of Sustainable Development, Utrecht University, P.O. Box 80115, 3508TC Utrecht, \\ The Netherlands; silvana.ilgen@gmail.com (S.I.); F.Sengers@uu.nl (F.S.) \\ 2 Department of Geography, King's College London, 40 Aldwych, London WC2B 4BG, UK \\ 3 Centre for the Study of the Sciences and the Humanities, University of Bergen, P.O. Box 7805, \\ 5020 Bergen, Norway \\ * Correspondence: J.A.Wardekker@uu.nl; Tel.: +31-30-253-4407
}

Received: 11 April 2019; Accepted: 7 May 2019; Published: 10 May 2019

\begin{abstract}
Cities worldwide are building 'resilience' in the face of water-related challenges. International networks have emerged through which urban communities draw on each other's experiences and expertise in order to become resilient cities. Learning is a key principle in resilience-building, but thus far little empirical research is available on city-to-city learning and learning for urban resilience. This paper presents an analysis of how policy relevant knowledge on the notion of 'Water Squares' is exchanged between Rotterdam and Mexico City. We mobilize a framework composed of four distinct phases: exploration and marketing (phase 1), building pipelines (phase 2), translation and adoption (phase 3), and internalization and reflection (phase 4). Critical in first phase was introspective analysis of one's own systems, strengths and weaknesses, rather than an outward-looking search for knowledge or mentees. During the second phase, the cities reframed their own narratives to match those of their counterparts as a way to create a mutual understanding of each other's struggles and histories. This facilitated policy and knowledge exchange as equal partners on a basis of trust. In the third phase, strong local leaders were recruited into the process, which was key to anchor knowledge in the community and to reduce the risks of losing institutional memory in centralized, hierarchical institutions. For the fourth phase it should be stressed that by internalizing such lessons, cities might strengthen not only their own resilience, but also enhance future exchanges with other cities.
\end{abstract}

Keywords: city-to-city learning; policy transfer; resilient cities; water squares

\section{Introduction}

More than half of the world's population lives in cities and these numbers are still rising [1]. Cities are under intensive pressure to accommodate the needs of these rapidly growing populations, including providing adequate and safe housing, production activities and work, and resources such as energy, food, and water. The expansions of cities and the urban adaptations that were made have given rise to sprawling metropolises beset by a range of social and environmental problems [2]. Many current and future global challenges relate to the interaction of urbanization and its social and environmental impacts, and cities may therefore host both the problems but also the potential solutions to these challenges [3].

Climate change is a key sustainability challenge to the future development of cities. Potential effects of climate change range from flooding to drought, impacts on water quality and availability, and impacts on critical infrastructures, health, food supply, tourism, biodiversity, housing, and communities [1]. These can result in short-term disruptions and disasters in cities, as well as have a broader and long-term influence on urban resource and population dynamics and environmental and 
social equity. In cities worldwide, and in developing countries in particular, these impacts are expected to also exacerbate numerous existing problems $[1,4,5]$. The impacts and their interactions with other societal challenges are, however, complex and uncertain [6]. The need is widely recognized for societies at large, and cities in particular, to better promote and govern a transition towards sustainability [7-9]. This includes mitigation, reducing greenhouse gas emissions, but also making cities more resilient to climate change and other social, economic, and environmental challenges [8-10].

The notion of 'urban resilience' has become prevalent in urban thinking. The Habitat III New Urban Agenda [9], for instance, focuses considerable attention on the need to improve urban resilience, including to climate change. Resilience is one among a number of urban sustainability concepts, such as 'smart', 'low carbon', and 'eco cities' [11]. The term 'resilient city' refers an urban area that has the ability to withstand and cope with a wide range of shocks and stresses, including the ability to plan/prepare, absorb, recover, and adapt to such disturbances [12,13]. The literature on urban resilience encompasses a wide range of scientific fields, including urban ecology $[14,15]$, urban hazards and disaster studies [16,17], urban and regional economics [18], governance and institutions [19], spatial planning [20-22], and climate change adaptation [12,23]. Resilience is particularly focused on living with change and coping with disturbances in complex adaptive systems, with multiple pressures, economic sectors, policy fields, and scientific disciplines involved, and high levels of uncertainty [22-27]. Urban water systems are a prime example of such a situation, combining highly interwoven social, ecological, and technical systems with changing and highly uncertain pressures and requirements due to climate change and a multitude of other urban trends [28,29]. In many places, water scarcity and uncertainty are already forcing a re-think about the way governments manage their water resource systems [19]. Urban water reforms and adaptations should result in resilient water systems that explicitly take into account complexity, uncertainty, and immediate and long-term change [30].

Many cities are now incorporating resilience thinking into urban planning at large, and specifically with regard to climate change adaptation. Different cities will (or may want to) opt for different strategies to improve resilience, and toolkits have been developed to design resilience strategies and policy options appropriate for a city (e.g., [31-35]), and to scrutinize choices and trade-offs made in that process (e.g., [36-39]). Several international organizations and networks have been established to stimulate resilience-building, as well as actively exchange policies and knowledge as a way to facilitate mutual learning. Examples include Local Governments for Sustainability (ICLEI), the Asian Cities Climate Change Resilience Network (ACCCRN), and 100 Resilient Cities. On the broader topic of sustainability, a wide range of such networks has emerged, often with a similar organization, large role for regionally-oriented cities, but irregular representation of developing regions [40]. The importance and potential of such networks for improving systems and building sustainability and resilience is widely recognized [40-44]. Policy exchange, knowledge transfer, and learning in these networks can help cities enhance policy innovation [44-46]. For urban policymakers, their peer network in other cities, and exchanges through conferences and city networks, are key sources of information and new ideas [47]. According to an UNESCO-IHE flyer [48], advantages of city-to-city learning include: accelerated transfer of knowledge and experience, joint knowledge creation, empowerment of local governments, reinforcing local networks, enhancing collective memory of participating cities, and increasing learning capacity. Learning is also described as a key characteristic of resilient socio-ecological systems, including cities [5,49]. However, individual cities learn in different ways [50], and full social learning can be hampered in situations of diverging perceptions, framing, values, interests, and levels of power [5]. Between cities, further difficulties may emerge due to differences in the culture and language, specifics of the local situation, institutions and regulations, and even the specific ways in which agents and persons involved in the knowledge and policy transfer act or handle the situation $[40,46]$. Consequently, while cities can learn much from each other, stimulated by the resources and reach of transnational city networks, such knowledge and policy transfer may not always run smoothly and requires constant dedicated work [51]. 
At the moment little is known about the mechanisms that underpin knowledge and policy transfer on urban resilience among cities, and about what barriers and stimuli that influence this process. The literature available on the topic is often prescriptive rather than descriptive [52]. Clearly, it is not simply a matter of cutting and pasting from one location to another. Cities are already actively trying to exchange ideas and best practices, and there is a need for more systematic knowledge on how this can be facilitated. This paper examines a case where such policy transfer is actively and intentionally pursued, using a preliminary analytical framework. Particular attention will be paid to the actors, processes, practices, and structures involved in the transfer. This study will focus on the transfer of resilience thinking and practices between Rotterdam and Mexico City, and will draw lessons from the observations made in this process. More specifically, we will investigate city-to-city learning around the notion of the Water Square-a best practice project already implemented Rotterdam and yet to be implemented in Mexico City.

\section{Materials and Methods}

To investigate city-to-city learning for the transfer of policy and adaptation measures to build urban resilience in the context of climate change, we conduct an empirical, in-situ analysis. Our approach can be described as an 'explanatory case study' because we do not only explore or describe in-situ learning but also develop theory to deepen our understanding of key processes or mechanisms and $[53,54]$. We examine the case of Mexico City and Rotterdam, two cities currently actively engaged in a process of policy and knowledge exchange, particularly on Rotterdam's concept of Water Squares (Section 2.1). Tangible best practices projects like water squares are of special interest here because they became focal points in collaboration efforts and a vessel that facilitated much wider transnational knowledge flows and broader lessons about urban resilience in general. We examine this process of city-to-city learning sparked by these water squares in action through semi-structured interviews, site visits, and participant observation (Section 2.2). This process is assessed using a preliminary analytical framework (Section 2.3).

\subsection{Case Study}

The resilience literature widely acknowledges learning as a key aspect in the resilience of complex adaptive systems, including cities, and crucial for policymaking under uncertainty and complexity $[5,12,52,55-58]$. In such cases knowledge is always incomplete and change and surprise are inevitable [48] Learning is related to capacities, such as innovativeness and resourcefulness, as well as to practices and relations, such as experimentation, knowledge sharing, and collaboration. Learning has been used loosely in the resilience literature, combining notions of individual, organizational, and social learning [57]. Bahadur and Thornton [52] observe that much of the resilience literature is prescriptive on learning-describing practices that cities employ to stimulate learning. They argue that a closer, more practical look at learning in empirical context is needed, exploring the situational aspects that determine whether learning occurs or faces barriers, in order to overcome the current idealized and prescriptive notions of knowledge and learning for urban resilience. In line with this reasoning, this paper will explore a case of learning for resilience from an empirical in-situ standpoint: as the process of learning unfolds.

To develop such an in-situ understanding, we investigate the case of policy and knowledge transfer between Rotterdam and Mexico City. This entails an effort to 'mobilize' knowledge from Rotterdam to enhance water resilience in Mexico City. Both cities have flooding-related vulnerabilities, and Rotterdam has been very active (and successful) in flood risk management. Both cities are still searching for options that will enhance their water resilience. Both have appointed 'Chief Resilience Officers' and recently published a 'Resilience Strategy' [59,60]. There are also notable differences, including geographic, cultural, political, and institutional, that could influence the successfulness and ease of policy and knowledge transfer. A coordinated effort has recently been started to exchange 
experiences and knowledge, providing a valuable opportunity to study this process in action. We will briefly discuss the background of both cities and the water squares case.

Mexico City (Mexico) is a city of 8.9 million residents (city proper), with a subtropical highland climate. The city is located in the lower part of the Mexico Valley Basin around $2200 \mathrm{~m}$ above sea level, in a former lakebed surrounded by mountains. The lake system used to act as natural drainage for precipitation run-off, which was carried down by rivers and streams from the higher elevations that surround the basin. The hydraulic cycle of the lake system has been extremely and irreversibly transformed. Mexico City has made some achievements in water management, but continues to face challenges and vulnerabilities to flooding and water availability due to the structural features of the water system, changed hydrological cycle in the basin, and unequal access to supply and to drainage services [61]. Mexico City has been faced with wet years and floods alternating with episodes of drought. Average yearly precipitation in Mexico City is $846.1 \mathrm{~mm}$. It is relatively concentrated in one half of the year. Key climate related challenges include flooding due to heavy precipitation and flash floods, heat waves (combined with a heavily urbanized area), and drought and water scarcity. Groundwater extraction from the aquifer below the city is also leading to soil subsidence.

Rotterdam (The Netherlands) is a city of 0.6 million residents (city proper), with a temperate oceanic climate. The city is located in Western Europe, at the Rhine-Meuse-Scheldt river delta and North Sea coast. The city is located on river banks, polders, and reclaimed land, and much of the city is below sea level (up to $-6 \mathrm{~m}$ ). Rotterdam hosts one of the largest harbors in the world, and its economy is heavily dependent on the careful control of water. The city has longstanding experience and expertise regarding water management, and is currently pairing urban renewal with water sensitive and resilient adaptation (e.g., [23,62]). Specific water challenges include precipitation runoff in the low-lying polders due to more intense rain showers, and riverine and sea-based flooding in unembanked areas and flood risks in the polders. Average yearly precipitation in Rotterdam is $855.6 \mathrm{~mm}$, relatively spread out over the year. Key climate related challenges include flooding due to heavy precipitation, flood risks from sea and rivers, and heat waves (combined with a heavily urbanized area). Drought and soil subsidence are an issue, but less than in Mexico City, partly also because drinking water is extracted from the river rather than the aquifer. Drinking water scarcity is no issue.

The 'Water Squares' in Rotterdam were demonstration projects developed in the context of the Rotterdam Water City 2035 program, and the earlier Water Plan 2. The Benthemplein Water Square [63], completed in 2013, is the best-known, but several other squares have been developed. The squares core concept is that they are dry under regular conditions, and can be used as a public square, but can temporarily store rainwater during downpours. The squares are recessed (one or more aboveground basins) and connected to underground basins and sometimes groundwater infiltration devices. These provide buffer capacity, allowing rainwater from the square and surrounding buildings to be retained until the city sewage system can better handle the discharge. The water squares explicitly aim for multi-functional solutions, such as rainwater buffering, making water management more visible to the public (communication), and enhancing the quality of public space. Rotterdam and Mexico City have taken such squares as focal point in their collaboration. In Rotterdam, water squares have been developed to the north and to the west of the city center, and lessons learned from these early designs have been included in the Zoho Climate-Proof District (north of the center), which expands on the earlier designs with broader climate and social resilience efforts, such as explicit attention for community initiatives. All of these locations are highly urbanized areas, and slightly below sea level $(0$ to $-1 \mathrm{~m}$ ), protected by dikes. In Mexico City, proposals focused on the Iztapalapa district, a highly urbanized, low elevation area on the former lake bed of Lake Texcoco. For a detailed description of the design process in Mexico City, see [64,65]. See Figures 1 and 2 for locations of the water squares and climatic profiles of the Netherlands and Mexico. Supplementary Materials S3 contains further details on the climate in both cities. 

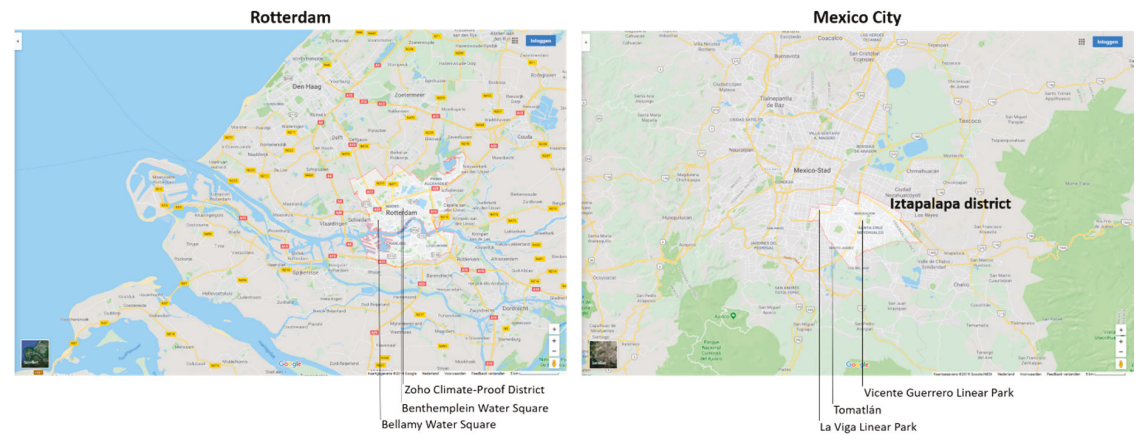

Figure 1. Locations of the water squares in Rotterdam (left) and proposed locations in Mexico City (right) (map source: Google Maps).
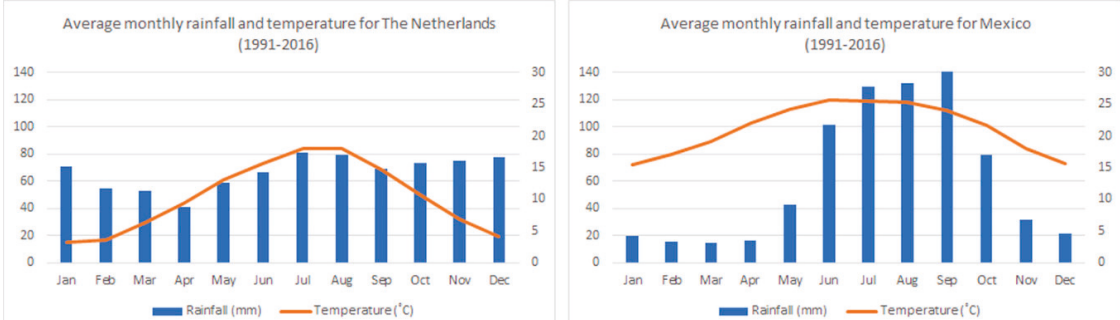

Figure 2. Temperature and precipitation profiles for the Netherlands (left) and Mexico (right) (data source: World Bank Climate Change Knowledge Portal; data from: CRU, University of East Anglia).

\subsection{Data Collection and Analysis}

To explore the actors and issues relevant to the case study, two helicopter interviews were conducted with the architectural firm that designed the water squares and with an international governmental organization involved in city-to-city knowledge transfer.

A first set of ten in-depth semi-structured interviews was conducted with actors in Mexico City, Rotterdam, and international organizations involved explicitly in the transfer of knowledge and policies concerning the water squares. These were focused interviews, exploring the specifics of the collaborations. A second set of ten semi-structured, but more open-ended interviews was held with various actors involved in the broader collaboration and knowledge exchange on water and resilience between the Netherlands and Mexico, including other water resilience projects. These interviews provided information on the local, national, and international context of the case study and potential barriers and stimuli that might and did arise. Interviews were transcribed, coded in nVivo, and qualitatively analyzed. An anonymized list of the interviews and the coding scheme can be found in the Supplementary Materials.

Other data was collected using site visits and participant observation. The first author was embedded in the Dutch embassy in Mexico, which is highly relevant because for the case of the water square this organization fulfilled the role of an 'innovation intermediary' [66]. The embassy played an important role in coordinating and facilitating knowledge exchange between Mexico City and Rotterdam. Specific project sites were visited to gain a good understanding of the local situation. Furthermore, the first author participated in local project meetings and workshops on the water square project as well as five other collaborative water resilience projects and events. As participant observer (cf. $[67,68])$, the researcher had a moderate to active level of participation in the resilience projects and could observe the collaboration, decision-making, and social interactions in this network at close hand and in-situ. Observations were recorded in a logbook and qualitatively analyzed. They provided 
valuable insight into the tacit aspects of city-to-city knowledge and policy exchange, such as social and cultural aspects, supplementing the more formal setting of individual interviews.

\subsection{Analytical Framework}

An empirical, in-situ analysis requires a process-based analytical framework, rather than a conceptual principle-based one. One challenge is that, as noted above, most literature on learning for resilience is prescriptive rather than empirical. Another challenge is that most sources focus on learning within communities and cities, not on learning between them. Orleans Reed et al. [5] do provide a process model for resilience learning in the context of the ACCCRN network. Steps include: gathering information and perspectives on hazards, socio-economic development and urban plans; vulnerability assessments; pilot projects and sector studies; developing a resilience strategy; city interventions; and learning from interventions, revisions, and further networking. However, this model also focuses on learning within cities ('shared learning' with local stakeholders), rather than knowledge and policy transfer between cities. Process frameworks like these are reminiscent of resilience analysis process methods (e.g., $[23,69,70])$, but with more focus on implementation design and testing, including pilots and strategy development. e.g., Wardekker et al. [70]: characterizing the system; characterizing the disturbances; inventorying options/plans; evaluating options/plans; follow-up analysis; and adjust plans/options and repeat if needed. Roughly, such frameworks contain an exploration/orientation phase on the context and issues, followed by inventory or design of pilots, options, plans or strategies (which may include implementing pilots or early measures), and an evaluation, testing, reflection, and refinement phase. While both in-city learning frameworks and general resilience assessment frameworks are relevant for city-to-city learning, they do not cover the full process of interaction that takes place between cities.

Contrasting this with the notions above, the framework would need to place more emphasis on the contact and interaction between cities (before detailed city-to-city subject-matter discussions and exchange take place) and the anchoring of the transferred knowledge (after the exchange of knowledge). Consequently, we have structured our analysis using a four-phased analytical model that describes different stages in the interaction and learning process between cities (see Figure 3 for an overview, elaboration per phase below).

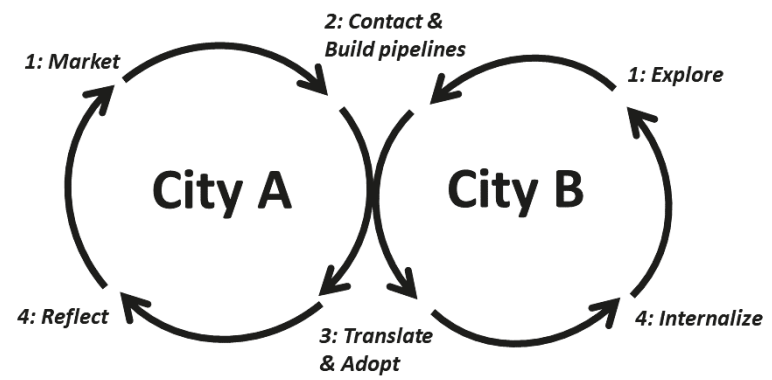

Figure 3. A circular model of the process of city-to-city knowledge transfer. City A imparts its knowledge on City B.

We start with the idea that communication channels for knowledge exchange can be purposely created to foster resilient urban development. Before these channels between knowledge providers and users can be constructed, urban actors need to become aware of their current knowledge resource and assess that is value based on comparison to others [2,5,71]. This includes critical reflection on the knowledge available, knowledge culture, local setting (institutions, regulations, history, ecology, geography, and socio-political dynamics), and physical water infrastructure in their own city and in other cities [28]. In reality not all other places can be assessed in the same way to see if they are 
viable candidates for knowledge exchange, and shortcuts are taken. Some actors are more adaptable than others in telling success stories and framing their city as a 'place of best practice' [51]. Notable examples include Copenhagen flaunting its expertise on cycling, Bogota peddling its knowledge on inclusive public transport across the globe and, most importantly for this paper, Rotterdam marketing its water know-how. Other cities are drawn to these cities and their best practice narrative in their exploration for policy relevant knowledge to reshape their urban environment in similar ways. We therefore refer to this first phase as the 'exploration and marketing phase', where knowledge providers in best-practice city A seek to market their knowledge and the knowledge users in city B seek to explore the wares that best-practice cities like A are selling.

Second, since the actors involved are anchored in different local settings, a concerted effort needs to be made by two cities to connect. The potential linkages dreamed up in phase 1, through the marketing and exploration of knowledge stocks, need to be translated into real connections and formalized collaboration agendas. This solidifies the transfer channels between city A and city B. To make this happen city A and city B will need to reflect on each other's situations and develop mutual expectations [72]. They also need to consider the transfer, translation, or transformation of policy models [46]. Similar to regular strategic program development [29], we expect that developing a shared vision and securing long-term commitment will also be important for knowledge and policy transfer programs. It is important to note that different kinds of policy-relevant knowledge travel through these transfer channels-not only codified knowledge (such as text in manuals and guide books about alleged best practices in city A) but also tacit knowledge (experimental and practical insights embodied in the actors of city A not ready made to be implemented in city B). Elements of both tacit- and codified knowledge can be exchanged locally and globally when the 'local buzz' of vibrant information exchange and interactive learning within local milieus of city A links up with receptive local milieus in city $B$. Knowledge is embodied in actors and actors engage in the building of 'pipelines' to communicate and harness extra-local knowledge flows [71,73]. Therefore, we refer to this as the 'build pipelines phase'.

Third, the policy-relevant knowledge from city A, which has travelled along with the relevant actors through the solidified channels, needs to be implemented in city B. This is not simply a matter of taking a policy from one location and implementing it in another. Rather, it involves adapting it to a specific local context, practice and policy community, with a focus on the political process $[45,46,74]$. Local adaptive capacity, in general and of local institutions, is a relevant factor in this stage (cf. [75]). In other words, a process of translation takes place before adoption. The eventual adoption of this knowledge results in concrete changes into the material and intuitional fabric of city B. We call this the 'translate and adopt' phase.

Fourth, looking back on this process over the previous phases, the hopeful expectation is that actors in city B-but also city A-have increased their knowledge pool and deepened their understanding of infrastructures and processes that foster urban resilience and that both are now more motivated and better equipped to transfer their knowledge to even more cities for the next round in the cycle. But equally important, the hope is also that this newfound knowledge is firmly anchored in material infrastructures and local practices of city B. Too often, unfortunately, experimental projects with innovative green infrastructure turn out to be isolated events that fade into oblivion without any effect on incumbent infrastructures and practices and the seemingly solid network connections that facilitated these projects might turn out to less robust when ties are not continually maintained or when a key individual is no longer part of a relevant organization [76,77]. To make this knowledge become robust, it is important that both cities 'reflect and internalize' the experiences in previous stages and to anchor these it in local practices and into vibrant and well-maintained knowledge transfer pipelines. We call this the 'reflect and internalize' phase. 


\section{Results}

In this section we will apply the four-phased analytical framework laid out above. For each of these four phases, we will interpret the events that took place, specifically examining water system variables such as the context, system, actors, processes, and structures [29]. This analysis sometimes also highlights the cognitive and institutional proximity or distance between the cities involved $[78,79]$.

\subsection{Phase 1: Explore and Market}

The Dutch Embassy was setting up a project called Holland Branding to increase business opportunities for the Netherlands in Mexico. This long-term Holland Branding strategy is a tool for the embassy and Dutch business and knowledge institutions to materialize the opportunities into concrete projects. It started with brainstorm sessions within the Embassy and interviews with multiple companies and organizations located in Mexico City to understand the (current) reputation of The Netherlands. The end result was a plan for a shared vision on Holland Branding that was discussed with all the employees involved in the focus sectors of the embassy. Several observations could be made during this process.

First, according to the actors involved, it is important to understand the strengths and weaknesses of The Netherlands before it is possible to search for market opportunities in Mexico. A strength of The Netherlands is its water systems. The sinking of coastal lands has continually increased the Netherlands' vulnerability to floods and made it more difficult to discharge drainage water. However, the Dutch have been able to cope with these problems through the centuries by increasing their control over water flows. This they have achieved through collective action, often involving very many people [80].

Second, research was needed on the Mexican market. Attention was given to drivers for Mexico to set up new projects in the focus sectors. Regarding the water sector, these are mostly preventing floods, droughts and shortages of water. Besides the drivers for Mexico, it was necessary to set up the identity of the Netherlands, in other words, the Dutch approach. A SWOT analysis of the Netherlands in Mexico was made based on the information of the interviews to match the identity with the drivers of Mexico. The information was formulated in general messages and themes were set up, in which the focus sectors were combined for a cross-sectoral approach. In each of these themes urban resilience plays a role.

The cross-sectoral approach was also a focus point in the concept of the water square in Rotterdam. The engineers developed it to benefit public space and water management. The idea was to bring the water back into the city and keep the water local instead of drainage. This one local system created international interest. An organization in Mexico City noticed an article published on the water squares, while they were searching for a project that combined public space with sustainable water management.

'Given the vulnerability in terms of water in Mexico City, I thought that it would be interesting to integrate water but in a more responsible manner. So that is when I started with a research and that is why I was asking my colleague about a kind of project which mixed water management or responsible use of water on spaces...'

This quote showed that the organization knew what it needed to enhance its current systems. On the opposite side, Rotterdam was showing the strengths of their concept and uniqueness. The Dutch Embassy was setting up a more holistic approach to connect concepts like the water square with the market of Mexico. The focus on strength and weaknesses and connecting them is also highlighted by observations made by participants. They indicated that it is key to understand your own systems first.

'One of the key things is that each organization recognizes their strengths and their weaknesses. And when you understand which are your weaknesses then you understand that you need help on those weaknesses. 
In short, before cities can search for complementary knowledge or market their knowledge they need to focus on their own systems. It is a time-consuming process to understand the strengths and weaknesses of a city's systems before marketing or exploring knowledge, namely research on the city's systems is necessary to form a framework of strengths and weaknesses. This is a step that leads to the possibility of building channels of communication to selected providers outside the local milieu to enhance knowledge.

\subsection{Phase 2: Build Pipelines}

Following the initial search and connection between the cities involved, broader contacts will need to be established between relevant actors in those cities. This contact will also need to be solidified into joint commitment towards the collaboration.

In case of the water squares, the process started when the Spatial Planning Office in Mexico City contacted the Dutch Embassy, late 2014, to explore interests and potential collaboration. A first meeting was held in February 2015 to discuss the knowledge that Mexico City was looking for in more detail. Following this meeting, the Embassy established contact between the Spatial Planning Office and the architectural firm that designed the water squares in Rotterdam. A series of phone and Skype calls followed, and a first face to face meeting was held in December 2015 in Mexico City with the Spatial Planning Office, Embassy, and architectural firm. This meeting helped to build trust, in the sense that the organizations established openness towards each other's views and willingness to cooperate. The actors shared ideas and established an agreement towards further collaboration (resp.9).

In February 2016 a workshop was organized to connect a wider base of key actors from both cities. The workshop was in the form of a round table discussion, with a more targeted focus on the potential of creating a multi-purpose water square project in Mexico City. This four-day "Water Workshop" gathered seven core actors, four Mexican and three Dutch (see Figure 4). During the first day, all actors gave presentations on their background, organization, and activities. Many participants left directly after the presentations, for unclear reasons. Only most Dutch participants, one participant of the Mexico City Resilience Office and two of the spatial planning agencies remained.

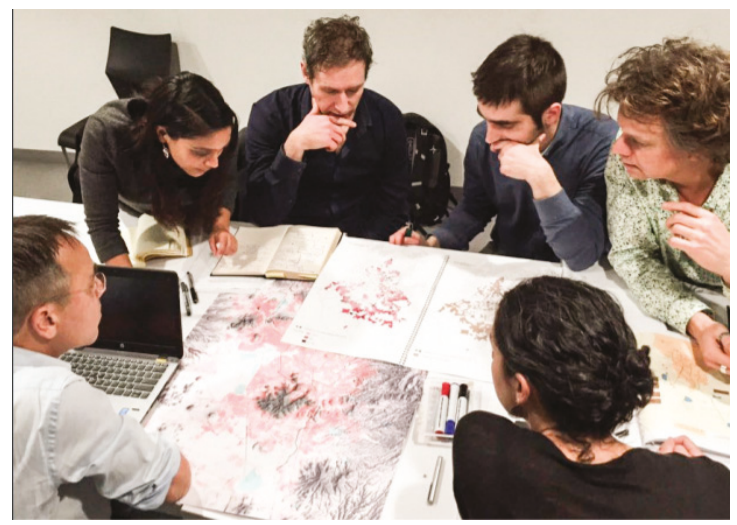

Figure 4. Impression of the water workshop in Mexico City (photo by: Víctor Manuel Rico Espínola) [64,65].

In the following two days, the Dutch participants attempted to gain further understanding of Mexico City by means of a more in-depth analysis of the city. The city was divided into five areas, each with its own environmental and social needs, and potential water-related solutions were explored using the 'CAPP Climate Adaptation App'. The information was then spatially structured and the potential and usefulness of water squares was explored per area. During the final day, this analysis was presented to the Mexican organizations, leading to further discussion. The effort and ideas presented 
were very well received and seemed to lead to an enhanced will to cooperate. Agreements were made on further steps, and the Dutch partners produced a report of the shared vision in collaboration with stakeholders.

Observations during the workshop and follow-up interviews suggested several factors that led to this success. First, the approach of exploring community needs per area in the city showed the Mexican participants that the Dutch were making a conscious effort at trying to understand their situation and specific needs, enhancing trust. This was important to overcome the cognitive distance between the participants due to the large geographical distance and differences, e.g., (resp.7):

"Knowledge from rich countries to poor countries does not translate easily. Because we have a very different political and cultural situation; we are in different stages. [ . . ] For example The Netherlands is very small and we have a lot of mountains. And then you get a lot of 'buts'. And it is not that it can't be done. It is just that it is so far away."

Second, the analysis was framed from the perspective of similarities between Rotterdam and Mexico City, revealing shared struggles and histories, rather than highlighting Rotterdam's accomplishments. Interviewees noted that this enhanced mutual understanding, as it highlighted mutual struggles with water, rather than implicitly suggesting superiority. As one interviewee described an experience with another country (resp. 7):

"So when I spoke, I said: We are very corrupt, just like you. And they were very happy to hear that, because that is an understanding. [ ... ] And I know that due to the Second World War, countries were very poor. However, when they come, they don't talk about how they were poor. They talk about how they are now the rich countries of the world."

In sum, for the second phase it was important to create a shared vision by involving a relatively broad set of key actors, more than just the linking-pin organizations. Some actors were less committed to the process initially. However, these differences were bridged by a strong effort by the visiting party and hosting linking-pin organizations to jointly explore the system and relevant context, i.e., the situation on the ground, the requirements for resilience and adaptation in different neighborhoods, and potential options. In addition, the geographic proximity was observed to be fairly low between the cities; one city a huge landlocked metropolis in a developing country and the other a medium-sized coastal city in a developed country. It was particularly valuable to highlight shared struggles between both cities to build trust and mutual understanding. This helped bridge the geographic distance and the willingness of all actors to collaborate, which enabled the actors to engage in building of 'pipelines' to communicate and harness extra local knowledge flows. As a result, the water squares became a potential lighthouse project.

\subsection{Phase 3: Translate and Adopt}

The agreements that were made in the first meetings, were written in a shared report. The intention was that this would lead to a joint project on water.

The differences in the organizations involved in the process provided some challenges. Particularly, the differences between the Dutch and Mexican government systems caused a lack of organizational proximity along with a cognitive distance between the actors. Much of the technical knowledge within the Dutch actors resided in privatized companies or (public or semi-public) knowledge institutions (Respondent 9). Dutch urban water management systems involve a number of different organizations that need to collaborate due to the spread of responsibilities and expertise, i.e., the government system is more decentralized. The Dutch government system is also known for the strong collaboration between different public and private actors (Observation 4). Mexican government organizations often involve a combination of technical and policy departments. For example, SACMEX is the water organization in Mexico City that contains governmental and technical knowledge. SACMEX, therefore, is almost independent and as a result more powerful and does not share its knowledge and expertise easily 
(Respondent 9). As a result, the organization was under less pressure to contribute to a collaborative project such as the water squares, and was difficult to reach by other participants during the process of designing them. Unlike the Dutch system, the Mexican government system is highly centralized.

A clear example of the challenges of the lack of organizational proximity presented itself when there was an unexpected change of director in the Mexican organization. Many new leaders are reluctant to continue with projects that started under the previous leadership due to the importance of personal image and reputation in Mexico. The important decision makers within the organization mostly change with a change of a governmental leader. Consequently, parties who are working together with the government need to set up new contacts all over again within the governmental organization. The combination of a centralized governance and changeable leadership makes it hard to set up projects that involve a longer time frame (Respondent 10).

However, in case of the water square, a local leader was directly involved in the organization supporting this project. The person actively promoted the project to the new director, and setup a meeting between the director and the Dutch Embassy to further emphasize the importance of the project and the Mexican-Dutch collaboration (Respondent 9). The report showcasing the water squares as a lighthouse project was completed and could help convince the new director. This showed that local leaders are necessary, both external to promote interaction with the communities and internal (within actors) to push the process within their organization.

The interviewees also elaborated on this need for local leaders for a successful implementation of an innovation. Local pressure is often needed to overcome obstacles, i.e., much practical progress comes from bottom-up initiatives. Local actors and communities are necessary to carry through on long-term, multi-purpose projects (Respondent 9, 10; Observation 4). As interviewees mentioned:

'So first we need to inform all these government agencies but at the same time we need to approach communities and we need to make sure to incorporate them into the design of the space. So in the end we learned that we design a process more than just a public space project or an architectural project.' (Respondent 6)

'And people, they create pressure. Awareness of the problem is also very important. If that is not there then it is very difficult to do something.' (Respondent 1)

'We have a strategy for that. What we are doing is, we are trying to establish a committee that is depended on the project. So we call people from the academy, and comparable important leaders and personalities and we are going to invite them to take part in this committee to keep this project alive for years to come.' (Respondent 5)

One of the challenges within the case was identified as the lack of organizational proximity that could negatively influence the policy learning and implementation of the water innovations. A lack of organizational proximity means that organizational flexibility will be required to tailor and adopt innovations [78]. Knowledge was also highly centralized, i.e., key experts from other organizations were not always available or left the office due to a change in leadership. This created a cognitive distance between the Mexican and Dutch actors that made it difficult for them to collaborate. These obstacles within the process show that city-to-city learning is not simply a matter of taking a policy from one location and implementing it in another. Rather, it involves adapting it to a specific local context, practice and policy community, with a focus on the political process $[45,46,74]$.

A secondary challenge, potentially reinforcing the former, was that few people involved were able to connect different disciplines. In Mexico City, there were many people who were highly educated and experienced in their specific discipline, but few people with an interdisciplinary focus (Respondent $1,2)$. Therefore, it proved difficult to translate the knowledge of individual disciplines towards interdisciplinary, multi-purpose projects, i.e., combining sector specific knowledge towards themes for projects (Observation 1). 
In sum, during the translation and adoption phase, we observed strong gaps in the organizational and cognitive proximity between the actors. Partly, this related to the different actors involved on both sides: primarily public for Mexico City; mixed public-private for Rotterdam. More important, however were differences related to the structures of the governance system, such as the institutional environment (e.g., modes of governance [81], styles of leadership, perspectives on fair governance) and the knowledge system (e.g., disciplinary-specialist versus interdisciplinary). Process-related differences played a role as well, such as the tendency of key decision-makers and experts to leave and organizational priorities and support for projects to shift strongly following a shift in leadership. The shared vision developed in phase two helped mediate these lacks in institutional and cognitive proximity. Key to overcoming the differences, however, was the presence and mobilization of local leaders, in the form of community leaders, broad societal committees that took ownership of the project, and leaders within key organizations that helped the project transition changes in leadership and kept parties on both sides activated.

\subsection{Phase 4: Internalize and Reflect}

The case of the water square is still in development and currently in phase three. In addition, the 100 Resilient Cities network reached its goal of a hundred cities in 2016 and the network is still developing (Respondent 3). So, unfortunately, there is not a lot of information on this phase yet. Nonetheless, it can be said that the intensity of the interaction between the cities decreases in this phase. Actors in Rotterdam will reflect on the whole process and incorporate the newly gained knowledge and experiences for the next round of knowledge transfer with another city. In its turn, actors in Mexico City need time to internalize the policy relevant knowledge that was transferred so that it can be incorporated in other systems of the city or be used in a next round of knowledge transfer with another city. In other words, both cities have increased their knowledge pool and deepened their understanding of infrastructures and processes that foster urban resilience. And both are now more motivated and better equipped to transfer their knowledge to even more cities for the next round in the cycle. Additionally, the increasing number of knowledge transfer rounds on urban resilience helps with defining the framework around the concept more precisely. Cities gain knowledge by experiencing more knowledge transfers on urban resilience. Both cities need to market the project, individually and together, to create new projects—new knowledge transfers-on the knowledge they gained. However, it can be expected that the highly centralized Mexican government system will influence the internalization process negatively due to organizational inflexibility. One interviewee already mentioned an aspect for progress that can be reached by reflecting on cases and implementing the new knowledge:

'It is totally important to exchange information and knowledge although it is also critical taking into account the particularities of each city. Even though the resilience initiative is of course a very remarkable international initiative, some people still think that it is still lacking precisely that adaptation layer so that the strategies make sense in each city. So it is a real challenge for the resilience strategy to come up with a toolkit that is really adaptable to the realities of each place.'

The quote shows that conceptual development is still highly needed in the field of resilience, in which networks can allow a faster learning experience due to knowledge transfers and combining the existing and new knowledge. The knowledge transfer model is a tool for supporting this process.

To summarize, several cultural, economic and geographical factors shaped the various phases of the city-to-city learning process between Rotterdam and Mexico City. To provide an overview of the dynamics discussed in this section, Figure 5 below present our empirical findings in terms of the four-phased analytical framework introduced in Section 2. 


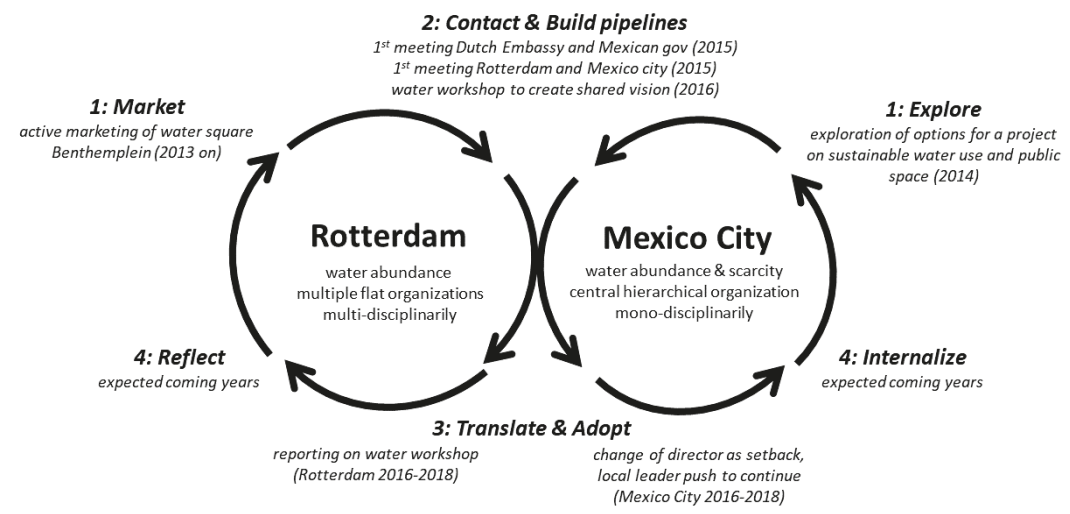

Figure 5. Representation of the process of city-to-city knowledge transfer between Rotterdam and Mexico City related to water squares.

\section{Discussion}

\subsection{City-To-City Learning for Urban Resilience}

The existing literature on learning for resilience is rather prescriptive and primarily focused on in-city learning. In contrast, our analysis is empirically descriptive and focused on city-to-city learning. This connotes a particular conceptualization of learning related to notions of organizational learning [82] and social learning [83]. Organizational learning can start in anticipation of ('front loop' learning) or reaction to ('back loop') disturbances. It can range from practical to more fundamental: from changing skills, routines and practices ('single loop' learning) to questioning and adjusting assumptions and policies ('double loop') to fundamental debate about values and norms ('triple loop') (e.g., [5,57,82]). Judging by the case study, city-to-city learning might help cities move from single loop learning, focused on fixing the errors in routines based on status quo thinking, to double loop learning. This holds particularly true in international urban resilience networks, and could be stimulated by actively exploring and comparing good (and less successful) practices in cities worldwide. Different cities will have a different take on how to adapt their water systems, providing novel ideas to other cities. In our case study, the idea of storing water in public space and using excess water and urban adaptation options to actively increase public spatial quality was a novel idea that provided an impetus for Mexico City to change their current approach. It may relate to triple loop learning as well, since it provides a different take on the value of public space. However, no explicit debate on underlying values was observed. In general, there may be a risk that policies and practices are taken up by a city based on novelty value, rather than an actual reflection on and matching with public values and norms.

More practically, the literature on learning for resilience discusses tools such as monitoring and experimentation, and the importance of broad participation of stakeholders in the learning process, the need for long-term collaborative learning that is able to withstand short-term politics, and the need for inclusion of multiple types of knowledge (e.g., in addition to formal scientific knowledge, also practical, tacit and experiential knowledge) and co-production of knowledge (e.g., [5,57,84-87]). The influence of power, politics, and institutional dynamics is also mentioned as a problematic aspect in social learning. In the Mexico City case, we could observe that many of the factors mentioned above were problematic. The stakeholders and even individuals involved in the learning process were a select group of mostly representatives of authorities and scientists, with only one Dutch private partner involved. There was no broader participation of citizens, NGOs and companies. The group involved was highly sensitive to the local institutional, political and power dynamics: the learning parties were those that were formally responsible, and the process was complicated by a shift in formal leadership in Mexico City, which risked removing key people—and with them the institutional memory—from office. Nonetheless, 
efforts were observed to anchor the knowledge through local leaders that were less vulnerable to such shifts in power and could help bridge the knowledge gained from the formal parties to other local actors. We would suggest that collaborative co-production, with attention for local power, political, and institutional dynamics, is a particularly sensitive and critical point in city-to-city learning. Formal city-to-city learning events such as local workshops and delegation visits easily result in a potentially vulnerable and technocratic form of learning rather than broader and well-anchored and internalized social learning. This calls for explicit attention in designing the city-to-city learning process.

In exploring the dynamics of city-to-learning we identified four phases. The first phase was described as the exploration and marketing of knowledge. It was initially expected that the main focus would be on the Rotterdam marketing existing knowledge of resilient systems by touting its pioneering water square and of Mexico City exploring by looking for best practice examples of innovative resilient systems around the world before stumbling on Rotterdam's example. In this conceptualization both transferring parties would be looking outward ('know the other'). However, this phase was much more introspective and to a large extent the actors tried to understand the strengths and weaknesses of their own city's systems during outreach ('know thyself'). This is in line with some of the work on Sustainability Transitions, which investigates how actors can break the lock-in of incumbent systems of water provision [88]. In particular with the approach of Transition Management, which stresses that a small group of agents who want to change the status quo needs to start with the introspective and mental work of developing shared conceptualizations and visions before linking up and build coalitions with other actors [89]. For instance, Ferguson et al. [29] use the Transition Management approach to develop a diagnostic framework to facilitate transformative change in urban water systems, which stresses the need for these kinds of introspective efforts by the actors in the early stages. For the second and third phase, we found that the differences in geographical and institutional environment in Mexico City turned a seemingly clear-cut one-directional transfer much more challenging endeavor. Successful transfer, then, is a two-way street not only in the in the sense that the transferring party also takes relevant knowledge back, but also in the sense that it requires alignment of the knowledge base between the two parties. This took place in the second phase, where we observed a conscious framing and reframing of the history, socio-political-cultural contexts, and challenges in each city. Participants attempted to rephrase their own positions in terms of that of the other, to match each other's situation in many aspects. This serves to better align the two cities. It should provide sufficient 'sameness' (cf. [90]) to establish mutual understanding and build trust- to argue that both cities' experiences and goals are sufficiently aligned to be a meaningful partner. Yet, there needs to be sufficient 'difference' as well [90], in order to highlight specific aspects in which the cities can learn something from the other. Ideally, this process also takes into account different framing of what urban resilience means, because different cities and different actors within a city can have very different approaches to resilience, leading to very different implementations into policies and practical interventions [91]. In the third phase, such further translation into practical policy projects (e.g., new policy designs or white papers, or pilot projects and interventions) is made. During this practical experimentation and implementation, learning can take multiple forms: technical, formal (hard data, e.g., documents, projects, official authorities) and informal (soft data, e.g., implicit/tacit knowledge, professional and social networks) (cf. [44,50]). In the context of a single tangible project, much broader policy-relevant knowledge can be said to 'hitch a ride'. For instance, Dutch ideas about interdisciplinary approaches and a less rigid and hierarchical institutional organization of the water sector also reached Mexican ears. The Dutch in turn might have appreciated the technical expertise available in the Mexican government organizations (which is quite often outsourced in Dutch governments). In another way broader policy-relevant can be said to be encapsulated within the tangible artefact of a single project. For instance, a water square doubles as a buffer in a large technical system and as a way to create vibrant public space, which makes the actors involved rethink the single-purpose and efficiency logic of urban infrastructure. Similarly, the local leaders recruited in the process serve both as a source of redundancy or omnivory for the knowledge learned, and as a source of polycentricity that facilitates alignment of the values and goals 
for resilience-building between authorities and communities and citizens. This can in turn be used to stimulate a broader social learning process (cf. [92]). As for the fourth phase, at the time of our analysis the process has not yet progressed to this stage. As we showed, actors can reflect on the process and internalize part of the lessons during earlier phases. It would be valuable to conduct an ex-post analysis once there is 'closure' around the project and its associated activities. Particularly, it would be interesting to analyze if the water square project has engendered changes broader institutions and organizational routines. It would also be interesting to see whether the actors involved can be enrolled as advocates for the further spread of water squares or if they have to some extent become disillusioned with this idea. Similarly, many other aspects might have strengthened, including the ability to work across disciplinary boundaries, the strength of knowledge networks, and the ability to better align and anchor resilience-building with the interests of local communities.

\subsection{Avenues for Further Research}

Our analysis city-to-city learning zoomed in on the transfer dynamics in case of one tangible project. The pioneering water square in Rotterdam, which was to be transplanted to Mexico City, is best conceived of as a single 'socio-technical experiment' — defined as a "practice-based and challenge-led initiative, which is designed to promote system innovation through social learning" [93]. The literature on socio-technical experiments suggests that individual projects in and of themselves are not enough to change the underlying principles of the broader water system, but that they are a key unit of analysis and that their wider learning and demonstration effects do provide a crucial starting point for such a transition [93]. Furthermore, for both the actors involved in the transfer and for us as academics, in conceptualizing this process the advantage of providing center stage to individual experiments such as water squares is that it provides a very tangible precursor and a of clear sense of direction. Another way to get to the essence of city-to-city learning would be to look at larger collections of projects and at broader processes of translation of policy-relevant knowledge. Whilst we believe that our approach of describing one concrete project as a vessel for policy translation as a way to study has certain important merits, we certainty recognize that this would be a worthy agenda for future research.

One consideration for expanding the research on city-to-city learning for urban resilience is the potential impact of situational factors and the progression of projects over time. Policy transfer risks resulting in policy failure, if the transfer does not take into account these situational differences (e.g., [94]). Geographic factors can influence the success or shape that projects take in a city. Rotterdam and Mexico City experience similar amounts of yearly precipitation and both developed water squares in low elevation locations that function as a 'bathtub'. However, Rotterdam's precipitation is relatively spread out over the years compared to Mexico City, and Mexico City has hills that drain into the valley as well. Drought and water scarcity are also much more an issue in Mexico City. Consequently, the shape that water squares take will likely differ. Rotterdam's are designed to drain on the main water system within days, while Mexico's squares might focus on retaining water for a longer period. Cultural factors can also play an important role. As discussed above, Mexico City has a culture of strong leadership, disciplinary expertise and concentration of expertise into a single management organization, whereas Rotterdam is more focused on collaboration, interdisciplinarity, and an ecosystem of multiple organizations with different expertise. Cultural factors are important in learning processes and transfer of policy proposals, but often difficult to pinpoint within and between cases. As the case showed, however, successful learning can take place when such factors are taken into account. Political factors are also highly important. Research in the Dutch context showed that the political interest of local aldermen and councilors is of key importance for the success of local adaptation [95], and the Mexican case in this paper showed similar processes, where leadership changes could strongly impact specific projects when the previous leader strongly identified with a project. Socio-economic factors are also important. Actors might push for very different locations and implementations of water squares, to strongly diverging effects. One risk of any pilot project, for example, might be that it becomes a prestige project that might be implemented in high visibility locations, such as tourist centers, 
business centers or richer neighborhoods, whereas they might be most needed in high density poorer neighborhoods. Similarly, governments might opt for high-tech implementations that involve the city's strategic business partners, potentially neglecting higher maintenance costs or the wishes of the neighborhoods in which projects are implemented. Rotterdam's first attempt at constructing a water square failed due to similar reasons: connections with that neighborhood were poor and the square was not accepted by the population. In next iterations, co-design with residents was a key point, leading to successful projects. In the case of Mexico City, the efforts to establish water squares has however specifically and intentionally focused on a poorer district, in the realization that such squares can also improve the spatial and social quality of the district [64,65]. In Rotterdam, the squares are also located in poorer areas. Such situational factors could impact the successful implementation of water squares, but could also determine their long term survival. For example, high-tech options might involve pumps and filtration systems that could be vulnerable to failures, neglect of maintenance (e.g., during periods of austerity), or debris and waste in runoff that enters the square. More low-tech and community-involved projects on the other hand could run the risk of deterioration when attention and community interest fade. Little is currently known of such long term survival factors for water squares and similar urban pilots and experiments, and this should be further investigated.

Another interesting point for future research would be to see if the four phases described here can also be identified in other cases studies of city-to-city learning or urban policy translation and whether describing these findings accordingly leads to productive insights. Attempts to do this could focus on other cases studies in water resilient cities or other related efforts. For instance, it would be interesting to compare actor coalitions and strategies of city-to-city learning in urban water projects with a 'resilient city' focus with those that are framed as contributing achieving 'smart city'. It would also be interesting to compare policy translation learning in the context of resilient water systems with resilient waste management or transportation systems. At least conceptually, there is nothing inherent in our four-phase framework that would limit the application to a focus on resilience or to the water domain.

\section{Conclusions}

We presented a policy practice analysis of the city-to-city exchange of policy relevant knowledge for building urban water resilience between two cities that are currently highly active on this topic: Mexico City and Rotterdam. Mexico City faces numerous water-related challenges and expects increasing pressure due to climate change [96]. Rotterdam is a city with well-known for its water expertise and experience. It is an often-used example of Dutch delta planning approaches, taken as 'good practice' in water management and climate adaptation worldwide [90,97]. Learning is seen as a key principle in resilience-building and cities worldwide are actively pursuing knowledge exchange through experimentation and collaboration with consultants, architects, and academics in bilateral or transnational networks. Many cities face urgent and worsening challenges today while public budgets are under pressure as they navigate through these slow and costly learning processes. Moreover, strong differences exist in the institutional, geographic, and cultural context of cities, which might limit the possibilities for knowledge and policy transfer. The analysis in this paper provided several lessons on barriers and stimuli for successful city-to-city learning in the context of water systems and urban resilience. To present these findings we mobilized a framework composed of four distinct phases.

During the first phase of the city-to-city knowledge transfer (exploration and marketing), a key success factor was that both cities did not start with an external search for sources or potential recipients of knowledge. Rather, they started with introspection. It was important to have clear picture of one's own systemic strengths and weaknesses, for both cities involved. This introspection helped the search for complementary partner cities, and it may also provide sufficient self-awareness and material for the reframing needed in phase 2 .

In the second phase (building pipelines), it was important to create a mutual understanding of struggles and histories, to overcome geographical and cultural differences. Creating a shared vision 
helped reduce misunderstandings in the process. It appeared particularly critical to heavily negotiate and reiteratively reframe one's own and each other's reality. The perceived situation of both cities needed to be both similar (to build trust and develop a shared vision) and different (to have something to offer to the other; to provide something that could be learned). This process also served to establish the cities as equal partners, rather than a mentor-mentee relationship which can be a detrimental framing for leaning [98]. While negotiation and reframing are normal in multi-actor settings, the tension between matching and differing in framing and situation is very high in city-to-city learning and warrants further research.

For the third phase (translation and adoption) we observed that differences in the institutional environment (e.g., modes of governance, level of interdisciplinarity) could hamper the implementation of 'imported' ideas. These barriers were reduced by recruiting strong local leaders, external to the official organizations, into the process. This required organizational flexibility of the official organizations. However, they pursued this course because it would also reduce the risk of losing institutional memory, which was high during leadership changes in the centralized, hierarchical organizations involved. Anchoring through local leaders provided some redundancy or omnivory in the knowledge system. These issues relate to resilience principles not necessarily associated with learning: in this (and the next) phase, the new knowledge and the local knowledge system themselves are made resilient.

In the fourth phase, which follows the actual exchange, cities will need to internalize the lessons and resilience thinking in general (internalization and reflection) so that this can be applied in other projects. This applies to lessons regarding resilience-building, but also to the learning process itself. Particularly pronounced lessons for city-to-city learning seem to be that the starting phases and their introspection and reframing processes are critical, and that in the later phases it is important to make the knowledge itself resilient by building internal and external networks. By internalizing such lessons, cities might strengthen not only their own resilience, but also enhance future exchanges with other cities.

Supplementary Materials: The following are available online at http://www.mdpi.com/2073-4441/11/5/983/s1, Document S1: List of interviews, Document S2: Coding scheme, Document S3: Temperature and precipitation profiles for Rotterdam and Mexico City.

Author Contributions: Conceptualization, S.I., F.S. and A.W.; Data curation, S.I.; Formal analysis, S.I., F.S., and A.W.; Investigation, S.I.; Methodology, S.I., F.S. and A.W.; Supervision, F.S. and A.W.; Validation, S.I.; Writing—original draft, S.I., F.S. and A.W.; Writing—review and editing, F.S. and A.W.

Funding: This research received no external funding.

Acknowledgments: We thank the Netherlands Embassy to Mexico for hosting one of the researchers for the duration of the study and we thank various practitioners throughout Mexico and the Netherlands for their time and effort to share their insights on the dynamics of knowledge exchange on urban resilience and water squares.

Conflicts of Interest: The authors declare no conflict of interest.

\section{References}

1. UN. World Urbanization Prospects: The 2014 Revision; Department of Economic and Social Affairs, United Nations: New York, NY, USA, 2014.

2. Knight, R.V. Knowledge-based development: Policy and planning implications for cities. Urban Stud. 1995, 32, 225-260. [CrossRef]

3. Gordon, I.; McCann, P. Innovation, agglomeration and regional development. J. Econ. Geogr. 2005, 5, 523-543. [CrossRef]

4. McGranahan, G.; Balk, D.; Anderson, B. The rising tide: Assessing the risks of climate change and human settlements in low elevation coastal zones. Environ. Urban. 2007, 19, 17-37. [CrossRef]

5. Orleans Reed, S.; Friend, R.; Toan, V.C.; Thinphanga, P.; Sutarto, R.; Singh, D. Shared learning for building urban climate resilience: Experiences from Asian cities. Environ. Urban. 2013, 25, 393-412. [CrossRef]

6. Capela Lourenço, T.; Rovisco, A.; Groot, A.; Nilson, C.; Füssel, H.M.; Van Bree, L.; Street, R.B. Adapting to an Uncertain Climate: Lessons from Practice; Springer: Cham, Switzerland, 2014. 
7. Markard, J.; Raven, R.; Truffer, B. Sustainability transitions: An emerging field of research and its prospects. Res. Policy 2012, 41, 955-967. [CrossRef]

8. UN. Transforming our World: The 2030 Agenda for Sustainable Development; United Nations: New York, NY, USA, 2015.

9. UN. Habitat III: The New Urban Agenda; United Nations: New York, NY, USA, 2016.

10. Collier, M.J.; Nedović-Budić, Z.; Aerts, J.; Connop, S.; Foley, D.; Foley, K.; Newport, D.; McQuaid, S.; Slaev, A.; Verburg, P. Transitioning to resilience and sustainability in urban communities. Cities 2013, 31, S21-S28. [CrossRef]

11. De Jong, M.; Joss, S.; Schraven, D.; Zhan, C.; Weijnen, M. Sustainable-smart-resilient-low carbon-eco-knowledge cities; making sense of a multitude of concepts promoting sustainable urbanization. J. Clean. Prod. 2015, 109, 25-38. [CrossRef]

12. Leichenko, R. Climate change and urban resilience. Curr. Opin. Environ. Sustain. 2011, 3, 164-168. [CrossRef]

13. Linkov, I.; Bridges, T.; Creutzig, F.; Decker, J.; Fox-Lent, C.; Kröger, W.; Lambert, J.H.; Levermann, A.; Montreuil, B.; Nathwani, J.; et al. Changing the resilience paradigm. Nat. Clim. Chang. 2014, 4, 407-409. [CrossRef]

14. Alberti, M.; Marzluff, J.M. Ecological resilience in urban ecosystems: Linking urban patterns to human and ecological functions. Urban Ecosyst. 2004, 7, 241-265. [CrossRef]

15. Schewenius, M.; McPhearson, T.; Elmqvist, T. Opportunities for increasing resilience and sustainability of urban social-ecological systems: Insights from the URBES and the cities and biodiversity outlook projects. AMBIO 2014, 43, 434-444. [CrossRef] [PubMed]

16. Zevenbergen, C.; Veerbeek, W.; Gersonius, B.; Van Herk, S. Challenges in urban flood management: Travelling across spatial and temporal scales. J. Flood Risk Manag. 2008, 81-88. [CrossRef]

17. Godschalk, D.R. Urban hazard mitigation: Creating resilient cities. Nat. Hazards Rev. 2003, 4, $136-143$. [CrossRef]

18. Douglas, M. From global intercity competition to cooperation for livable cities and economic resilience in Pacific Asia. Environ. Urban. 2002, 14, 53-68. [CrossRef]

19. Rijke, J.; Farrelly, M.; Brown, R.; Zevenbergen, C. Configuring transformative governance to enhance resilient urban water systems. Environ. Sci. Policy 2013, 25, 62-72. [CrossRef]

20. Eraydin, A.; Taşan-Kok, T. Resilience Thinking in Urban Planning; Springer: Dordrecht, The Netherlands, 2013.

21. Jabareen, Y. Planning the resilient city: Concepts and strategies for coping with climate change and environmental risk. Cities 2013, 31, 220-229. [CrossRef]

22. Deppisch, S. Resilience Thinking as Leitmotif in Urban and Regional Planning Dealing with Climate Change Impacts. In Urban Regions Now \& Tomorrow: Between Vulnerability, Resilience and Transformation; Springer Nature: Wiesbaden, Germany, 2017; pp. 165-188.

23. Wardekker, J.A.; De Jong, A.; Knoop, J.M.; Van der Sluijs, J.P. Operationalising a resilience approach to adapting an urban delta to uncertain climate changes. Technol. Forecast. Soc. Chang. 2010, 77, 987-998. [CrossRef]

24. Ernstson, H.; Van der Leeuw, S.E.; Redman, C.L.; Meffert, D.J.; Davis, G.; Alfsen, C.; Elmqvist, T. Urban transitions: On urban resilience and human-dominated ecosystems. AMBIO 2010, 39, 531-545. [CrossRef] [PubMed]

25. Davoudi, S.; Brooks, E.; Mehmood, A. Evolutionary resilience and strategies for climate adaptation. Plan. Pract. Res. 2013, 28, 307-322. [CrossRef]

26. Berbés-Blázquez, M.; Mitchell, C.L.; Burch, S.L.; Wandel, J. Understanding climate change and resilience: Assessing strengths and opportunities for adaptation in the Global South. Clim. Chang. 2017, 141, 227-241. [CrossRef]

27. Olazabal, M. Resilience, Sustainability and Transformability of Cities as Complex Adaptive Systems. In Urban Regions Now \& Tomorrow: Between Vulnerability, Resilience and Transformation; Springer Nature: Wiesbaden, Germany, 2017; pp. 73-97.

28. Brown, R.R.; Keath, N.; Wong, T.H. Urban water management in cities: Historical, current and future regimes. Water Sci. Technol. 2009, 59, 847-855. [CrossRef] [PubMed]

29. Ferguson, B.C.; Brown, R.R.; Deletic, A. Diagnosing transformative change in urban water systems: Theories and frameworks. Glob. Environ. Chang. 2013, 23, 264-280. [CrossRef] 
30. Folke, C.; Hahn, T.; Olsson, P.; Norberg, J. Adaptive Governance of Social-Ecological Systems. Annu. Rev. Environ. Resour. 2005, 30, 441-473. [CrossRef]

31. da Silva, J.; Morera, B. City Resilience Framework; Arup \& Rockefeller Foundation: London, UK; New York, NY, USA, 2014; Available online: http://publications.arup.com/Publications/C/City_Resilience_Framework.aspx (accessed on 6 April 2019).

32. Koop, S.H.; Van Leeuwen, C.J. Assessment of the sustainability of water resources management: A critical review of the city blueprint approach. Water Resour. Manag. 2015, 29, 5649-5670. [CrossRef]

33. Meerow, S.; Newell, J.P. Urban resilience for whom, what, when, where, and why? Urban Geogr. 2016. [CrossRef]

34. Wardekker, A. Resilience principles as a tool for exploring options for urban resilience. Solutions 2018, 9. Available online: https://www.thesolutionsjournal.com/article/resilience-principles-tool-exploring-optionsurban-resilience/ (accessed on 6 April 2019).

35. Šakić Trogrlić, R.; Rijke, J.; Dolman, N.; Zevenbergen, C. Rebuild by design in Hoboken: A design competition as a means for achieving flood resilience of urban areas through the implementation of green infrastructure. Water 2018, 10, 553. [CrossRef]

36. Brown, C.; Shaker, R.R.; Das, R. A review of approaches for monitoring and evaluation of urban climate resilience initiatives. Environ. Dev. Sustain. 2018, 20, 23-40. [CrossRef]

37. Chelleri, L.; Waters, J.J.; Olazabal, M.; Minucci, G. Resilience trade-offs: Addressing multiple scales and temporal aspects of urban resilience. Environ. Urban. 2015, 27, 181-198. [CrossRef]

38. Wardekker, A.; Wilk, B.; Brown, V.; Uittenbroek, C.; Mees, H.; Driessen, P.; Wassen, M.; Molenaar, A.; Walda, J.; Runhaar, H. A diagnostic tool for supporting policymaking on urban resilience. Cities. (under review).

39. Wilk, B. Translating the Scientific Concepts of Resilience into a Diagnostic Tool for Urban Climate Resilience Building. Master's Thesis, Utrecht University, Utrecht, The Netherlands, November 2016.

40. Keiner, M.; Kim, A. Transnational city networks for sustainability. Eur. Plan. Stud. 2007, 15, 1369-1395. [CrossRef]

41. Betsill, M.M.; Bulkeley, H. Transnational networks and global environmental governance: The Cities for Climate Protection program. Int. Stud. Q. 2004, 48, 471-493. [CrossRef]

42. Betsill, M.M.; Bulkeley, H. Cities and the multilevel governance of global climate change. Glob. Gov. 2006, 12, 141-159. [CrossRef]

43. Bulkeley, H. Reconfiguring environmental governance: Towards a politics of scales and networks. Polit. Geogr. 2005, 24, 875-902. [CrossRef]

44. Bontenbal, M.; Van Lindert, P. Transnational city-to-city cooperation: Issues arising from theory and practice. Habitat Int. 2009, 33, 131-133. [CrossRef]

45. Van Ewijk, E.; Baud, I.; Bontenbal, M.; Hordijk, M.; van Lindert, P.; Nijenhuis, G.; van Westen, G. Capacity development or new learning spaces through municipal international cooperation: Policy mobility at work? Urban Stud. 2015, 52, 756-774. [CrossRef]

46. McCann, E. Urban policy mobilities and global circuits of knowledge: Toward a research agenda. Ann. Assoc. Am. Geogr. 2011, 101, 107-130. [CrossRef]

47. Seymoar, N.K.; Mullard, Z.; Winstanley, M. City to City Learning; International Centre for Sustainable Communities: Vancouver, BC, Canada, 2009.

48. UNESCO-IHE. City-to-City Learning for Disaster Resilience: Towards Secure, Sustainable and Vibrant Cities; UNESCO-IHE: Delft, The Netherlands, 2016; Available online: https://www.un-ihe.org/sites/default/files/ city_to_city_flyer_vs200516.pdf (accessed on 6 April 2019).

49. Biggs, R.; Schlüter, M.; Schoon, M.L. Principles for Building Resilience: Sustaining Ecosystem Services in Social-Ecological Systems; Cambridge University Press: Cambridge, UK, 2015.

50. Campbell, T. Learning cities: Knowledge, capacity and competitiveness. Habitat Int. 2009, 33, $195-201$. [CrossRef]

51. Sengers, F.; Raven, R. Toward a spatial perspective on niche development: The case of Bus Rapid Transit. Environ. Innov. Soc. Transit. 2015, 17, 166-182. [CrossRef]

52. Bahadur, A.V.; Thornton, H. Analysing urban resilience: A reality check for a fledgling canon. Int. J. Urban Sustain. Dev. 2015, 17, 196-212. [CrossRef]

53. Mills, A.J.; Durepos, G.; Wiebe, E. Encyclopedia of Case Study Research; SAGE Publications: Thousand Oaks, CA, USA, 2010. 
54. Yin, R.K. Case Study Research: Design and Methods; SAGE Publications: Thousand Oaks, CA, USA, 2013.

55. Carpenter, S.; Walker, B.; Anderies, J.M.; Abel, N. From metaphor to measurement: Resilience of what to what? Ecosystems 2001, 4, 765-781. [CrossRef]

56. Folke, C.; Colding, J.; Berkes, F. Synthesis: Building Resilience and Adaptive Capacity in Social-Ecological Systems. In Navigating Social-Ecological Systems: Building Resilience for Complexity and Change; Cambridge University Press: Cambridge, UK, 2003; pp. 352-387.

57. Biggs, R.; Schlüter, M.; Biggs, D.; Bohensky, E.L.; BurnSilver, S.; Cundill, G.; Dakos, V.; Daw, T.M.; Evans, L.S.; Kotschy, K.; et al. Toward principles for enhancing the resilience of ecosystem services. Annu. Rev. Environ. Resour. 2012, 37, 421-448. [CrossRef]

58. Tyler, S.; Moench, M. A framework for urban climate resilience. Clim. Dev. 2012, 4, 311-326. [CrossRef]

59. CDMX. CDMX Resilience Strategy: Adaptive, Inclusive and Equitable Transformation; Ciudad de México (CDMX): Mexico City, Mexico, 2016; Available online: http://www.data.sedema.cdmx.gob.mx/resiliencia/descargar. html (accessed on 6 April 2019).

60. Gemeente Rotterdam. Rotterdam Resilience Strategy: Ready for the 21st Century; Gemeente Rotterdam, Rotterdam, The Netherlands, 2016; Available online: https://www.resilientrotterdam.nl/download (accessed on 6 April 2019).

61. Lankao, P.R. Water in Mexico City: What will climate change bring to its history of water-related hazards and vulnerabilities? Environ. Urban. 2010, 22, 157-178. [CrossRef]

62. De Graaf, R.; Van der Brugge, R. Transforming water infrastructure by linking water management and urban renewal in Rotterdam. Technol. Forecast. Soc. Chang. 2010, 77, 1282-1291. [CrossRef]

63. De Urbanisten. Water Square Benthemplein. Available online: http://www.urbanisten.nl/wp/?portfolio= waterplein-benthemplein (accessed on 8 April 2019).

64. Boer, F.; Salinas, E.M.; Van de Pas, B.; Rico Espínola, V.M. Hacia una Ciudad de México Sensible al Agua-Towards a Water Sensitive Mexico City; De Urbanisten, Deltares \& Autoridad del Espacio Público: Rotterdam, The Netherlands; Mexico City, Mexico, 2016. Available online: http://www.urbanisten.nl/wp/?portfolio=towardsa-water-sensitive-MexicoCity (accessed on 6 April 2019).

65. Salinas, E.M.; Boer, F.; Van de Pas, B.; Rico Espínola, V.M. Towards a Water Sensitive Mexico City; De Urbanisten: Rotterdam, The Netherlands, 2016; Available online: https://www.deltares.nl/app/uploads/2018/01/20160629_ WS-CDMX_final-version-report-smsize.pdf (accessed on 6 April 2019).

66. Howells, J. Intermediation and the role of intermediaries in innovation. Res. Policy 2006, 35, 715-728. [CrossRef]

67. Pearsall, M. Participant observation as role and method in behavioral research. Nurs. Res. 1965, 14, 37-41. [CrossRef]

68. Spradley, J.P. Participant Observation; Holt, Rinehart \& Winston: New York, NY, USA, 1980.

69. Resilience Alliance. Assessing Resilience in Social-Ecological Systems: Workbook for Practitioners; Version 2.0; Resilience Alliance: Wolfville, NS, Canada, 2010.

70. Wardekker, J.A.; Wildschut, D.; Stemberger, S.; Van der Sluijs, J.P. Screening regional management options for their impact on climate resilience: An approach and case study in the Venen-Vechtstreek wetlands in the Netherlands. SpringerPlus 2016, 5, 750. [CrossRef]

71. Bathelt, H.; Malmberg, A.; Maskell, P. Clusters and knowledge: Local buzz, global pipelines and the process of knowledge creation. Prog. Hum. Geogr. 2004, 28, 31-56. [CrossRef]

72. Trompenaars, F. Riding the Waves of Culture; Nicholas Brealey Publishing: London, UK, 1993.

73. Owen-Smith, J.; Powell, W.W. Knowledge networks as channels and conduits: The effects of spillovers in the Boston biotechnology community. Organ. Sci. 2004, 15, 5-21. [CrossRef]

74. Stone, D. Learning lessons and transferring policy across time, space and disciplines. Politics 1999, 19, 51-59. [CrossRef]

75. Gupta, J.; Termeer, C.; Klostermann, J.; Meijerink, S.; Van den Brink, M.; Jong, P.; Nooteboom, S.; Bergsma, E. The adaptive capacity wheel: A method to assess the inherent characteristics of institutions to enable the adaptive capacity of society. Environ. Sci. Policy 2010, 13, 459-471. [CrossRef]

76. Hoogma, R.; Kemp, R.; Schot, J.; Truffer, B. Experimenting for Sustainable Transport: The Approach of Strategic Niche Management; Routledge: London, UK, 2005.

77. Schot, J.; Geels, F.W. Strategic niche management and sustainable innovation journeys: Theory, findings, research agenda, and policy. Technol. Anal. Strat. Manag. 2008, 20, 537-554. [CrossRef] 
78. Boschma, R. Proximity and innovation: A critical assessment. Reg. Stud. 2005, 39, 61-64. [CrossRef]

79. Boschma, R.; Frenken, K. The Spatial Evolution of Innovation Networks. A Proximity Perspective. In The Handbook of Evolutionary Economic Geography; Edward Elgar: London, UK, 2010; pp. 120-135.

80. Kaijser, A. System building from below: Institutional change in Dutch water control systems. Technol. Cult. 2002, 43, 521-548. [CrossRef]

81. Driessen, P.; Dieperink, C.; van Laerhoven, F.; Runhaar, H.; Vermeulen, W. Towards a conceptual framework for the study of shifts in modes of environmental governance: Experiences from the Netherlands. Environ. Policy Gov. 2012, 22, 143-160. [CrossRef]

82. Argyris, C.; Schön, D. Organizational Learning: A Theory of Action Perspective; Addison-Wesley: Boston, MA, USA, 1978.

83. Bandura, A. Social Learning Theory; Prentice-Hall: Englewood Cliffs, NJ, USA, 1977.

84. Kolb, D. Experiential Learning: Experience as the Source of Learning and Development; Prentice Hall: Englewood Cliffs, NJ, USA, 1984.

85. Cundill, G.; Fabricius, C. Monitoring in adaptive co-management: Toward a learning based approach. J. Environ. Manag. 2009, 90, 3205-3211. [CrossRef] [PubMed]

86. Bremer, S.; Wardekker, A.; Dessai, S.; Sobolowski, S.; Slaattelid, R.; Van der Sluijs, J. Toward a multi-faceted conception of co-production of climate services. Clim. Serv. 2019, 13, 42-50. [CrossRef]

87. Hegger, D.L.T.; Dieperink, C. Joint knowledge production for climate change adaptation: What is in it for science? Ecol. Soc. 2015, 20, 1. [CrossRef]

88. Brown, R.R.; Farrelly, M.A. Delivering sustainable urban water management: A review of the hurdles we face. Water Sci. Technol. 2009, 59, 839-846. [CrossRef]

89. Loorbach, D. Transition Management: New Mode of Governance for Sustainable Development; International Books: Utrecht, The Netherlands, 2007.

90. Zegwaard, A.; Zwarteveen, M.; Van Halsema, G.; Petersen, A. Sameness and difference in delta planning. Environ. Sci. Policy 2019, 94, 237-244. [CrossRef]

91. Wardekker, A. Framing 'Resilient Cities': System versus Community Focused Interpretations of Urban Climate Resilience. In Urban Resilience: Methodologies, Tools and Evaluation; Springer: Cham, Switzerland, 2019. (in press)

92. Van Herk, S.; Zevenbergen, C.; Ashley, R.; Rijke, J. Learning and Action Alliances for the integration of flood risk management into urban planning: A new framework from empirical evidence from The Netherlands. Environ. Sci. Policy 2011, 14, 543-554. [CrossRef]

93. Sengers, F.; Wieczorek, A.J.; Raven, R. Experimenting for sustainability transitions: A systematic literature review. Technol. Forecast. Soc. Chang. 2016. [CrossRef]

94. Dolowitz, D.P.; Marsh, D. Learning from abroad: The role of policy transfer in contemporary policy-making. Governance 2000, 13, 5-23. [CrossRef]

95. Runhaar, H.; Mees, H.; Wardekker, A.; Van der Sluijs, J.; Driessen, P. Adaptation to climate change-related risks in Dutch urban areas: Stimuli and barriers. Reg. Environ. Chang. 2012, 12, 777-790. [CrossRef]

96. Kimmelman, H. Mexico City, Parched and Sinking, Faces a Water Crisis. New York Times. 2017. Available online: https://www.nytimes.com/interactive/2017/02/17/world/americas/MexicoCity-sinking.html (accessed on 6 April 2019).

97. Kimmelman, H. The Dutch have Solutions to Rising Seas: The world is Watching. New York Times. 2017. Available online: https:/www.nytimes.com/interactive/2017/06/15/world/europe/climate-change-rotterdam. html (accessed on 6 April 2019).

98. Moodley, S. Defining city-to-city learning in southern Africa: Exploring practitioner sensitivities in the knowledge transfer process. Habitat Int. 2019, 85, 34-40. [CrossRef] 

Article

\title{
Pluvial Flooding in Utrecht: On Its Way to a Flood-Proof City
}

\author{
Romy C. Brockhoff ${ }^{1}$, Steven H. A. Koop ${ }^{1,2, *}$ and Karin A. W. Snel ${ }^{1}$ \\ 1 Faculty of Geosciences, Utrecht University, Princetonlaan 8a, 3584 CB Utrecht, The Netherlands \\ 2 KWR Watercycle Research Institute, Groningenhaven 7, 3433 PE Nieuwegein, The Netherlands \\ * Correspondence: stef.koop@kwrwater.nl
}

Received: 24 May 2019; Accepted: 17 July 2019; Published: 19 July 2019

\begin{abstract}
Downpours are increasing in frequency and severity due to climate change. Cities are particularly susceptible to flooding from downpours because of their large share of impervious surfaces. Minimising pluvial flood risk requires all involved stakeholders to collaborate and overcome various barriers. Although an increase in citizen engagement in climate adaptation is generally preferred, experiences with inclusive decision-making are often limited. The aim of this paper is to obtain a deeper understanding of how the capacity to govern pluvial flood risk can be developed through citizen engagement. We scrutinised the capacity of local actors to govern pluvial flood risk in the city of Utrecht, the Netherlands. For the analysis of Utrecht's problem-solving capacity, the Governance Capacity Framework provided a consistent assessment of the key governance components. The results indicate that Utrecht's capacity to govern pluvial flooding is relatively well-developed. Collaboration between public authorities is advanced, sufficient financial resources are available, and smart monitoring enables high levels of evaluation and learning. However, citizen awareness and engagement in policy making is rather low. Accordingly, citizens' willingness to pay for flood adaptation is limited. Stimulating flood risk awareness by combining financial incentives with more advanced arrangements for active citizen engagement is key for Utrecht and other cities.
\end{abstract}

Keywords: citizen engagement; flood risk governance; governance capacity; climate adaptation

\section{Introduction}

Extreme weather events, such as heavy rainfall, are likely to increase in frequency and intensity as a consequence of climate change [1]. In the past few decades, physical, societal, and economic damages of natural disasters have increased considerably [2]. In particular, floods are expected to substantially threaten the quality of urban life in the near future [3,4], demanding sound flood risk management. Urban areas are particularly vulnerable to downpours due to their impermeable surfaces-such as roads, parking lots, and roof tops- that prevent rainwater from infiltrating and, as a consequence, generate increased surface-runoff and thus increase the pluvial flood risk of urban areas [5]. Pluvial urban flooding may lead to large-scale economic damage and traffic congestion. It may also induce irregularities in the provision of electricity [6-8]. In 2011, for instance, the city of Copenhagen (Denmark) was hit by a downpour of 150 millimetres in less than three hours. The concomitant damage was estimated at around one billion US dollars [9]. Therefore, making cities more flood-resilient is an urgent challenge for sustainable urban living.

Urban expansion and insufficient water storage capacity regularly lead to rainfall runoff peaks that exceed the water system's drainage capacity, resulting in pluvial flooding $[5,10,11]$. This is a pressing issue in many Western-European cities because the water infrastructure in these places is becoming increasingly obsolete and requires costly refurbishments $[12,13]$. These drainage systems are generally not designed for the climate-change-induced increase in frequency and intensity of storm events. 
Moreover, these systems are typically a combined drainage of storm water and sewerage (i.e. Combined Sewer System; CSS). This type of drainage system is more vulnerable to surface water flooding [4,14]. Thus, growing precipitation extremes together with a large percentage of impermeable urban surfaces and an increasingly obsolete drainage system, call for more advanced urban flood adaptation.

In many countries in Europe, governmental institutions have been solely responsible for flood risk management [15-17]. Their main objective is to ensure that floods do not affect economic growth, national security, or welfare standards [18]. However, the intensity and frequency of storm events is changing and affecting all types of land use. Accordingly, the division of responsibilities related to flood risk management is changing. A decentralising trend in flood risk management has been recognised [19], which results in a greater role for non-governmental actors [20]. These transformations are related to a more general trend, namely the shift from government to governance. This implies a relocation of power and authority both among governmental organisations, such as delegating certain tasks from the national government to local authorities, as well as from governmental organisations to private actors [21]. This trend towards governance is widely adopted in, for instance, the European Union's (EU) Flood Directive, the EU Water Framework Directive, and the Aarhus Convention [22]. These policies mandate the engagement of non-governmental actors in flood risk management [23]. The involvement of non-governmental stakeholders, such as citizens, project developers, housing corporations, and businesses, in local flood risk management is crucial in fostering climate adaptation in cities [21,24]. Citizen engagement is increasingly important for adapting to climate-related risks, including pluvial flooding [25-27]. However, the specific responsibilities borne by public and private actors in climate adaptation and flood risk management are often unclear [8].

Even though citizen engagement in flood risk management is encouraged and acknowledged by global organisations (e.g., Intergovernmental Panel on Climate Chance [1] and Organisation for Economic Co-operation and Development (OECD) [22]), it remains a challenge to effectively engage citizens in climate adaptation projects and decision-making of local governments [25]. To start, municipalities appear to have limited experience with citizen engagement in climate adaptation [28]. Wamsler [29] analysed city-citizen collaboration for climate change adaptation in eight German municipalities and concluded that this cooperation is 'practically non-existent' as individuals are insufficiently aided by city authorities and urban policy does not support collaboration. Accordingly, Brink and Wamsler [30] observed that Swedish municipalities rarely involve citizens in local flood or climate change adaptation. Moreover, a cross-country comparison between the United Kingdom, Italy, and the Netherlands shows that overall citizen engagement is limited when examining the respective types of interactions between citizens and authorities and the impact of citizen engagement on decision-making [23]. In the Netherlands, citizens are held responsible by the law for managing rainwater on their own property. In practice however, it has been found that Dutch residents often rely on local governments [31,32]. The downside of this national commitment to flooding is that citizens' initiatives in the implementation phase are considered as a 'backup strategy' in addition to collective flood risk measures [17]. Another consequence is that citizens lack awareness of their responsibility regarding rainwater on their own property [6]. The lack of clarity in duties, good examples, and experiences with this more inclusive form of decision-making and implementation may explain the slow progress in citizen engagement in climate adaptation that has been observed $[8,33]$. For example, citizens' motivation to participate does not only depend on their risk perception but also on their sense of self-efficacy and the financial means made available to genuinely let citizens influence the end-result of decision-making processes [34]. Thus, active citizen engagement in urban flood adaptation seems to be challenging in practice, although it is often claimed to be essential for implementing climate adaptation measures.

The overall capacity of stakeholders to collaborate and address water-related challenges together, such as pluvial flooding, may be much more decisive than the capacity of individual organisations and stakeholders [35-37]. From this more holistic perspective, it becomes essential to scrutinise how citizens can contribute in formulating and implementing policies and objectives related to pluvial flooding. 
In our study we apply the governance capacity analysis. This methodology is based on Likert scale descriptions of indicators that together are argued to form the capacity to govern water challenges. Although this method is well-embedded in existing literature on adaptive management, co-management, and water governance [32], it is important to note there is a plethora of frameworks developed to assess the key conditions that together constitute governance capacity (e.g., [22,38,39]). The Governance Capacity Framework (GCF) is selected because it is one of the most standardised approaches in terms of definitions, operationalisation, research approach, and geographical scope, which enables high levels of scientific reproducibility and falsifiability of the empirical results. An overview of the operational indicators and key references to literature can be found here [40]. A second reason for selecting the GCF relates to its (graphical) design, which aims to be intelligible for a variety of non-experts such as policymakers, operators, and citizens. Thirdly, although other governance assessment frameworks have been developed for institutions at various scales such as social-ecological systems, bioregions, countries, river basins, or organisations (e.g., [22,39,41,42]), there are not that many frameworks focussing on the urban context, particularly with respect to governance capacity. However, cities are important and well-established institutional entities where integration of water with different sectors, objectives, and interests is perhaps most prevalent and concrete. In fact, the direct interaction between citizens, governments, and smaller and larger private stakeholders may be most widespread in cities $[43,44]$.

The GCF consists of nine key conditions for good governance such as awareness, useful knowledge, continuous learning, stakeholder engagement, and implementing capacity. This paper specifically addresses how citizen engagement can effectively contribute to each condition, and thereby improve the overall capacity to govern pluvial flood risk. In this way, both the engagement of citizens in decision-making processes, as well as the implementation of (individual) adaptation measures, are scrutinised in the case study of Utrecht. Accordingly, the aim of this paper is to obtain a deeper understanding of how the capacity to govern pluvial flood risk can be developed and further improved through citizen engagement. We first analyse Utrecht's capacity to govern pluvial floods and second, we scrutinise the role of citizen engagement in strengthening the governance capacity. In this paper, we use citizen engagement as a conceptual umbrella that captures both the participation of citizens within the local decision-making process and an active involvement in the implementation phase by taking climate adaptive measures. Additionally, 'Utrecht' will be used to refer to the local network of stakeholders (including local authorities and citizens), i.e., 'governance structure', within the administrative municipal area of Utrecht, the Netherlands.

Section 2 provides the conceptual framework, research methodology, and case study description. Section 3 presents the results of the governance capacity assessment of Utrecht and specifically addresses the role of citizen engagement. Finally, Sections 4 and 5 cover the discussion and conclusion, respectively.

\section{Conceptual Framework}

\subsection{Governance Capacity Framework}

To assess the capacity of Utrecht to govern pluvial flood risk, we apply the Governance Capacity Framework (GCF), developed by Koop, et al. [45]. The framework consists of three dimensions and nine conditions and is supported by 27 indicators (Table 1). The dimension knowing refers to the need to be aware (e.g., [46]), understand (e.g., [47]), and learn (e.g., [48]) about the risks and impacts of environmental challenges and policy. Wanting alludes to the willingness and motivation of various actors to cooperate (e.g., [34]), act upon ambitions (e.g., [49]), and devote oneself to finding solutions (e.g., [50]). Enabling refers to the network's ability to collaborate (e.g., [51]), coordinate, and implement action plans through various policy instruments and available resources (e.g., [38,52]). The selected nine conditions are based on a literature review in the field of water governance, environmental governance, and adaptive management [45], and are well aligned with the much-accredited principles for water governance proposed by the Organisation for Economic Co-operation and Development [22]. 
For detailed references to key literature for each of the framework's 27 indicators, we refer to [40]. The GCF provides a diagnosis of urban water challenges. These challenges generally require different organisations to collaborate and align their activities. The framework's indicators are consistently scored according to an indicator-specific Likert scale ranging from very limiting $(--)$ to very encouraging $(++)$ to the governance capacity. The GCF has been applied to assess 41 water-related challenges in 15 cities across the globe $[32,45,53-58]$.

Table 1. Overview of the Governance Capacity Framework (GCF) adopted from Koop et al. [45].

\begin{tabular}{|c|c|c|}
\hline Dimensions & Conditions & Indicators \\
\hline \multirow{3}{*}{ Knowing } & 1 Awareness & $\begin{array}{l}\text { 1.1 Community knowledge } \\
\text { 1.2 Local sense of urgency } \\
\text { 1.3 Behavioural internalisation }\end{array}$ \\
\hline & 2 Useful knowledge & $\begin{array}{l}\text { 2.1 Information availability } \\
\text { 2.2 Information transparency } \\
\text { 2.3 Knowledge cohesion }\end{array}$ \\
\hline & 3 Continuous learning & $\begin{array}{l}\text { 3.1 Smart monitoring } \\
\text { 3.2 Evaluation } \\
\text { 3.3 Cross-stakeholder learning }\end{array}$ \\
\hline \multirow{3}{*}{ Wanting } & 4 Stakeholder engagement process & $\begin{array}{l}\text { 4.1 Stakeholder inclusiveness } \\
\text { 4.2 Protection of core values } \\
\text { 4.3 Progress and variety of options }\end{array}$ \\
\hline & 5 Management ambition & $\begin{array}{l}\text { 5.1 Ambitious and realistic management } \\
\text { 5.2 Discourse embedding } \\
\text { 5.3 Management cohesion }\end{array}$ \\
\hline & 6 Agents of change & $\begin{array}{l}\text { 6.1 Entrepreneurial agents } \\
\text { 6.2 Collaborative agents } \\
6.3 \text { Visionary agents }\end{array}$ \\
\hline \multirow{3}{*}{ Enabling } & 7 Multi-level network potential & $\begin{array}{l}\text { 7.1 Room to manoeuvre } \\
\text { 7.2 Clear division of responsibilities } \\
\text { 7.3 Authority }\end{array}$ \\
\hline & 8 Financial viability & $\begin{array}{l}\text { 8.1 Affordability } \\
\text { 8.2 Consumer willingness-to-pay } \\
\text { 8.3 Financial continuation }\end{array}$ \\
\hline & 9 Implementing capacity & $\begin{array}{l}\text { 9.1 Policy instruments } \\
\text { 9.2 Statutory compliance } \\
\text { 9.3 Preparedness }\end{array}$ \\
\hline
\end{tabular}

\subsection{Method}

The 27 indicators are scored according to three consecutive steps:

1. Policy review: For all 27 indicators, data (documents, reports, policy) were gathered. By performing this desk study of grey literature and other relevant sources, prior knowledge on all indicators has been obtained. Through this extensive and comprehensive analysis on existing data, a valuable insight into each indicator was acquired. The obtained information formed the core of the analysis. The interviews conducted in step 2 provided further improvements in accuracy, comprehensiveness, awareness and support for the study's results.

2. Interviews: To refine the preliminary scores, more in-depth and case-specific information was collected through nine face-to-face interviews with a wide variety of stakeholders. To select the interviewees, the importance/influence matrix was used. Importance can be defined as a measure for a stakeholder's (first) concern and interest with a certain activity; whereas Influence alludes to the power and opportunity of a stakeholder to negatively or positively change the 
accomplishment of that activity [59]. The importance/influence matrix consists of four classes: (1) Subjects (high importance, low influence), (2) Key players (high importance, high influence), (3) Crowd (low importance, low influence) and (4) Context setters (low importance, high influence). For an in-depth understanding of the local urban context, this study focussed on key players and subjects for the interview selection. The nine interviews lasted approximately one hour and were recorded after permission was given. This ensured accuracy and enabled easy comparisons of specific indicators.

3. Score determination: Finally, the preliminary score of the policy review and the results of interviews were compared and led to a final score per indicator.

A coding system is applied in this paper to refer to interviewees while guaranteeing their anonymity. Accordingly, codes such as [SR01], [SR02], [SR03] refer to the individual interviews respectively. The interviewees included stakeholders that participate in collaborative regional networks and can be classified in the groups 'key players' and 'subjects'. As key players, we selected two policy advisors on urban water and public green spaces (Municipality of Utrecht), a spatial adaptation expert (Province of Utrecht) and representatives of the regional water authority (HDSR; in Dutch: Hoogheemraadschap De Stichtse Rijnlanden). For flood risk management in the city of Utrecht, the regional partnerships Winnet (in Dutch: Water Innovatie Netwerk), Coalition Spatial Adaptation (CSA; in Dutch: Coalitie Ruimtelijke Adaptatie), and Nature and Environment Federation Utrecht (NEFU; in Dutch: Natuur en Milieu Federatie Utrecht) form the subjects. Winnet is a regional cooperation in Utrecht, consisting of 14 municipalities and the regional water authority HDSR, and aims at a sustainable and efficient waste water cycle. Similarly, CSA is a regional platform facilitated by the engineering consultancy Sweco that addresses drought, heat stress, and flooding by joining forces with the Province of Utrecht, six municipalities, HDSR, and Safety Region Utrecht (in Dutch: Veiligheidsregio Utrecht). Finally, NEFU unites various stakeholders (e.g., citizens, local authorities, businesses, housing corporations) to achieve a sustainable province and to tackle climate adaptation, including pluvial flooding.

\subsection{Case Study: Utrecht (the Netherlands)}

In July 2014, the city of Utrecht was hit by the heaviest rainfall ever recorded, with measurements ranging from 75 to over 100 millimetres in 24 hours [60]. Utrecht has limited capacity to store such downpours as only $21.8 \%$ of the city centre is green (vegetation) or blue (water) [4]. Besides, the city is characterised by an ageing sewer system, and has only 384 kilometres of stormwater sewers and 630 kilometres of combined sewers (both rainwater and sanitary water) [61]. The combined sewer system is common in many Dutch cities and as risks of pluvial flooding increase [6], the exposure to Combined Sewer Overflows (CSOs) increases as well. This may result in urban surface water pollution that may negatively affect both the environment and human health $[14,57]$.

The municipality of Utrecht has approximately 352,941 inhabitants (1 January 2019) and prognoses are that it will reach over 400,000 citizens by the year 2025 [62]. When comparing the four largest Dutch municipalities, Utrecht grew most rapidly from 2010-2018 (13.16\%) and it is expected to continue growing at this rate [63]. The involvement of citizens in addressing pluvial flooding is important, as they own, together with businesses, approximately $60 \%$ of Utrecht's land surface [64]. Citizens can thus make a large contribution, for instance by installing green roofs on their property or removing pavements in their gardens, to respectively store and infiltrate rainwater. This clearly shows the potential of citizens' actions to help address downpours. In 2018, 3716 square metres of green roofs were installed in Utrecht, financially stimulated through a municipal subsidy programme [65]. Although this coverage has more than tripled compared to 2017, the installation of green roofs in Utrecht by citizens is still in its infancy.

Urbanisation, in combination with extreme rainfall and the aforementioned limitations regarding sewerage and water storage capacities, calls for more understanding of how to adequately govern these challenges. Knowledge will help local policymakers and other stakeholders to implement climate adaptive policies. As many other Western-European cities face the challenge of pluvial flooding and 
share the same characteristics as Utrecht (e.g., ageing water infrastructures, urbanisation, and sealed urban surfaces), our lessons may also benefit other cities.

\section{Results}

Figure 1 shows the capacity profile that indicates how well stakeholders work together to govern pluvial flood risk in Utrecht. Overall, the governance capacity is well-developed (Figure 1). However, note that all neutral $(0)$ or encouraging $(+)$ scores can still improve substantially. Section 3.1 provides the key results of the governance capacity analyses, which is structured according to the framework's three dimensions knowing, wanting, and enabling, and ends with a synthesis of these results. Section 3.2 focusses on the role of citizen engagement, which turned out to be a priority for future efforts to mitigate pluvial flood risk in Utrecht.

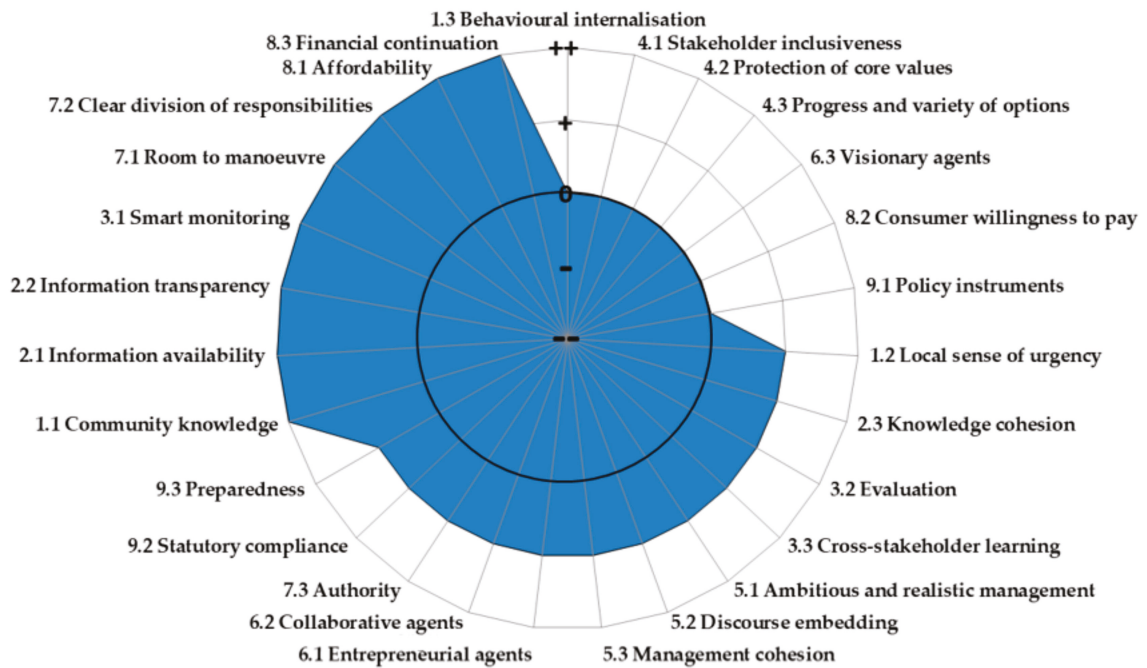

Figure 1. Results of the Governance Capacity of Utrecht to address pluvial flood risk. The indicators are arranged clockwise from very limiting $(--)$ to very encouraging $(++)$. Key message is "the bluer, the better".

\subsection{Utrecht's Capacity to Govern Pluvial Flood Risk}

\subsubsection{Dimension 1: Knowing}

The city of Utrecht performed a mandatory 'climatic stress test' in 2018. This test [66] contributed to identifying locations that are vulnerable to floods, heat stress, and water scarcity issues [SH02, SH09]. Moreover, sewer systems are adequately monitored, and precipitation prediction models are upgraded by a collaboration of the municipality of Utrecht, cooperation Winnet, and the regional water authority (indicator 3.1 [SH02, SH03, SH07]). Utrecht's current strategy is, however, not aimed at sewer pipe dimensioning to store excess water in case of a heavy rain event. Sewer pipes will only be enlarged when standard precipitation norms are exceeded [SH05]. This emphasises the need for alternative solutions. In addition, cross-stakeholder learning (indicator 3.3) is well-embedded in Utrecht, for instance in the form of knowledge sharing between many networks and cooperations [SH06]. Knowledge sharing with a broader audience than specialist networks is somewhat limited, specifically the citizens of Utrecht are largely overlooked.

Despite awareness campaigns such as 'Waterproof030' and 'Water-friendly Garden', a widespread sense of urgency about pluvial flood risk (indicator 1.2) has not been established yet. However, a sense of urgency does exist in flood-prone neighbourhoods: Lombok and Zeeheldenbuurt [SH01]. 
It seems that a more profound sense of urgency requires a downpour, as SH07 describes: "What we actually need, is another cloudburst as a kind of wake-up call to raise the urgency of the water issue." Citizens of Utrecht seem to be informed about the impacts and probabilities of pluvial floods (indicator 1.1). In addition, some communities are starting to engage in flood alleviation initiatives such as placing rain barrels in the street (indicator 1.3 [67]). However, in general, people do not feel an urgency to change their behaviour by taking precautionary measures (indicator 1.3). In fact, most people do not act because they perceive such adaptation measures as a primary responsibility of local authorities (i.e. the regional water authority and municipality) [SH01, SH02, SH06]. These results are in line with the OECD study [31] that observes a water awareness gap amongst Dutch citizens who take water services for granted. Contrary to this awareness gap, the availability of transparent and intelligible information about pluvial flood risk is well-organised through various channels such as websites, newspapers, television, or policy documents (indicator 2.1 and 2.2 [SH01, SH03, SH05, SH07]). For example, the municipality published an online manual for citizens on how to make dwellings and gardens waterproof [68]. In short, citizens in Utrecht know about the risk of pluvial flooding, yet do not consider this issue as a priority and do not seek for information until they experience 'wet feet' themselves.

\subsubsection{Dimension 2: Wanting}

Stakeholder engagement (condition 4) is important for joint problem framing, gaining access to resources, and creating support for successful implementation of measures and policies. Although stakeholder engagement is an integrated part of governing pluvial flood risk related issues in Utrecht, its current application is rather limited. In fact, for pluvial flooding specifically, stakeholder engagement is hardly considered [SH07]. More generally, stakeholder engagement in Utrecht consists merely of consultation sessions where people can ask for amendments to proposed policy plans. In a number of cases, these consultations occur at the end-stage of the decision-making process (indicator 4.1-[SH07]), resulting in a low influence of stakeholders on the end-result and arguably low stakeholder engagement in the implementation phase [34]. In addition, only public parties and one consultancy company are represented in the main regional partnerships CSA and Winnet, whereas citizens and housing corporations have yet to be included.

Utrecht's sustainability ambition (condition 5) is found to be well-embedded and goals for water policy and green policy on the municipal level are more or less aligned and are thus enhancing cohesion (indicator 5.3 [SH07, SH08]). Besides, Utrecht has adopted the seven ambitions of the national Delta Programme [69], which aim at making the Netherlands water-resilient and climate-proof. However, the pathways to reach this goal are yet to be formulated by local authorities [SH09]. The role of local citizens who promote initiatives, bring actors together, and mobilise required local resources, can be improved (condition 6). In Utrecht, such agents of change are rather limited to small-scale neighbourhood initiatives as individual initiatives to install rain barrels [67]. Though limited in scale, these types of initiatives may spur neighbours to do the same [SH05, SH07]. As SH05 argues: "It is crucial to have examples in practice. If your neighbours take measures, this may encourage other residents to take action as well."

At the municipal level, the city mayor for instance, can be considered a visionary agent of change regarding sustainability initiatives, but he does not (yet) perceive pluvial flooding as a priority. By contrast, municipal representatives of the neighbouring smaller city of Houten are more engaged with pluvial flood risk adaptation [SH07]. Utrecht cannot fully rely on local agents of change but could facilitate more initiatives when the municipality recognises pluvial flooding as a priority.

\subsubsection{Dimension 3: Enabling}

The results show that stakeholders who participate in collaborative regional networks (e.g., CSA and Winnet) have sufficient room to manoeuvre and find solutions to pluvial flood risks (indicator 7.1). However, these cooperations and local authorities are not the only stakeholders who bear responsibility, 
as multiple interviewees acknowledge that citizens have to make an effort as well [SH06, SH07, SH09]. To enable actors to implement their ambitions and ideas concerning flood resilience, sufficient financial resources are crucial. For citizens in Utrecht, taking climate adaptation measures to cope with pluvial flooding is financially supported by the regional water authority and the municipality through multiple subsidy schemes [SH02, SH04, SH06, SH08]. This financial support enhances the affordability of various adaptation measures (indicator 8.1), such as the replacement of pavements by greenery in private gardens. According to SH04, there is, in general, a willingness to pay among citizens for taxes levied by the regional water authority. However, the willingness to invest in pluvial flooding solutions is found to be moderate among citizens in the flood-prone neighbourhood Lombok (indicator 8.2). The municipality realised a separate drainage of rainwater in this low-lying part of Utrecht and connected 68 semi-based dwellings to this system [SH07]. As these houses are private entities, homeowners bear responsibility as well. However, not every household was willing to invest, as SH07 explains: "About half of the 68 homeowners in Lombok signed an agreement with the municipality to contribute in implementing pluvial flooding measures on their property."

In fact, these limitations in the willingness to pay are a recurring pattern for Dutch municipalities. For example, a survey conducted by the Dutch Broadcast Foundation among 1700 Dutch citizens that experienced serious pluvial flooding issues, showed that the community would like to see the municipality invest more in the sewer system, while only $25 \%$ of them are willing to pay more municipal sewer taxes [70]. A study on Dutch water governance recommends strengthening the finance system by implementing polluter-pays principles, such as abstraction charges [31]. Following this report, a special commission appointed by all Dutch water authorities investigated optimising the regional water authority's tax system [SH04]. At present, rainwater accounts for approximately a third of the water treatment costs [71]. To minimise this share, the commission suggests increasing incentives to decouple rainwater pipes from the drain to relieve the sewer system and reduce treatment costs [71]. The commission's proposal is hitherto not implemented in Utrecht or elsewhere in the Netherlands.

Nonetheless, monetary aid or financial incentives are no guarantee for successful adaptation by citizens. For instance, the municipal subsidy for green roofs has had minimal effect because many people do not yet fully grasp the added value of having a vegetated roof [SH07, SH08]. To date, stimulating rather than implementing sustainable behaviour through binding guidelines has been preferred by local authorities [SH07]. Citizens are financially supported through various subsidy schemes to take climate adaptive measures (e.g., removing pavements, installing green roofs, or building climate-proof playgrounds), yet do not take advantage of this. This may be explained by the low sense of urgency and limited awareness that has been observed.

\subsubsection{Synthesis}

Overall, Utrecht can considerably improve its capacity to govern pluvial flood risk. In particular, the following indicators and conditions showed the most room for improvement and therefore should form the core focus for future action. First, there is a relatively low willingness to pay (indicator 8.2) for climate adaptive solutions such as infrastructure augmentations (i.e. separate rainfall runoff from the sewer systems). Accordingly, local communities and the private sector show limited efforts to understand, react, and anticipate risks of pluvial flooding such as applying green roofs (indicator 1.3). Limitations in awareness among citizens and private stakeholders (condition 1) and a suboptimal use of policy instruments (indicator 9.1) both require additional effort to better address the increasing downpours that Utrecht is projected to have. Governmental bodies, such as the municipality and the regional water authority, are aware and are actively initiating action through multi-level collaborative networks (condition 7). However, with respect to private actors and citizen engagement, considerable progress is required to effectively address pluvial flood risk (condition 4). To achieve this, Utrecht may need to formulate an action plan in close collaboration with its citizens and local enterprises (indicator 9.3). In this way, stakeholder engagement (condition 4) can be improved to better serve both the policy development and implementation phase. 


\subsection{Citizen Engagement}

Despite serious efforts made by the municipality and regional water authority (e.g., through campaigns and provision of information and advice), the level of awareness among citizens on pluvial flooding in Utrecht is limited. In general, they lack a sense of urgency to act as they hold local authorities responsible for taking climate adaptation measures to alleviate the risk of urban floods. If they do feel accountable, citizens show reactive behaviour (i.e. taking measures after pluvial floods occurred) rather than proactive. This reactive behaviour is mainly visible among citizens who are exposed to the negative effects of extreme rainfall in their garden or inside their dwelling, as SH05 explains: "A sense of urgency among citizens does not occur until they are confronted with pluvial floods themselves. They purely react upon pluvial flooding issues."

To change this reactive behaviour into (pro)active behaviour regarding pluvial adaptation, both the municipality and regional water authority in Utrecht make an effort to support its inhabitants by providing various grant schemes. Despite this, citizens' willingness to pay still appears to be low. Taken together, the combination of information provisions (e.g., through policy documents, campaigns, manuals, guest lectures at schools) and financial aid (e.g., grant schemes) provided by local authorities does not yield the desired result, namely, citizens taking climate adaptive measures to minimise the adverse effects of pluvial flooding.

What is largely missing is an active involvement of citizens in (municipal) decision-making. Citizens are expected to be actively engaged in addressing pluvial flooding, yet they have little influence on municipal flood-related policies. At present, the municipality is only obliged to ask for consultation from the regional water authority and province [SH07].

To stimulate citizens to adapt to pluvial flooding, an important incentive is to actively engage them in the development and implementation of flood adaptation policy plans. To do so, their level of influence should go beyond being informed or consulted. The opportunity to be actively engaged and coproduce policy plans may be essential in motivating citizens to take part. Active engagement usually takes much more time than more unilateral decision-making. However, many authors argue that this is generally more than offset by time gains in the implementation phase, not the least because citizens become more aware of the relevance and their role in flood mitigation [34,72,73]. Our results indicate that the stakeholder engagement process (condition 4; Table 1) of Utrecht can be improved for flood decision-making. Stakeholders should be given the opportunity to be actively engaged so that the municipality can structurally stimulate their active engagement. More precisely, additional effort may be required to engage all relevant stakeholders in an early stage of policy coproduction processes. In these processes, it is crucial that stakeholders (e.g., citizens and local experts) develop a range of different alternatives and, when all alternatives are considered, commit themselves to a final decision. In addition, clear and realistic procedures with clear exit moments may ensure sufficient progress for stakeholders to continue their initial engagement and ensure that they feel confident that their core values are not being harmed (i.e. creating trust).

On another note, the policy instruments which are currently applied in Utrecht have a suboptimal effect. The municipal subsidy which is supposed to stimulate citizens to implement green roofs, for instance, has been adopted by citizens on a rather limited scale [SH08]. In addition, the municipal sewer levies, which are mandatory for all citizens, are currently not related to the discharge quantity of wastewater into the sewer system. This indicates that the polluter-pays principle is not implemented, and therefore, producing less wastewater is not rewarded by tax reductions. This demonstrates that Utrecht is implementing soft policies (e.g., providing information and subsidies) over hard policies (e.g., binding rules or punishment, such as charging citizens if over $70 \%$ of their garden consists of impermeable pavements). Although the latter strategy requires considerable paperwork (and thus resources), it is likely to have a substantially better result than the current package of non-binding soft policies. These stricter baseline instruments are an important contribution to spur active citizen engagement and may simultaneously contribute to improved water quality and drought alleviation. 


\section{Discussion}

The adverse effects of extreme rainfall on urban areas demand for adequate water governance to prevent pluvial flooding. We used the GCF [45] to assess the water governance capacity of all water-related stakeholders within the city of Utrecht to govern (the effects of) pluvial flooding. Our results demonstrate that the overall capacity of Utrecht to govern pluvial flooding is relatively well-developed. However, there is also room for improvement. In particular, the engagement and behavioural change of citizens seems to be essential for addressing pluvial flood risk. This result seems to be well-aligned with other studies of Utrecht and the main municipalities in the Netherlands (e.g., $[6,31,74])$.

\subsection{Method Validity and Limitations}

The GCF method integrates a wide range of governance gaps to assess a city's capacity to adequately manage water challenges [45]. This plethora of divergent aspects of water governance offers the opportunity to identify barriers and enablers, and thus reveals a city's current position on governing a specific water challenge. The applied methodology is comprehensive, enables reproducible results and includes both a policy review of local authorities and organisations as well as in-depth interviews with various local stakeholders. The results provide relevant insights for city planners and policymakers at the local level and can thus help the urban network in place to implement sound strategies and policies to alleviate the risk of pluvial flooding.

However, this study has also revealed limitations. The outcomes of the governance capacity analyses emphasised the role of citizen engagement in addressing pluvial flood risk. Since this study is based on a literature review and expert interviews, an assessment of how citizens consider their role in addressing flood risk is not accounted for. As such, a suggestion for future research is an in-depth study that explicitly includes citizens, for example through surveys. This will be relevant to further substantiate our findings related to citizen engagement in urban flood risk management.

There are also other frameworks that assess the governance capacity of environmental challenges, most notably, the adaptive capacity wheel [39] and the framework proposed by Mees and Driessen [75] to assess the governance capacity for green urban areas. Like the GCF, these frameworks rely on similar literature related to adaptive capacity, environmental governance, and water governance. Hence, elements such as social learning, division of responsibilities, resources, leadership, or accounting for uncertainty, are included. Moreover, the starting point of these frameworks is the comprehension of different values, viewpoints and alternatives in problem framing, decision-making, and implementation. Gupta, et al. [39] identify six dimensions: Variety, learning capacity, room for autonomous change, leadership, availability of resources, and fair governance. These dimensions and their 22 criteria assess the adaptive capacity of institutions (including their ideological values and norms), predominantly at the national level. This approach differs from the GCF's focus on how well different stakeholders collaborate and jointly address urban environmental challenges. In this respect, Mees and Driessen [75] have a similar approach as the GCF but focus specifically on green urban areas. They identify five key capacities: Learning, legal, managerial, political, and resources. Their framework also includes legal capacity and stakeholder engagement. Likewise, the GCF specifically includes indicators such as policy ambition, institutional compliance, smart monitoring, implementing capacity, and stakeholder engagement. The adaptive capacity wheel is, however, less focussed on the stakeholders and legal or policy aspects. When considering the scoring system, Gupta, et al. [39] apply a generic Likert scoring, which implies that there is more room for a researcher's interpretation when compared to the GCF's indicator specific Likert descriptions and standardised data gathering procedure. Moreover, Mees and Driessen [75] apply a more descriptive analysis of each component of their framework. Since this paper aimed to provide insights that may apply beyond the case study itself, a more standardised method has been selected that enables a better reproducibility and comparability of different cases. Given the similarities between the scope of this paper and that of Mees and Driessen [75], the frameworks can be considered complementary and may be combined in future research about the capacity of cities to 
govern pluvial flood risk. In particular, the indicators of Mees and Driessen that specifically address urban green areas may strengthen the more generic scope of the GCF and thus enable a more accurate analysis of pluvial flood risk.

\subsection{Promising Multi-Sectorial Linking Opportunities}

This study revealed barriers (e.g., limited citizen engagement) and opportunities (e.g., many local partnerships working on the issue of heavy rainfall) that require action by the entire network of stakeholders in Utrecht. Although the city is generally adopting sustainable pathways, it hitherto insufficiently recognises the multifaceted benefits of implementing integrated climate adaptation plans. For example, improving soil permeability, adding green spaces, adapting underground water infrastructures, installing green roofs, and even relocating buildings may reduce pluvial flooding and urban heat island effects. Such measures have additional benefits, such as better air quality, urban surface water quality, biodiversity, human health, and the overall attractiveness of the city $[4,13,22]$. For instance, green roofs offer multiple environmental benefits, such as efficient temperature control of buildings (using less energy), retaining rainwater (reducing pluvial flood risk), restoring biodiversity, and enhancing air and stormwater runoff quality [76]. The benefits of these 'linking opportunities' [70] may outweigh their costs and may ultimately improve the attractiveness and liveability of the city of Utrecht.

\subsection{The Role of Citizen Engagement in Municipal Water Management and Climate Adaptation}

The importance of the involvement of both public and private actors in climate adaptation and flood risk management has been frequently stressed (e.g., [1,21,22,24,26]). For example, leading concepts such as integrated water resources management and adaptive management include principles of engagement of a variety of stakeholders. Influential organisations include International Water Management Institute, the Food and Agriculture Organization, the World Bank, and various regional authorities. In addition, the United Nations Sustainable Development Goals and the European River Basin Approach also emphasise the authentic participation of a variety of public and private stakeholders [77-79]. However, how to engage stakeholders and citizens is a key challenge in many contexts. Through our case study of Utrecht, we found that citizens are hardly involved in the local decision-making process on pluvial flooding. Similarly, recent studies on the engagement of local stakeholders (e.g., citizens and/or other private actors) in climate adaptation and flood risk management show that involvement of local (private) stakeholders tends to be limited (e.g., [25,27,80]). Moreover, city-citizen collaborations on climate adaptation are scarce [29,30]. We found that Utrecht's public actors' (i.e. municipality and regional water authority) current strategy is primarily focussed on supplying information about climate adaptation to spur civic action. Through an extensive study of 402 urban areas, Klein, et al. [27] found similar results as they argue that local authorities steer citizens solely through information provision. These residents are, in turn, expected to use this information to implement adaptation measures [27]. In addition to solely providing information in a one-way direction (i.e. from government to citizens), local authorities may consider citizens' capability to collect data or information themselves. With respect to this, the concept of 'citizen science' is repeatedly referred to. Citizen science is defined as a practice in which individuals voluntarily participate in data collection or observations for scientific purposes and viewed as a form of collaborative research [81,82]. Sy et al. [83] emphasise that citizens play a crucial role in flood hazard assessment through various techniques, such as monitoring rainfall or analysing messages on rainfall on social media. Moreover, citizen science contributes to an increased understanding of the investigated subject by all involved actors [82]. In turn, a better understanding results in a higher level of awareness [84]. Five recent citizen science projects in the Dutch surface and drinking water sector show promising results on the effects of citizen participation; $70 \%$ of these projects' participants indicated that their level of awareness regarding water had increased, and even $87 \%$ of them described participation in the project as a 'learning experience' [84]. Thus, citizen science can be seen as a valuable form of citizen engagement 
(condition 4) through which awareness, knowledge, and transparency (conditions 1 and 2) on pluvial flooding can be enhanced.

In addition to citizen science, citizens may be further engaged in addressing pluvial flooding by taking measures on their private properties. These initiatives include, for example, the decoupling of rainwater from the sewer system, placing rain barrels, removing pavements, or installing a green roof (e.g., $[25,27,85])$. As our study shows, the implementation of these property-level protection measures (i.e. 'coproduction') often takes place after the occurrence of pluvial floods or solely in flood-prone areas. To address pluvial flooding more effectively, it is crucial to shift towards proactive actions, instead of reactive behaviour.

It has been suggested that involving citizens in decision-making processes is time-consuming and involves higher costs for the government $[30,86]$. However, the costs do not outweigh the positive effects of citizen participation, such as gaining legitimacy of decisions, trust-building, and learning from citizens [86]. Moreover, Mees, et al. [17] argue that 'coproduction' (i.e. interaction between citizen and public authorities during decision-making processes and in practice) can be seen as a way to reduce additional governmental investment in flood risk management. If citizen engagement becomes business as usual in governing pluvial flood risk, this may have a positive impact on the financial viability (condition 8) of dealing with the specific risk.

Furthermore, we found that citizens' willingness to pay (indicator 8.2) for flood protection measures in Utrecht is limited. This may be related to the observed limited risk perception (sense of urgency; indicator 1.2). In addition to this, Owusu, et al. [87] conclude that the scale of flood events and their impacts also relate to the extent to which people are open to adaptation measures. In other words, a large-scale flood event results in more citizens who might consider implementing adaptation measures on their property. Furthermore, Torgersen and Navrud [88] stress that citizens in high-risk flood areas have a greater willingness to pay for adaptation measures. Besides, Henstra, et al. [89] found that willingness to pay for property-level flood protection measures has a positive relationship with age, housing type, and level of education. However, the present study shows that living in a flood-prone neighbourhood does not automatically lead to investments (i.e. adaptation measures) to reduce pluvial flood risk. This might relate to the perception citizens of Utrecht have regarding the flood risk they face. This is in line with Bubeck, et al. [33], who argue that the supposed positive relation between flood risk perceptions and taking private adaptation measures is found to be limited in current empirical studies.

The available financial aid (e.g., subsidies) provided by Utrecht is currently suboptimal (indicator 9.1). The results of this study indicate that the dissemination of information in combination with financial incentives (i.e. 'soft policies') does not yield the desired effect of taking adaptive action. With respect to this, Dai, et al. [6] suggest that more binding rules instead of soft policies may be a valuable contribution. These regulations may contribute to the engagement of citizens in the implementation of climate adaptation measures. For example, if local authorities decide to levy taxes on heavily paved gardens (for example when $>70 \%$ of a private garden is paved), citizens have a stronger incentive to take action. Likewise, Mees, et al. [90] conducted a comparative study on the installation of green roofs and concluded that hierarchical arrangements (steering through regulations) are the most effective. However, local governments should play a facilitating role in supporting citizens [85]. Hence, a well-balanced use of both soft and hard policy instruments seems key. For instance, Kamperman and Biesbroek [91] advocate for a combination of 'hard' and 'soft' modes, because the existing Dutch regional water authorities' strategy of soft policies seems to be insufficient to spur climate change adaptation.

This research may support this finding. One way to achieve an improved governance capacity includes regulations such as levies or taxes on heavily paved gardens or large wastewater discharges (according to the polluter-pays principle). Another way to enhance the overall governing capacity to address pluvial flooding is through an increased engagement of citizens in local decision-making processes. Providing sufficient examples of good local practices (i.e. adaptation measures of fellow 
citizens) may contribute to getting citizen engagement off the ground in practice. Further research may be required through various neighbourhood experiments where different combinations of 'soft' and 'hard' measures are applied. In such an experimental setting, behaviour influencing tactics, other than just information transfer, should be tested to develop an optimal package that triggers citizen engagement in climate adaptation measures both in home and within their city. In such an experimental approach, different citizen groups could be identified based on their socio-economic characteristics, behaviours, and attitudes with respect to climate adaptation. Engagement of each of these groups could be effectively triggered by a different approach. Such experimental knowledge seems promising for obtaining valuable knowledge to effectively engage citizens and trigger climate adaptive behaviour.

Raising awareness is often perceived as crucial to realise more citizen engagement. However, a more nuanced balance between effective policy instruments, stakeholder engagement processes, and the development of local private initiatives is needed to effectively engage citizens to adapt to urban flood risk. To obtain a better insight into how to engage different citizen groups, further empirical research is needed to examine citizen engagement in urban flood risk management in practice.

\section{Conclusions}

The aim of this study in Utrecht (the Netherlands) is to obtain a deeper understanding of how the capacity to govern pluvial flood risk can be developed through citizen engagement. We applied citizen engagement as an umbrella term for the participation of citizens in the local decision-making process and for active involvement in the implementation phase by taking climate adaptive measures. The results of this study indicate that solely providing information and subsidies, i.e., 'soft policy instruments', does not yield the desired effect of citizens taking climate adaptive measures to protect themselves against pluvial flooding. Residents in Utrecht are currently insufficiently engaged in the local decision-making processes, which may explain the limited flood risk awareness among citizens. Their limited awareness, in combination with a low willingness to pay, may explain why they rarely take climate adaptation measures to alleviate the risk of pluvial flooding. The city of Utrecht might consider: (1) Including citizens more explicitly in the decision-making process regarding (pluvial) flood risk management; and (2) broadening the scope of its policy instruments by implementing more binding rules, such as taxes on heavily paved gardens. In doing so, residents are expected to become more aware of and more engaged with pluvial flooding. Improved citizen engagement can also be enhanced through citizen science projects. By creating such initiatives to establish more meaningful citizen engagement, Utrecht's capacity to govern pluvial flood risk can be strengthened substantially. Because other cities in the Netherlands and Europe face similar challenges of increasing downpours, aging infrastructure, and inexperience with citizen engagement, these lessons may be of value for them as well.

Author Contributions: Conceptualization, R.C.B., S.H.A.K., and K.A.W.S.; methodology, R.C.B. and S.H.A.K.; validation, R.C.B., S.H.A.K., and K.A.W.S.; formal analysis, R.C.B.; investigation, R.C.B.; resources, R.C.B., S.H.A.K. and K.A.W.S.; data curation, R.C.B.; writing-original draft, R.C.B.; writing-review and editing, R.C.B., S.H.A.K., and K.A.W.S.; visualization, R.C.B.; supervision, S.H.A.K. and K.A.W.S.; funding acquisition, S.H.A.K.

Funding: This research was funded by the European Commission, in the POWER H2020 project under grant number 687809 .

Acknowledgments: We would like to express our gratitude to all interviewees who have participated for providing valuable information for this research. Moreover, we would like to thank C.J. van Leeuwen for his suggestions during the writing process of this paper. The Governance Capacity Framework is part of the City Blueprint Approach, developed at KWR Research Institute in the context of Watershare (http://www.watershare.eu). The City Blueprint Action Group is part of the European Innovation Partnership on Water of the European Commission (http://www.eip-water.eu/City_Blueprints). The European Commission is acknowledged for funding POWER in H2020-Water under grand agreement no. 687809.

Conflicts of Interest: The authors declare no conflict of interest. 


\section{References}

1. Intergovernmental Panel on Climate Change. Climate Change 2014: Synthesis Report. Contribution of Working Groups I, II and III to the Fifth Assessment Report of the Intergovernmental Panel on Climate Change; IPCC: Geneva, Switserland, 2014; p. 151.

2. Kreibich, H.; Seifert, I.; Thieken, A.H.; Lindquist, E.; Wagner, K.; Merz, B. Recent changes in flood preparedness of private households and businesses in Germany. Reg. Environ. Chang. 2011, 11, 59-71. [CrossRef]

3. Hartmann, T. Clumsy Floodplains-Responsive Land Policy for Extreme Floods; Ashgate: Farnham Surrey, UK, 2011.

4. EEA. Urban Adaptation to Climate Change in Europe: Challenges and Opportunities for Cities Together with Supportive National and European Policies; EEA Report No 2/2012; EEA: Copenhagen, Denmark, 2012.

5. Zhou, Q. A Review of Sustainable Urban Drainage Systems Considering the Climate Change and Urbanization Impacts. Water 2014, 6, 976-992. [CrossRef]

6. Dai, L.; Wörner, R.; van Rijswick, H.F.M.W. Rainproof cities in the Netherlands: Approaches in Dutch water governance to climate-adaptive urban planning. Int. J. Water Resour. Dev. 2018, 34, 652-674. [CrossRef]

7. Gaitan, S.; van de Giesen, N.C.; Ten Veldhuis, J.A.E. Can urban pluvial flooding be predicted by open spatial data and weather data? Environ. Model. Softw. 2016, 85, 156-171. [CrossRef]

8. Runhaar, H.A.C.; Uittenbroek, C.J.; van Rijswick, H.F.M.W.; Mees, H.L.P.; Driessen, P.P.J.; Gilissen, H.K. Prepared for climate change? A method for the ex-ante assessment of formal responsibilities for climate adaptation in specific sectors. Reg. Environ. Chang. 2016, 16, 1389-1400. [CrossRef]

9. Liu, L.; Jensen, M.B. Climate resilience strategies of Beijing and Copenhagen and their links to sustainability. Water Policy 2017, 19, 997-1013. [CrossRef]

10. Mikovits, C.; Rauch, W.; Kleidorfer, M. Dynamics in Urban Development, Population Growth and their Influences on Urban Water Infrastructure. Procedia Eng. 2014, 70, 1147-1156. [CrossRef]

11. EEA. Climate Change, Impacts and Vulnerability in Europe 2016: An Indicator-Based Report; EEA Report No 1/2017; EEA: Copenhagen, Denmark, 2017.

12. Tscheikner-Gratl, F.; Hammerer, M.; Rauch, W.; Kleidorfer, M. Integrated Rehabilitation management for different infrastructure sectors. In Coecor. Ceocor, Florence; DIV Deutscher Industrieverlag GmbH: München, Germany, 2013; pp. 1-18.

13. Koop, S.H.A.; van Leeuwen, C.J. The challenges of water, waste and climate change in cities. Environ. Dev. Sustain. 2017, 19, 385-418. [CrossRef]

14. Koop, S.H.A.; van Leeuwen, C.J. Application of the Improved City Blueprint Framework in 45 Municipalities and Regions. Water Resour. Manag. 2015, 29, 4629-4647. [CrossRef]

15. Johnson, C.L.; Priest, S.J. Flood Risk Management in England: A Changing Landscape of Risk Responsibility? Int. J. Water Resour. Dev. 2008, 24, 513-525. [CrossRef]

16. Wiering, M.; Green, C.; van Rijswick, M.; Priest, S.; Keessen, A. The rationales of resilience in English and Dutch flood risk policies. J. Water Clim. Chang. 2014, 6, 38-54. [CrossRef]

17. Mees, H.; Crabbé, A.; Alexander, M.; Kaufmann, M.; Bruzzone, S.; Lévy, L.; Lewandowski, J. Coproducing flood risk management through citizen involvement: Insights from cross-country comparison in Europe. Ecol. Soc. 2016, 21. [CrossRef]

18. Penning-Rowsell, E.; Johnson, C.; Tunstall, S. 'Signals' from pre-crisis discourse: Lessons from UK flooding for global environmental policy change? Glob. Environ. Chang. 2006, 16, 323-339. [CrossRef]

19. Meijerink, S.; Dicke, W. Shifts in the Public-Private Divide in Flood Management. Int. J. Water Resour. Dev. 2008, 24, 499-512. [CrossRef]

20. Forrest, S.; Trell, E.-M.; Woltjer, J. Civil society contributions to local level flood resilience: Before, during and after the 2015 Boxing Day floods in the Upper Calder Valley. Trans. Inst. Br. Geogr. 2019, 44, 422-436. [CrossRef]

21. Mees, H. Local governments in the driving seat? A comparative analysis of public and private responsibilities for adaptation to climate change in European and North-American cities. J. Environ. Policy Plan. 2017, 19, 374-390. [CrossRef]

22. OECD. Stakeholder Engagement for Inclusive Water Governance; OECD Publishing: Paris, France, 2015.

23. Wehn, U.; Rusca, M.; Evers, J.; Lanfranchi, V. Participation in flood risk management and the potential of citizen observatories: A governance analysis. Environ. Sci. Policy 2015, 48, 225-236. [CrossRef] 
24. Driessen, P.P.J.; Hegger, D.L.T.; Kundzewicz, Z.W.; Van Rijswick, H.F.M.W.; Crabbé, A.; Larrue, C.; Matczak, P.; Pettersson, M.; Priest, S.; Suykens, C.; et al. Governance strategies for improving flood resilience in the face of climate change. Water 2018, 10, 1595. [CrossRef]

25. Hegger, D.L.T.; Mees, H.L.P.; Driessen, P.P.J.; Runhaar, H.A.C. The Roles of Residents in Climate Adaptation: A systematic review in the case of the Netherlands. Environ. Policy Gov. 2017, 27, 336-350. [CrossRef]

26. Brink, E.; Wamsler, C. Citizen engagement in climate adaptation surveyed: The role of values, worldviews, gender and place. J. Clean. Prod. 2019, 209, 1342-1353. [CrossRef]

27. Klein, J.; Araos, M.; Karimo, A.; Heikkinen, M.; Ylä-Anttila, T.; Juhola, S. The role of the private sector and citizens in urban climate change adaptation: Evidence from a global assessment of large cities. Glob. Environ. Chang. 2018, 53, 127-136. [CrossRef]

28. Wamsler, C.; Pauleit, S. Making headway in climate policy mainstreaming and ecosystem-based adaptation: Two pioneering countries, different pathways, one goal. Clim. Chang. 2016, 137, 71-87. [CrossRef]

29. Wamsler, C. From Risk Governance to City-Citizen Collaboration: Capitalizing on individual adaptation to climate change. Environ. Policy Gov. 2016, 26, 184-204. [CrossRef]

30. Brink, E.; Wamsler, C. Collaborative Governance for Climate Change Adaptation: Mapping citizen-municipality interactions. Environ. Policy Gov. 2018, 28, 82-97. [CrossRef]

31. OECD. Water Governance in the Netherlands: Fit for the Future? OECD Publishing: Paris, France, 2014.

32. Koop, S.; Monteiro Gomes, F.; Schoot, L.; Dieperink, C.; Driessen, P.; Van Leeuwen, K. Assessing the Capacity to Govern Flood Risk in Cities and the Role of Contextual Factors. Sustainability 2018, 10, 2869. [CrossRef]

33. Bubeck, P.; Botzen, W.J.W.; Aerts, J.C.J.H. A Review of Risk Perceptions and Other Factors that Influence Flood Mitigation Behavior. Risk Anal. 2012, 32, 1481-1495. [CrossRef]

34. Cernesson, F.; Echavarren, J.M.; Enserink, B.; Kranz, N.; Maestu, J.; Maurel, P.; Mostert, E.; Otter, H.; Patel, M.; Ridder, D.; et al. Learning Together to Manage Together. Improving Participation in Water Management; Harmonising Collaborative Planning (HarmoniCOP): Onasbrück, Germany, 2005; p. 99.

35. Plummer, R.; Crona, B.; Armitage, D.R.; Olsson, P.; Tengö, M.; Yudina, O. Adaptive Comanagement: A Systematic Review and Analysis. Ecol. Soc. 2012, 17. [CrossRef]

36. Emerson, K.; Nabatchi, T.; Balogh, S. An Integrative Framework for Collaborative Governance. J. Public Adm. Res. Theory 2011, 22, 1-29. [CrossRef]

37. Patterson, J.J.; Smith, C.; Bellamy, J. Understanding enabling capacities for managing the 'wicked problem' of nonpoint source water pollution in catchments: A conceptual framework. J. Environ. Manag. 2013, 128, 441-452. [CrossRef]

38. Moser, S.C.; Ekstrom, J.A. A framework to diagnose barriers to climate change adaptation. Proc. Natl. Acad. Sci. USA 2010, 107, 22026-22031. [CrossRef]

39. Gupta, J.; Termeer, C.; Klostermann, J.; Meijerink, S.; van den Brink, M.; Jong, P.; Nooteboom, S.; Bergsma, E. The Adaptive Capacity Wheel: A method to assess the inherent characteristics of institutions to enable the adaptive capacity of society. Environ. Sci. Policy 2010, 13, 459-471. [CrossRef]

40. European Commission. European Innovation Partnership on Water. Indicators of the Governance Capacity Framework. Available online: https://www.eip-water.eu/sites/default/files/Indicators\%20of\% 20the\%20Water\%20Governance\%20Capacity\%20Framework_0.pdf (accessed on 20 May 2019).

41. Alexander Ballard Ltd. Adaptive Capacity Benchmarking: A Handbook and Toolkit; Alexander Ballard Ltd.: Berkshire, UK, 2008.

42. Engle, N.L.; Lemos, M.C. Unpacking governance: Building adaptive capacity to climate change of river basins in Brazil. Glob. Environ. Chang. 2010, 20, 4-13. [CrossRef]

43. Haus, M.; Heinelt, H.; Stewart, M. Urban Governance and Democracy: Leadership and Community Involvement; Routledge: London, UK, 2004.

44. Yang, K.; Callahan, K. Assessing citizen involvement efforts by local governments. Public Perform. Manag. Rev. 2005, 29, 191-216.

45. Koop, S.H.A.; Koetsier, L.; Doornhof, A.; Reinstra, O.; Van Leeuwen, C.J.; Brouwer, S.; Dieperink, C.; Driessen, P.P.J. Assessing the Governance Capacity of Cities to Address Challenges of Water, Waste, and Climate Change. Water Resour. Manag. 2017, 31, 3427-3443. [CrossRef]

46. Raaijmakers, R.; Krywkow, J.; van der Veen, A. Flood risk perceptions and spatial multi-criteria analysis: An exploratory research for hazard mitigation. Nat. Hazards 2008, 46, 307-322. [CrossRef] 
47. Rowley, J. The wisdom hierarchy: Representations of the DIKW hierarchy. J. Inf. Sci. 2007, 33, 163-180. [CrossRef]

48. Pahl-Wostl, C. A conceptual framework for analysing adaptive capacity and multi-level learning processes in resource governance regimes. Glob. Environ. Chang. 2009, 19, 354-365. [CrossRef]

49. Brown, R.R.; Farrelly, M.A. Delivering sustainable urban water management: A review of the hurdles we face. Water Sci. Technol. 2009, 59, 839-846. [CrossRef]

50. Brouwer, S.; Biermann, F. Towards adaptive management: Examining the strategies of policy entrepreneurs in Dutch water management. Ecol. Soc. 2011, 16. [CrossRef]

51. Folke, C.; Hahn, T.; Olsson, P.; Norberg, J. Adaptive governance of social-ecological systems. Annu. Rev. Environ. Resour. 2005, 30, 441-473. [CrossRef]

52. Mees, H.L.; Dijk, J.; van Soest, D.; Driessen, P.P.; van Rijswick, M.H.; Runhaar, H. A method for the deliberate and deliberative selection of policy instrument mixes for climate change adaptation. Ecol. Soc. 2014, 19, 58. [CrossRef]

53. Schreurs, E.; Koop, S.; van Leeuwen, K. Application of the City Blueprint Approach to assess the challenges of water management and governance in Quito (Ecuador). Environ. Dev. Sustain. 2018, 20, 509-525. [CrossRef]

54. Šteflová, M.; Koop, S.; Elelman, R.; Vinyoles, J.; Van Leeuwen, K. Governing Non-Potable Water-Reuse to Alleviate Water Stress: The Case of Sabadell, Spain. Water 2018, 10, 739. [CrossRef]

55. Aartsen, M.; Koop, S.; Hegger, D.; Goswami, B.; Oost, J.; Van Leeuwen, K. Connecting water science and policy in India: Lessons from a systematic water governance assessment in the city of Ahmedabad. Reg. Environ. Chang. 2018, 18, 2445-2457. [CrossRef]

56. Kim, H.; Son, J.; Lee, S.; Koop, S.; Van Leeuwen, K.; Choi, Y.J.; Park, J. Assessing Urban Water Management Sustainability of a Megacity: Case Study of Seoul, South Korea. Water 2018, 10, 682. [CrossRef]

57. Feingold, D.; Koop, S.; van Leeuwen, K. The City Blueprint Approach: Urban water management and governance in cities in the U.S. Environ. Manag. 2018, 61, 9-23. [CrossRef]

58. Madonsela, B.; Koop, S.; van Leeuwen, K.; Carden, K. Evaluation of Water Governance Processes Required to Transition towards Water Sensitive Urban Design-An Indicator Assessment Approach for the City of Cape Town. Water 2019, 11, 292. [CrossRef]

59. DFID. Tools for Development: A Handbook for Those Engaged in Development Activities; DFID: London, UK, 2003.

60. Van Schaik, M.; Boelhouwer, G.; Harms, M. Plan van Aanpak Ruimtelijke Adaptatie; Coalitie Regio Utrecht: Utrecht, The Netherlands, 2016.

61. Brockhoff, R.C. Pluvial Flooding in Utrecht: On Its Way to a Water-Wise City; Utrecht University: Utrecht, The Netherlands, 2018.

62. WistUdata Utrecht. Municipal Database. Available online: https://wistudata.nl/ (accessed on 2 May 2019).

63. Statistics Netherlands. StatLine Database. Available online: www.cbs.nl (accessed on 6 May 2019).

64. Wateroverlast Voorkomen: Waterproof030. Available online: https://www.utrecht.nl/wonen-en-leven/ duurzame-stad/wateroverlast-voorkomen/ (accessed on 10 July 2019).

65. Janssen, I.; van Lochem, J.B. Sustainability Report 2018. Duurzaamheidsverslag 2018; Municipality of Utrecht: Utrecht, The Netherlands, 2019.

66. Climatic Stress Test Utrecht. Available online: https://livinglabutrecht.maps.arcgis.com/apps/MapSeries/ index.html?appid=3242b2dbca544f99a714abc1f63aeefe\&entry=2 (accessed on 20 May 2019).

67. Willemsen, C. Utrechtse Bankstraat aan de Regenton, Dankzij Ellen. Available online: https://www.ad.nl/ utrecht/utrechtse-bankstraat-aan-de-regenton-dankzij-ellen \{\}af4570d1/ (accessed on 2 May 2019).

68. Online Manual Waterproof Dwellings. Waterproof: Handleiding Maatregelen aan de Woning en Tuin Tegen Wateroverlast; Municipality of Utrecht: Utrecht, The Netherlands, 2016.

69. Delta Programme 2019. Continuing the Work on the Delta: Adapting the Netherlands to Climate Change in Time; Ministry of Infrastructure and Water Management, the Ministry of Agriculture, Nature, and Food Quality, and the Ministry of the Interior and Kingdom Relations: The Hague, The Netherlands, 2018; p. 119.

70. Meindertsma, B.; van der Parre, H. Burgers Met Natte Voeten kijken Naar Overheid, Maar Willen Niet Meer Betalen. Available online: https://nos.nl/artikel/2230728-burgers-met-natte-voeten-kijken-naar-overheidmaar-willen-niet-meer-betalen.html (accessed on 29 April 2019).

71. Commission Adjustment Tax System (Commissie Aanpassing Belastingstelsel). Een Stevige Basis Voor de Toekomst: De Nieuwe Waterschapsbelastingen. Available online: https://www.uvw.nl/wp-content/uploads/ 2018/06/Eindrapport-Commissie-Aanpassing-Belastingstelsel.pdf (accessed on 19 May 2019). 
72. Glucker, A.N.; Driessen, P.P.J.; Kolhoff, A.; Runhaar, H.A.C. Public participation in environmental impact assessment: Why, who and how? Environ. Impact Assess. Rev. 2013, 43, 104-111. [CrossRef]

73. Pahl-Wostl, C.; Nilsson, C.; Gupta, J.; Tockner, K. Societal learning needed to face the water challenge. Ambio 2011, 40, 549-553. [CrossRef]

74. Ernst, L.; de Graaf-Van Dinther, R.; Peek, G.-J.; Loorbach, D. Sustainable urban transformation and sustainability transitions; conceptual framework and case study. J. Clean. Prod. 2016, 112, 2988-2999. [CrossRef]

75. Mees, H.-L.P.; Driessen, P.P. Adaptation to climate change in urban areas: Climate-greening London, Rotterdam, and Toronto. Clim. Law 2011, 2, 251-280. [CrossRef]

76. Vijayaraghavan, K. Green roofs: A critical review on the role of components, benefits, limitations and trends. Renew. Sustain. Energy Rev. 2016, 57, 740-752. [CrossRef]

77. UN-Water. Coordinating the UN's Work on Water and Sanitation. Available online: www.unwater.org/ about-unwater/ (accessed on 6 June 2019).

78. Medema, W.; McIntosh, B.; Jeffrey, P. From premise to practice: A critical assessment of integrated water resources management and adaptive management approaches in the water sector. Ecol. Soc. 2008, 13, 29. [CrossRef]

79. Rahaman, M.M.; Varis, O. Integrated water resources management: Evolution, prospects and future challenges. Sustain. Sci. Pract. Policy 2005, 1, 15-21. [CrossRef]

80. Begg, C.; Callsen, I.; Kuhlicke, C.; Kelman, I. The role of local stakeholder participation in flood defence decisions in the United Kingdom and Germany. J. Flood Risk Manag. 2018, 11, 180-190. [CrossRef]

81. Kullenberg, C.; Kasperowski, D. What Is Citizen Science?-A Scientometric Meta-Analysis. PLoS ONE 2016, 11, e0147152. [CrossRef]

82. Bonney, R.; Phillips, T.B.; Ballard, H.L.; Enck, J.W. Can citizen science enhance public understanding of science? Public Underst. Sci. 2016, 25, 2-16. [CrossRef]

83. Sy, B.; Frischknecht, C.; Dao, H.; Consuegra, D.; Giuliani, G. Flood hazard assessment and the role of citizen science. J. Flood Risk Manag. 2018, e12519. [CrossRef]

84. Brouwer, S.; Hessels, L.K. Increasing research impact with citizen science: The influence of recruitment strategies on sample diversity. Public Underst. Sci. 2019, 28, 606-621. [CrossRef]

85. Mees, H.L.P.; Uittenbroek, C.J.; Hegger, D.L.T.; Driessen, P.P.J. From citizen participation to government participation: An exploration of the roles of local governments in community initiatives for climate change adaptation in the Netherlands. Environ. Policy Gov. 2019, 29, 198-208. [CrossRef]

86. Irvin, R.A.; Stansbury, J. Citizen Participation in Decision Making: Is It Worth the Effort? Public Adm. Rev. 2004, 64, 55-65. [CrossRef]

87. Owusu, S.; Wright, G.; Arthur, S. Public attitudes towards flooding and property-level flood protection measures. Nat. Hazards 2015, 77, 1963-1978. [CrossRef]

88. Torgersen, G.; Navrud, S. Singing in the rain: Valuing the economic benefits of avoiding insecurity from urban flooding. J. Flood Risk Manag. 2018, 11, e12338. [CrossRef]

89. Henstra, D.; Thistlethwaite, J.; Brown, C.; Scott, D. Flood risk management and shared responsibility: Exploring Canadian public attitudes and expectations. J. Flood Risk Manag. 2019, 12, e12346. [CrossRef]

90. Mees, H.L.P.; Driessen, P.P.J.; Runhaar, H.A.C.; Stamatelos, J. Who governs climate adaptation? Getting green roofs for stormwater retention off the ground. J. Environ. Plan. Manag. 2013, 56, 802-825. [CrossRef]

91. Kamperman, H.; Biesbroek, R. Measuring Progress on Climate Change Adaptation Policy by Dutch Water Boards. Water Resour. Manag. 2017, 31, 4557-4570. [CrossRef] 

Article

\title{
Exploring Science-Policy Interactions in a Technical Policy Field: Climate Change and Flood Risk Management in Austria, Southern Germany, and Switzerland
}

\author{
Ralf Nordbeck ${ }^{1}$, Lukas Löschner ${ }^{2, *}$, Melani Pelaez Jara ${ }^{3}$ and Michael Pregernig ${ }^{3}$ \\ 1 Institute of Forest, Environmental, and Natural Resource Policy, \\ University of Natural Resources and Life Sciences, Vienna, 1180 Vienna, Austria \\ 2 Institute of Spatial Planning, Environmental Planning and Land Rearrangement, \\ University of Natural Resources and Life Sciences, Vienna, 1180 Vienna, Austria \\ 3 Institute of Environmental Social Sciences and Geography, Albert-Ludwigs-University Freiburg, \\ 79085 Freiburg, Germany \\ * Correspondence: lukas.loeschner@boku.ac.at
}

Received: 28 June 2019; Accepted: 7 August 2019; Published: 13 August 2019

\begin{abstract}
This paper analyses the science-policy interactions in the field of flood risk governance against the background of climate change. By the example of three neighbouring Alpine regions (Switzerland, Southern Germany and Austria), the study strives to shed further light on how flood risk governance regimes embrace the possible impacts of climate change. It builds on the assumption that flood risk management, as a 'technical' policy field, is strongly influenced by scientific evidence and that differences in how countries incorporate climate change can be explained by the way science and policy are brought together in the respective national arenas. We structure the empirical analysis along three dimensions: (i) dynamics of knowledge creation; (ii) institutionalization of the science-policy interface; and (iii) pathways of influence of expertise on policy development. We find that there is a mixed, though increasing influence of climate change on flood risk governance in the three selected Alpine regions. Climate adaptation has become an important issue of flood policy in all three study areas, and this shift has been strongly supported by evidence-based arguments.
\end{abstract}

Keywords: science-policy interface; flood risk management; climate change; adaptation

\section{Introduction}

The influence of climate change on future flood risk in Europe is still highly debated. Analyses of past trends show no clear patterns of robust and ubiquitous climate-driven change in flood magnitude and frequency of high discharge in European rivers during the last decades. Rather in contrast, there are strong regional and sub-regional variations in the observed trends [1]. Similarly, the results of climate models are uncertain regarding the prediction of future changes in frequency and magnitude of floods, inter alia, because of uncertain information on phenomena such as an increased spatio-temporal variability of precipitation and changes in extreme rainfall events [1,2]. This provides extensive challenges for policy-makers in charge of flood risk management and climate change adaptation "because it is naive to expect availability of trustworthy quantitative projections of future flood hazard" any time soon [3] (p. 1). Dealing with these highly uncertain changes requires new approaches to policy-making that support the move from resistance-based strategies to more resilience-oriented approaches. While resistance-based approaches can provide effective protection and minimize costs up to certain design floods, they "do not cope well with uncertainty" [4] (p. 291). Resilience-based strategies, on the other hand, embrace adaptability and flexibility as a means to respond to the 
climate-induced increase in flood discharge and thus better cope with the shocks and stresses of (extreme) flood events [5-7].

Climate adaptation policies emerge from the interplay of a varied set of actors, including policy-makers, scientists, engineers, and many other stakeholders, leading to numerous ambiguities, since successful policy-making is not about finding the objective truth in a scientific sense, but about finding a balance between different positions. While the interlinking between climate chance and flood risks has been widely studied in the field of engineering and the natural sciences, there are only a few studies on the influence of climate change on flood risk governance. In a European context, the project STAR-FLOOD [8] delved into this question. In a comparative study of six EU countries, the project found that climate change as a risk driver has only a fairly modest impact on flood risk governance overall [9]. For five of the six countries, the authors found that the discourse on climate change tends to stabilize existing governance arrangements with their emphasis on prevention and defense: In England, the climate adaptation discourse influenced the broader discussions on the financial sustainability and cost-efficiency of the current flood risk governance, yet the overarching risk approach did not fundamentally alter [10]. In Poland, the influence of climate change has been limited, both because climate change projections are considered uncertain for Poland and because of lacking political and societal support for policy changes [11]. A mentionable exception is Sweden where climate change has played a pivotal role in the observed shift of flood risk governance [12].

This paper strives to shed further light on the question of how flood risk governance regimes embrace the possible impacts of climate change. Thereby, we build on the assumption that flood risk governance, being quite a 'technical' policy field, is strongly influenced by scientific evidence and that differences in how countries incorporate climate change might be explained by the way science and policy are brought together in the respective national arenas. Against this background, we delve into the following analytical questions: What are the implications of scientific evidence on climate change for flood risk governance? How do policy-makers deal with those high degrees of uncertainty, both in terms of causal drivers and impacts? What is the role of science and expertise in this technical policy field? These are the questions we are going to explore in this paper. Empirically, we draw on a comparative case study of flood risk management in the context of climate change in three Alpine regions: Austria, Southern Germany, and Switzerland.

The remainder of this paper is structured as follows: Section 2 summarizes the state of science-policy research and presents the analytical dimensions along which we explore the science-policy interactions in the field of flood risk governance. Section 3 presents the empirical findings for the three study regions Austria, (Southern) Germany and Switzerland. Finally, in Section 4 we discuss our main findings based on the cross-case comparison.

\section{State of the Research and Own Conceptual Framework}

Flood risk management is a highly complex and technical policy domain. It entails understanding the underlying factors that drive flood risks, including the complex drivers related to land use changes, socioeconomic developments, and climate change [13]. Further, it requires modelling these dynamics to assess changes in flood risk [14], and devising instruments to mitigate those risks-from designing and constructing flood defenses and other technical infrastructure to developing and adjusting land use plans and building codes [15]. Consequently, flood risk governance-understood as the structures and processes in which public and private actions and resources are coordinated for solving collective problems [16] - is expected to be informed by an evidence-based approach. This expectation has been partly substantiated by research in the abovementioned STAR-FLOOD project. As part of this project, Wiering et al. [9] provided a typology of varieties of flood risk governance in Europe. For the six countries studied in detail, the authors found national approaches to flood risks and their governance to be marked by a dominance of public actors (especially in the Netherlands, Poland, France, and Belgium) as well as central authorities with strong legal powers (especially in Poland and France). Similarly, Liefferink et al. [17] reported on the strong and powerful role of expertise and expert bodies (especially 
in the Netherland and Poland), an observation confirmed by other authors, like Lange and Garrelts [18] for Germany, or Mostert et al. [19] and Bergsma [20] for the Netherlands.

The literature on flood risk governance is still quite fragmented [21,22], and there are only a few studies explicitly focusing on the question of what role science and expertise play therein. There is more research on science-policy interactions in the broader field of water governance; however, also these studies have a strong bias towards more instrumental, managerial perspectives. Many of those studies start from the observation-or rather assumption —-that there is a "gap" between science, on the one hand, and management or policy, on the other hand. This is seen as a problem because, as Timmerman and Langaas argue, "[c]onsistent and relevant information on the status of water systems is indispensable for rational and cost-effective water management" [23] (p. 177). Similarly, Xu and Tung postulate that "[d]ecision-making in water management requires the delivery of accurate scientific information" [24] (p. 535). As these two examples indicate, studies often build on a rather simple, linear model of "information transfer" and a quite a-political, if not to say "naïve", understanding of the policy process (for a critique of the linear model in general, cf. Refs. [25,26]).

Recent studies have overcome some of this linearity in that they do not just call for the more effective transfer of information from science to management or policy, but rather first try to better understand the context in which management or policy decisions are taken. For example, Leskens et al. investigate how information from flood models "is exchanged among participants in flood disaster organizations and how this exchange affects the use of modelling information" [27] (p. 53). Similarly, Höllermann and Evers analyses "how practitioners perceive and handle uncertainties in their daily decision-making routines at the knowledge/decision interface and how they evaluate and integrate uncertainty information into their decision-making" [28] (p. 9).

All of the above-mentioned studies focus on the micro level of individual decision-makers, mapping for example the information that managers have available, describing the organizational contexts in which they operate, and assessing the decision support tools on which they can draw similarly [29-32]. In contrast to that, there are only few studies that look at the macro level and take a more policy-oriented perspective. In a European context, those policy-oriented studies have often been developed around the EU Floods Directive (2007/60/EC) and its implementation in Member States. Empirically, most of those studies took a rather narrow perspective by looking at the role of participation as one of the key governance principles enshrined in the Directive (e.g., Refs. [33,34] for Germany; Ref. [35] for the UK; Ref. [36] for Sweden).

A more comprehensive assessment of flood risk governance arrangements (FRGAs) was provided by the STAR-FLOOD project: The project was comparative in scope, analyzing and contrasting FRGAs in six European countries. It went beyond the EU Floods Directive and its national implementation by taking a more long-term perspective, analyzing FRGA dynamics from the 1970s up to the present, thus, trying to explain stability and change in the sector [17]. In addition to that, similar to our paper, STAR-FLOOD engaged in the question of whether and how climate change might have an impact on FRGAs. On that topic, Wiering et al. [9] reported that in five of the six countries studied, discussions on climate change showed a rather modest impact on national risk approaches; only in Sweden, climate change was seen to play a key role in observed shifts of risk governance.

Our paper deals with some of the questions also addressed in STAR-FLOOD, however, we strive to not only look at the macro level of national arenas but we also incorporate meso-level structures and dynamics. For that, we take an explicit, more fine-grained look at the role of science and expertise in flood risk governance, a perspective that is missing in all more policy-oriented studies in the sector (except for Ref. [20]). In our paper, we explore the question of science-policy interactions in the field of flood risk governance along three distinct analytical dimensions:

1. Dynamics of knowledge creation: The impact of climate change on flood risks became an important topic especially after the publication of the IPCC's Second Assessment Report [37]. Subsequently, in many European countries, one c seen extensive efforts of knowledge creation and the related consolidation of expertise on flood risks and related management options [3,38]. At the same 
time, the state of knowledge is-as almost necessarily seen in any complex policy arena-still highly provisional, uncertain and incomplete $[13,39,40]$. Against this background, our case studies address the following questions: How did the state of knowledge in the field develop over time, and was there consensus on key insights or did experts disagree? What kind of policy recommendations, if any, did scholars provide?

2. Institutionalization of the science-policy interface: The interaction between science and policy-making has often been conceptualized by means of a dichotomization between the two realms of knowledge production and knowledge use and, relatedly, the clear institutional separation of the two. Recently, this "two-communities" model has given place to a more differentiated picture: Science-policy studies indicate that sectoral arenas are frequently marked by a great variety of "knowledge actors" - beyond the simple binary classification between "scientist" and "policy-maker"; often with one and the same actors taking different roles depending on the context. This is also reflected in different models of organizational integration, where especially in neo-corporatist policy cultures, like the Netherlands or the German-speaking countries, one often finds "mixed" advisory bodies in which policy-makers, administrative officials, interest group representatives, and scientists sit side-by-side without a clear separation of roles [41,42]. Before this background, we ask the following questions: Who are the main "knowledge actors" in the policy domain of flood risk governance? How is the interface between science and policy-making organized?

3. Influence of expertise on policy development: Flood risk management is seen as a highly technical field in which scientific expertise is expected to play an important role. As shown above, part of the management-oriented literature has been calling for a (more) evidence-based approach to address flood risks often building on an overly simplified linear "get-the-facts-then-act" model [43] (p. 406). In the light of recent scholarship, the naïve hopes of the cascade-like "scientification of the non-scientific world" [44] (p. 382) turned out to be untenable, both from a theoretical and an empirical perspective $[26,45]$. The critique goes in two directions: First, scholars point out that research findings are rarely directly employed in a specific policy, however, they can still exert a powerful influence over the terms used and the way issues are framed and understood (i.e., "conceptual use", [46]). Second, authors highlight that political actors can use scientists, their expertise, but also their nimbus of objectivity, as an additional resource to increase their authority or legitimation. Advisors are selected not only for their knowledge but also for the legitimation that they provide for policies as well as for policy makers and interest groups involved in policy processes [41] (p. 31). Before this background, we ask the following questions: How evidence-based are flood risk policies? How much influence and authority did science hold and how much is accrued to other modes of knowing and deciding?

We explore these research questions in a comparative case study for three neighboring countries/states in the wider Alpine region: Austria, Southern Germany (namely, the states/Länder of Baden-Württemberg and Bavaria) and Switzerland (see Figure 1). We selected these three cases for our comparison because they are all located within the wider Alpine region and thus share similar challenges with regard to flooding. For one, due to the mountainous topography, these regions are particularly exposed to a high frequency of heavy precipitation events, while the concentration of vulnerable land uses in valley basins results in high economic losses in the event of flooding [13,47]. Secondly, Austria, Germany and Switzerland are federal countries, where flood policies are marked by a complex distribution of responsibilities between the national, state and municipal levels, with the state level (i.e., Länder/cantons) assuming strong operational responsibilities in flood risk management and climate change adaptation. This also explains why we decided to analyze two Länder (Baden-Württemberg and Bayern) rather than the entire country for the case of Germany. 


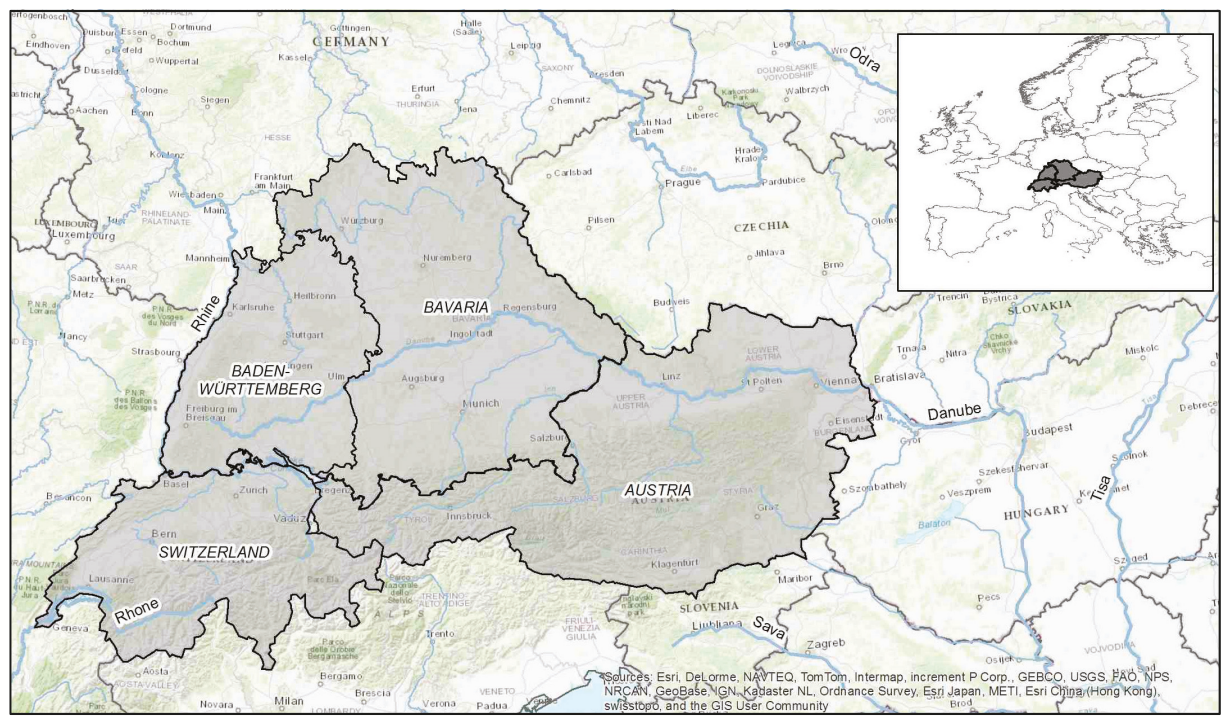

Figure 1. Overview of the case study regions Austria, Switzerland and Southern Germany (Bavaria and Baden-Württemberg).

Despite their parallels, the three regions, however, exhibit considerable differences in the way they deal with the possible climate-related influences on flooding. Methodologically, the paper is based on a qualitative analysis [48,49] of scientific and grey literature as well as relevant policies, strategies, and project documents. Complementary to the document analysis, we conducted a total of 24 semi-structured interviews with scientists, water policy experts, engineers, and policy-makers of the three regions (between June 2016 and June 2018) (for a list of interviews see Table A1 in the Appendix A). The collected data set has been anonymized, coded and interpreted using the qualitative data application MAXQDA 12.

\section{The Role of Climate Change in Flood Risk Management in Austria, Southern Germany and Switzerland}

This section explores science-policy interactions in the field of flood risk governance for the case study regions in Austria, Southern Germany and Switzerland. We structure the empirical analysis along the three dimensions outlined above, namely (i) dynamics of knowledge creation; (ii) institutionalization of the science-policy interface; and (iii) pathways of influence of expertise on policy development.

\subsection{Austria: Flood Risk Adaption without Climate Change Allowances}

Austria experienced a series of major flood events in 2002, 2005 and 2013. Those events caused flood risk management in Austria to shift to new priorities. A broad discussion about future flood risks and the impact of climate change thereon has emerged since 2002. Until today, Austria has not introduced specific adaptation instruments such as climate change allowances, but future uncertainties are incorporated into the planning practice by various alternative means.

\subsubsection{Dynamics of Knowledge Creation}

The first studies on the possible effects of climate change for individual regions in Austria were published in the early 2000s [50-52]. Due to the different characteristics of the investigated catchment areas, but also because of the different methodological procedures and different input 
data, the results of these studies in individual catchment areas are not directly comparable. However, the main results of these studies were quite similar. Godina [52] showed-based on 120 annual series of observations-different trends for three rivers in Austria: rising trend on the Salzach, falling trend on the Enns and a slightly falling trend on the Inn. Nachtnebel and Fuchs [51] found no indication for a climate signal leading to higher flood hazards based on their scenario analyses. Blöschl and Merz [53] analyzed different flood events (period 1828-2005) on the Danube near Vienna. The overall time period showed an increase in small floods, but no trend in large floods and an increase in winter floods at the expense of summer floods. From all these studies, no climate-induced changes in the discharge peaks could be detected [54].

The extreme flood event of 2005 and two studies (commissioned by the World Wide Fund for Nature and the State of Upper Austria) by Refs. [54,55] renewed the discussion. In spite of being cautious in their conclusions, both studies argued that climate change would increase future flood risks: "In general, although it is not possible to quantify how ultimately the overall flood risk in Upper Austria will change as a result of climate change, changes must be expected in any case, in particular seasonal and regional shifts in risk" [56] (p. 21). This initiated a new wave of studies in the following years that took a closer look at the effects of climate change on flood hazards [57-60].

In the early 2010s, the Austrian Ministry of Agriculture, Forestry, Environment and Water Management (BMLFUW) and the Water Resources Divisions of the State Governments commissioned a comprehensive sectoral study on water management as part of the Austrian Climate Adaptation Strategy [61]. The aim of the study was to assess climate impacts on water resources based on the most recent data and methods, and to derive policy recommendations on climate change adaptation strategies for water resources management in Austria [62]. The study shows that during the period 1976-2007, increasing trends occurred in about $20 \%$ of the catchments, particularly north of the main Alpine ridge. However, if one extends the analysis period to 1955-2007, the trends are much less clear because a number of major floods happened in the period 1955-1975. It also shows that winter floods have increased significantly more than summer floods. The authors conclude that the accumulation of flooding in recent decades lies within the natural variability of flood decades, but that an influence of climate change cannot be ruled out. Furthermore, they conclude that the introduction of a general climate allowance for design values is not required at the current state [61,62].

The findings of the so-called "Blöschl study" [61] settled the scientific discussion for the following years. The study was updated in 2018 [54]. The new findings confirmed many of the previous results, but showed a somewhat stronger influence of climate change. In the future (time horizon 2021-2050), regionally different changes in flood discharge are expected to be in the range of -4 to $+10 \%$ (for one-year flood events). The updated study reiterates the conclusion that a climate change allowance is currently not required in Austria, but it points to a higher number of catchment areas with rising trends and highlights the increasing risk from pluvial floods.

\subsubsection{Institutionalization of the Science-Policy Interface}

Scientific expertise is very important for decision-makers in Austrian flood policy. As two of our interview partners stated: "Science is certainly the basis for the flood risk management that we have developed in recent years" (Interview AT02), and there is "a great deal of openness towards scientific findings" (Interview AT03 (all direct quotes from interviews are translated from German)).

After the extreme flood event of 2002, a research program called FloodRisk was initiated. FloodRisk brought together scientists and public officials from a variety of fields such as meteorology, hydrology, geomorphology, natural hazards, damage assessment, law, spatial planning, and disaster protection. It followed a broad approach, which one of our interview partners describes as follows: "As a result of the 2002 events, actors suddenly realized that this has much, much wider dimensions and much of what went wrong in Austria, in my view, has to do with the fact that key players (...) have not used science to reflect on how to improve flood risk management" (Interview AT04). Despite its broad approach, the FloodRisk program did not focus on climate change in particular. Shortly after the final 
report of FloodRisk was published, in 2005, another extreme flood event hit Austria and a follow-up program (FloodRisk II) was established, this time including a sub-project on the impact of climate change on floods [57].

While FloodRisk stands for a disaster-driven type of science-policy interaction, there are also more structural, long-term venues in which decision-makers, professionals and scientists interact. An important network is the Austrian Water and Waste Management Association (ÖWAV) (Interviews AT02; AT05). The ÖWAV acts as an information and communication hub that provides early information on legal, technical and economic developments and supports the exchange of experience in the field of water management. It has established a working group on flood protection in particular to engage with municipalities and flood water associations. The aim of the working group is to provide a platform for decision-makers, municipalities, authorities, planners, universities and industry in flood risk management and to develop, coordinate and bundle activities for this target group. The ÖWAV has organized seminars in 2009, 2016 and 2018 to discuss the impact of climate change on water management in Austria [63]. In 2014, it published an expert paper to assess the impact of climate change on water management based on the ZAMG/TU Wien study and to discuss the need for further adaptation measures [64].

\subsubsection{Influence of Expertise on Policy Development}

The close relationship between scientists and public officials, and the regular exchange among members of the flood community led to an evidence-based flood policy in Austria. The findings of the major studies on the impact of climate change are mentioned in every relevant policy document, often cited literally. The first document of the federal ministry that referred to climate change as a possible driver of flood hazard was published in 2006, and it was clearly influenced by the earlier studies of Refs. [49-51]. In this document, the federal ministry asserts that "whether the hydrologic extremes of 2002 and 2005 and the increasing frequency of local heavy precipitation in the last years are signs of a global climate change cannot yet be clearly determined. Developments are to be followed closely and-if necessary-need to be taken into consideration for flood protection" [65] (p. 7). After the "Blöschl study" was published in 2011, it became the new point of reference. The Austrian Climate Change Adaptation Strategy from 2012 states: "Due to the prognostic uncertainties about the actual effects of climate change on the different regions in Austria, a general increase in these design values by a factor $X$ is currently discouraged by the scientific community" [66] (p. 172). The report of the Austrian Panel on Climate Change [67], the expert paper of the ÖWAV [64], and the National Flood Risk Management Plan [68] all refer to the Blöschl study and basically copy-and-paste the findings as well as the policy recommendations. The update of the Blöschl study in 2018 will probably become the new reference point. The latest publication by the federal ministry has already taken into account some of the findings: "The hydrological extremes of local intensive rainfall events currently still match the historical variation. However, it becomes ever more likely that they are a consequence of global climate change" [69] (p. 11).

Adaptation to likely future flood risks is a multi-causal process in Austria in which uncertain climatic factors are overshadowed by highly likely socioeconomic trends such as land-use change induced by population and economic growth [70,71]. For various reasons, Austrian flood policy makers are not willing to account for possible climate-induced changes in flooding, e.g., in form of a precautionary climate allowance to runoff calculations (as in parts of Germany, see Section 3.2). First, they point to the lack of scientific evidence suggesting that flooding will increase in Austria due to climate change (see Section 3.1.1). Second, since implementing a precautionary climate allowance would increase the costs of structural flood protection drastically (Interviews AT02; AT05; AT07), this would reduce the number of projects that can be implemented with the same budget (Interviews AT05; AT06). Third, some experts see such a precautionary orientation in structural flood defence to be in conflict with the federal prioritisation of non-structural measures, and they assume that a "levee effect" could increase the damage potential in protected areas (Interviews AT02; AT08). 
Despite the fact that Austria has not added a climate change allowance to its design values, it would be short-sighted to conclude that until now Austria has not actively factored-in the effects of future climate change into its flood risk management strategies. Policy-makers and scientific experts stress that in many areas, potential climate change influences are already incorporated into planning practice, as extreme events lead to an adaptation of the design values for flood protection measures (Interviews AT02; AT07). The federal government also improved design standards such as the safety allowance (called "freeboard" in Austria), which is added to the calculated design of flood defence infrastructure as a "buffer" to accommodate for epistemic and modelling uncertainties. On the state level, water management authorities started to take the issue of local intensive rainfall more seriously. Facing an increase in heavy rainfall, as a likely result of climate change, for instance the Governments of Lower Austria and Styria have recently developed a state-wide hazard map for surface runoff, which could provide a comprehensive hazard information base for flood proofing measures in areas prone to pluvial floods.

\subsection{Southern Germany: Early Awareness and Institutionalization of Climate Change Impacts}

The Southern German states of Baden-Württemberg (BW) and Bavaria (BY) witnessed several major flood events with devastating losses: Rhine floods in 1993 and 1995; Alpine floods in 2000 and 2005; and Danube floods in 1999, 2002, and 2013. Scientists and professionals engaged in looking at possible connections between climate change and regional extreme flood events already early on, i.e., in the 1990s. Consequently, BW and BY became the first federal states in Germany to introduce a technical flood risk instrument explicitly focused on addressing the impact of climate change, namely the Climate Change Factor.

\subsubsection{Dynamics of Knowledge Creation}

During the early 1990s, the hydrologists Bárdossy and Caspary published the first studies on the connections between climate change, European atmospheric circulation patterns, and extreme flood events for Southern Germany [72,73]. Their statistical analyses indicated for some catchments in BW a connection between increased temperatures and changes in the stationarity and frequency of flood events [73]. At first, those studies triggered negative reactions from policy-makers and some scientists of the Southern German water management community, who criticized the methodological approach and, consequently, cast doubt on the relevance of human-induced climate change for floods (Interviews DE01, DE02, DE05). Professionals argued that the sector always had to deal with climatic variability and natural climatic cycles and their related impacts on flood-proneness (Interview DE03). Additionally, flood risks were seen to be contingent on land use changes and other societal dynamics. Therefore, some experts argued that the sector was not dealing with a "fundamentally new situation" [74]. This early criticism and rebuff later turned into generally high interest, political and technical, to systematically examine the causality between climate change and flood risks, and to develop their own regional climate and hydrological models (Interviews DE01, DE02).

The ensuing studies produced during the late 1990s and early 2000s showed high degrees of variance and uncertainty with regards to a possible link between climate change and extreme flood events in Southern Germany. Study results varied among different catchments (especially depending on whether catchments are influenced mainly by precipitation or also by snowmelt), but they also varied along the technical parameters used in the different case studies, including the length of historical data series, or the chosen modelling methods and ensembles [75-77]. Long-term analyses of hydrological parameters showed for the period 1932-1998 no significant, area-wide trends of flood discharge increase. Only when reducing the period under consideration to the last 30 to 40 years of recorded data, most of the analyzed gauging stations showed increases, especially during the winter half year [74]. Regarding future scenarios, early KLIWA-studies presented estimates of an increase of mean annual floods and their frequency, again especially during the winter half year [74,78-80]. At the same time, studies on extreme and rare flood events under climate change influence showed a relatively 
low increase [79]. Overall, scientists largely agreed on their assessment that human-induced climate change would not have sweeping effects on flooding patterns in Southern Germany, however, it might lead to a locally differentiated increase in floods [77].

In the late 2000s and 2010s, KLIWA continued its monitoring program based on historical data while developing more complex climate and impact models and partly extending its research focus by paying larger attention to heavy precipitation [81-83]. Overall, the key messages resulting from those studies have not changed much, but one still sees some minor shifts: Studies of long term flood discharge behavior (1932-2015) now show positive trends for the majority of gauging stations as well as an increase in the significance of those trends, both for the whole year as well as for the winter half year [84-87]. Concerning future scenarios (2021-2050, 2071-2100), simulations of the mean monthly flood discharge for the winter half year indicate for BW an increase of flood discharge trends for the nival flow regime and a strong increase for the pluvial flow regime [86]. For BY, flood discharge projections show mixed results with strong spatial variations $[82,86]$. These findings are also supported by Hatterrmann et al. [88], who showed that a considerable increase in flood-related losses can be expected in Germany in a future, warmer climate.

Given the unclear trends and the high degrees of uncertainty inherent in early studies, it is interesting - if not to say surprising - to see that KLIWA scientists in 2004 explicitly suggested implementing a Climate Change Factor (CCF). They presented the CCF as a flexible non-regret adaptation instrument to be included in the planning of all new technical flood protection measures. As will be described in more detail in Section 3.2.3, the CCF was readily taken up by policy-makers both in BW and BY. In recent years, KLIWA has become more cautious with specific policy recommendations: Emphasizing the inherent uncertainties that come with future projections, scientists tend to suggest rather "soft" instruments such as guidelines for municipal management of heavy rainfall risk [83,89].

\subsubsection{Institutionalization of the Science-Policy Interface}

In both fields of climate change policy and flood policy, South-German decision-makers have for a long time strongly relied on the technical expertise of their respective environmental agencies, that are the Baden-Württemberg State Institute for the Environment, Survey and Nature Conservation (LUBW) and the Bavarian State Office for the Environment (LfU) (Interview DE06). In our interviews, those agencies were described as the first-hand technical and scientific advisory bodies that connect, translate, and moderate between science and policy (Interviews DE01, DE04, DE07, DE09). Also, in institutional terms, both agencies occupy a hybrid space as they collaborate with scientists, private engineering firms, communities, and federal state policy-makers. They draw on external technical expertise in various ways, mostly under the formats of commissioned research and short-term project work, either through public tendering or by approaching research groups or scientists directly (Interview DE04). The water management sector is described as a closed community with strong ties between science, engineering and policy-making (Interview DE10).

A new space for science-policy interactions was introduced with the Cooperation Project Climate Change and Consequences for Water Management (KLIWA) in 1999. The formation of KLIWA was, among other reasons, a reaction to the scientific debate of the early 1990s publications mentioned above and the first and second IPCC reports (Interview DE01). KLIWA has been led by the respective environmental agencies of BW and BY in cooperation with the German Meteorological Service (DWD). With its explicit focus on climate change, KLIWA has been seen as a pioneer initiative in the water sector, not only for Southern Germany but also at the federal level (Interview DE01, DE02, DE03). Its purpose is to scientifically and technically examine the connection between climate change, extreme floods and other impacts on the water sector as well as to provide science-based recommendations for decision-makers (Interviews DE01, DE04, DE07) [90].

KLIWA has been organized along the areas of long-term observations of meteorological and hydrological data; modelling future developments; monitoring and assessing current impacts; adaptation strategies; and public outreach $[90,91]$. Central to the ongoing work of KLIWA has 
been its communication to the expert community and decision-makers through different formats e.g., symposiums and experts' conferences, monitoring reports, project publications, and short informative posters.

\subsubsection{Influence of Expertise on Policy Development}

The tight institutional coupling of science and policy-making, as most prominently enshrined in KLIWA, is also reflected on the policy level. In our interviews, both policy-makers and scientists approved and valued their close cooperation and they emphasized the benefits of evidence-based policy-making (Interviews DE03, DE08, DE10). The most direct impact of expertise on policy-making goes back to the early 2000s. In 2004/2005, both BW and BY introduced the Climate Change Factor (CCF) as a first concrete policy instrument to address possible future climate change risks. KLIWA played a crucial role in that: In KLIWA reports, the CCF was presented as a flexible, non-regret adaptation instrument to be used in design floods and the planning of new technical flood protection measures [74,92]. BW introduced the CCF based on rigorous scientific analyses of regional data by LUBW and the Karlsruhe Institute of Technology. LUBW, in cooperation with engineering partner companies, developed the "Guideline for Determining Design Floods for Technical Flood Protection". Those guidelines recommend the use of a set of regionalized factors (ranging from $0 \%$ to $+75 \%$ ) in design floods and corresponding technical flood protection measures. In BY, a CCF was introduced at the same time as in BW, even though regionalized results were not yet available for all BY catchments. In BY, decision-makers chose to adopt a general factor of $+15 \%$ for all catchments. The political decision to adopt the CCF was announced at the KLIWA Symposium 2004 in Würzburg. With the adoption of the CCF, policy-makers claimed to follow the precautionary idea of taking action in spite of uncertainties, but allowing for future corrections of data and modelling ("no regret strategy") (Interviews DE01, DE04, DE07, DE05, DE02, DE03).

The CCF in BW and BY was an early instrument that was developed and adopted before Germany reformed its Water Act (2009), implemented the EU Flood Risks Directive (2007), and developed its Climate Change Adaptation Strategy Program (2008). The CCF was introduced as a non-binding recommendation to be adopted only under cost-benefit considerations in BW [93], and as an obligatory measure in BY, where exceptions can be considered in individual cases [94]. In practice, it is applied only on new linear technical flood protection measures of narrow scope, and not on larger technical measures such as dams, polders, and wide retention measures. The CCF can be seen as a rather stand-alone instrument, which is still technically implemented, but it has not been explicitly revised or updated, and its effectiveness, applied scope or impact have not been assessed (Interviews DE04, DE07).

Since the implementation of the CCF, the flood risk management sector in BW and BY has introduced several other measures, all of them driven by the precautionary principle. Yet, the sector is still oriented towards a more technical approach of flood protection. This can be seen by a recent initiative in BY: Based on studies of estimation, flood waves and in-depth impact analyses of the Bavarian Danube conducted by the Technical University of Munich [95,96], the State Government adopted the "Bavarian Polder Program". This program accounts for 12 potential sites for the construction of controlled polders along the Danube. The Polder Program has been presented as a means to increase the resilience of flood protection infrastructure by expanding retention volume and to reduce flood risk for downstream cities in the case of overload $[96,97]$.

\subsection{Switzerland: Integrating Climate Change Adaptation into Flood Risk Management}

Following a "disaster gap" between the late 1880s and the late 1970s [98], Switzerland experienced an active period of flooding in the past three decades, including two particularly damaging events in 1987 and 2005 [99]. Swiss flood policies responded to the deficiencies of technical flood defenses by adopting a more integrated approach to flood management. Flood policy-makers at an early stage acknowledged the likely adverse consequences of climate change and integrated climate adaptation strategies into flood risk management. 


\subsubsection{Dynamics of Knowledge Creation}

In the late 1980s, a long-term study of flood discharge changes in Swiss rivers found no significant trends in the majority of catchments [100]. A sequence of damaging events in the 1990s (1992, 1993, 1994, 1999), however, prompted scientists to take a closer look at the observed changes in flood frequency. In one of the first encompassing studies, Frei et al. [101] explored the linkages between climate change and flooding for Switzerland. The study (i) suggests an interrelationship between changes in atmospheric circulation and the frequency of extreme events, and (ii) indicates that climate change will result in a "growing proportion of rainfall ( . . ) which will accelerate the runoff formation process" (p. 296). In a study on "Extreme Events and Climate Change" [102], scientists underline the difficulties to "identify or exclude a statistically valid trend in the frequency of rare extreme events". A follow-up study, however, confirms that, "as a result of the expected changes in the precipitation regime, more frequent and in part larger floods are expected (...), in particular in winter and the transitional seasons" [103] (p. 60).

In response to the 2005 flood events, Switzerland's Federal Office for the Environment (BAFU) commissioned two studies to explore the long-term changes in observed flood frequencies in Switzerland since 1850 and 1500, respectively [104,105]. The studies show that periods with frequent flooding historically alternated with quieter periods. While the analysis since 1850 indicates a large number of measuring stations with upward trends, from a long-term perspective (i.e., since 1500) it becomes evident that the recent flood-rich period (starting in the late 1970s) "is still in the range of formerly observed ones (...) and might continue for some decades under natural climate variation" [105] (pp. 1591-1592). However, the recent accumulation of large flood events in northern Switzerland "suggests that the (observed) changes in flood frequency in Switzerland are due to changes in atmospheric circulation" [104] (p. 6).

Climate projections are detecting increasingly clear signals that both seasonality and magnitude of floods in Switzerland will change in the future. With rising temperatures, more heavy rainfall events and a pronounced shift from solid (snow) to liquid (rain) precipitation is expected, which could increase the frequency of occurrence of extreme events, especially during the winter season [106-109]. These findings are supported by a more recent report by the Swiss Academy of Sciences, which points to the difficulties of projecting future change in extreme flood events but highlights that climate effects on the hydrological cycle lead to an increase in flood volumes and that an increase in flood risk is expected [110].

The latest Climate Change Scenarios for Switzerland (CH2018) substantiate the above projections with more robust climate evidence. They highlight that "heavy rainfall is projected to intensify in all seasons (...) for all event categories". Across Switzerland, flood events relevant for infrastructure planning (i.e., 10-year floods and 100-year floods) "may intensify strongly in all seasons". Compared to earlier reports "confidence in heavy rainfall intensification is now substantially higher", inter alia due to improvements in the resolution and accuracy of the new generation of climate models [111] (p. 10).

Regarding their advice for flood policy, climate scientists in Switzerland are rather cautious. For instance, Schmocker-Fackel and Naef [104] recommend that "future flood protection measures should (...) take into consideration the observed cyclical behavior of flood frequency" (p. 7), while Frei et al. [101] highlight the importance "to invest in reducing the negative impacts of extreme events, irrespective (and not knowing) whether these are of anthropogenic or natural origin" (p. 297).

\subsubsection{Institutionalization of the Science-Policy Interface}

Switzerland's flood risk management builds on strong institutional ties with research institutions and scientists. This goes back to the origins of modern flood defense, when scientific experts were commissioned by governmental authorities to investigate the root-cause of the seminal flood events in 1868. Their expertise and recommendations provided the basis for the legislative organization of responsibilities in Switzerland's natural hazard management [112]. More than 100 years later, following the disastrous floods in 1987 and 2005, scientific expertise yet again provided impetus for 
policy change. Together with policy officials and practitioners, scientists played a leading role in the post-event documentation and analysis [113], and thus, provided the necessary evidence base for the subsequent changes in flood policies (see Section 3.3.3).

Organizational integration of knowledge actors plays an important role in the institutionalization of science-policy interactions in Switzerland. This becomes evident by the example of BAFU, which is responsible for setting strategic priorities and for co-funding disaster risk reduction measures, and guides the federal governments' efforts to assess the impacts of climate change on natural hazards [114]. BAFU bundles expertise related to flood risk management in different organizational divisions and traditionally has strong personal and institutional ties to the leading research institutions in the field, which serve not only as partners in climate-related contract research but also as a recruitment pool for administrative officials (Interview CH02). Given its role as a pivotal administrative authority on the federal level, BAFU thus assumes an intermediary role between science and politics in flood risk management: whereas the latter provides the financial and legal frameworks for flood risk management, science delivers the knowledge base to further develop and implement flood risk management in practice (Interview CH01).

To facilitate climate-related research and to strengthen linkages between scientists and policy-makers, in 1988 the Swiss Academies of Sciences launched the ProClim initiative as part of the wider Platform Science and Policy. As an "interface for communication between science, public administration, politics, economy and the public", the platform plays a strong role in preparing the existing knowledge in climate research to support decision-making (Interview $\mathrm{CH} 01$ ). A more specific platform for the exchange of knowledge actors in natural hazard and flood risk management is the so-called FAN Association (Fachleute Naturgefahren Schweiz), which includes more than 460 members with different institutional and disciplinary backgrounds. The majority of members are private actors $(44 \%)$, such as engineering consultants, but with a large share of actors from the administrative sector $(21 \%)$ and academia (18\%), the association assumes an important function to foster knowledge exchange between a range of actors in the field of gravitational hazards ([115]; Interview CH01).

Finally, the National Platform for Natural Hazards (PLANAT), established in 1997 by the Swiss Federal Council, provides an overarching framework for the interaction between science, public administrations and private actors. PLANAT has the mandate to set strategic priorities for an inter-sectoral, whole-of-society approach in risk management and to coordinate activities and foster knowledge exchange $[114,116]$. In that capacity, PLANAT also acts as an editor of guiding documents, including the national strategies for the integrated management of natural risk $[117,118]$ but also for specialized policy reports e.g., concerning risk-based spatial planning [119].

\subsubsection{Influence of Expertise on Policy Development}

Already at an early stage, Switzerland adopted a proactive stance regarding the possible climate-related effects on flooding. In the late 1990s, the founding document of PLANAT highlighted that "climate change and the tendency towards extreme weather events may further increase related risks" ([115]; translation from German). A few years later, a guiding policy document in hydraulic engineering suggested that "the risk of [flood] hazards could generally intensify in coming decades due to external influences (e.g., global climate change)" [120] (p. 7).

The above policy documents were issued before publication of the respective scientific studies (cf. Section 3.3.1), indicating that they were informed by the mounting awareness for climate change in the late 20th century, inter alia following the Second IPCC Assessment Report in 1996 [121]. In particular, following the succession of large flood events in the late 1990s and early 2000s, policy makers were eager to learn more about the climate-related effects on flooding (Interview $\mathrm{CH} 03$ ). In response to the 2005 floods, BAFU commissioned two scientific studies to build a stronger evidence base concerning the long-term changes in flooding and the possible climate influences [104,105]. Later policy documents explicitly refer to the scientific literature, although the statements concerning the climate effects on flooding are not necessarily more concrete [122-124]. 
Despite — or rather, given — the lack of hard evidence of climate change effects on flooding, scientific studies nevertheless supported the shift from hazard defense towards an integrated approach in flood risk management $[125,126]$. Following the 1987/2005 flood events, Switzerland's flood policies were oriented towards reducing flood discharge and increasing the "robustness" of technical defenses against flood overload $[127,128]$. The integrated approach in Swiss flood policy aims at planning for extreme events irrespective of the actual influence of climate on flood discharge. According to a leading policy-maker, the nascent paradigm may thus be described as "congruent" with Switzerland's precautionary stance in climate change adaptation (Interview CH01).

The synergies between this reorientation in flood policies and climate change adaptation are specifically reflected in the trans-sectoral pilot program "Adaptation to Climate Change", which was launched under the auspices of BAFU to support cantonal and municipal efforts in meeting climate adaptation challenges [129]. Within the framework of the program, a total of 31 projects were implemented between 2014 and 2016, thereof two directly related to the nascent flood policies. The pilot projects had an experimental format where scientific expertise played a lesser role. Although research institutions were eligible for funding, the selected projects mainly involved public authorities (cantons, municipalities) as well as professionals/practitioners (e.g., consultants, engineering bureaus) to support the practical implementation of the respective climate adaptation measures [129].

In sum, Switzerland strongly aligns climate change adaptation and flood risk management [122]. Flood policy's active stance in implementing Switzerland's Climate Change Adaptation Strategy as well as the involvement of administrative authorities in the assessment and monitoring of climate change demonstrates that policy actors in this field "consider adaptation increasingly on equal terms with other sectoral policy objectives" [130]. Climate science plays an important part in the reorientation of flood policy by providing the much-needed evidence to assess the climate effects on flooding. To support the implementation of future-oriented risk management strategies, flood policy, however, also relies on expertise from other disciplines (e.g., spatial planning), while non-scientific knowledge actors, in particular technical experts and municipalities, are important partners for implementing in practice the nascent paradigm of integrated flood risk management.

\section{Cross-Case Comparison and Discussion}

This paper analyzed the science-policy interactions in the field of flood risk governance against the background of climate change for the case studies of Austria, Southern Germany and Switzerland. We structured the empirical analysis along three dimensions: (i) dynamics of knowledge creation; (ii) institutionalization of the science-policy interface; and (iii) pathways of influence of expertise on policy development. Based on the current literature, we started with the assumption that climate change would not (yet) be widely and explicitly reflected in flood risk governance [9]. However, our case studies show that there is a mixed, though increasing impact of climate change on flood risk governance in the three selected Alpine regions. Climate adaptation has become an important issue of flood policy in all three case study regions and this shift has been strongly supported by evidence-based arguments (see Table 1 for a comparative overview of the case study findings).

Concerning our first analytical dimension, i.e., the dynamics of knowledge creation, our case studies indicate that there has not yet been scientific closure on the impact of climate change on flood hazards. In the 1990s and early 2000s, studies were often afflicted by methodological problems and data gaps. This created dissent in the Austrian and German scientific communities, when the findings of some studies were criticized. In the last 10 years, many of these problems were solved due to more comprehensive historical data and better climate and hydrological models. Nowadays, there is a broad consensus among scientists in all three regions about the potential impact of climate change. Nevertheless, epistemological and methodological uncertainties remain, in particular with regard to major flood events, which are difficult to predict in the Alpine region. This can, inter alia, be seen when comparing insights derived from historical trend analyses with those of modelling approaches: For Austria and Germany, those insights converge, however, content-wise they point to opposite 
directions (with Austrian studies seeing few and German studies seeing numerous indications of climate change signals). In contrast to that, for Switzerland, historical trend analyses show a weak signal, whereas models indicate a strong(er) influence, particular concerning heavy rainfall events. This strong variation on the regional and sub-regional level in both the observed and expected changes in flooding is somewhat surprising, but can be explained by the topographic effects of the Alps and the countries' different susceptibility to cyclone tracks (cf. Ref. [100]).

The case studies further indicate that scientists adjusted their expertise to political expectations: When climate change emerged prominently on the political agenda, the production of application-oriented expertise followed suit. This can be interpreted as an effort of experts to ensure that they remain a valid source of knowledge for decision-makers. Strassheim and Kettunen [131] and Van Enst et al. [132] denote this phenomenon with the concept of "policy-based evidence"—as compared to the classical notion of "evidence-based policy" with a more linear understanding of science-policy interactions.

However, the case studies still show some variance in the degree to which experts lend themselves as advisors for policy: In Austria and Germany, experts provided quite explicit recommendations, with German scholars recommending the introduction of an explicit climate change instrument, i.e., the Climate Change Factor, and Austrian scholars explicitly recommending not to implement such an instrument. In Switzerland, scientists provided more cautious and partly ambiguous recommendations, thereby leaving the final decisions to policy-makers. These divergent patterns between countries are notable in various respects: On empirical grounds, it is interesting to see that even though the expert communities of the three regions regularly exchange views and experiences, we observe convergence neither on the level of recommended policy instruments nor on the level of advisory styles. With regards to the latter, the comparative science-policy literature would have made us expect that the three regions, because they share a similar neo-corporatist policy culture, would show similar patterns of interaction between science and policy-making [42,133-135]. Similarities can, for sure, be seen with regard to knowledge actors and organizational formats (see Table 1), however, not for the way scientists wriggle into politics.

With regard to the second analytical dimension, i.e., the institutionalization of the science-policy interface, we find that these are characterized in all three regions by a rather narrow set of actors consisting of scientists, public administrators, and political decision-makers. In the last decade, the scientific networks expanded and now include hydrology, meteorology, and spatial planning. Scientists play an important role in particular for risk assessments, while professionals and practitioners become more important when the discussion turns to risk management. In all three regions, we see a close cooperation between scientists and policy-makers, often including double roles and changes of roles. This is also reflected in hybrid platforms of knowledge exchange: In Austria and Switzerland, hybrid platforms mostly consist of scientists, administrative officials and political decision-makers, while in Germany those platforms are largely confined to scientists and administrative officials. The degree of institutionalization of those exchange platforms varies in the three regions, with the highest level of institutionalization in Switzerland, followed by Southern Germany, and the prevalence of more ad hoc, often event-driven, formats in Austria. Overall, there is a broad spectrum of science-policy interfaces: First, we have highly specialized organizations and research frameworks with a long continuity, such as ÖWAV in Austria, KLIWA in Germany, and PLANAT in Switzerland; second, we have specific research programs to generate focused research, such as FloodRisk in Austria and the pilot program on climate adaption in Switzerland, which are more event-driven and temporary; and finally, we have short-term contract research for ministries that deliver studies on the impact of climate change, such as the Blöschl study in Austria. 


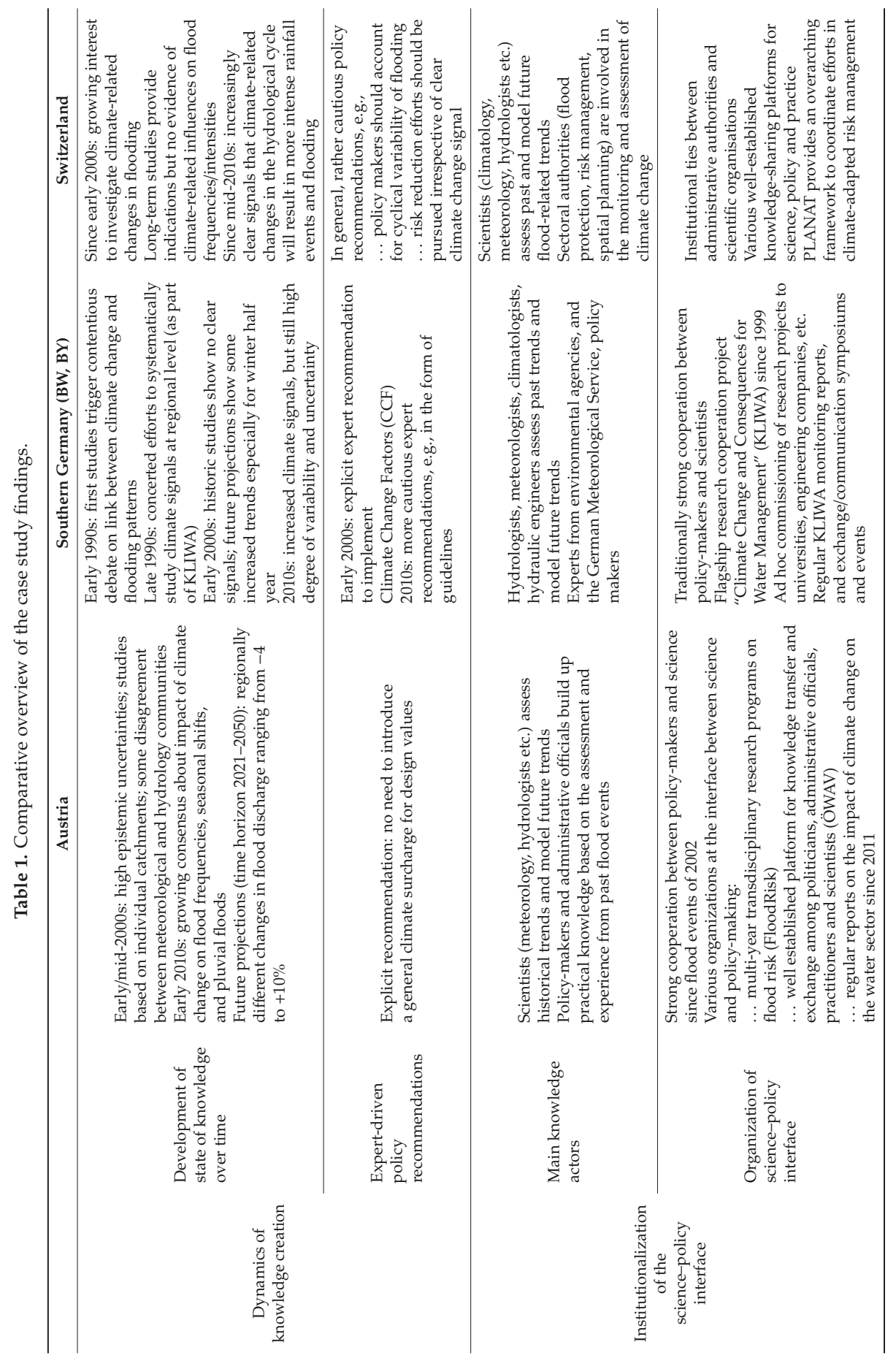




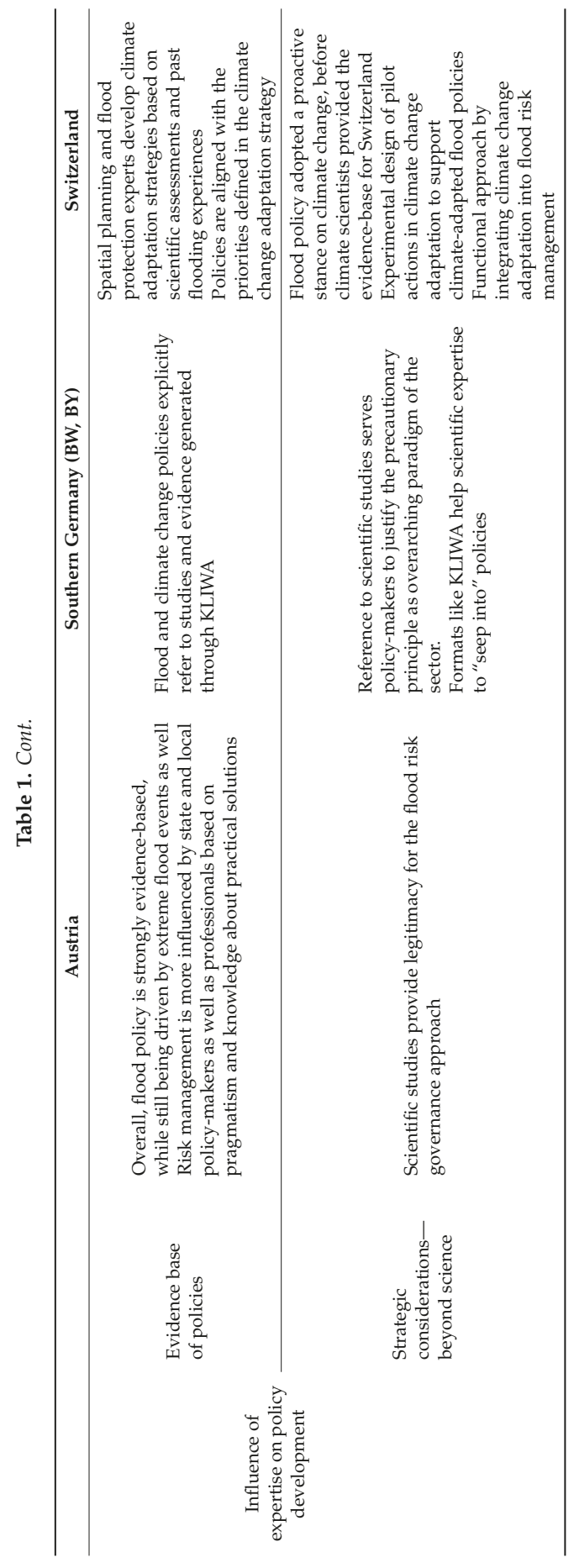


Concerning our third analytical dimension, i.e., the influence of expertise on policy development, our case studies show that experts had an important influence on flood policy-making in Austria, Southern Germany and Switzerland and that flood risk governance in these regions is to a great extent evidence-based. The close relationship between scientists and policy-makers described above creates policy frames that, by identifying the potential impact of climate change on flood hazards and specifying policy solutions for adaptation, constructed a coherent story around the "problem of future flood risks". Policy-makers in all three regions to a certain extent depend upon scientific expertise to act, which provides experts with an important source of influence in the policy-making process. At the same time, our case studies also reveal that policy-makers set limits on the influence of those experts: Scientists had to "tailor" their knowledge to the new political issue of climate adaptation to get their expertise recognized. This can most explicitly be seen using the example of the Climate Change Factor in Southern Germany, where a generally high political sensitivity for climate change questions led scientists to recommend the Factor in spite of a very uncertain scientific basis.

Against the above, we find that the influence of experts on flood risk governance can best be understood as being "socially embedded" [131] or "contextually embedded" [36]. The notion of "social embeddedness" [131] emphasizes that "expertise and evidence [need to be seen as] socially embedded in authority relations and cultural contexts" (p. 259). In the case of flood risk management, this embeddedness most prominently played out in the flood paradigms that the three regions embrace: Switzerland was an early mover towards integrated risk management ("risk-based spatial planning"), a shift primarily caused by the extreme flood event in 1987. Climate change became an issue in the early 1990s, but the explicit consideration of climate adaptation in the form of planning for flood overload was driven by the 2005 extreme event. Switzerland's risk-based approach to the management of natural hazard is also reflected in the recently updated PLANAT strategy [118]. Entitled "Management of Risks from Natural Hazards", the strategy not only differs semantically from the previous strategy "Protection against natural hazards" [136]. Against the likely climate-related increase in hazard potential and the accumulation in vulnerable assets, it importantly embraces the need to "adapt in a timely manner to changes in conditions" (p. 6), as a core principle of resilience-oriented flood risk management strategies [4]. In Germany, the flood community discovered climate change as a problem also in the early 1990s, which is embedded in a national debate in which climate change is of high importance. Based on the precautionary principle, Germany introduced an explicit instrument (CCF) for hazard mitigation already in 2004, yet the CCF was still embedded in the classical safety paradigm of technical flood protection. More integrated approaches were developed later on in Germany, and with that, the CCF took a back seat and became one among many other measures. In Austria, the new integrated paradigm of flood risk management was adopted somewhat later than in Germany and Switzerland, specifically after the extreme flood events in 2002 and 2005. The new flood paradigm has been consistently implemented since then through the avoidance of new risk and the reduction of existing risks. The discussion about the impact of climate change emerged also relatively late in 2006/2007 in Austria, and until today has yielded only a few specific climate change-related measures.

\section{Conclusions}

Our analysis of science-policy interactions in the flood risk management sectors of Austria, Southern Germany and Switzerland showed that there are clear imprints of climate change on the sectors' governance arrangements and dynamics, though we also observed marked differences between the three countries. Climate adaptation has become an important issue of flood policy in all three countries, and this policy shift has been strongly supported by evidence-based arguments. However, uncertainties, inter alia due to lack or incompleteness of trend data and/or discrepancies in flood hazard projections, still remain. This provides challenges for policy-making, both with regards to the question of how to technically deal with flood risk in the face of imminent but still unpredictable climate change impacts (an issue that our social-scientific paper cannot address) and with regards to the question of which role to assign to science and expertise and how to organize the science-policy interface 
in an effective way. On the last-mentioned question, our comparative analysis of science-policy interactions in three Alpine regions provides insights that might be of interest for decision-makers in other countries as well.

Our reconstruction of the temporal dynamics of knowledge creation showed that, over the last three decades, one sees an increasing scientific agreement about the possible impacts of climate change on the frequency and magnitude of floods. However, as our case studies demonstrated, the progression of knowledge in the field has been far from linear; we rather observed some marked shifts in the construction and interpretation of scientific knowledge, partly due to methodological innovations or the availability of new data sets, partly due to changes in the political environment (such as increased public sensitivities for climate change). Against the background of those observed discontinuities in knowledge dynamics, it seems to be wise for policy-makers to opt for adaptation strategies that are flexible and robust enough to account for changes in flood hazards in the future. Ideally, decision-makers should identify and implement "no-regret" or "low-regret" adaptation measures that are effective under different climate change scenarios and that can be modified in the face of new scientific evidence. Incorporating the potential effects of climate change into flood design guidelines by an adjustment for uncertainties or a climate change allowance like in Austria and Germany is one example for that kind of adaption. Shifting flood policies from structural flood defense to a broader portfolio of vulnerability-oriented flood risk management measures like in Austria and Switzerland is another complementary option for adaptation.

Our comparative analysis of the institutionalization of the science-policy interfaces revealed a broad spectrum of approaches with some conspicuous differences between the three case study regions (e.g., with Switzerland showing the most formally structured science-policy landscape and with Austria hinging more towards informal, ad-hoc setups). What all three regions have in common-and what we see as prerequisite for effective knowledge translation-is that there are firmly established institutions that enable an exchange between scientists and policy-makers. Otherwise, there might be a danger that in the disaster-driven sector of flood risk management, scientific arguments only get heard in the direct aftermath of severe flood events and get sidelined as soon as the public attention has shifted to another exigent topic.

Finally, our study on the influence of expertise on policy making confirmed that scientists and other experts had quite a strong role to play in the formulation of flood risk policies and the implementation of flood risk management strategies and measures. In the three case studies, we could identify a large number of partly divergent factors that might help to explain the influence of expertise, however, there are also some overarching insights that might be singled out as success factors. The flood risk governance arenas in Austria, Southern Germany, and Switzerland are marked by various venues in which scientists and policy-makers can interact on a regular basis. The most long-lasting-and probably also the most influential-venues are the ones with diverse membership, that is, venues in which scientists, administrators, planners, and ideally politicians come together on equal terms. Given the variety of challenges that flood risk governance is facing, it seems to be desirable to have a spectrum of some more 'political' science-policy arenas and some more 'scientific' arenas. Eventually, what has proven helpful is the publication of policy-targeted scientific reports on the impact of climate change on floods, like the sectoral adaptation studies in Austria, KLIWA studies in Southern Germany, and the Climate Change Scenarios for Switzerland.

Author Contributions: This research article was developed in a collaborative effort based on the following author contributions: conceptualization, R.N., L.L., M.P.J. and M.P.; methodology, R.N., L.L., M.P.J. and M.P.; validation, R.N., L.L., M.P.J. and M.P.; formal analysis, R.N., L.L., M.P.J. and M.P.; investigation, R.N., L.L. and M.P.J.; writing—original draft preparation, R.N., L.L., M.P.J. and M.P.; writing—review and editing, R.N., L.L., M.P.J. and M.P.

Funding: This research was funded by the AUSTRIAN CLIMATE AND ENERGY FUND, grant number KR14AC7K11809.

Acknowledgments: The open access publishing was supported by BOKU Vienna Open Access Publishing Fund. 
Conflicts of Interest: The authors declare no conflict of interest. The funders had no role in the design of the study; in the collection, analyses, or interpretation of data; in the writing of the manuscript, or in the decision to publish the results.

\section{Appendix A}

Table A1. List of expert interviews conducted in Austria, Germany and Switzerland.

\begin{tabular}{|c|c|c|}
\hline Code & Function & Date \\
\hline AT01 & $\begin{array}{l}\text { University of Natural Resources and Life Sciences, Vienna (BOKU); } \\
\text { Institute of Meteorology }\end{array}$ & 28 June 2016 \\
\hline AT02 & $\begin{array}{c}\text { Austrian Ministry for Sustainability and Tourism (BMNT); } \\
\text { Federal Water Engineering Administration }\end{array}$ & 12 July 2016 \\
\hline AT03 & Austrian Conference on Spatial Planning (ÖROK) & 13 July 2016 \\
\hline AT04 & Austrian Institute of Economic Research (WIFO) & 15 July 2016 \\
\hline AT05 & $\begin{array}{l}\text { University of Natural Resources and Life Sciences, Vienna (BOKU); } \\
\text { Institute of Water Management, Hydrology and Hydraulic Engineering }\end{array}$ & 19 July 2016 \\
\hline AT06 & State Government of Vorarlberg; State Office for Spatial Planning & 22 September 2016 \\
\hline AT07 & State Government of Vorarlberg; State Office for Water Management & 22 September 2016 \\
\hline AT08 & State Government of Vorarlberg; State Office for Hydraulic Engineering & 23 September 2016 \\
\hline DE01 & $\begin{array}{l}\text { LUBW, Baden-Württemberg Institute for the Environment, } \\
\text { Survey and Nature Conservation }\end{array}$ & 24 May 2017 \\
\hline DE02 & Technical University Stuttgart & 30 May 2017 \\
\hline DE03 & Karlsruhe Institute of Technology & 4 July 2017 \\
\hline DE04 & $\begin{array}{l}\text { LUBW, Baden-Württemberg Institute for the Environment, } \\
\text { Survey and Nature Conservation }\end{array}$ & 4 July 2017 \\
\hline DE05 & University of Stuttgart & 5 July 2017 \\
\hline DE06 & Baden-Württemberg Ministry for Environment & 12 July 2017 \\
\hline DE07 & LfU, Bavarian State Office for the Environment & 8 August 2017 \\
\hline DE08 & LfU, Bavarian State Office for the Environment & 4 September 2017 \\
\hline DE09 & $\begin{array}{l}\text { LUBW, Baden-Württemberg Institute for the Environment, } \\
\text { Survey and Nature Conservation }\end{array}$ & 10 April 2018 \\
\hline DE10 & Technical University of Munich & 15 June 2018 \\
\hline $\mathrm{CH} 01$ & Federal Office for the Environment, Flood Protection Section & 8 June 2017 \\
\hline $\mathrm{CH} 02$ & Federal Office for the Environment, Section Risk Management Section & 8 June 2017 \\
\hline $\mathrm{CH} 03$ & Federal Office for the Environment, Hydrology Division & 8 June 2017 \\
\hline $\mathrm{CH} 04$ & University Bern, Mobiliar Lab & 9 June 2017 \\
\hline $\mathrm{CH} 05$ & Consultant in Risk Management & 9 June 2017 \\
\hline $\mathrm{CH} 06$ & Consultant in Risk Management & 19 September 2017 \\
\hline
\end{tabular}

\section{References}

1. Kundzewicz, Z.W. Climate change track in river floods in Europe. Proc. Int. Assoc. Hydrol. Sci. 2015, 369, 189-194. [CrossRef]

2. Kundzewicz, Z.W.; Lugeri, N.; Dankers, R.; Hirabayashi, Y.; Döll, P.; Pińskwar, I.; Dysarz, T.; Hochrainer, S.; Matczak, P. Assessing river flood risk and adaptation in Europe-Review of projections for the future. Mitig. Adapt. Strateg. Glob. Chang. 2010, 15, 641-656. [CrossRef] 
3. Kundzewicz, Z.W.; Krysanova, V.; Dankers, R.; Hirabayashi, Y.; Kanae, S.; Hattermann, F.F.; Huang, S.; Milly, P.C.D.; Stoffel, M.; Driessen, P.P.J.; et al. Differences in flood hazard projections in Europe-Their causes and consequences for decision making. Hydrol. Sci. J. 2017, 62, 1-14. [CrossRef]

4. Morrison, A.; Westbrook, C.J.; Noble, B.F. A review of the flood risk management governance and resilience literature. J. Flood Risk Manag. 2018, 11, 291-304. [CrossRef]

5. Tempels, B. Flood Resilience: A Co-Evolutionary Approach. Residents, Spatial Developments and Flood Risk Management in the Dender Basin; Ghent University: Ghent, Belgium, 2016.

6. Mens, M.J.P.; Klijn, F.; de Bruijn, K.M.; van Beek, E. The meaning of system robustness for flood risk management. Environ. Sci. Policy 2011, 14, 1121-1131. [CrossRef]

7. Restemeyer, B.; Brink, M.; van den Woltjer, J. Between adaptability and the urge to control: Making long-term water policies in the Netherlands. J. Environ. Plan. Manag. 2017, 60, 920-940. [CrossRef]

8. STAR-FLOOD|Towards More Resilient Flood Risk Governance. Available online: http://www.starflood.eu/ (accessed on 9 August 2019).

9. Wiering, M.; Kaufmann, M.; Mees, H.; Schellenberger, T.; Ganzevoort, W.; Hegger, D.L.T.; Larrue, C.; Matczak, P. Varieties of flood risk governance in Europe: How do countries respond to driving forces and what explains institutional change? Glob. Environ. Chang. 2017, 44, 15-26. [CrossRef]

10. Alexander, M.; Priest, S.; Mees, H. A framework for evaluating flood risk governance. Environ. Sci. Policy 2016, 64, 38-47. [CrossRef]

11. Matczak, J.; Lewandowski, J.; Chorynski, A.; Szwed, M.; Kundzewicz, Z.W. Analysing and Evaluating Flood Risk Governance in Poland: Looking for Strategic Planning in a Country in Transition; STAR-FLOOD Consortium: Poznan, Poland, 2016.

12. Ek, K.; Goytia, S.; Pettersson, M.; Spegel, E. Analysing and Evaluating Flood Risk Governance in Sweden: Adaptation to Climate Change? STAR-FLOOD Consortium: Poznan, Poland, 2016.

13. Kron, W.; Eichner, J.; Kundzewicz, Z.W. Reduction of flood risk in Europe-Reflections from a reinsurance perspective. J. Hydrol. 2019, 576, 197-209. [CrossRef]

14. Winsemius, H.C.; Aerts, J.C.J.H.; Van, B.; Bierkens, M.F.P.; Bouwman, A.; Jongman, B.; Kwadijk, J.C.J.; Ligtvoet, W.; Lucas, P.L.; Van, V.; et al. Global drivers of future river flood risk. Nat. Clim. Chang. 2016, 6, 381-385. [CrossRef]

15. Alfieri, L.; Feyen, L.; Baldassarre, G.D. Increasing flood risk under climate change: A pan-European assessment of the benefits of four adaptation strategies. Clim. Chang. 2016, 136, 507-521. [CrossRef]

16. Hogl, K.; Kvarda, E.; Nordbeck, R.; Pregernig, M. Legitimacy and effectiveness of environmental governance: Concepts and perspectives. In Environmental Governance: The Challenge of Legitimacy and Effectiveness; Hogl, K., Kvarda, E., Nordbeck, R., Pregernig, M., Eds.; Edward Elgar: Cheltenham, UK; Northampton, MA, USA, 2012; pp. 1-26.

17. Liefferink, D.; Wiering, M.; Crabbé, A.; Hegger, D. Explaining stability and change. Comparing flood risk governance in Belgium, France, the Netherlands, and Poland. J. Flood Risk Manag. 2018, 11, 281-290. [CrossRef]

18. Lange, H.; Garrelts, H. Risk Management at the Science-Policy Interface: Two Contrasting Cases in the Field of Flood Protection in Germany. J. Environ. Policy Plan. 2007, 9, 263-279. [CrossRef]

19. Mostert, E.; Pahl-Wostl, C.; Rees, Y.; Searle, B.; Tàbara, D.; Tippett, J. Social learning in European river-basin management: Barriers and fostering mechanisms from 10 river basins. Ecol. Soc. 2007, 12, 19. [CrossRef]

20. Bergsma, E. From Flood Safety to Spatial Management: Expert-Policy Interactions in Dutch and US Flood Governance; Springer: Berlin, Germany, 2018; ISBN 978-3-319-96716-5.

21. Araral, E.; Wang, Y. Water Governance 2.0: A Review and Second Generation Research Agenda. Water Resour. Manag. 2013, 27, 3945-3957. [CrossRef]

22. Hegger, D.L.T.; Driessen, P.P.J.; Dieperink, C.; Wiering, M.; Raadgever, G.T.T.; van Rijswick, H.F.M.W. Assessing Stability and Dynamics in Flood Risk Governance. Water Resour. Manag. 2014, 28, 4127-4142. [CrossRef]

23. Timmerman, J.G.; Langaas, S. Water information: What is it good for? The use of information in transboundary water management. Reg. Environ. Chang. 2005, 5, 177-187. [CrossRef]

24. Xu, Y.-P.; Tung, Y.-K. Decision-making in Water Management under Uncertainty. Water Resour. Manag. 2008, 22, 535-550. [CrossRef] 
25. Beck, S. Moving beyond the linear model of expertise? IPCC and the test of adaptation. Reg. Environ. Chang. 2011, 11, 297-306. [CrossRef]

26. Pregernig, M. Framings of science-policy interactions and their discursive and institutional effects: Examples from conservation and environmental policy. Biodivers. Conserv. 2014, 23, 3615-3639. [CrossRef]

27. Leskens, J.G.; Brugnach, M.; Hoekstra, A.Y.; Schuurmans, W. Why are decisions in flood disaster management so poorly supported by information from flood models? Environ. Model. Softw. 2014, 53, 53-61. [CrossRef]

28. Höllermann, B.; Evers, M. Perception and handling of uncertainties in water management—A study of practitioners' and scientists' perspectives on uncertainty in their daily decision-making. Environ. Sci. Policy 2017, 71, 9-18. [CrossRef]

29. Morss, R.E.; Wilhelmi, O.V.; Downton, M.W.; Gruntfest, E. Flood Risk, Uncertainty, and Scientific Information for Decision Making: Lessons from an Interdisciplinary Project. Bull. Am. Meteorol. Soc. 2005, 86, 1593-1602. [CrossRef]

30. Frick, J.; Hegg, C. Can end-users' flood management decision making be improved by information about forecast uncertainty? Atmos. Res. 2011, 100, 296-303. [CrossRef]

31. Colosimo, M.F.; Kim, H. Incorporating innovative water management science and technology into water management policy. Energy Ecol. Environ. 2016, 1, 45-53. [CrossRef]

32. Nakanishi, H.; Black, J. Implicit and explicit knowledge in flood evacuations with a case study of Takamatsu, Japan. Int. J. Disaster Risk Reduct. 2018, 28, 788-797. [CrossRef]

33. Newig, J.; Challies, E.; Jager, N.; Kochskämper, E. What Role for Public Participation in Implementing the EU Floods Directive? A Comparison with the Water Framework Directive, Early Evidence from Germany and a Research Agenda. Environ. Policy Gov. 2014, 24, 275-288. [CrossRef]

34. Newig, J.; Kochskämper, E.; Challies, E.; Jager, N.W. Exploring governance learning: How policymakers draw on evidence, experience and intuition in designing participatory flood risk planning. Environ. Sci. Policy 2015, 55, 353-360. [CrossRef]

35. Fritsch, O. Integrated and adaptive water resources management: Exploring public participation in the UK. Reg. Environ. Chang. 2017, 17, 1933-1944. [CrossRef]

36. Hedelin, B. The EU floods directive in Sweden: Opportunities for integrated and participatory flood risk planning. J. Flood Risk Manag. 2017, 10, 226-237. [CrossRef]

37. IPCC Second Assessment. Climate Change 1995. A Report of the Intergovernmental Panel on Climate Change; IPCC, Ed.; Intergovernmental Panel on Climate Change: Geneva, Switzerland, 1996; ISBN 978-0-7881-3923-9.

38. Kundzewicz, Z.W.; Kanae, S.; Seneviratne, S.I.; Handmer, J.; Nicholls, N.; Peduzzi, P.; Mechler, R.; Bouwer, L.M.; Arnell, N.; Mach, K.; et al. Flood risk and climate change: Global and regional perspectives. Hydrol. Sci. J. 2014, 59, 1-28. [CrossRef]

39. Bäckstrand, K. Scientisation vs. Civic Expertise in Environmental Governance: Eco-feminist, Eco-modern and Post-modern Responses. Environ. Politics 2004, 13, 695-714. [CrossRef]

40. Kundzewicz, Z.W.; Krysanova, V.; Benestad, R.E.; Hov, Ø.; Piniewski, M.; Otto, I.M. Uncertainty in climate change impacts on water resources. Environ. Sci. Policy 2018, 79, 1-8. [CrossRef]

41. Pregernig, M.; Böcher, M. The role of expertise in environmental governance: Theoretical perspectives and empirical evidence. In Long-Term Governance for Social-Ecological Change; Siebenhüner, B., Arnold, M., Eisenack, K., Jacob, K., Eds.; Routledge: London, UK; New York, NY, USA, 2013; pp. 29-46.

42. Hermann, A.T.; Hogl, K.; Pregernig, M. Science-policy interactions in Austrian, Dutch, and Swiss climate policy: A comparative account. J. Environ. Policy Plan. 2017, 19, 168-182. [CrossRef]

43. Pielke, R.A. When scientists politicize science: Making sense of controversy over The Skeptical Environmentalist. Environ. Sci. Policy 2004, 7, 405-417. [CrossRef]

44. Beck, U.; Bonß, W. Soziologie und Modernisierung. Zur Ortsbestimmung der Verwendungsforschung. Soz. Welt 1984, 35, 381-406.

45. Grundmann, R. The role of expertise in governance processes. For. Policy Econ. 2009, 11, 398-403. [CrossRef]

46. Weiss, C.H. Knowledge Creep and Decision Accretion. Knowl. Creat. Diffus. Util. 1980, 1, 381-404. [CrossRef]

47. Fuchs, S.; Röthlisberger, V.; Thaler, T.; Zischg, A.; Keiler, M. Natural Hazard Management from a Coevolutionary Perspective: Exposure and Policy Response in the European Alps. Ann. Am. Assoc. Geogr. 2017, 107, 382-392. [CrossRef] 
48. Witt, H. Volume Strategies in Qualitative and Quantitative Research. Forum Qualitative Sozialforschung/Forum: Qualitative Social Research; 2001; Volume 2. Available online: http://www.qualitative-research.net/index.php/ fqs/article/view/969 (accessed on 2 June 2019).

49. Gläser, J.; Laudel, G. Experteninterviews und Qualitative Inhaltsanalyse: Als Instrumente Rekonstruierender Untersuchungen, 4th ed.; VS Verlag für Sozialwissenschaften: Wiesbaden, Germany, 2010; ISBN 978-3-531-17238-5.

50. Hebenstreit, K. Auswirkungen von Klimaänderungen auf die Hydrologie Alpiner Einzugsgebiete. In Wiener Mitteilungen. Wasser, Abwassser, Gezwässer; TU Wien/BOKU/ÖWAV: Wien, Austria, 2000; Volume 160.

51. Nachtnebel, H.; Fuchs, M. Beurteilung der hydrologischen Veränderungen in Österreich infolge globaler Klimaänderungen. Österr. Wasser Abfallwirtsch. 2004, 7-8, 79-92.

52. Godina, R. Veränderungen in hydrologischen Zeitreihen. In Auswirkungen des Klimawandels auf Hydrologie und Wasserwirtschaftin Österreich; ÖWAV, Ed.; Österreichischer Wasser-und Abfallwirtschaftsverband: Wien, Austria, 2010; pp. 35-49.

53. Blöschl, G.; Merz, B. Bestimmung von Bemessungshochwässern gegebener Jährlichkeit—Aspekte einer zeitgemäßen Strategie. Wasserwirtschaft 2008, 11, 12-18.

54. Blöschl, G.; Blaschke, A.P.; Haslinger, K.; Hofstätter, M.; Parajka, J.; Salinas, J.; Schöner, W. Auswirkungen der Klimaänderung auf Österreichs Wasserwirtschaft-Ein aktualisierter Statusbericht. Österr. Wasser Abfallwirtsch. 2018, 70, 462-473. [CrossRef]

55. Formayer, H.; Kromp-Kolb, H. Hochwasser und Klimawandel. Auswirkungen des Klimawandels auf Hochwasserereignisse in Österreich (Endbericht WWF 2006). BOKU-Met. Report 7; University of Natural Resources and Life Sciences: Vienna, Austria, 2009.

56. Formayer, H.; Kromp-Kolb, H.; Schwarzl, I. Auswirkungen des Klimawandels auf Hochwasserereignisse in Oberösterreich. BOKU-MET Report 14; Universität für Bodenkultur Wien: Wien, Austria, 2009.

57. Blöschl, G.; Viglione, A.; Heindl, H. Dynamik von Hochwasserbemessungsgrößen und Konsequenzen-Klimawandel. FloodRisk II, Teilprojekt 6.2; Bundesministerium für Land-und Forstwirtschaft, Umwelt und Wasserwirtschaft (BMLFUW): Wien, Austria, 2008.

58. Nachtnebel, H. Auswirkungen von möglichen Klimaänderungen auf die Hydrologie und Wasserwirtschaft in einigen österreichischen Regionen. In Auswirkungen des Klimawandels auf Die Österreichische Wasserwirtschaft; BMLFUW, ÖWAV, Eds.; Bundesministerium für Land-und Forstwirtschaft, Umwelt und Wasserwirtschaft: Wien, Austria, 2008.

59. Holzmann, H.; Lehmann, T.; Formayer, H.; Haas, P. Auswirkungen möglicher Klimaänderungen auf Hochwasser und Wasserhaushaltskomponenten ausgewählter Einzugsgebiete in Österreich. Österr. Wasser Abfallwirtsch. 2010, 62, 7-14. [CrossRef]

60. Nachtnebel, H.; Stanzel, P. Auswirkungen von möglichen Klimaänderungen auf den Wasserhaushalt und Extremwerte. In Auswirkungen des Klimawandels auf Hydrologie und Wasserwirtschaft in Österreich; ÖWAV, Ed.; Österreichischer Wasser- und Abfallwirtschaftsverband: Wien, Austria, 2010.

61. Anpassungsstrategien an den Klimawandel für Österreichs Wasserwirtschaft; ZAMG/TU WIEN, Ed.; Bundesministerium für Land-und Forstwirtschaft, Umwelt und Wasserwirtschaft: Wien, Austria, 2010.

62. Blöschl, G.; Viglione, A.; Merz, R.; Parajka, J.; Salinas, J.L.; Schöner, W. Auswirkungen des Klimawandels auf Hochwasser und Niederwasser. Österr. Wasser Abfallwirtsch. 2011, 63, 21-30. [CrossRef]

63. Auswirkungen des Klimawandels auf Hydrologie und Wasserwirtschaft in Österreich. Präsentation der aktuellen Studien; ÖWAV, Ed.; Österreichischer Wasser-und Abfallwirtschaftsverband: Wien, Austria, 2010.

64. Klimawandelauswirkungen und Anpassungsstrategien in der Österreichischen Wasserwirtschaft. ÖWAV-ExpertInnenpapier; ÖWAV, Ed.; Österreichischer Wasser-und Abfallwirtschaftsverband: Wien, Austria, 2014.

65. Hochwasserschutz in Österreich. Flood protection in Austria; BMLFUW, Ed.; Bundesministerium für Land- und Forstwirtschaft, Umwelt und Wasserwirtschaft: Wien, Austria, 2006.

66. The Austrian Strategy for Adaptation to Climate Change; BMLFUW, Ed.; Bundesministerium für Land- und Forstwirtschaft, Umwelt und Wasserwirtschaft: Vienna, Austria, 2012.

67. APCC. Österreichischer Sachstandsbericht Klimawandel 2014 (AAR14); Austrian Panel on Climate Change; Verlag der Österreichischen Akademie der Wissenschaften: Wien, Austria, 2014; ISBN 978-3-7001-7699-2.

68. Nationaler Hochwasserrisikomanagementplan 2015; BMLFUW, Ed.; Bundesministerium für Land- und Forstwirtschaft, Umwelt und Wasserwirtschaft: Wien, Austria, 2016. 
69. Flood Risk Management in Austria. Objectives-Measures-Good Practice; BMNT, Ed.; Austrian Federal Ministry for Sustainability and Tourism: Vienna, Austria, 2018.

70. Thieken, A.H.; Cammerer, H.; Dobler, C.; Lammel, J.; Schöberl, F. Estimating changes in flood risks and benefits of non-structural adaptation strategies-A case study from Tyrol, Austria. Mitig. Adapt. Strateg. Glob. Chang. 2016, 21, 343-376. [CrossRef]

71. Löschner, L.; Herrnegger, M.; Apperl, B.; Senoner, T.; Seher, W.; Nachtnebel, H.P. Flood risk, climate change and settlement development: A micro-scale assessment of Austrian municipalities. Reg. Environ. Chang. 2017, 17, 311-322. [CrossRef]

72. Bárdossy, A.; Caspary, H.J. Detection of climate change in Europe by analyzing European atmospheric circulation patterns from 1881 to 1989. Theor. Appl. Climatol. 1990, 42, 155-167. [CrossRef]

73. Caspary, H.J.; Bárdossy, A. Markieren die Winterhochwasser 1990 und 1993 das Ende der Stationarität in der Hochwasserhydrologie infolge von Klimaänderungen? Wasser Boden 1995, 47, 18-24.

74. KLIWA. 2. KLIWA-Symposium: Am 03. und 04.05.2004 in Würzburg: Fachvorträge Klimaveränderung und Konsequenzen für Die Wasserwirtschaft; Klimaveränderung und Wasserwirtschaft: München, Germany, 2004; p. 249.

75. Dankers, R.; Feyen, L. Climate change impact on flood hazard in Europe: An assessment based on high-resolution climate simulations. J. Geophys. Res. 2008, 113. [CrossRef]

76. Madsen, H.; Lawrence, D.; Lang, M.; Martinkova, M.; Kjeldsen, T.R. Review of trend analysis and climate change projections of extreme precipitation and floods in Europe. J. Hydrol. 2014, 519, 3634-3650. [CrossRef]

77. Bronstert, A.; Bormann, H.; Bürger, G.; Haberlandt, U.; Hattermann, F.; Heistermann, M.; Huang, S.; Kolokotronis, V.; Kundzewicz, Z.; Menzel, L.; et al. Hochwasser und Sturzfluten an Flüssen in Deutschland. In Klimawandel in Deutschland: Entwicklung, Folgen, Risiken und Perspektiven; Brasseur, G., Jacob, D., Schuck-Zöller, S., Eds.; Springer Spektrum: Berlin, Germany, 2017; pp. 87-102, ISBN 978-3-662-50396-6.

78. Bayerisches Landesamt für Umwelt; KLIWA. Kurzbericht "Der Klimawandel in Bayern für den Zeitraum 2021-2050" (Kenntnisstand Januar 2005); KLIWA: Münster, Germany, 2005; p. 14.

79. KLIWA. Regionale Klimaszenarien für Süddeutschland: Abschätzung der Auswirkungen auf den Wasserhaushalt; KLIWA: München, Germany, 2006; p. 93.

80. Hennegriff, W.; Kolokotronis, V. Methodik zur Ableitung von Klimaänderungsfaktoren für Hochwasserkennwerte in Baden-Württemberg. WasserWirtschaft 2007, 9, 31-35.

81. KLIWA. 4. KLIWA-Symposium am 3. und 4. Dezember 2009 in Mainz. Fachvorträge Klimaveränderung und Konsequenzen für Die Wasserwirtschaft; Klimaveränderung und Wasserwirtschaft: Karlsruhe, Germany, 2010.

82. KLIWA. 5. KLIWA-Symposium am 6. und 7. Dezember 2012 in Würzburg. Fachvorträge Klimaveränderung und Konsequenzen für Die Wasserwirtschaft; KLIWA: Kasendorf, Germany, 2013; p. 258.

83. KLIWA. 6. KLIWA-Symposium am 22. und 23. Mai 2017 in Baden-Baden. Fachvorträge Risiko Klima-Herausforderungen Managen; Klimaveränderung und Wasserwirtschaft: Baden-Baden, Germany, 2018; p. 278.

84. KLIWA. Klimawandel in Süddeutschland. Veränderung der Kenngrößen Lufttemperatur, Niederschlag und Hochwasserabfluss, Klimamonitoring im Rahmen des Kooperationsvorhabens KLIWA. Monitoringbericht 2008; KLIWA: Münster, Germany, 2008; p. 24.

85. KLIWA. Klimawandel in Süddeutschland, Veränderungen von Meteorologischen und Hydrologischen Kenngrößen, Klimamonitoring im Rahmen des Kooperationsvorhabens KLIWA. Monitoringbericht 2011; KLIWA: Münster, Germany, 2012; p. 40.

86. KLIWA. Klimawandel in Süddeutschland Veränderungen von Meteorologischen und Hydrologischen Kenngrößen. Klimamonitoring im Rahmen der Kooperation KLIWA. Monitoringbericht 2016; KLIWA: Münster, Germany, 2017; p. 60.

87. Magel, H.; Franke, S. Zukunftsstrategien im Ländlichen Raum für die Bayerische Wasserwirtschaftsverwaltung im Lichte von Good Governance; Technische Universität München: München, Germany, 2008; p. 205.

88. Hattermann, F.F.; Huang, S.; Burghoff, O.; Willems, W.; Österle, H.; Büchner, M.; Kundzewicz, Z. Modelling flood damages under climate change conditions-A case study for Germany. Nat. Hazards Earth Syst. Sci. 2014, 14, 3151-3168. [CrossRef] 
89. Koch, M.; Hennegriff, W.; Moser, M.; Groteklaes, M.; Krause, L.; Röder, S.; Gosch, L.; Weinbrenner, D.; Cassel, M.; Wilkinson, K.; et al. Leitfaden Kommunales Starkregenrisikomanagement in Baden-Württemberg; LUBW Landesanstalt für Umwelt, Messungen und Naturschutz Baden-Württemberg, Ed.; LUBW Landesanstalt für Umwelt, Messungen und Naturschutz Baden-Württemberg: Karlsruhe, Germany, 2016; ISBN 978-3-88251-391-2.

90. KLIWA. KLIWA-Symposium vom 29. und 30.11.2000 in Karlsruhe; KLIWA: Münster, Germany, 2000; p. 276.

91. KLIWA. Über KLIWA. Available online: https://www.kliwa.de/kliwa.htm (accessed on 2 June 2019).

92. Landesanstalt für Umwelt Messungen und Naturschutz Baden-Württemberg. Climate Change in Southern Germany. Challenges-Adaptation. Consequences for Water Management; Klimaveränderung und Wasserwirtschaft: Karlsruhe, Germany, 2017; p. 12.

93. Landesanstalt für Umweltschutz Baden-Württemberg. Festlegung des Bemessungshochwassers für Anlagen des technischen Hochwasserschutzes_Leitfaden; 1; Landesanstalt für Umweltschutz Baden-Württemberg: Mannheim, Germany, 2005; ISBN 3-88251-288-1.

94. Bayerisches Staatsministerium für Umwelt und Gesundheit. Berücksichtigung von Klimaänderungen; Bemessung von Hochwasserschutzeinrichtungen; Gesetz Nr. 7535-UG.; StMUV: Munich, Germany, 2009.

95. Rutschmann, P.; Asenkerschbaumer, M.; Skublics, D. Verzögerung und Abschätzung von Hochwasserwellen entlang der bayerischen Donau. Abschlussbericht 2012; Technische Universität München: München, Germany, 2012; p. 166.

96. Rutschmann, P.; Giehl, S.; Skublics, D.; Scandroglio, R. Vertiefte Wirkungsanalyse zu: "Verzögerung und Abschätzung von Hochwasserwellen Entlang der Bayerischen Donau". Schlussbericht Teil I; Technische Universität München: München, Germany, 2017; p. 195.

97. Rutschmann, P.; Skublics, D.; Giehl, S. Vertiefte Wirkungsanalyse zu: "Verzögerung und Abschätzung von Hochwasserwellen Entlang der bayerischen Donau". Zwischenbericht; Technische Universität München: München, Germany, 2014; p. 81.

98. Pfister, C. Die "Katastrophenlücke" des 20. Jahrhunderts und der Verlust traditionalen Risikobewusstseins. GAIA-Ecol. Perspect. Sci. Soc. 2009, 18, 239-246.

99. Andres, A.; Badoux, A. The Swiss flood and landslide damage database: Normalisation and trends. J. Flood Risk Manag. 2018. [CrossRef]

100. Spreafico, M.; Stadler, K. Hochwasserabflüsse in Schweizerischen Gewässern. Landeshydrologie und-geologie 1988, 7, 17-25.

101. Frei, C.; Davies, H.C.; Gurtz, J.; Schär, C. Climate dynamics and extreme precipitation and flood events in Central Europe. Integr. Assess. 2000, 1, 281-300. [CrossRef]

102. Extreme Events and Climate Change; OcCC, Ed.; Organe Consultatif sur les Changements Climatiques: Berne, Switzerland, 2003.

103. Climate Change and Switzerland 2050. Expected Impacts on Environment, Society and Economy; OcCC, ProClim, Eds.; OcCC/ProClim: Bern, Switzerland, 2007.

104. Schmocker-Fackel, P.; Naef, F. More frequent flooding? Changes in flood frequency in Switzerland since 1850. J. Hydrol. 2010, 381, 1-8. [CrossRef]

105. Schmocker-Fackel, P.; Naef, F. Changes in flood frequencies in Switzerland since 1500. Hydrol. Earth Syst. Sci. 2010, 14, 1581-1594. [CrossRef]

106. CH2011; C2SM, MeteoSwiss, ETH, NCCR Climate, OcCC, Eds.; Swiss Climate Change Scenarios CH2011: Zurich, Switzerland, 2011.

107. CH2014-Impacts. Toward Quantitative Scenarios of Climate Change Impacts in Switzerland; OCCR, BAFU, MeteoSwiss, C2SM, Agroscope, ProClim: Bern, Switzerland, 2014.

108. Köplin, N.; Schädler, B.; Viviroli, D.; Weingartner, R. Seasonality and magnitude of floods in Switzerland under future climate change. Hydrol. Process. 2014, 28, 2567-2578. [CrossRef]

109. Beniston, M.; Stoffel, M. Rain-on-snow events, floods and climate change in the Alps: Events may increase with warming up to $4{ }^{\circ} \mathrm{C}$ and decrease thereafter. Sci. Total Environ. 2016, 571, 228-236. [CrossRef]

110. Brennunkt Klima Schweiz Grundlagen, Folgen und Perspektiven; Akademien der Wissenschaften Schweiz, Ed.; Akademien der Wissenschaften Schweiz: Bern, Switzerland, 2016. 
111. CH2018 - Climate Scenarios for Switzerland. Technical Report; National Centre for Climate Services: Zurich, Switzerland, 2018.

112. Summermatter, S. Die instrumentalisierte Katastrophe: Die Schweizer Wasserbaupolitik vor und nach den Überschwemmungen von 1868. Hist. Soc. Res. 2007, 32, 200-214.

113. Hochwasser 2005 in der Schweiz. Synthesebericht zur Ereignisanalyse; BAFU, Ed.; Bundesamt für Umwelt BAFU: Bern, Switzerland, 2008.

114. Boosting Disaster Prevention through Innovative Risk Governance. Insights from Austria, France and Switzerland; OECD, Ed.; OECD Publishing: Paris, France, 2017.

115. FAN. Fachleute Naturgefahren Schweiz. Available online: http://www.fan-info.ch/ (accessed on 9 May 2019).

116. Von der Gefahrenabwehr zur Risikokultur; PLANAT (Ed.) National Platform for Natural Hazards (PLANAT), Bundesamt für Umwelt (BAFU), Bundesamt für Raumplanung (ARE): Berne, Switzerland, 1998.

117. PLANAT. Sicherheit vor Naturgefahren. Vision und Strategie; PLANAT Reihe 1/2004; Nationale Plattform Naturgefahren PLANAT: Biel, Switzerland, 2004.

118. PLANAT. Management of Risks from Natural Hazards. Strategy 2018; Platform on Natural Hazards of the Alpine Convention PLANALP: Biel, Switzerland, 2018.

119. Risikobasierte Raumplanung: Synthesebericht zu zwei Testplanungen auf Stufe Kommunaler Nutzungsplanung; PLANAT, ARE, BAFU: Berne, Switzerland, 2014.

120. FOWG. Flood Control at Rivers and Streams. Guidelines of the FOWG; Federal Office for Water and Geology: Berne, Switzerland, 2001.

121. Umgang mit Naturgefahren in der Schweiz. Bericht des Bundesrats in Erfüllung des Postulats 12.4271 Darbellay vom 14.12.2012; BAFU, Ed.; Bundesamt für Umwelt BAFU: Bern, Switzerland, 2016.

122. Anpassung an den Klimawandel in der Schweiz. Ziele, Herausforderungen und Handlungsfelder. Erster Teil der Strategie des Bundesrates vom 2. März 2012; BAFU, Ed.; Bundesamt für Umwelt BAFU: Bern, Switzerland, 2012.

123. Klimabedingte Risiken und Chancen. Eine schweizweite Synthese; BAFU, Ed.; Bundesamt für Umwelt BAFU: Bern, Switzerland, 2017.

124. PLANAT. Strategie 2018 "Umgang mit Risiken aus Naturgefahren"; Platform on Natural Hazards of the Alpine Convention PLANALP: Biel, Switzerland, 2018.

125. OECD. Financial Management of Flood Risk; OECD Publishing: Paris, France, 2016.

126. Zaugg, M. Philosophiewandel im Schweizerischen Wasserbau: Zur Vollzugspraxis des Nachhaltigen Hochwasserschutzes. Ph.D. Thesis, Universität Zürich, Zürich, Switzerland, 2006.

127. Leitsätze zum Hochwasserschutz und zur Revitalisierung an Fliessgewässern; BAFU, Ed.; Bundesamt für Umwelt BAFU: Bern, Switzerland, 2015.

128. Living with Natural Hazards. Objectives and Priorities for Action of the Federal Office for the Environment (FOEN) in Dealing with Natural Hazards; BAFU, Ed.; Federal Office for the Environment: Berne, Switzerland, 2011.

129. Impulse für eine klimaangepasste Schweiz. Erkenntnisse aus 31 Pilotprojekten zur Anpassung an den Klimawandel; BAFU, Ed.; Bundesamt für Umwelt BAFU: Bern, Switzerland, 2017.

130. Widmer, A. Mainstreaming climate adaptation in Switzerland: How the national adaptation strategy is implemented differently across sectors. Environ. Sci. Policy 2018, 82, 71-78. [CrossRef]

131. Strassheim, H.; Kettunen, P. When does evidence-based policy turn into policy-based evidence? Configurations, contexts and mechanisms. Evid. Policy 2014, 10, 259-277. [CrossRef]

132. Van Enst, W.I.; Driessen, P.P.J.; Runhaar, H.A.C. Towards productive science-policy interfaces: A research agenda. J. Environ. Assmt. Policy Manag. 2014, 16, 1450007. [CrossRef]

133. Halffman, W.; Hoppe, R. Science/Policy Boundaries: A Changing Division of Labour in Dutch Expert Policy Advice. In Democratization of Expertise? Exploring Novel Forms of Scientific Advice in Political Decision-Making; Maasen, S., Weingart, P., Eds.; Sociology of the Science Yearbook-Vol. 24; Springer: Dordrecht, The Netherlands, 2005; pp. 135-151.

134. Brand, U.; Pawloff, A. Selectivities at Work: Climate Concerns in the Midst of Corporatist Interests. The Case of Austria. J. Environ. Prot. 2014, 5, 780-795. [CrossRef] 
135. Hermann, A.T.; Pregernig, M.; Hogl, K.; Bauer, A. Cultural Imprints on Scientific Policy Advice: Climate science-policy interactions within Austrian neo-corporatism. Environ. Policy Gov. 2015, 25, 343-355. [CrossRef]

136. Protection against Natural Hazards. Vision and Strategy (Englisch Summary); Nationale Plattform Naturgefahren PLANAT: Biel, Switzerland, 2004.

(C) 2019 by the authors. Licensee MDPI, Basel, Switzerland. This article is an open access article distributed under the terms and conditions of the Creative Commons Attribution (CC BY) license (http://creativecommons.org/licenses/by/4.0/). 
Article

\title{
The Costs of Living with Floods in the Jamuna Floodplain in Bangladesh
}

\author{
Md Ruknul Ferdous ${ }^{1,2, *}$, Anna Wesselink ${ }^{1}$, Luigia Brandimarte ${ }^{3}$, Kymo Slager ${ }^{4}$, \\ Margreet Zwarteveen ${ }^{1,2}$ and Giuliano Di Baldassarre ${ }^{1,5,6}$ \\ 1 Department of Integrated Water Systems and Governance, IHE Delft Institute for Water Education, \\ 2611 AX Delft, The Netherlands; a.wesselink@un-ihe.org (A.W.); m.zwarteveen@un-ihe.org (M.Z.); \\ giuliano.dibaldassarre@geo.uu.se (G.D.B.) \\ 2 Faculty of Social and Behavioural Sciences, University of Amsterdam, \\ 1012 WX Amsterdam, The Netherlands \\ 3 Department of Sustainable Development, Environmental Science and Engineering, KTH, \\ SE-100 44 Stockholm, Sweden; luigia.brandimarte@abe.kth.se \\ 4 Deltares, 2600 MH Delft, The Netherlands; Kymo.Slager@deltares.nl \\ 5 Department of Earth Sciences, Uppsala University, SE-75236 Uppsala, Sweden \\ 6 Centre of Natural Hazards and Disaster Science, CNDS, SE-75236 Uppsala, Sweden \\ * Correspondence: r.ferdous@un-ihe.org
}

Received: 25 April 2019; Accepted: 10 June 2019; Published: 13 June 2019

\begin{abstract}
Bangladeshi people use multiple strategies to live with flooding events and associated riverbank erosion. They relocate, evacuate their homes temporarily, change cropping patterns, and supplement their income from migrating household members. In this way, they can reduce the negative impact of floods on their livelihoods. However, these societal responses also have negative outcomes, such as impoverishment. This research collects quantitative household data and analyzes changes of livelihood conditions over recent decades in a large floodplain area in north-west Bangladesh. It is found that while residents cope with flooding events, they do not achieve successful adaptation. With every flooding, people lose income and assets, which they can only partially recover. As such, they are getting poorer, and therefore less able to make structural adjustments that would allow adaptation in the longer term.
\end{abstract}

Keywords: flooding; erosion; coping; adaptation; Jamuna River; Bangladesh

\section{Introduction}

The image of Bangladesh as a country that is adapting well stems from its long history of living with floods. Bangladesh is a riverine country and one of the most flood-prone countries in the world [1-3]. The country is in the largest delta of the world, which developed, and is continuously changing, through processes of sedimentation and erosion by the three mighty rivers Ganges, Brahmaputra, and Meghna. Bangladesh is also a very densely populated country with most people depending on agriculture and fisheries for their livelihoods [4]. Most of the population lives in floodplain areas, with varying degrees of exposure to riverine flooding and riverbank erosion [5]. In Bangladesh, floods can be both resources and hazards. In the monsoon season, $25-30 \%$ of the floodplain area is typically inundated by the so-called normal floods (borsha). This is considered beneficial as flooding increases the fertility of the land by depositing fresh silt on the soil and replenishing soil moisture without doing too much damage to property or disruption to traffic and commerce. However, an abnormal flood (bonna) is considered a hazard because of the damage it does to crops and properties, and the threat to human lives [6,7]. Riverbank erosion is another hazard in times of flood and occurs almost in every year, whether the flood is normal or abnormal. Abnormal floods and riverbank erosion not 
only cause substantial damage to inhabitants' agricultural lands, crops, and properties, they also have wider socio-economic consequences, for example a decline in agricultural production [8] and a steady flow of migrants to urban areas [9-11]. Each year several thousands of people become temporarily or permanently homeless and/or landless and take refuge to nearby embankments or on neighbors' or relatives' land. The extremely poor people who live on the islands in the wide (up to $16 \mathrm{~km}$ ) rivers (called chars) are most exposed to and affected by flood hazards and riverbank erosion. In the 1988 flood, more than 45 million people were displaced and over 3000 died [12,13]. Flood mortality rates have declined since 1988 because of better institutional support during floods [14]. Yet, the socio-economic disruption caused by flooding events is still considerable [3,15].

"Living in a low-lying and densely populated country on the front line of climate change, Bangladeshis are taking a lead in adapting to rising temperatures and campaigning to limit climate change. Bangladeshis will keep their heads above water, but at huge costs" [1]. This back cover summary of the recent book "Bangladesh Confronts Climate Change: Keeping Our Heads Above Water" [1] portrays a common, positive image of Bangladesh as being able to respond successfully, or adapt, to climate change (see also [12,16-19]). However, it also indicates that this response comes with huge costs. Floodplain inhabitants use a wide range of tried-and-tested strategies to cope with the conditions during and after the flooding. However, repeated exposure to flooding events often means impoverishment.

Only a few authors have paid sufficient attention to this effect, which can be seen as a sign of maladaptation [20]. Most research done on people's abilities to cope or adapt is based on qualitative statements from floodplain inhabitants, without looking at the cumulative effect of floods over a longer time period (i.e., across decades). As time series of quantitative data to substantiate these claims are not available from secondary sources, estimates of flood damage often rely on unverifiable proxies [21]. More specifically, various studies assert that people are getting poorer because of recurring floods $[12,22,23]$, but most of these do not provide quantitative substantiation. One of the processes that may lead to impoverishment is diminished agricultural production in times of disastrous floods [8]. Rural people are most affected by these floods; they are also suffering from the persistent effects of labor market disruption and income deficiency [24]. Moreover, they must spend a large portion of their income on food and repairing or constructing new houses, as their old houses are often ruined by floods and riverbank erosion. Their savings are reduced to zero and the other necessary expenses to survive are only increasing their burden [25].

A few studies quantify the average household losses due to severe floods and the associated riverbank erosion. Chowdhury [26] presents a figure of 47 and 88 USD/year for the years 1986-1987, in two locations. Ten years later Thompson and Tod [27] estimate losses to homesteads to be 132 and 190 USD/year for the 1988 and 1991 floods, again in two locations. The most complete figures are given by Paul and Routray [3], who estimate income losses at 82 and 108 USD/year and asset losses 191 and 257 during the 2005 flood, again in two locations. Combined with direct loss of assets in floods, and loss of the key productive asset (land) to erosion, severe floods in the chars make vulnerable households and the community poorer [27]. Finally, they are falling into debt and impoverishment $[12,22,23,28]$. Further indebtedness leads to even more drastic regimes of "eating simpler food", increased malnutrition, increased levels of disease, increased numbers of wives left to feed children alone while their husbands are temporarily migrated for work, increased sales of remaining assets, increased rural landlessness, increased migration to the cities, and increased vulnerability to future floods.

Moreover, only a few authors investigate the distributional effects of flood impacts. Paul and Routray [3] show how the adoption of a particular set of adjustment strategies depends on people's socio-economic circumstances, such as education, income, and occupation. Islam et al. [29] look at adjustment strategies against flood and riverbank erosion of the char inhabitants of the Jamuna River. They also find that household's ability to cope with flood and river erosion depends on people's socio-economic and environmental conditions. Hutton and Haque [28] assert that impoverishment and marginalization in part reflect inequitable access to land and other resources. The likelihood of 
impoverishment of the household is further increased not only by social and demographic factors (including gender, education, health and age), but also by underlying economic and social relationships which can increase human vulnerability to risk. Indra [30] investigates the forced migration due to riverbank erosion (and hence loss of land) in the Jamuna floodplain, and concludes that most people displaced by riverbank erosion are already poor and disempowered before being uprooted by the shifting channels of the Jamuna River.

This paper critically assesses the idea that Bangladeshis have a good adaptive capacity to changing environmental conditions. To this end, it examines the socio-economic effects of repeated floods and riverbank erosion on rural households, and assesses whether and how different households deal with this flooding. The aim is to uncover whether and how households succeed in adapting to flood conditions, as opposed to those who are merely coping. As defined by Berman et al. [31] coping refers to immediate responses to events, while adapting prepares households for expected future events. These definitions are extended as follows: coping includes long-term adjustments where the net result can be a decline in socio-economic conditions, while adapting means that people continue to live as well, or better than before, and are as well, or better than before, able to cope with future events. Both coping and adapting require the mobilization of a variety of technologies and social or institutional changes, which is defined as adjustments. The actions and strategies for adjustment may be the same, but have a different result: coping or adapting. In general, coping strategies are those that are possible within the current settings, and adaptation strategies are more likely to involve more fundamental changes in the type of livelihood activity or location [32].

\section{Case Study}

To understand how Bangladeshi cope with flooding, this study focuses on the floodplain area along a $30 \mathrm{~km}$ reach of the Jamuna River in the north of Bangladesh. The study area includes parts of Gaibandha district and parts of Jamalpur district (Figure 1). The total surface is about $500 \mathrm{~km}^{2}$ and the total population is approximately 0.36 million people $[4,33]$. This is a unique case study since three adjacent areas are inhabited by people with similar socio-economic conditions, but different levels of flood protection and exposure to riverbank erosion (Figure 1).

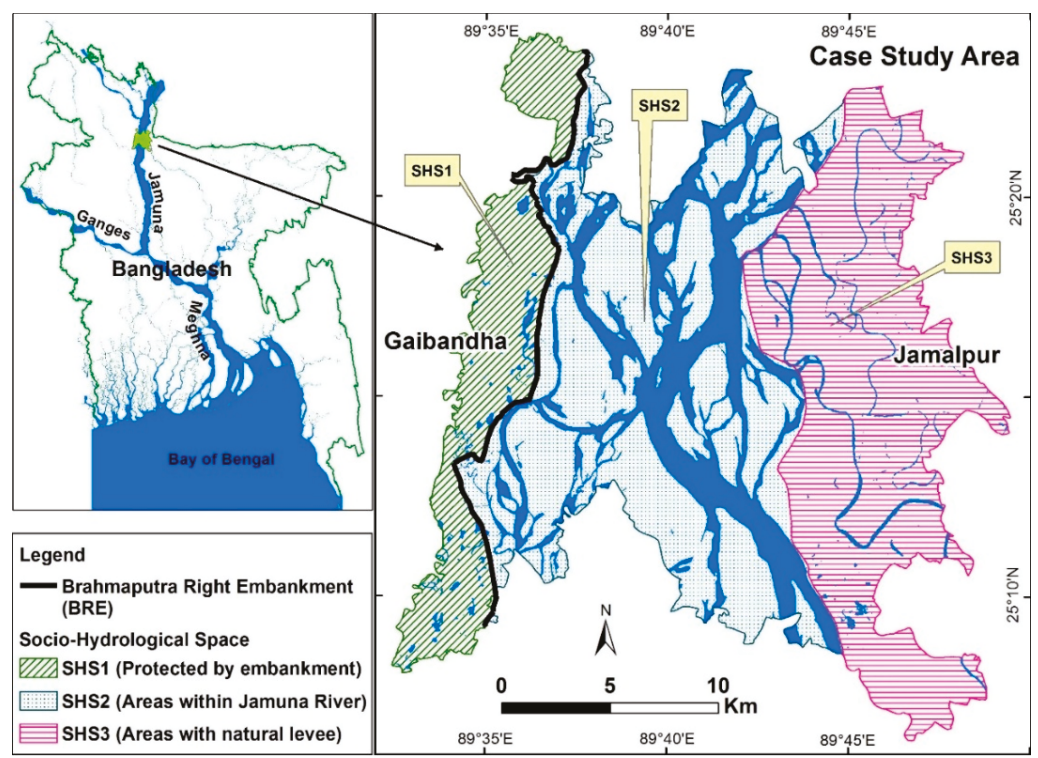

Figure 1. Bangladesh map with study area [34]. 
To investigate the effect of floods and riverbank erosion on livelihood conditions, the area is divided into three socio-hydrological spaces [34]. The socio-economic situations are also classified based on income levels and assets (Section 2.2).

\subsection{Socio-Hydrological Spaces}

Figure 1 shows the braided riverbed, which includes many inhabited river islands (chars) that get flooded with varying frequency (some every year, some only with severe floods). The area to the west of the river is protected by a human-made embankment, while the area to the east of the river only has a natural levee deposited by the river. These different physical conditions create different flood protection levels, which in turn give rise to different socio-economic responses and conditions. To reflect this socio-spatial differentiation, the authors have elsewhere explained and motivated the classification of the study area into three socio-hydrological spaces, abbreviated to socio-hydrological spaces (SHS) [34] (Figure 1). These spaces are briefly described below.

SHS1 is an area protected by an artificial levee (the Brahmaputra Right Embankment, BRE) constructed in the 1960s to limit flooding and increase the agricultural production of that area. This area is protected from regular annual flooding, but the maintenance of the BRE in the study area has been sporadic, and breaches occur during abnormal floods, causing catastrophic floods and damages [35]. Also, two small rivers Ghahot and Alai inundate some parts of the area, and other parts are frequently inundated with excess rainwater, due to their low elevation and limited drainage capacity. The total area is about $74 \mathrm{~km}^{2}$ with a population of approximately 111,000 [4].

SHS2 is the floodplain within the embankment on the west bank and the natural levee on the east bank. In SHS2, flooding occurs most frequently, essentially every year. This area includes extensive chars (river islands), where multiple channels crisscross within the outer boundary of the riverbed. These chars can shift in space due to continuous processes of deposition and erosion of river sediments. The stability of the chars depends on their age. Some older chars have higher elevations than the areas in SHS1 and remain dry during flood conditions. If a new char develops, homeless people analyze the stability of the new char and after 2-3 years start activities such as farming or living on the char. When the age of the char exceeds about 20 years it is called a stable char [36]. Nevertheless, all chars can shift during the flooding events. The total area is about $246 \mathrm{~km}^{2}$ with a population of approximately $104,000[4]$.

SHS3 is the area on the east bank which is without any man-made flood protection. Flooding occurs here more frequently than SHS1, around once in two years [34]. This area is sometimes flooded by adjacent small rivers, in this case the Old Brahmaputra and Jinjira, as well as by excess rainfall. Riverbank erosion is also prominent in this area. Inhabitants take the initiative to build small spurs and bank protection made from bamboo and wood, to try to stop erosion. However, while these encourage sedimentation at a local scale, they are not sufficient to stop large scale erosion. The total area is about $174 \mathrm{~km}^{2}$ with a population of approximately $146,000[4,33]$.

Decadal data from 1961 to 2011 show that the population density has increased from 300 persons $/ \mathrm{km}^{2}$ to about 800 persons $/ \mathrm{km}^{2}$ over the whole study area [4,33]. However, population density in the three spaces differs substantially. In SHS1 it has always been higher than in the SHS2 and SHS3 (Figure 2). The density in SHS1 has increased from 600 to 1500 person $/ \mathrm{km}^{2}$, a rate of 18 persons $/ \mathrm{km}^{2} /$ year. In SHS2 population density has increased from 200 to 400 person $/ \mathrm{km}^{2}$, a rate of 4 persons $/ \mathrm{km}^{2} /$ year, and in SHS3 has increased from 300 to 800 person $/ \mathrm{km}^{2}$, a rate of 10 persons $/ \mathrm{km}^{2} /$ year. 


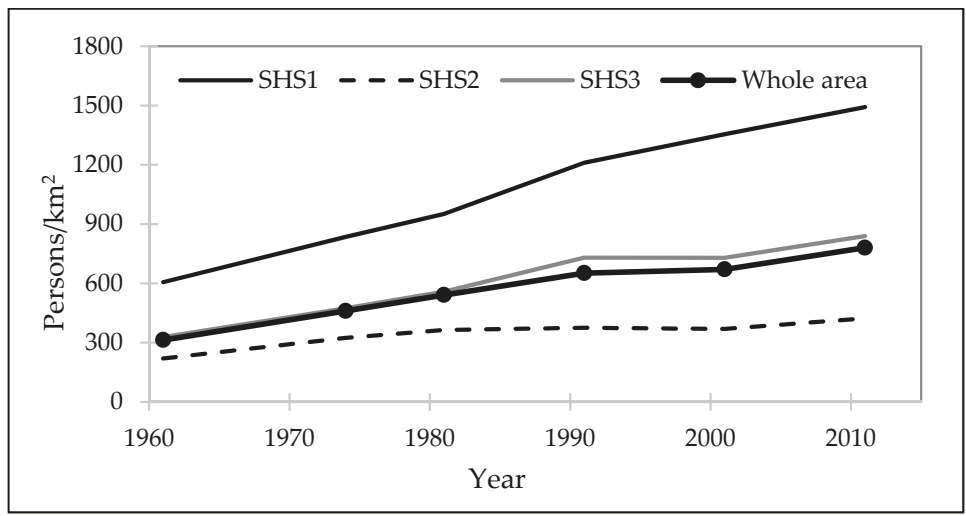

Figure 2. Population density of the study area in the period 1961-2011.

\subsection{Socio-Economic Conditions}

Data on socio-economic activities are sparse. The only historic economic data (from 1971) pertain to the number of commercial establishments developed for non-farming activities. These data are aggregated by districts that are larger than the SHS considered here. An establishment is defined an enterprise or part of an enterprise that is situated in a single location and in which only a single (non-ancillary) productive activity is carried out or in which the principal productive activity accounts for most of the value added [37,38]. Table 1 shows that the socio-economic situation in Gaibandha district was a little better than in Jamalpur district in 1971, but they were almost the same in 2013. The growth in the number of establishments changed dramatically around the year 2000 (Table 1). To get information about the company size and its impact on the local economy, this research uses the number of employees as a proxy. This information is only available for 2003 and 2013 (Table 1).

Table 1. Non-farm economic activities: number of establishments and employees $[37,38]$.

\begin{tabular}{ccccccc}
\hline & \multicolumn{3}{c}{ Gaibandha District } & \multicolumn{3}{c}{ Jamalpur District } \\
\cline { 2 - 6 } Year & Establishments & $\begin{array}{c}\text { Persons } \\
\text { Engaged }\end{array}$ & $\begin{array}{c}\text { Persons/ } \\
\text { Establishment }\end{array}$ & Establishments & $\begin{array}{c}\text { Persons } \\
\text { Engaged }\end{array}$ & $\begin{array}{c}\text { Persons/ } \\
\text { Establishment }\end{array}$ \\
\hline 1971 & 2675 & & & 1931 & & \\
1989 & 10,540 & & & 9329 & & \\
1999 & 33,651 & & & 32,304 & & \\
2003 & 62,655 & 155,094 & 0.404 & 54,724 & 128,366 & 0.426 \\
2009 & 121,495 & & & 127,012 & & \\
2013 & 151,052 & 318,579 & 0.474 & 159,156 & 299,997 & 0.531 \\
\hline
\end{tabular}

Table 1 seems to suggest that long-term economic trend in the area is upwards. Yet, agricultural farm sizes decreased in the study area since the 1960s (Figure 3). This is a potential sign of impoverishment. Figure 3 shows that the number of large farms decreased from $10 \%$ to only $1 \%$ during the period 1960 s to 2016 and the number of landless households increased from $10 \%$ to about $37 \%$ during the same period. 


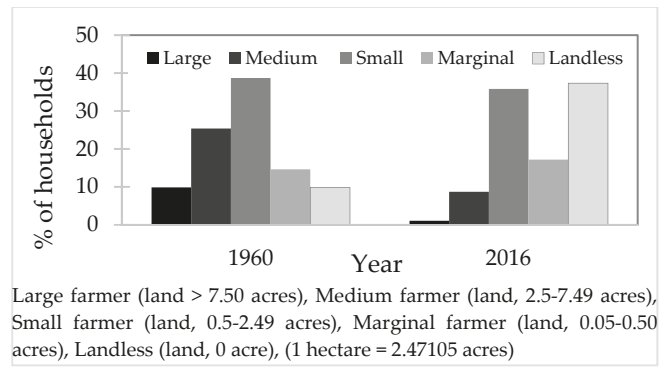

Figure 3. Number of non-farming establishments and change in agricultural farms in the study area.

In the study area, more than $80 \%$ of households rely principally on farm incomes, so agricultural income and assets are key indicators for socio-economic status. The existing Bangladesh Government classification of farm sizes only accounts for land holding size [39]. However, households have other assets (homesteads, equipment, cash or jewelry) that help them survive in case of flooding or riverbank erosion. Moreover, differences in average income affect how households can cope with such events. Data of this research include current annual income, annual expenditure and total wealth (see Section 3 for details about data collection). Using these data, the surveyed households are divided into five socio-economic classes that combine current wealth and income (Table 2). To increase the statistical significance of comparisons between classes, the class boundaries are chosen in such a way that each class contains an almost equal number of households.

Table 2. Classification of socio-economic status of the people in the study area.

\begin{tabular}{cc}
\hline Socio-Economic Classes & Total Wealth and Yearly Income \\
\hline Poor & Little wealth $\leq 5000$ USD, Low income $\leq 750$ USD \\
Moderate poor & Little wealth $\leq 5000$ USD, Moderate income $>750$ USD \\
Moderate & Moderate wealth $5000-30,000$ USD, Moderate income $\leq 1000$ USD \\
Moderate rich & Moderate wealth 5000-30,000 USD, Moderate income $>1000$ USD \\
Rich & High wealth $>30,000$ USD, Moderate income $>1000$ USD \\
\hline
\end{tabular}

By comparing the current distribution of socio-economic classes in the three SHS, see Section 2.1 and Figure 1), one can see remarkable differences (Figure 4a). In SHS1, 10\% of the households are poor and 35\% are rich, while in SHS2 it is just opposite. SHS3 takes an intermediate position, with $15 \%$ poor households and $25 \%$ rich. Using the Government farm size classification for comparison (Figure $4 \mathrm{~b}$ ), it is observed that more than $35 \%$ of households are landless in the study area and only $1 \%$ of households are large (Figure 4b). Most of the landless farmers are found in the SHS2 as they are experiencing much more land erosion than SHS1 and SHS3.
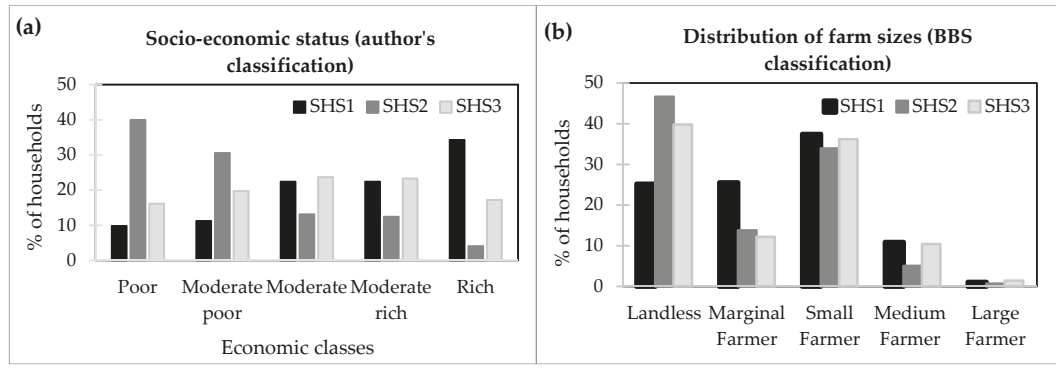

Figure 4. Current socio-economic status of the households in the study area by socio-hydrological space. (a) Socio-economic status (author's classification); (b) Distribution of farm sizes (BBS classification). 


\subsection{Adjustment Strategies in the Study Area}

Inhabitants of the study area employ a range of strategies to adjust with flooding. These can be categorized into those that allow survival in times of flood and those that allow long-term living with floods and riverbank erosion.

To survive during flooding, people eat fewer meals, borrow money or take a loan, or sell their labor cheaply in advance [25]. If necessary they also sell their land, livestock, housing materials and other personal belongings, including jewelry and household goods [27]. In char areas (SHS2, Figure 1) the inhabitants only leave their homes when their lives are at risk. When high floods erode their land, they dismantle their houses and transport them to another char which is less (or not) affected by flooding and erosion [40]. If necessary, people take shelter on the embankments, with their livestock, in the hope that they might return in the near future to the re-emerged land, where they have property rights [15]. In most cases, these hopes are not fulfilled because it may take decades for land to re-appear [41]. Others move to a nearby relative's or friend's house or migrate temporarily to other districts looking for temporary work $[9,30,42-45]$. It is noted that main roads and railways are built on embankments to raise them above high flood levels. Rural roads and paths between settlements generally follow the highest land available and are usually also built on embankments to raise them above normal flood levels. This somewhat limits disruptions during floods, and provide an emergency refuge.

To structurally improve their chances of survival during a flood, inhabitants adjust their homes. In the char areas (SHS2), houses are built in a way that they can be easily dismantled [30,42]. In SHS1 and SHS3, homesteads are generally built on natural elevations, or on artificial earthen mounds, the height of which is determined by local experience of previous high flood levels [17]. The plinth of houses is further raised by digging earth from local depressions. Especially on the chars (SHS2) people also build platforms inside their homes to take shelter using bamboo, straw, water hyacinth, and banana stalks during abnormal flooding years [12].

To improve livelihoods, rural inhabitants have developed farming practices that are adjusted to the height, duration, and timing of normal floods, i.e., that commence and recede in time and attain normal height [6,45]. Rasid and Mallik [46] observe that the most common adjustment of rice cropping to the uncertainties of the flood regime is evident from the practice of intercropping two rice varieties, aus and aman, together. This measure ensures that at least flood-tolerant aman would be secured during an abnormal flood regime, even if the flood-vulnerable aus is lost or damaged. During a normal flood regime both aus and aman would succeed, often resulting in a bumper crop. Farmers have made a careful selection of the best adjusted varieties of rice over the centuries, to enable them to face floods [16], and they select other crops to sow off-season to fit the land elevation [12]. Other adjustment strategies include early harvesting of aus in case of excess or early flooding, planting older and taller seedlings on lands liable to repeated flooding, re-transplanting salvaged seedlings, protection of rice plants from water hyacinth by floating bamboo fences, and the post-flood cultivation of lentils, pulses, mustard, as well as winter vegetables and wheat [46].

While temporary migration can be a survival strategy (see above), migration can also be a long-term adjustment to increase household incomes and livelihood security [45]. Very few people move permanently to towns and cities $[10,28,41]$; the majority of flood affected people try to stay near their homes because kinship ties mean that local inhabitants help each other in crisis situations [2]. In that case, migration often concerns one or more family members who migrate, usually men. This can be on a seasonal basis, to other rural areas as agricultural laborer, or to urban areas as unskilled laborer or rickshaw driver, or more permanently to work in factories. Permanent migration out of the area of origin is rare, and mostly related to the loss of land due to riverbank erosion, while loss of livestock and crop failure more likely leads to temporary migration [10,30]. However, migration often comes at a cost: working conditions tend to be challenging and dangerous. People who are forced to migrate permanently from rural to urban areas often end up in slums with difficult living conditions. 


\section{Data and Methods}

Primary data and secondary data were collected to explore how households in the study area adjust to regular flooding and riverbank erosion, as well as the long-term socio-economic effects of these adjustments.

Household surveys and focus group discussions (participants selected from the previously surveyed households) were performed during the dry seasons of 2015 and 2016. The principal set of primary data consists of 863 questionnaires dealing with several themes: general information (location of settlement and agricultural land, main occupation, age, income and expenditures, wealth and origin of the households), information on different flood experiences (depth of floods, frequency, duration, flood damages, effects on agricultural income and expenditures, other adjustment options such as migration) and experiences with river erosion (frequency, damages, migration, adjustment options etc.). For several of these aspects the respondents were asked to compile a historical record going back to 1960 , which is why the households headed by older men or (occasionally) women were selected. This is a limitation of the study. Many old men were surveyed since they experienced many flooding events. Although other members of the family were typically present during the surveys, this choice may have introduced a selection bias. 12 focus group discussions were also set up in the study area to validate and contextualize survey data.

Since the respondents were asked to recollect their flood experiences going back to 1960, inaccuracies due to memory loss is one of the limitations of the household survey data. When asked to recollect major flood events and details of flood damages, respondents could easily remember events in the last two decades, but they were not so confident about the floods before 1980s. To handle this issue, the questionnaires were filled in in the presence of other family members, who helped the primary respondent to remember details about the past. The surveyors also used references to remarkable years, such as the year of independence of Bangladesh in 1971, or the construction period of embankments, to connect the respondents with years of major flood events.

To further check the reliability of the respondent's flood memory, the surveyed data are compared with both Government data and published journal articles. Based on flood duration, exposure, depth, and damage, the Flood Forecasting and Warning Centre (FFWC) of Bangladesh Water Development Board (BWDB) classifies flood events into three categories: normal, moderate, and severe. According to this classification, Bangladesh has experienced 9 severe floods since 1950s, namely in 1954, 1955, 1974, 1987, 1988, 1998, 2004, 2007 and 2017 [47]. However, according to household surveys a total of 33 major floods were experienced in the study area since the 1960s. A plausible reason for this difference is that the study area is very close to the Jamuna River, so households are facing huge damages almost every year. As such, almost all floods have severe consequences in the study area.

In the literature different lists of severe floods are presented. Hossain et al. [48] report major flood events in 1954, 1955, 1956, 1962, 1963, 1968, 1970, 1971, 1974, and 1984. Brammer [17] mentions that 16 major floods struck Bangladesh in the years between 1950 and 2000, with additional floods in 1977, 1980, 1987, 1988, 1998, and 2000. The respondents in the study could easily remember those flood events mentioned by Brammer [17] except the flood of 1977. According to Paul [16], Bangladesh has experienced 28 major floods in the past 42 years (1954-1996), of which 11 were classified as "devastating" and five as "most devastating". Summarizing all published flood information in the journal articles, 30 major floods were observed during 1962-2017. This flood count is very close to the numbers that the study collected from the household surveys. This suggest that the memory of the respondents is good enough to compile a record of historical flood events in the study area.

For the data on land loss due to riverbank erosion, all respondents were confident that they could remember the actual losses and the years they occurred. According to them, the loss of land is never forgotten. Respondents claimed to remember very well how much lands they had in 1960s, how much land had eroded since then, and in which year. They said that it is possible to recover from flooding, but that it is not possible to recover losses from riverbank erosion. 


\section{Results}

Statistical analyses are performed for the whole study area, for each SHS (Figure 1), and for the different socio-economic classes (Table 2). This is done through statistical analysis of single variables and correlation between variables. ANOVA test $(\mathrm{p}<0.05)$ and Chi-square tests are also performed to verify the significance of the outcomes. Statistical test summaries are given in the Electronic Supplementary Material (ESM).

\subsection{Adjustment Strategies}

Relocation means to settle permanently in another place with the whole household. Households in the study area do not normally relocate due to flooding events. In case of severe flooding, some people may temporally evacuate over a short distance, to return to their houses after the flood. When households were asked about permanent relocation, many of them have expressed that "it is very hard to live here but we are born here, our forefather lived here then why should we leave?" They relocate permanently only when they face riverbank erosion. About $49 \%$ of households relocated during the entire period 1962-2016, and more than $95 \%$ of households claimed that riverbank erosion is the main reason of relocation. As expected, the maximum number of relocations occurred in the char areas, i.e., SHS2 (Figure 5a). By considering the socio-economic status, the maximum number of relocations occurred in poor $(76 \%)$ and moderately poor $(70 \%)$ households (Figure $5 \mathrm{~b}$ ). More than $90 \%$ of respondents relocated within $5 \mathrm{~km}$ from their previous locations and about $40 \%$ poor and $30 \%$ moderately poor households are considering relocating again because of riverbank erosion. A statistical analysis was performed and it was found that there exists a significant difference in relocation by the respondents between SHS and socio-economic groups (with $\alpha=0.05$ ).

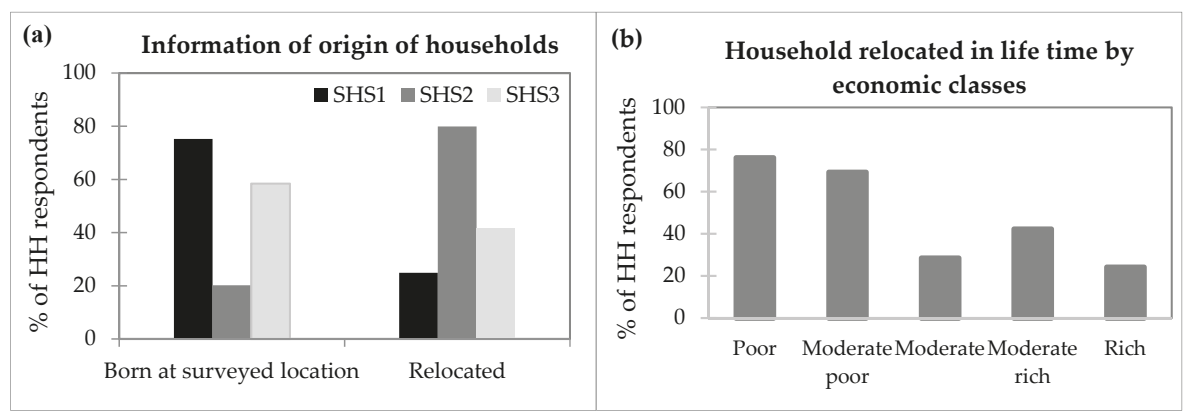

Figure 5. Households relocated due to riverbank erosion. (a) Information of origin of households. (b) Household relocated in lifetime by economic classes.

Only $5 \%$ of households mentioned that members had to change their occupation due to flood (Figure 6a). They were mainly from the poor and moderately poor classes (Figure 6b). They changed their occupation mainly from farmer to day laborer, rickshaw puller, and fishermen. The number of households reporting a change in occupation is low because alternative employment opportunities are limited. More than $90 \%$ of households mentioned that they have nothing to do during flood events and a scarcity of work arises during those periods. Normally, they look for day laborer work during flood events. A statistical analysis was performed and it showed that there is no significant difference in change in employment by the respondents between the SHS but there exists a significant difference in change in employment by socio-economic groups (with $\alpha=0.05$ ). 


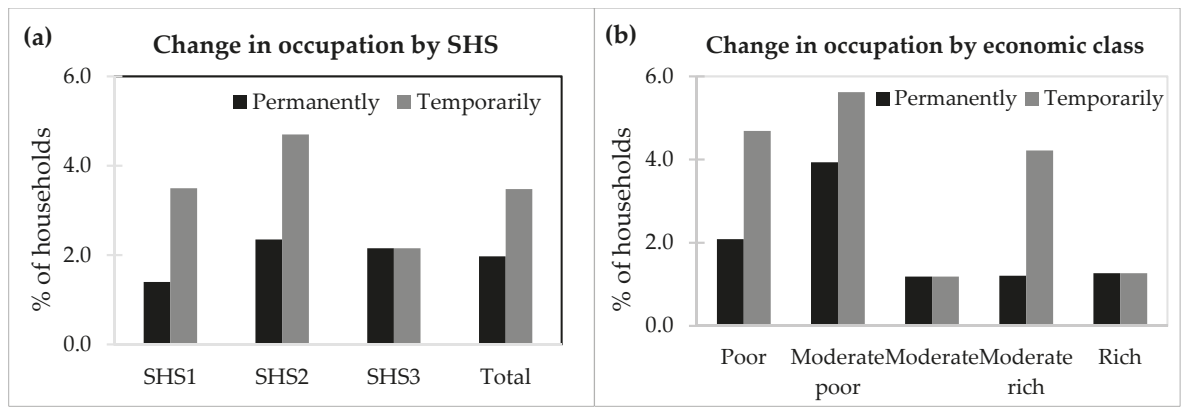

Figure 6. Change in occupation of households in the study area. (a) Change in occupation by SHS. (b)

Change in occupation by economic class.

The results show that most households do not change their cropping pattern due to flooding. Using indigenous knowledge, they developed a unique technique to cultivate rice which they follow every year. However, in severe floods this technique does not work and they lose the whole harvest. About $20 \%$ of households cultivated fast growing crops after the severe flood in 1988, and about $15 \%$ of households did so after the flood events in 2007 and 2015. A few farmers mentioned that they keep their lands fallow during the flood season to avoid losses.

In the study area, inhabitants raise the plinth of their houses to prevent flood water to get into their home. Only 11\% of household respondents have also raised their homestead platform. They all are from rich and moderately rich socio-economic classes.

Inhabitants of the study area are undertaking some other adjustment strategies such as storing food for flood event, constructing houses with movable materials, planting trees to avoid erosion. A few of them are also temporarily going to big cities to earn some money as day laborers to overcome the flood losses.

\subsection{Impacts of Flooding and Riverbank Erosion}

By analyzing the negative impacts of flooding and riverbank erosion, it was found that the average income is decreasing over time. About $98 \%$ of household experienced decrease in income in every year. Households claim to lose about $90 \%$ of their monthly income during severe flood events (Table 3). A statistical analysis was performed and it showed that there is no significant difference in income loss of the respondents between the SHS and by socio-economic groups (with $\alpha=0.05$ ).

Table 3. Decrease of income due to floods in the study area.

\begin{tabular}{|c|c|c|c|c|c|c|c|c|c|}
\hline \multirow[b]{2}{*}{ Parameters } & \multicolumn{3}{|c|}{ Socio-Hydrological Spaces } & \multicolumn{5}{|c|}{ Socio-Economic Classes } & \multirow{2}{*}{$\begin{array}{l}\text { Whole } \\
\text { Study Area }\end{array}$} \\
\hline & SHS1 & SHS2 & SHS3 & Poor & $\begin{array}{l}\text { Moderate } \\
\text { Poor }\end{array}$ & Moderate & $\begin{array}{l}\text { Moderate } \\
\text { Rich }\end{array}$ & Rich & \\
\hline $\begin{array}{c}\% \text { of households experiencing } \\
\text { a decrease of income }\end{array}$ & $97 \%$ & $99 \%$ & $96 \%$ & $97 \%$ & $98 \%$ & $97 \%$ & $97 \%$ & $99 \%$ & $98 \%$ \\
\hline $\begin{array}{l}\% \text { of monthly income lost } \\
\text { during severe floods }\end{array}$ & $86 \%$ & $88 \%$ & $91 \%$ & $88 \%$ & $88 \%$ & $89 \%$ & $88 \%$ & $90 \%$ & $89 \%$ \\
\hline
\end{tabular}

Moreover, $71 \%$ of households face an increase in monthly expenses in times of floods (Table 4). Such an increase is about $60 \%$ of the monthly income with little (but not significant, see ESM) differences between SHS and by socio-economic groups (Table 4). Decrease in income loss and increase in monthly expenses due to flood and riverbank erosion are generating the indebted situation for the households in the long run. 
Table 4. Increase in expenses due to flood in the study area.

\begin{tabular}{|c|c|c|c|c|c|c|c|c|c|}
\hline \multirow[b]{2}{*}{ Parameters } & \multicolumn{3}{|c|}{ Socio-Hydrological Spaces } & \multicolumn{5}{|c|}{ Socio-Economic Classes } & \multirow{2}{*}{$\begin{array}{l}\text { Whole } \\
\text { Study Area }\end{array}$} \\
\hline & SHS1 & SHS2 & SHS3 & Poor & $\begin{array}{l}\text { Moderate } \\
\text { Poor }\end{array}$ & Moderate & $\begin{array}{l}\text { Moderate } \\
\text { Rich }\end{array}$ & Rich & \\
\hline $\begin{array}{l}\% \text { of households facing an } \\
\text { increase in expenses in time } \\
\text { of flood }\end{array}$ & $71 \%$ & $77 \%$ & $66 \%$ & $78 \%$ & $67 \%$ & $69 \%$ & $71 \%$ & $70 \%$ & $71 \%$ \\
\hline $\begin{array}{l}\% \text { of monthly income of the } \\
\text { average increase of expenses }\end{array}$ & $63 \%$ & $62 \%$ & $60 \%$ & $66 \%$ & $50 \%$ & $61 \%$ & $52 \%$ & $78 \%$ & $62 \%$ \\
\hline
\end{tabular}

\subsection{Impoverishment}

Land loss caused by river erosion is the major loss for the inhabitants of the study area. Land loss data were used to better analyze whether impoverishment differs by SHS and socio-economic classes. On average, 0.9 ha of land per household was lost between 1962 and 2016. As expected, the inhabitants of SHS2 had the highest losses with 1.4 ha per household (Figure 7a). About 10\% of households lost all their land since 1962 and 20\% of households lost more than $80 \%$ of their land. Analyzed by socio-economic status, it is found that the poor households have lost the most, i.e., 1.5 ha per household (Figure 7b). Moreover, poor and moderately poor households lost the highest proportion of their land, many ending up with no land at all (Figure 7c,d). The households of SHS2 have lost about $80 \%$ of their lands during this period. A statistical analysis was performed and it showed that these differences in land loss between the SHS and socio-economic groups are significant (with $\alpha=0.05$ ).

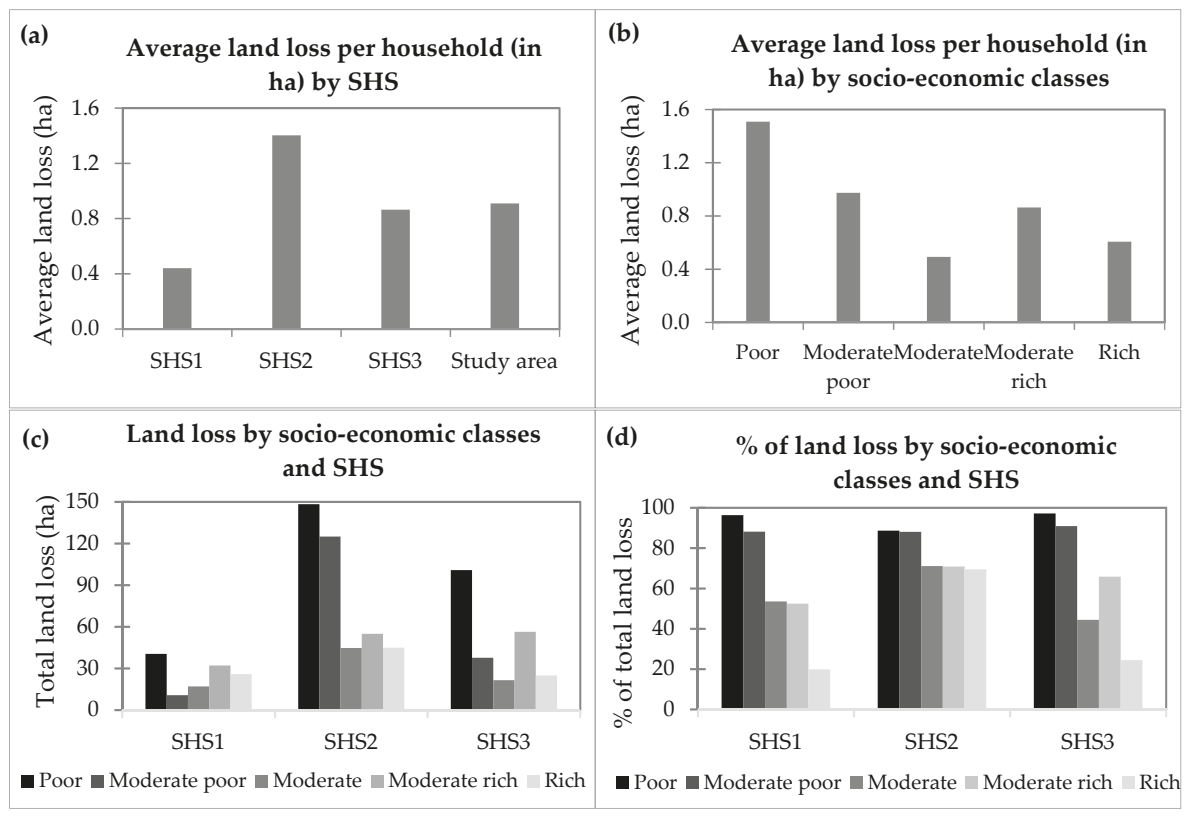

Figure 7. Total land loss by SHS and economic classes in the study area from 1962 to 2016. (a) Average land loss per household (in ha) by SHS; (b) Average land loss per household (in ha) by socio-economic classes; (c) Land loss by socio-economic classes and SHS; (d) \% of land loss by socio-economic classes and SHS.

The survey data also include time series on agricultural crop loss, homestead loss, and other asset losses caused by flooding and riverbank erosion. In terms of total asset losses, households in SHS3 have lost the most, around 2000 USD per year, while the households in SHS2 have lost the least, around 
1250 USD per year. Households in SHS2 are better prepared, since they live in the char area, and have less to lose because they are, on average, poorer. By analyzing asset losses by socio-economic status, one can see that poor households have lost most assets (more than 2000 USD). Most poor people today claimed to be richer back in the 1960s, but that they became poorer because of repeated asset losses caused by flooding the riverine erosion. Yet, it should be mentioned that no significant correlations between flood severities and reported losses were found (details are given in ESM).

The respondents were asked about their recovery processes to explore how they recover from losses caused by consecutive events. "Flood and riverbank erosion have snatched everything from us, and we become destitute", is one of the most commonly heard expressions in the char area (SHS2). People in the areas also like to ease their situation by believing that "Almighty Allah (God) has sent this flood towards us and so we have to accept it. This is our fate". Most respondents informed us that it is almost impossible to recover from the riverbank erosion. About $53 \%$ of the respondents mentioned that they could not recover at all from the combined losses of flooding and riverbank erosion (Figure 8a). Only $5 \%$ of the households recovered a little but not enough to get back to their previous position. They recovered partially with hard working as agricultural laborer, other day laborer employment, and by selling properties or taking loans to do business, cattle farming, or send a household member to temporarily migrate to cities to earn some money. Also, more than $80 \%$ of the households in SHS2 could not recover at all, which is highest among the SHS. Looking at socio-economic classes, one can see that more than $70 \%$ of poor and moderately poor households could not recover at all (Figure $8 \mathrm{~b}$ ). A statistical analysis was performed and it showed that there is no significant difference in recovery from loss by the respondents between the SHS but there exists a significant difference in recovery of loss by socio-economic groups (with $\alpha=0.05$ ).

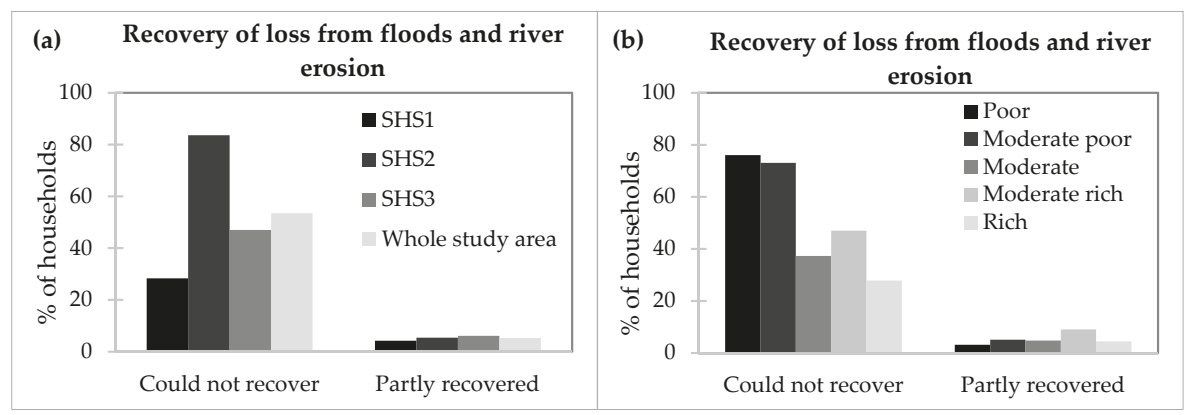

Figure 8. Recovery of loss from floods and riverbank erosion in the study area. (a) Recovery of loss from floods and river erosion; (b) Recovery of loss from floods and river erosion.

These statistics do not tell the whole story, since they present averages. During the field survey a few exceptions were found to the overall picture sketched above. While most of the people suffer, a few rich households benefited from flooding and riverbank erosion by giving loans with very high interest to the flood victims. Statistics do not show the richness of individual experiences either, where each household has its own story to tell such as the one presented in Box 1. The situation of Mr Abdul Baki Khan is typical for some char dwellers, but the number of times his family moved is also quite exceptional compared to other households. 
Box 1. An example of a life course of impoverishment in the study area.

\begin{abstract}
Story of Mr Abdul Baki Khan, an example of living with floods in the study area
Mr Khan, who is 63 years of age, lives in a char of the Jamuna River in Uria union of Fulchari upazila of Gaibandha district. He is a landless farmer whose household consists of seven members. They organize their livelihoods around the river. They grow maize, jute and rice on a field by the Jamuna River char. The occurrence of regular flooding events, associated with eroding land, forces them to relocate every two to three years. Over the period 1978-2018, the family moved 13 times. Because of growing population in the area, finding possible places to live and farm has become increasingly difficult. In the past, he used to have access to some 9 hectares of land (large famer according to the agricultural land size), but today he has become landless. Now he is working on the lands of others and his eldest son is also working with him. His income from agricultural land is often not enough for the family, so they limit their daily needs. From morning to afternoon, he and his son go to the field and work hard. Despite these efforts, their monthly income is only about 50 USD. Their house is made of locally available materials with earthen floor, wood, paddy straw with tin on the top of the house. Mr Khan is an example of many people living in the Jamuna floodplain and its char. Many people like him used to be richer earlier, but they have become poorer because of flooding and erosion.
\end{abstract}

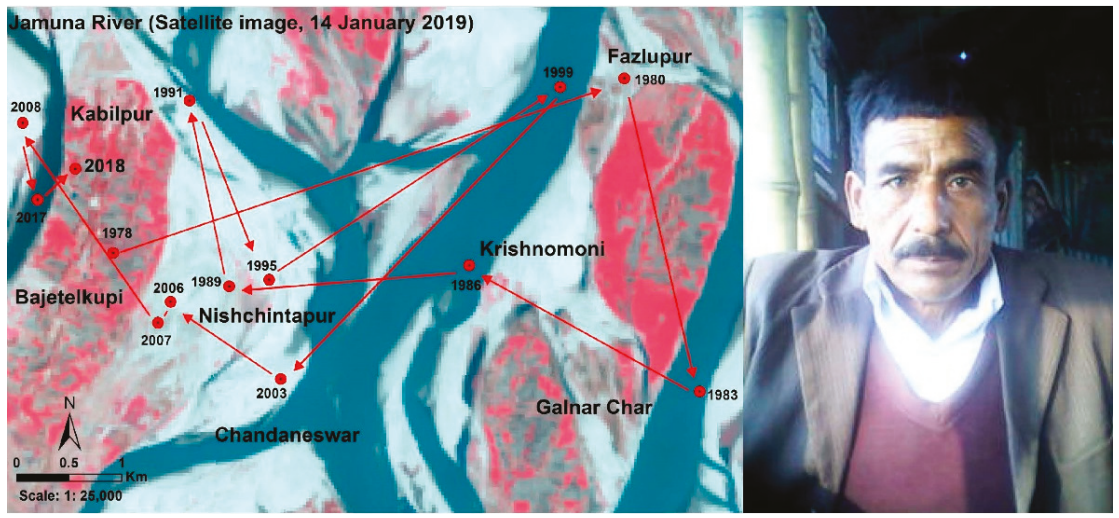

All relocations of Mr Khan and his family mapped onto the current Jamuna River pattern.

\title{
5. Discussion and Conclusions
}

Primary and secondary data were analyzed to reveal how the three SHS and the socio-economic classes are affected by flooding and bank erosion, and their inhabitants adopt adjustment measures to face these hazards and reduce or mitigate the related risks. This study quantified the costs of living with floods and showed that this can lead to general impoverishment in the long term.

While the country (Bangladesh as a whole) has become more prosperous [14], the per capita gross domestic product (GDP) of Bangladesh is accelerating rapidly [49], and the percentage of the population living below the national poverty line is decreasing [50]. Yet, the prosperity of the study area is below the national level, partly because growing GDP in Bangladesh is mainly urban [39]. According to the National Accounts Statistics for the year 2016 [51], the per capita annual income of the study area is estimated at 1160 USD compared with the national average of 1544 USD. Based on the surveyed data, it is estimated that per capita annual income in SHS1 at USD 1200, in SHS2 at USD 700, and in SHS3 at USD 1000 (below BBS estimates). It is also estimated that the percentages of households below poverty line is about 18\% in SHS1, 32\% in SHS2 and 15\% in SHS3. Given that the main source of income in this area is represented by farming [34], the occurrence of flooding in the area highly impacts income generation. In SHS2, inhabitants only cultivate one crop per year and experience flooding essentially every single year. In SHS1 and SHS3, flooding occurs roughly once every two years. In all three SHSs, over $90 \%$ of the respondents experienced over the years an average income loss of about 80 USD which they attribute to flooding, which corresponds to about $85 \%$ of their monthly income. In addition, riverbank erosion is responsible for loss of land and assets in the area. 
According to the surveys, households from all three SHS and all socio-economic classes have lost land over the past 50 years. SHS2 people have lost up to $80 \%$ of their land and many households in the poorest socio-economic class stated that they have lost all their land. Inhabitants that relocated several times became poorer more quickly than those who did not need to relocate as frequently. Bank erosion victims tend to relocate to nearby land, hoping that they can recuperate their land in the near future. There are no many alternatives to recover from income, land, and asset loss. They either change their occupation from farmer to day laborer, fisherman, or temporarily migrate to cities to earn. However, recovery rate is very low: income loss and asset loss recovery is marginal even for rich class people. Furthermore, due to the lack of employment alternatives in the area, many people need to take loans with high interest during the flood season. In an attempt to increase their loss recovery capacity, people try to save some money for the flood season; however, their savings evaporate rapidly during the flood season when monthly expenses can be higher than incomes. As a result, they move towards impoverishment over time. Household respondents are affected by flooding and riverbank erosion in terms of income losses (Table 3), increases in expenses (Table 4) as well as land losses (Figure 7). The household respondents have also mentioned that it is almost impossible to fully recover the loss (Figure 8). This study analysis showed that although flood mortality rates in Bangladesh have been significantly decreasing over time [52,53], the costs of adjusting to flooding and riverine erosion are very high and can negatively impact the livelihood of local people. While households mainly blame flooding and bank erosion, there can be other socio-economic factors, such as a lack of investments in alternative types of employment, which also can significantly contribute to the impoverishment of the area.

Figure 9 depicts the definitions of coping and adapting introduced in Section 1. This research shows that households in the study area are coping (but not adapting) with flooding and riverbank erosion, since the net result of their adjustments is a decline in socio-economic conditions (see orange trajectory in Figure 9).

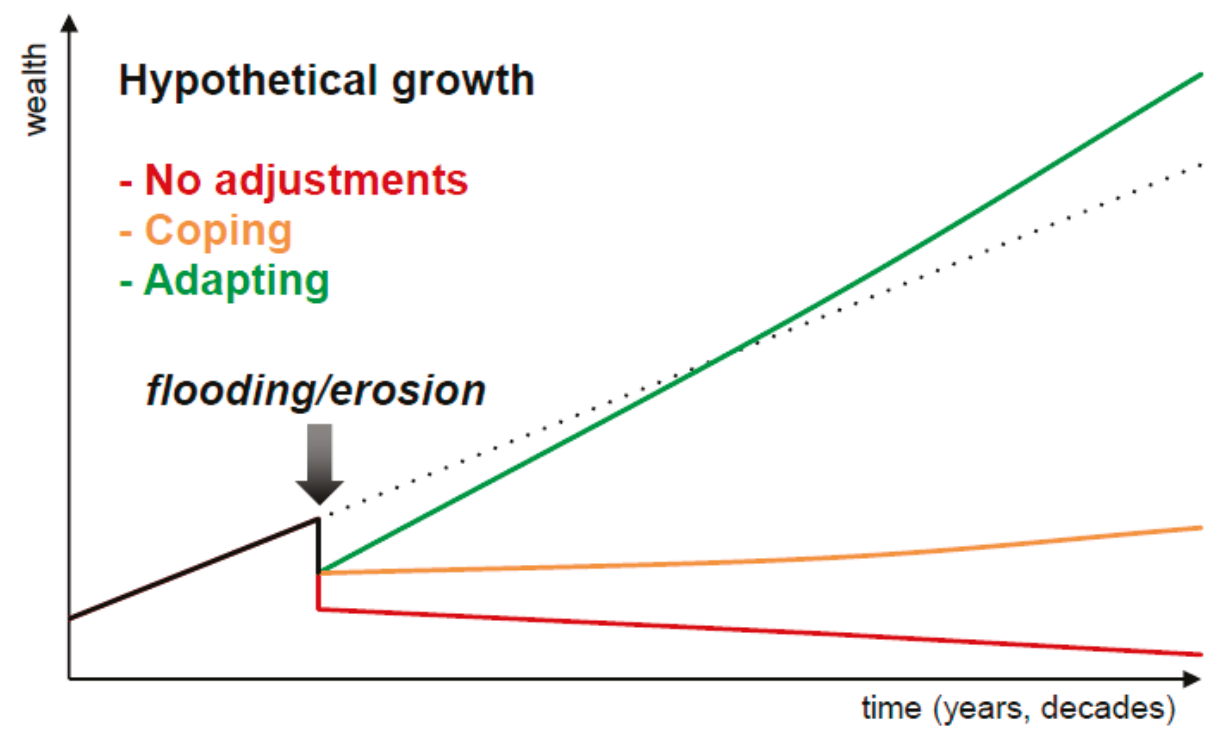

Figure 9. Coping or adapting? Deviation from a hypothetical trajectory of socio-economic growth (black line) caused by flooding and erosion, in case of: (i) no adjustments (red line), (ii) coping (orange line), and (iii) adapting (green line).

Loss of homesteads forces people to move to new places without any option and puts them in desperate situations. Despite these extreme living conditions, the char inhabitants do not leave this area 
because of various obstacles, the lack of available land elsewhere being foremost. They try to stay as long as possible in their home during high floods and in the case of erosion, dismantle it and transport it to another char which is less or not affected by erosion at that moment. While the situation in the char area (SHS2) is extreme, in every location of the study area people are losing income and assets, since they can only partially recover from flood events. Overall, they are getting poorer and therefore less able to make the further adjustments for the next flooding event. Although there are most likely other factors at play, repeated flooding and associated bank erosion contribute to overall impoverishment (in relative terms compared with national figures of economic growth) of the floodplain people of Bangladesh, despite their use of multiple strategies to respond to flooding and riverbank erosion. Due to the scale of works, the flood control measures constructed by the Government are not likely to ever be sufficient to prevent flooding or riverbank erosion. This research posits that indigenous adjustments, such as the adoption of different types of crops to varied flood depths, should be reinforced to reduce the negative impacts of flooding on agriculture and therefore slow down the rate of impoverishment in the area.

This research work does not only contribute to advance the knowledge about socio-hydrological dynamics in Bangladesh, but also provides more general insights for flood risk management in low-income regions of the world. There is an ongoing discussion about the need for a shift from hard (fighting floods) to soft (living with floods) approaches [54]. It has been argued that low-income countries such as Bangladesh should not implement hard engineering work to increase levels of structural flood protection, as it has been done in most Western countries, but stick to their traditional softer approach of living with floods [55]. Indeed, some of the polders that were constructed in 1970s had negative impacts on ecosystems and livelihoods and are currently being revised to re-establish a workable sediment and water balance [56]. However, the Jamuna case study demonstrates that living with floods has enormous costs and it prevents socio-economic growth in the areas. As such, there are no clear-cut answers to the question of how low-income countries should deal with flooding. This research argues that universal recipes do not exist. Instead, there is a need to find trade-offs between hard and soft options depending on the values given by local communities, experts, practitioners, and governments to environmental, social, and economic benefits and costs of alternative strategies. A better understanding of socio-hydrological dynamics, such as the one provided with the Jamuna case study, can help identify these trade-offs by shading light on both the positive and negative effects of living with floods.

Supplementary Materials: The following are available online at http://www.mdpi.com/2073-4441/11/6/1238/s1, Document S1: ESM Living with flooding in the Jamuna floodplain in Bangladesh: limits to adaptation, Table S1: EMS Literature review: Living with flooding in the Jamuna floodplain in Bangladesh: limits to adaptation.

Author Contributions: Conceptualization: M.R.F., A.W., L.B., K.S., M.Z. and G.D.B.; Data curation: M.R.F.; Formal analysis: M.R.F., A.W., L.B. and K.S.; Investigation: M.R.F., A.W., L.B. and K.S.; Methodology: M.R.F., A.W., L.B. and K.S.; Supervision: A.W., L.B., M.Z. and G.D.B.; Writing-original draft preparation: M.R.F., A.W. and L.B.; Writing-review and editing: M.R.F., A.W., L.B., M.Z. and G.D.B.

Funding: The research is funded by NWO-WOTRO grant W 07.69.110 "Hydro-Social Deltas: Understanding flows of water and people to improve policies and strategies for disaster risk reduction and sustainable development of delta areas in the Netherlands and Bangladesh". Giuliano Di Baldassarre is also supported by the European Research Council (ERC) within the project "HydroSocialExtremes: Uncovering the Mutual Shaping of Hydrological Extremes and Society", ERC Consolidator Grant No. 771678. Luigia Brandimarte is supported by the Swedish Strategic research programme StandUP for Energy.

Acknowledgments: Special thanks to Md Mahabubar Rahman, Md Enamul Haque, and Md Shahrier Islam for collecting household data from the study area. Special thanks to Abdul Baki Khan for allowing us to use his photo and life story in this paper. Special thanks to Engr. Md Waji Ullah, Executive Director, CEGIS for providing satellite images of Jamuna River for the study.

Conflicts of Interest: The authors declare no conflict of interest. 


\section{References}

1. Roy, M.; Hanlon, J.; Hulme, D. Bangladesh Confronts Climate Change: Keeping Our Heads Above Water, 1st ed.; Anthem Press: London, UK; New York, NY, USA, 2016; pp. 1-173.

2. Mamun, M.Z. Awareness, Preparedness and Adjustment Measures of River-bank Erosion-prone People: A Case Study. Disasters 2016, 20, 68-74. [CrossRef]

3. Paul, S.K.; Routray, J.K. Flood proneness and coping strategies: The experiences of two villages in Bangladesh. Disasters 2010, 34, 489-508. [CrossRef] [PubMed]

4. BBS. Bangladesh Population \& Housing Census-2011. In Community Report: Gaibandha; Bangladesh Bureau of Statistics: Dhaka, Bangladesh, 2013; pp. 1-547.

5. Tingsanchali, T.; Karim, M.F. Flood hazard and risk analysis in the southeast region of Bangladesh. Hydrol. Process. 2005, 19, 2055-2069. [CrossRef]

6. Paul, B.K. Perception of and agricultural adjustment to floods in Jamuna floodplain, Bangladesh. Hum. Ecol. 1984, 12, 3-19. [CrossRef]

7. Brammer, H. Floods in Bangladesh: II. Flood mitigation and environmental aspects. Geogr. J. 1990, 156, 158-165. [CrossRef]

8. Banerjee, L. Creative destruction: Analysing flood and flood control in Bangladesh. Environ. Hazards 2011, 9, 102-117. [CrossRef]

9. Gray, C.L.; Mueller, V. Natural disasters and population mobility in Bangladesh. PNAS 2012, 109, 6000-6005. [CrossRef]

10. Joarder, M.A.M.; Miller, P.W. Factors affecting whether environmental migration is temporary or permanent: Evidence from Bangladesh. Glob. Environ. Chang. 2013, 23, 1511-1524. [CrossRef]

11. Fenton, A.; Paavola, J.; Tallontire, A. Autonomous adaptation to riverine flooding in Satkhira District, Bangladesh: Implications for adaptation planning. Reg. Environ. Chang. 2017, 17, 2387-2396. [CrossRef]

12. Haque, C.E.; Zaman, M.Q. Human responses to riverine hazards in Bangladesh: A proposal for sustainable floodplain development. World Dev. 1993, 21, 93-107. [CrossRef]

13. Zaman, M.Q. Rivers of life: Living with floods in Bangladesh. Asian Surv. 1993, 33, 985-996. [CrossRef]

14. Khandker, S.R. Coping with flood: Role of institutions in Bangladesh. Agric. Econ. 2007, 36, 169-180. [CrossRef]

15. Brouwer, R.; Akter, S.; Brander, L.; Haque, E. Socioeconomic vulnerability and adaptation to environmental risk: A case study of climate change and flooding in Bangladesh. Risk Anal. Int. J. 2007, 27, 313-326. [CrossRef] [PubMed]

16. Paul, B.K. Flood research in Bangladesh in retrospect and prospect: A review. Geoforum 1997, 28, 121-131. [CrossRef]

17. Brammer, H. Can Bangladesh be Protected from Floods? 1st ed.; The University Press Limited: Dhaka, Bangladesh, 2004; pp. 1-262.

18. Di Baldassarre, G.; Viglione, A.; Carr, G.; Kuil, L.; Yan, K.; Brandimarte, L.; Blöschl, G. Debates—Perspectives on socio-hydrology: Capturing feedbacks between physical and social processes. Water Resour. Res. 2015, 51, 4770-4781. [CrossRef]

19. Ciullo, A.; Viglione, A.; Castellarin, A.; Crisci, M.; Di Baldassarre, G. Socio-hydrological modelling of flood-risk dynamics: Comparing the resilience of green and technological systems. Hydrol. Sci. J. 2017, 62, 880-891. [CrossRef]

20. Barnett, J.; O’Neill, S. Maladaptation. Glob. Environ. Chang. 2010, 2, 211-213. [CrossRef]

21. Yang, Y.C.E.; Ray, P.A.; Brown, C.M.; Khalil, A.F.; Yu, W.H. Estimation of flood damage functions for river basin planning: A case study in Bangladesh. Nat. Hazards 2015, 75, 2773-2791. [CrossRef]

22. Alamgir, M. Famine in South. Asia, 1st ed.; Oelgeschlager, Gunn \& Hain: Cambridge, UK, 1980.

23. Rahman, A. Human Responses to Natural Hazards: The Hope Lies in Social Networking. In Proceedings of the 23rd Bengal Studies Conference, Winnipeg, MB, Canada, 9-11 June 1989.

24. Sultana, N.; Rayhan, M.I. Coping strategies with floods in Bangladesh: An empirical study. Nat. Hazards 2012, 64, 1209-1218. [CrossRef]

25. Yasmin, T.; Ahmed, K.M. The comparative analysis of coping in two different vulnerable areas in Bangladesh. Int. J. Sci. Technol. Res. 2013, 2, 26-38. 
26. Chowdhury, M. The 1987 flood in Bangladesh: An estimate of damage in twelve villages. Disasters 1988, 12, 294-300. [CrossRef]

27. Thompson, P.; Tod, I. Mitigating flood losses in the active floodplains of Bangladesh. Disaster Prev. Manag. Int. J. 1998, 7, 113-123. [CrossRef]

28. Hutton, D.; Haque, C.E. Human vulnerability, dislocation and resettlement: Adaptation processes of river-bank erosion-induced displacees in Bangladesh. Disasters 2004, 28, 41-62. [PubMed]

29. Islam, M.S.; Hasan, T.; Chowdhury, M.S.I.R.; Rahaman, M.H.; Tusher, T.R. Coping techniques of local people to flood and river erosion in char areas of Bangladesh. J. Environ. Sci. Nat. Resour. 2013, 5, 251-261. [CrossRef]

30. Indra, D. Not Just Dis-Placed and Poor: How Environmentally Forced Migrants in Rural Bangladesh Recreate Space and Place under Trying Conditions. In Rethinking Refuge and Displacement: Selected Papers of Refugees and Immigrants; Gozdziak, E.M., Shandy, D., Eds.; American Anthropological Association: Washington, DC, USA, 2000; Volume VIII, pp. 163-191.

31. Berman, R.; Quinn, C.; Paavola, J. The role of institutions in the transformation of coping capacity to sustainable adaptive capacity. Environ. Dev. 2012, 2, 86-100. [CrossRef]

32. Rahman, T.M.A.; Islam, S.; Rahman, S.H. Coping with flood and riverbank erosion caused by climate change using livelihood resources: A case study of Bangladesh. Clim. Dev. 2015, 7, 185-191. [CrossRef]

33. BBS. Bangladesh Population \& Housing Census-2011. In Community Report: Jamalpur; Bangladesh Bureau of Statistics: Dhaka, Bangladesh, 2014; pp. 1-654.

34. Ferdous, M.R.; Wesselink, A.; Brandimarte, L.; Slager, K.; Zwarteveen, M.; Di Baldassarre, G. Socio-hydrological spaces in the Jamuna River floodplain in Bangladesh. Hydrol. Earth Syst. Sci. 2018, 22, 5159-5173. [CrossRef]

35. Sarker, M.H. River Bank Improvement Program: Annex A, Vol. 1, Morphology, Feasibility Report and Detailed Design Priority Reach; Bangladesh Water Development Board: Dhaka, Bangladesh, 2015; pp. 1-127.

36. Sarker, M.H.; Huque, I.; Alam, M.; Koudstaal, R. Rivers, chars and char dwellers of Bangladesh. Int. J. River Basin Manag. 2003, 1, 61-80. [CrossRef]

37. BBS. Economic Census 2013. In District Report Gaibandha; Bangladesh Bureau of Statistics: Dhaka, Bangladesh, 2016; pp. 1-472.

38. BBS. Economic Census 2013. In District Report Jamalpur; Bangladesh Bureau of Statistics: Dhaka, Bangladesh, 2016; pp. 1-518.

39. BBS. Yearbook of Agricultural Statistics-2017, 29th ed.; Bangladesh Bureau of Statistics: Dhaka, Bangladesh, 2018; pp. 1-576.

40. Schmuck, H. An Act of Allah: Religious Explanations for Floods in Bangladesh as Survival Strategy. Int. J. Mass Emerg. Disasters 2000, 18, 85-95.

41. Haque, C.E. Human adjustments to river bank erosion hazard in the Jamuna floodplain, Bangladesh. Hum. Ecol. 1988, 16, 421-437. [CrossRef]

42. Shaw, R. Living with floods in Bangladesh. Anthropol. Today 1989, 5, 11-13. [CrossRef]

43. Rahman, M.R. Impact of riverbank erosion hazard in the Jamuna floodplain areas in Bangladesh. J. Sci. Found. 2013, 8, 55-65. [CrossRef]

44. Findlay, A.M. Migration: Flooding and the scale of migration. Nat. Clim. Chang. 2012, 2, 401-402. [CrossRef]

45. Ayeb-Karlsson, S.; van der Geest, K.; Ahmed, I.; Huq, S.; Warner, K. A people-centred perspective on climate change, environmental stress, and livelihood resilience in Bangladesh. Sustain. Sci. 2016, 11, 679-694. [CrossRef] [PubMed]

46. Rasid, H.; Mallik, A. Flood adaptations in Bangladesh: Is the compartmentalization scheme compatible with indigenous adjustments of rice cropping to flood regimes? Appl. Geogr. 1995, 15, 3-17. [CrossRef]

47. FFWC/BWDB. Annual Flood Report 2017. In Flood Forecasting and Warning Centre; Bangladesh Water Development Board: Dhaka, Bangladesh, 2018; pp. 1-108.

48. Hossain, M.; Islam, A.T.M.A.; Saha, S.K. Floods in Bangladesh-An Analysis of their Nature and Causes. In Floods in Bangladesh Recurrent Disaster and People's Survival; Universities Research Centre: Dhaka, Bangladesh, 1987; pp. 1-21.

49. The World Bank National Accounts Data, and OECD National Accounts Data Files. Available online: https://data.worldbank.org/indicator/NY.GDP.PCAP.CD?locations=BD (accessed on 16 January 2019). 
50. The World Bank. Global Poverty Working Group. Available online: https://data.worldbank.org/country/ bangladesh (accessed on 16 January 2019).

51. BBS. National Accounts Statistics (Provisional Estimates of GDP, 2017-2018 and Final Estimates of GDP, 2016-2017); Bangladesh Bureau of Statistics: Dhaka, Bangladesh, 2018; pp. 1-88.

52. Kreibich, H.; Di Baldassarre, G.; Vorogushyn, S.; Aerts, J.C.J.H.; Apel, H.; Aronica, G.T.; Arnbjerg-Nielsen, K.; Bouwer, L.M.; Bubeck, P.; Caloiero, T.; et al. Adaptation to flood risk: Results of international paired flood event studies. Earth's Future 2017, 5, 953-965. [CrossRef]

53. Mechler, R.; Bouwer, L.M. Understanding trends and projections of disaster losses and climate change: Is vulnerability the missing link? Clim. Chang. 2015, 133, 23-35. [CrossRef]

54. Opperman, J.J.; Galloway, G.E.; Fargione, J.; Mount, J.F.; Richter, B.D.; Secchi, S. Sustainable Floodplains Through Large-Scale Reconnection to Rivers. Science 2009, 326, 1487-1488. [CrossRef]

55. Cook, B.R.; Lane, S.N. Communities of knowledge: Science and flood management in Bangladesh. Environ. Hazards 2010, 9, 8-25. [CrossRef]

56. Ferdous, M.R.; Di Baldassarre, G.; Brandimarte, L.; Wesselink, A. Exploring the interplay of flood vulnerability and structural protection levels in Bangladesh. Reg. Environ. Chang. under review.

(C) 2019 by the authors. Licensee MDPI, Basel, Switzerland. This article is an open access article distributed under the terms and conditions of the Creative Commons Attribution (CC BY) license (http://creativecommons.org/licenses/by/4.0/). 
Article

\title{
Adaptive Capacities for Diversified Flood Risk Management Strategies: Learning from Pilot Projects
}

\author{
Flavia Simona Cosoveanu *, Jean-Marie Buijs *, Marloes Bakker and Teun Terpstra \\ Department of Technology, Water \& Environment; HZ University of Applied Sciences, Het Groene Woud 1, \\ 4331 NB Middelburg, The Netherlands; m.h.n.bakker@hz.nl (M.B.); t.terpstra@hz.nl (T.T.) \\ * Correspondence: coso0002@hz.nl (F.S.C.); jm.buijs@hz.nl (J.-M.B.)
}

Received: 17 October 2019; Accepted: 10 December 2019; Published: 14 December 2019

\begin{abstract}
Diversification of flood risk management strategies (FRMS) in response to climate change relies on the adaptive capacities of institutions. Although adaptive capacities enable flexibility and adjustment, more empirical research is needed to better grasp the role of adaptive capacities to accommodate expected climate change effects. This paper presents an analytical framework based on the Adaptive Capacity Wheel (ACW) and Triple-loop Learning. The framework is applied to evaluate the adaptive capacities that were missing, employed, and developed throughout the 'Alblasserwaard-Vijfheerenlanden' (The Netherlands) and the 'Wesermarsch' (Germany) pilot projects. Evaluations were performed using questionnaires, interviews, and focus groups. From the 22 capacities of ACW, three capacities were identified important for diversifying the current FRMS; the capacity to develop a greater variety of solutions, continuous access to information about diversified FRMS, and collaborative leadership. Hardly any capacities related to 'learning' and 'governance' were mentioned by the stakeholders. From a further reflection on the data, we inferred that the pilot projects performed single-loop learning (incremental learning: 'are we doing what we do right?'), rather than double-loop learning (reframing: 'are we doing the right things?'). As the development of the framework is part of ongoing research, some directions for improvement are highlighted.
\end{abstract}

Keywords: adaptive capacities; diversified flood risk management strategies; pilot project; governance networks; learning

\section{Introduction}

Climate change will result in increased exposure of low-lying coastal areas to risks associated with sea level rise. Human and ecological systems will be faced with increased saltwater intrusion, flooding, and damage to infrastructure [1]. In response to the increasing risks, EU countries are making efforts to diversify their flood risk management strategies (FRMS) by combining flood risk measures spanning the whole disaster risk management cycle (pro-action, protection, mitigation, preparation, and recovery). This includes dyke reinforcements, compartments, flood proof houses, retention areas, and crisis management [2-5]. The diversification of FRMS has enabled more options for flexibility and adaptability of flood risk management [3]. The potential for diversification of strategies (e.g., emergency plans, zoning of flood prone areas, etc.) in response to climate change depends on the adaptation space and capacity of institutions [6]. Adaptive capacities enable a flexible response, learning, and adjustment by governance networks [7-10]. However, there is a gap of theoretical formulations that connects adaptive capacity and adaptation outcomes [11], such as the role of adaptive capacities to accommodate expected climate change effects [12].

In addition, more empirical research is needed to learn from ongoing attempts to diversify FRMS and investigate how governance challenges are addressed [4]. In particular, a better understanding of the required governance arrangements and how these are formed is lacking [13]. Transforming 
existing or forming new arrangements depends upon a larger variety of skills and capabilities of governance networks [14]. Herein, governance networks are defined as 'the set of conscious steering attempts or strategies of actors within governance networks aimed at influencing interaction processes and/or the characteristics of these networks'. When applying these strategies, actors produce outcomes such as changes or new solutions, policies, or services [15] (p. 11). Working towards these changes/transformations in FRM is typically done in pilot projects which provide an opportunity for experimenting and learning $[16,17]$. Knowledge and experiences acquired from pilot projects are often valuable lessons for upscaling of pilot project results $[16,18]$. Moreover, by learning from new insights and experiences, actors foster their capacities in governance networks to cope with uncertainty and change [14].

This research work attempts to fill these knowledge gaps by analysing the role of adaptive capacities for the development and implementation of diversified FRMS. The study was conducted by analysing the adaptive capacities of governance networks in two pilot projects in The Netherlands and Germany to better understand the required adaptive capacities of governance networks for implementing more diversified FRMS. The two pilot projects in this study are the 'Alblasserwaard-Vijfheerenlanden' located in the downstream area of the river Rhine in The Netherlands, and the 'Wesermarsch' located at the German coast. Both pilot projects are part of the EU Interreg project Flood Resilient Areas by Multi-layered Safety (FRAMES, [19]). Traditionally, both Dutch and German FRM is primarily based on flood protection through dykes and barriers. In addition, both countries are working on further diversification of FRMS by investing in preparedness. This includes the development of evacuation strategies, raising risk awareness, and stimulating preparedness among citizens.

The following sections present the theoretical framework (Section 2), research questions (Section 3), and the methodology for analyzing adaptive capacities (Section 4). Sections 5-7 present the results, the discussion of the outcomes, and the conclusion of this research, respectively.

\section{Theoretical Framework}

The theoretical framework aims to understand and learn from pilot projects regarding capacity development in the transition towards more diversified FRMS. Pilot projects are spaces where learning processes occur $[20,21]$, and new insights arise related to transition dynamics [20]. The theoretical framework is grounded in the Adaptive Capacity Wheel (ACW) [22] and the Triple-loop Learning approach [23].

\subsection{The Adaptive Capacity Wheel}

The ACW is an analytical framework that enables the evaluation of institutions' ability to foster the adaptive capacity of governance networks over time and across scales. It defines six main dimensions divided into 22 adaptive capacities (Table 1). The ACW has been applied to a myriad of water related topics, including climate change [24], droughts and floods [25], sustainability of water governance systems [26,27], and policy content analysis [28] but has not yet been applied to the diversification of FRM.

Previous studies, dealing with adaptive capacities, encountered various challenges rooted in understanding the capacities' definitions [25,28], and weighting can lead to misinterpretations [27]. Because of the downsides encountered by scholars, for this study, the ACW is applied only as a qualitative method, not as a quantitative or measurable approach. 
Table 1. Dimensions and adaptive capacities definitions [22].

\begin{tabular}{|c|c|}
\hline Adaptive Capacities & Definitions \\
\hline \multicolumn{2}{|l|}{ 1. Variety } \\
\hline 1.1 Variety of problem frames & Room for multiple frames of references, opinions, and problem definitions \\
\hline $\begin{array}{l}\text { 1.2 Multi-actor, multi-level, } \\
\text { multi-sector (stakeholders) }\end{array}$ & Involvement of different actors, levels and sectors in the governance process \\
\hline 1.3 Diversity of solutions & Availability of a wide range of different solutions/pathways/actions to tackle a problem \\
\hline 1.4 Redundancy (duplication) & $\begin{array}{l}\text { Presence of overlapping solutions/measures and back-up systems; not cost-effective. } \\
\text { Redundancy in the short-term to promote the best solutions in the long-term }\end{array}$ \\
\hline \multicolumn{2}{|l|}{ 2. Learning Capacity } \\
\hline 2.1 Trust & Presence of authorities patterns that promote mutual respect and trust \\
\hline 2.2 Single-loop learning & Ability of authorities patterns to learn from past experiences and improve their routines \\
\hline 2.3 Double-loop learning & $\begin{array}{l}\text { Evidence of changes in assumptions underlying authorities patterns (re-evaluates and } \\
\text { reframes goals, values, etc.) }\end{array}$ \\
\hline 2.4 Discuss doubts & Authorities openness towards uncertainties (deal with uncertainties) \\
\hline 2.5 Institutional memory & $\begin{array}{l}\text { Authorities provision of monitoring and evaluation processes of pathways/actions } \\
\text { experiences }\end{array}$ \\
\hline \multicolumn{2}{|c|}{ 3. Room for Autonomous Change } \\
\hline $\begin{array}{l}3.1 \text { Continuous access to } \\
\text { information }\end{array}$ & $\begin{array}{l}\text { Accessibility of data within authorities memory and early warning systems to } \\
\text { individuals }\end{array}$ \\
\hline 3.2 Act according to a plan & $\begin{array}{l}\text { Increasing the ability of individuals to act by providing plans and scripts for action, } \\
\text { especially in case of disasters }\end{array}$ \\
\hline 3.3 Capacity to improvise & Increasing the capacity of individuals to self-organize and innovate; foster social capital \\
\hline \multicolumn{2}{|l|}{ 4. Leadership } \\
\hline 4.1 Visionary & Room for long-term visions and reformist leaders \\
\hline 4.2 Entrepreneurial & Room for leaders that stimulate actions and undertakings; leadership by example \\
\hline 4.3 Collaborative & $\begin{array}{l}\text { Room for leaders who encourage collaboration between different actors; adaptive } \\
\text { co-management }\end{array}$ \\
\hline \multicolumn{2}{|l|}{ 5. Resource } \\
\hline 5.1 Authority & $\begin{array}{l}\text { Provision of accepted or legitimate forms of power; whether or not authorities } \\
\text { rules/procedures are embedded in constitutional laws }\end{array}$ \\
\hline 5.2 Human resources & Availability of expertise, knowledge and human labour \\
\hline 5.3 Financial resources & Availability of financial resources to support measures and financial incentives \\
\hline \multicolumn{2}{|l|}{ 6. Fair Governance } \\
\hline 6.1 Legitimacy & Whether there is public support for a specific authority \\
\hline 6.2 Equity & Whether or not authorities rules/procedures are fair \\
\hline 6.3 Responsiveness & Whether or not authorities patterns show response to society \\
\hline 6.3 Accountability & Whether or not authorities patterns provide accountability procedures \\
\hline
\end{tabular}

\subsection{Learning Loops}

Pahl-Wostl [23] argues that social learning is essential for developing and sustaining the capacity of different authorities, experts, interest groups, and the public to manage water resources effectively and translate goals into actions. Social learning occurs through interactions between actors within social networks [29]. Learning can be seen as a feedback process consisting of three iterative learning loops. Single-loop learning refers to improving the performance of established routines, i.e., are we doing what we do right? [23], for example, should the dyke height be increased by 10 or $20 \mathrm{~cm}$ ? [30]. Double-loop learning reframes the goal, the problem and assumptions (e.g., about cause-effect relationships) within a value-normative framework, i.e., are we doing the right things? For example, what strategies might facilitate more effective future transboundary flood management? Or how should vulnerability to other climate change impacts be included in FRM? [30]. Learning outcomes include, for example, changes in the organization's knowledge base, new objectives, or new policy frames [31]. Triple-loop learning refers to a transformation of the structural context and factors that determine the frame of reference and reconsiders underlying values, beliefs, and world views [23], i.e., how do we decide what is right, for example, should resources be allocated toward protecting the existing built environment, or should these assets be relocated or abandoned once certain risk thresholds are crossed? [30]. Learning outcomes 
include changes to defining principles—-for example, underlying governance protocols and structures or new learning strategies [32].

The learning process can also be linked to pilot projects and their outcomes in relation to diversification of FRMS. Change in water governance is conceptualized as a stepwise approach from single to double and to triple-loop learning. It can be explained as a feedback loop between the expected outcomes within a specific governance context and considering the structural changes, which result in an iterative cycle (Figure 1). In this cycle, triple-loop learning is directly related to transformations, while single- and double-loop learning play an indirect role in these processes. Although social learning is key to learn from and support changes/transformations in water governance, empirical evidence is lacking [33]. More empirical research is needed that addresses the underlying triggers of double- and triple-loop learning processes and links them to broader governance mechanisms and structures [34].

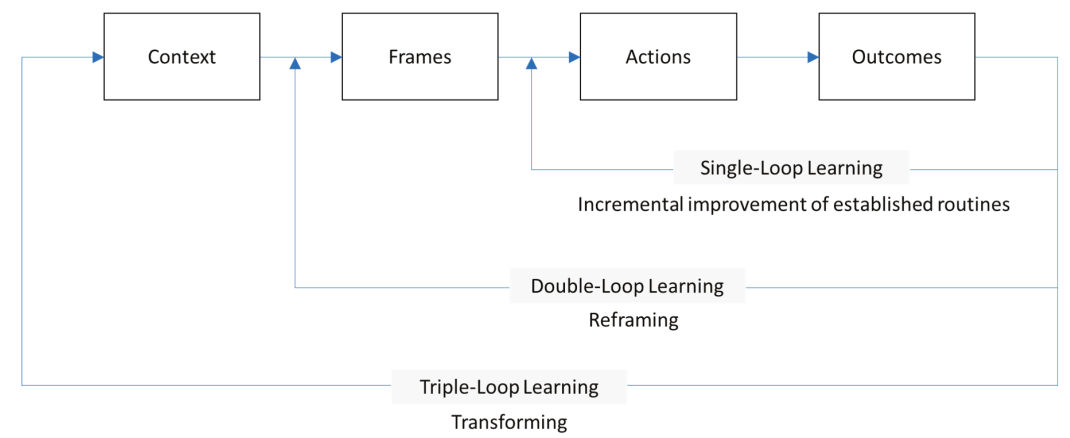

Figure 1. The concept of triple-loop learning applied to governance regimes [23].

\subsection{Evaluating Adaptive Capacities and Learning Processes in Pilot Projects}

In order to assess adaptive capacities and learning, the concepts of the ACW and the three loops of learning are combined in one analytical framework (Figure 2). Herewith, the framework aims to identify and analyze the adaptive capacities of governance networks and their importance for developing more diversified FRMS. Based on the Dynamic Adaptive Policy Pathways approach [35,36], six relevant steps for pilot projects were identified as part of adaptive planning processes. These steps are further divided into the situation before, during, and after the pilot projects. New diversified strategies, which include new actors, institutions, policies, and other aspects, require new knowledge, types of collaboration, and other capacities. Therefore, the goal is to understand how the concept of adaptive capacities supports the identification of requirements for diversified FRMS.

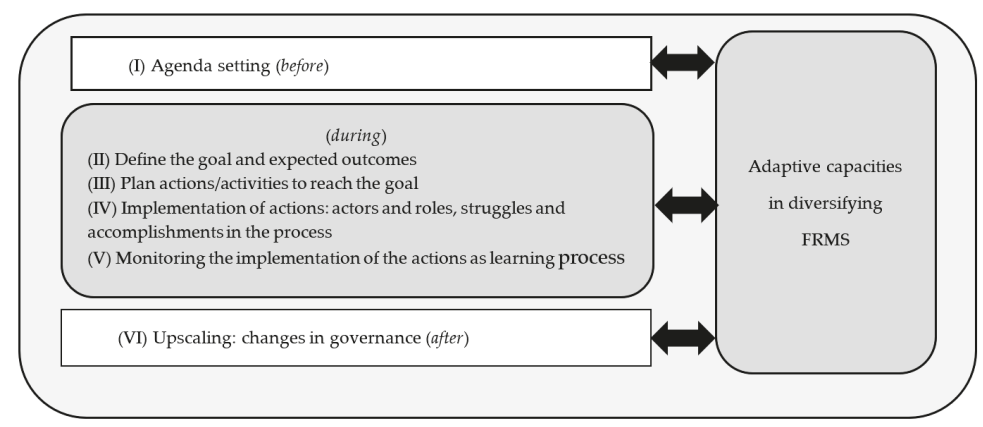

Figure 2. Framework for the analysis of adaptive capacities in pilot projects. 
'Before' refers to the current FRMS as a result of the historical co-evolution of FRMS at the national and/or regional level within a specific governance setting [36]. It is important to have insight into this situation to understand the pilot outcomes within a specific governance context. Adaptive capacities that result in improvements of actions in the current strategy are considered as single-loop learning and have no direct effect on diversification of the current FRMS. 'During' refers to the implementation of actions during the pilot project and learnings from this implementation process. Employed adaptive capacities in this process can result both in single-loop learning and double-loop learning. The key question is whether developed adaptive capacities result in improvement and/or reframing of the FRMS. 'After' refers to outcomes of the pilot projects and upscaling of outcomes in order to change or transform the FRMS. Developed adaptive capacities lead to new frames (double-loop) or lock-in of the current strategy, with or without improvements of current actions (single-loop).

\section{Research Questions}

The main research question of this paper is: Which adaptive capacities support the learning process in pilot projects to achieve diversification of FRMS? The following three sub-questions are addressed:

(a) Which adaptive capacities were determined to be missing before the pilot project?

(b) Which adaptive capacities are employed during the pilot project?

(c) Which adaptive capacities are developed as a result of the pilot project?

Missing capacities refer to capacities that are not present, or present but not applied in the governance network of the pilot project. Employed capacities refer to the capacities present and applied throughout the pilot project. Developed capacities refer to the capacities improved or emerged in the governance network as a result of the pilot project.

\section{Materials and Methods}

Data were collected as part of the Interreg FRAMES project [19] comprising 16 FRM pilot projects in five countries: Belgium, Denmark, England, Germany, and The Netherlands. Pilot projects varied substantially in terms of their content (e.g., risk analyses of critical infrastructure, implementation of nature-based solutions, increasing community resilience, see Table A1 in the Appendix A). For the purpose of comparison, two pilot projects with a similar focus were selected. In order to gain a broad understanding of the context and focus, both pilots were visited and explained by the involved stakeholders (Figure 1). During the pilot project, empirical data were collected through questionnaires, focus groups, and semi-structured interviews.

The questionnaires provided the initial and the expected state of flood resilience before and after the pilot project, respectively. Interviews were conducted with the pilot managers to get a more in-depth understanding of the specific lacking, employed, and developed capacities in the pilot projects. The transnational focus groups (TFG) were organized to gain insight into the most needed adaptive capacities for flood mitigation and flood preparedness actions in the pilot projects. Additionally, this data was complemented additional information from FRAMES project meetings and documents to make the finding more robust.

\subsection{Pilot Projects}

Two pilot projects were selected as case studies: the 'Alblasserwaard-Vijfheerenlanden' in The Netherlands and the 'Wesermarsch' in Germany. These two cases were selected from a total of 16 pilot projects in the FRAMES project (see Appendix A for an overview of pilots and selection). These pilot projects were selected because flood risk governance is comparable in both countries (Table 2). In both countries, defence/protection strategies are dominant but are also looking into more integrated strategies: Multi-layered safety [37] in the Netherlands and the LAWA approach in Germany [38]. This is part of a paradigm shift from a safety to risk-based approach [39-42]. Traditionally, responsibilities 
in Dutch flood control are divided between the centralised Rijkswaterstaat and decentralised water boards [43]. Local actors are involved only when traditional defence approaches are not feasible anymore. In Germany, the federal states (Länder) have the main responsibility for all water issues and civil protection [44]. Actors from spatial planning play an important role in zoning plans or mitigation and flood risk management strategies in Germany [40]. However, the use of spatial planning instruments has increased in The Netherlands, as well as within flood risk management [43]. As part of developing the risk-based approach, both pilot projects aim to enhance the integration of mitigation and preparedness measures, including the development of evacuation strategies, raising risk awareness, and stimulating preparedness among citizens.

Table 2. Flood risk governance in countries of the selected pilot projects. Based on [43].

\begin{tabular}{ccc}
\hline Characteristics of Governance & The Netherlands & Germany \\
\hline Diversification and dominance & $\begin{array}{c}\text { Low diversification, } \\
\text { defence dominant }\end{array}$ & Moderate diversified, focus on defence \\
\hline Multi-sector & Water sector dominant & $\begin{array}{c}\text { Multi-sector involvement and integrated } \\
\text { by spatial planning }\end{array}$ \\
\hline Multi-actor & Public (state dominant) & Public (state and federal states) dominant \\
\hline Multi-level & Both central and regional level & $\begin{array}{c}\text { Central guidance and decentralization to } \\
\text { federal state and local level }\end{array}$ \\
\hline
\end{tabular}

\subsection{Questionnaire}

For each pilot project, a questionnaire (Appendix B) was completed by the pilot managers together with local relevant stakeholders. The pilot managers selected key stakeholders of their pilot project. In Alblasserwaard, the questionnaire was filled by four relevant stakeholders and in Wesermarsch, it was filled by seven local stakeholders (see Table A2, Appendix B). The actors filled out the questionnaire by organization prior to the start of the pilot project (October 2017) to identify the current (i.e., before the pilot) and the expected future (i.e., after the pilot project) level of diversification in the FRMS, and the perceived current and future level of flood resilience among authorities and communities. Closed questions were presented on rating scales 1 (not at all) to 10 (to a great extent). Open questions were asked to explain the indicated ratings. Finally, the answers to the open questions were aggregated, and scores to the closed questions were averaged.

Diversification. Using the disaster management cycle-pro-action (1), protection (2), mitigation (3), preparation (4), recovery (5)—stakeholders were asked 'To what extent is (...) a strong characteristic of the pilot area?' on a 1-10 rating scale. This question was asked for the current situation (i.e., before the pilot project) with respect to the main pillars of FRMS in The Netherlands and Germany; i.e., for pro-action (1) and protection (2). For the diversifying elements mitigation (3), preparation (4) and recovery (5), stakeholders answered this question both, for the current and the expected situation, after the pilot project. In total, stakeholders responded to eight items. This information was used to qualitatively estimate the ambitions of authorities in diversifying FRMS. Open questions were used to further tap into these ambitions for elements $3-5$ by asking 'What will be done in the pilot with regard to ( ... ) that improves the (a) 'physical resilience in the pilot area?', (b) 'capacities of local organisations/institutions in the pilot area?', and (c) 'capacities of local communities (citizens, businesses) in the pilot area?'

Resilience of authorities and communities. Stakeholders were asked to name the institutions and citizen groups that would be involved in and/or informed about the pilot project. Subsequently, stakeholders were asked to respond to the items: 'In general, to what extent is ( . . ) embedded in policy and practice of these organisations, in your opinion?' and 'In general, to what extent is ( ... ) embedded in the behaviour of these communities, in your opinion?' Both items were presented on a 1-10 rating scale. These items were presented separately for mitigation (3), preparation (4), and recovery (5), and in 
the situation before the pilot project and the expected situation after the pilot project. Thus, overall stakeholders responded to twelve items. For each item, a written clarification was requested.

\subsection{Interviews}

Based on the theoretical framework, a comprehensive interview guideline (Appendix C) was developed and validated by the four involved knowledge institutes. The definitions of the adaptive capacities (Table 1) were integrated into an interview guideline through open questions to gain detailed insight into the opinions and arguments, but also to avoid social desirability bias. Interviewees were asked to reflect on past and current FRMS in the pilot project, any struggles encountered, the main accomplishments, the role of actors involved, and how these factors could contribute to mainstream the pilot project outcomes into the governance regime. All pilot managers were interviewed, and two interviews were used for the selected pilot projects (i.e., Alblasserwaard-Vijfheerenlanden, 28 February 2019; and Wesermarsch, 23 January 2019). The interviews were transcribed and checked by the pilot managers. Data analysis was performed using systematic coloured coding [45] to determine the adaptive capacities that were lacking, employed, and developed before, during, and after the pilot project. In order to facilitate data analysis, colours were assigned to each dimension of the ACW, and the criterions or adaptive capacities were numbered (see Table 1) to differentiate these in the interviews' transcripts and in the Results section. The results are presented in narratives to provide detailed storylines of the case studies [46]. The narratives of both pilot projects were reviewed by the pilot managers.

\subsection{Transnational Focus Groups}

Three transnational focus groups (TFG) were organized to gain insight into adaptive capacities before, during, and after the pilot projects and their relation to FRMS. This was done in parallel with the interviews of the pilot managers. Each TFG focused on a different FRM action (Table A3, Appendix D), that was typical for mitigation (via spatial planning), preparedness (integrating emergency response in FRM), and community resilience to address the actions by inhabitants in relation to mitigation, preparedness, and recovery. Each group was requested to select and discuss the five most relevant adaptive capacities (Table 1) needed for a specific action in an FRMS.

The three TFG were organized on 27 March 2019 in Oldenburg (Germany) and included 32 participants from five countries, representing (mainly regional) authorities with responsibilities in water management, spatial planning, crisis management, and community resilience. In order to facilitate transnational learning, each TFG consisted of participants from the 16 pilot projects and countries (Appendix D). Each group was moderated by an author of this paper.

\subsection{Additional Information}

In addition to the interviews held with pilot managers, presentations by other stakeholders of the pilot projects were attended during visits to the pilot projects (Alblasserwaard-Vijfheerenlanden, 22 February 2019; Wesermarsch, 28-29 March 2019). The presentations and discussions provided more background and insights into the role that these actors played in the pilot projects and FRMS.

\section{Results}

\subsection{Diversification of FRMS in Two Pilot Projects}

Both pilot projects are located in low lying areas that are exposed to flood risks. Results from both questionnaires (Table 3) confirm that current FRMS lean on flood protection by dykes. Protection levels are regarded as 'high', but further enforcements are required to meet the legal flood protection standards. Flood preparedness can be regarded as the second pillar in the current situation as it has been embedded already in current policy and practice of crisis management authorities. However, both pilot projects aimed to make small improvements in flood preparedness. Mitigation is less developed, 
and both pilot projects aimed for improvement. Recovery is least developed and is not particularly focused on in the pilot projects.

To achieve the improvements in mitigation and preparedness among authorities, the Dutch pilot project expected that stronger involvement of local authorities would increase awareness and lead to improvements in spatial planning (mitigation) and better evacuation plans (preparedness). Currently, stakeholders rely strongly on protection measures, increasing their knowledge and awareness will take time. Likewise, embedding flood risk mitigation and preparedness in current policies and practices also requires long term planning. Similarly, the German pilot project focused on increased involvement of actors and cooperation aiming to improve the incorporation of flood risk in regional planning (mitigation) and to improve contingency planning by reviewing plans collectively (preparedness).

In order to improve mitigation, especially preparedness among communities, both pilot projects focused on providing better information about the warning systems and increasing their knowledge and awareness.

Table 3. Perceived diversification of risk management strategies (FRMS) before and expected after the pilot projects. Scores on scale 1-10 (* left number refers to before and right number after the pilot project).

\begin{tabular}{|c|c|c|c|c|c|c|}
\hline Pilot & Aspects of Embeddedness of FRMS & $\begin{array}{l}\text { Pro-Action } \\
\text { (1) }\end{array}$ & $\begin{array}{l}\text { Protection } \\
\text { (2) }\end{array}$ & $\begin{array}{l}\text { Mitigation } \\
\text { (3) }\end{array}$ & $\begin{array}{c}\text { Preparation } \\
\text { (4) }\end{array}$ & $\begin{array}{c}\text { Recovery } \\
\text { (5) }\end{array}$ \\
\hline \multirow{3}{*}{$\begin{array}{c}\text { Alblasserwaard } \\
\text { NL }\end{array}$} & \multirow{3}{*}{$\begin{array}{c}\text { Strong characteristic of area } \\
\text { Embedded in policy and practice of } \\
\text { authorities } \\
\text { Embedded in the behaviour of } \\
\text { communities }\end{array}$} & \multirow[t]{3}{*}{5} & \multirow[t]{3}{*}{10} & $4-5 *$ & $7-6$ & $2-2$ \\
\hline & & & & $5-4$ & $8-7$ & $3-2$ \\
\hline & & & & $5-4$ & $7-6$ & $2-2$ \\
\hline \multirow{3}{*}{ Wesermarsch GE } & \multirow{3}{*}{$\begin{array}{c}\text { Strong characteristic of area } \\
\text { Embedded in policy and practice of } \\
\text { authorities } \\
\text { Embedded in the behaviour of } \\
\text { communities }\end{array}$} & \multirow[t]{3}{*}{3} & \multirow[t]{3}{*}{8} & $5-3$ & $8-7$ & $1-1$ \\
\hline & & & & $6-5$ & $7-6$ & $1-1$ \\
\hline & & & & $4-3$ & $7-6$ & $1-1$ \\
\hline
\end{tabular}

\subsection{Lacking, Employed, and Developed Adaptive Capacities in Both Pilot Projects}

Table 4 summarizes the main characteristics of both pilot projects. Neither of the pilot projects had upscaling as its objective, but through interviews, several capacities needed for upscaling were identified that were not present.

Table 4. Main characteristics of both pilots.

\begin{tabular}{|c|c|c|}
\hline Characteristic & Alblasserwaard-Vijfheerenlanden & Wesermarsch \\
\hline \multirow{3}{*}{ Goal of the pilot } & $\begin{array}{l}\text { Mitigation: combine evacuation with } \\
\text { spatial planning }\end{array}$ & $\begin{array}{l}\text { Mitigation: improve spatial database use for } \\
\text { crisis management }\end{array}$ \\
\hline & $\begin{array}{l}\text { Preparedness: improve emergency } \\
\text { management (risk maps, evacuation routes, } \\
\text { etc.), investigate social capital for emergency } \\
\text { evacuation, improve collaboration between } \\
\text { water and crisis management authorities }\end{array}$ & $\begin{array}{l}\text { Preparedness: improve emergency planning, } \\
\text { provide access to citizens about self-preparedness } \\
\text { in case of flooding, improve collaboration between } \\
\text { water and crisis management authorities }\end{array}$ \\
\hline & $\begin{array}{l}\text { Recovery: no direct actions but increase in } \\
\text { flood risk awareness will decrease recovery } \\
\text { actions }\end{array}$ & $\begin{array}{l}\text { Recovery: no direct actions but increase in flood } \\
\text { risk awareness will decrease recovery actions }\end{array}$ \\
\hline Lead Organization & Province of Zuid Holland & Jade University of Applied Sciences \\
\hline \multirow{2}{*}{ Main actors involved } & Ministry of defence & $\begin{array}{l}\text { NLWKN: State Agency on water management, } \\
\text { coastal protection and nature conservation }\end{array}$ \\
\hline & Rijkswaterstaat & $\begin{array}{l}\text { Aid organisations: German Red Cross, } \\
\text { Technisches Hilfswerk, Federal Armed Forces, } \\
\text { Police, German Lifeguard Association }\end{array}$ \\
\hline
\end{tabular}


Table 4. Cont.

\begin{tabular}{lll}
\hline \multicolumn{1}{c}{ Characteristic } & \multicolumn{1}{c}{ Alblasserwaard-Vijfheerenlanden } & \multicolumn{1}{c}{ Wesermarsch } \\
\hline & Safety Region & $\begin{array}{l}\text { Drinking water company } \\
\text { (Oldenburgisch-Ostfriesischer Wasserverband) }\end{array}$ \\
\cline { 2 - 3 } & Water board & Regional power supplier (Energieversorger Weser) \\
\cline { 2 - 3 } 3 Local municipalities & Wesermarsch County \\
\cline { 2 - 3 } & Drinking water company & Municipality of Butjadingen \\
\cline { 2 - 3 } & Local businesses & $\begin{array}{l}\text { Local groups: farmers' association and veterinary } \\
\text { group }\end{array}$ \\
\cline { 2 - 3 } & & 6 water boards and 2 dyke boards \\
\cline { 2 - 3 } & & LAVES: State Agency for food security \\
\hline Timeline of the project & $2016-2019$ & 2016-2019 \\
\hline
\end{tabular}

\subsubsection{Case Study 1: Alblasserwaard-Vijfheerenlanden Pilot Project}

The goal of this pilot project was to achieve more diversified FRMS by linking spatial planning and emergency management. The main characteristics of the pilot project, the pilot goal, the leading organization, the actors involved, and the duration of the project can be found in Table 4 . The specific actions of this pilot project were to ensure that dyke roads are suitable for emergency vehicles, to build social capacity for evacuation involving local groups, and to improve evacuation management plans in case of flooding.

The pilot project faced a number of difficulties during set-up, that were identified as 'lacking capacities before the pilot project' (Table 5, indicated with - in column 'before'). The pilot manager determined that there was a lack of variety in FRM solutions (1.3) in the Alblasserwaard area because the FRMS rely mainly on protection. The second difficulty encountered was that local mayors had a lack of information about the diversification of FRMS. They thought that FRM beyond hard infrastructure was not possible or limited (e.g., existing evacuation plans are not clear). Moreover, there was low social capital (3.3) because there were not enough volunteers to improve preparedness and heavy reliance on governmental flood protection. The third issue was a lack of collaboration (4.3) between crisis and water management authorities. For example, prior to this pilot project, the safety region, water board, and local municipalities did not collaborate on integrated flood risk management projects (combining evacuation and spatial development). The fourth difficulty was limited human resources. Local municipalities have limited staff (5.2), and sometimes, one person is responsible not only for FRM but many other subjects.

In order to define the goal of the pilot project and implement the planned activities, multiple capacities were employed during the pilot project (Table 5, indicated with + in column 'during'). The implementation of diversified FRMS required the involvement of multiple actors (1.2) from a variety of levels and sectors (the safety region, the province, the water board, and municipalities) at an early stage of the pilot project. They met regularly to discuss problems and needs (1.1) related to the current FRMS and together came up with a diversity of solutions (1.3). For example, one of the problems was that emergency vehicles might not be able to use the dyke roads during evacuation because the water board needs it for equipment or because of the risk dyke failure due to instability under extreme conditions. Based on the discussions among the actors involved, the agreement was to align their needs in case of future dyke reinforcements integrating protection, infrastructure planning, and emergency response. The actors involved gathered in regular project meetings to define the (long term) goals (4.1) and specific objectives of the pilot project. The pilot manager highlighted that collaboration (4.3) was positive during the pilot project, and early collaboration started with existing initiatives in the area. Problems, needs, solutions, and next steps were discussed (2.4) with the actors. As a result, learning from the past and the current actions in FRMS (2.2) during the pilot project is an essential capacity. Moreover, pilot projects offer a higher availability of resources when human capacity (5.2) and finances (5.3) are combined to experiment with innovative solutions in FRM. For example, the safety region had the human capacity for modelling the evacuation routes while the province had the financial resources for it. 
Table 5. Adaptive capacities before, during, and after the pilot projects and their perceived relevance for FRMS.

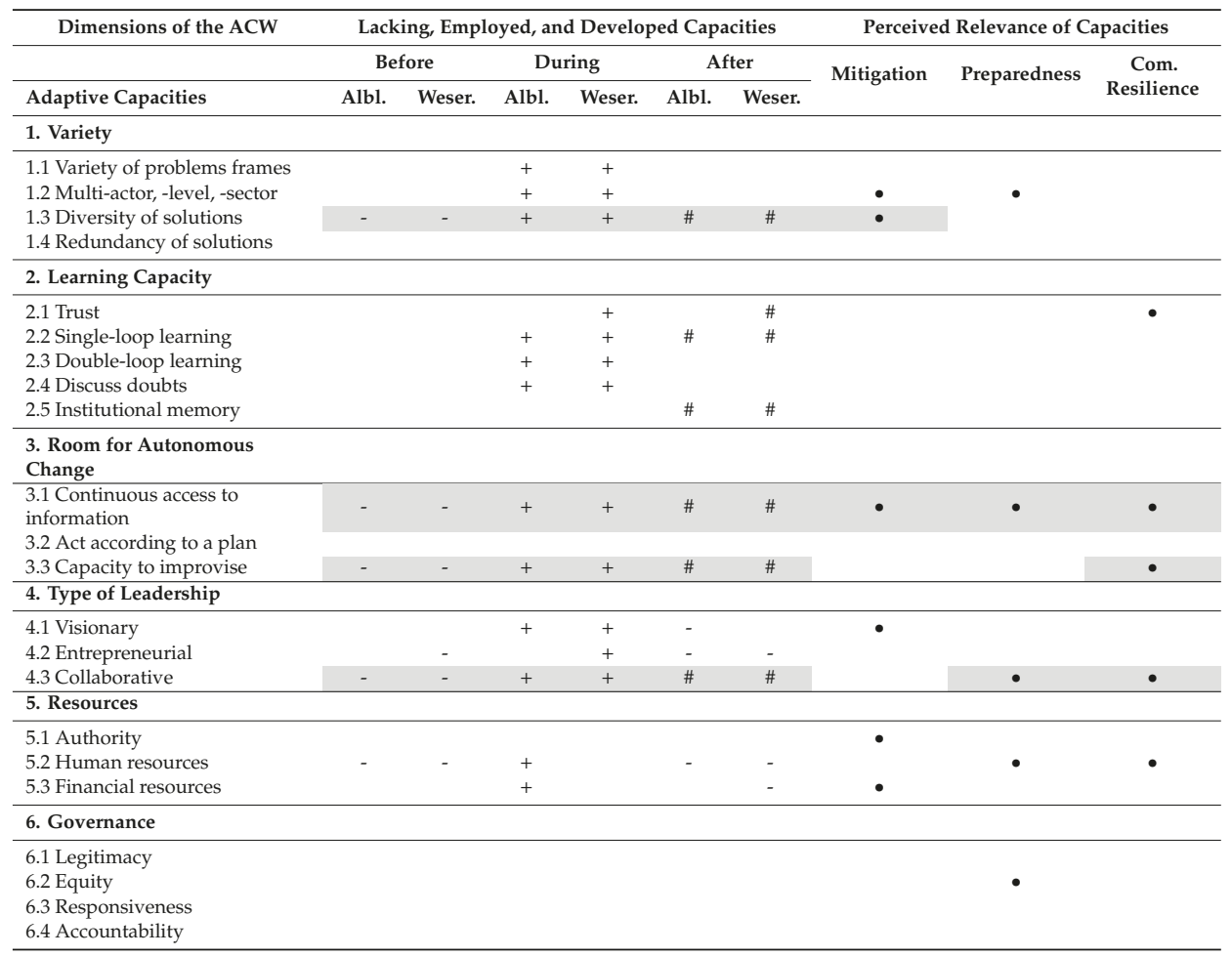

Albl. = Alblasserwaard pilot project, Weser. $=$ Wesermarschpilot project. - refers to lacking capacities; + refers to employed capacities; \# refers to developed capacities; $\bullet$ refers to 5 most important adaptive capacities selected by the transnational focus groups (TFG). The grey colour reflects the lacking capacities before but developed as a result of the pilot projects, which were also emphasized as important capacities by the TFG.

Based on the pilot project outcomes, several capacities were developed (Table 5, indicated with \# in the column 'after'). The first and the most important developed capacity was that more innovative solutions were applied in the pilot project to diversify the FRMS (1.3) by combining evacuation with spatial development. The second capacity that was developed as a result of the pilot project is the collaboration between actors (4.3) with respect to crisis management improved. For example, actors (from the Safety Region, the water board, and municipalities) who did not collaborate on this subject prior to this pilot project, currently they understand the significance of linking evacuation and spatial planning in relation to FRM. A relevant outcome of this pilot project is providing more detailed information (3.1) about the applicability of diversified FRMS in the area and making it accessible for everyone. For example, when this information was provided to the municipalities, they expressed more interest to participate in the project. Thus, sharing information resulted in capacity building (3.3) and awareness of the role of citizens and local authorities in evacuation management. Another developed capacity is the learning from pilot projects when actors share knowledge and learn from each other. For instance, during a meeting with local entrepreneurs, it became clear that several local entrepreneurs had already taken actions to protect themselves against floods in the current FRMS (2.2). Moreover, at the end of the pilot project, the lead authority provided a final report that included pilot project results and policy recommendations. This was an evidence-based document (2.5) that can be used by other actors to replicate the pilot project. 
Finally, two capacities were identified as 'lacking capacities for upscaling of the pilot project' (Table 5, indicated with - in column 'after'). On the one hand, the pilot manager pinpointed that visionary leadership (4.1) is required in the process of diversification of FRMS. However, this can be hampered, for example, by a change of government representatives every four years. Likewise, it is not clear who takes the lead (4.2) to adapt or change current policies based on the pilot project outcomes. On the other hand, human resources (5.2) are lacking because generally, governments do not have enough human capacity to cooperate in projects related to the diversification of FRMS.

\subsubsection{Case Study 2: Wesermarsch Pilot Project}

The goal of the Wesermarsch pilot project was to develop a more balanced FRMS, taking actions in spatial planning (mitigation) and emergency management (preparedness). The main characteristics of the pilot project, the goal of the pilot project, the leading authority, the actors involved, and the duration of the project are described in Table 4. The actions of the pilot project are to develop informative products (brochure for both individual farmers preparedness), to improve the current database with flood risk maps, to develop an app to organize volunteers during a disaster, and to organize a 'flood risk awareness day' and a 'flood partnership event'.

'Lacking capacities before the pilot project' were identified by using data from a previous EU project [47], and the outcomes of interviews conducted by Jade University (Table 5, indicated with - in column 'before'). Traditionally, the main focus in the Wesermarsch is on flood protection through hard infrastructure and far less on flood mitigation through spatial planning, and preparation and recovery from a flood event. Therefore, it was determined that there were insufficient varieties of solutions (1.3) in FRMS. Moreover, when the EU previous project ended [47], the communication and further actions between the actors involved (water management actors) also stopped. However, generally in Germany, there is a shortage of collaboration (4.3) among authorities responsible for diverse aspects of the current FRMS. Likewise, there are no local groups who take the lead (4.2) to prepare volunteers in case of an evacuation. Furthermore, it was also identified that citizens had limited access to information (3.1) about flood risk preparedness and thus, they had a low social capital (3.3) in order to prepare themselves in case of flooding. An additionally lacking capacity was an unsuitable procedure (5.2) for the use of spatial databases (e.g., elevation maps, evacuation routes, etc.) to improve decision making for spatial planning at a local level.

During the pilot project, different capacities were employed (Table 5, indicated with + in the column 'after'). First, the pilot manager involved multiples actors (1.2) in the pilot process (local and regional actors from disaster, water, flood risk management, and aid organizations, see Table 4). The actors met and discussed the diversification of FRM problems (1.1) to provide diverse solutions (1.3) for these problems. For example, flood risk maps used for evacuation exercises did not consider the topography behind the dyke, and no local group existed to organize volunteers in case of a disaster intervention. Secondly, leadership was promoted through the implementation process of the pilot project. Regional fora were organized (4.3) where key actors discussed problems and solutions. Afterwards, a priority list of activities with a long term vision (4.1) was made. Six activities were selected, and voluntarily actors took the lead (4.2) to implement them. Thirdly, the previous project [47] in the area was utilized as a learning example (2.2) to find out what did or did not work in the past and why. Likewise, the actors' discussions about undefined challenges (2.4) also contributed to the learning process.

As a result of the pilot project, multiple capacities were developed (Table 5, indicated with \# in the column 'after'). The pilot outcomes resulted in a diversity of solutions (1.3) for FRM in the Wesermarsch area. For example, increased self-preparedness of local citizens and an improved spatial database for spatial emergency management planning. The development of informative products, regional fora to exchange information, and experiences resulted in diversified FRMS. Therefore, making information more accessible (3.1) for citizens leads to improved flood risk awareness and social capital (3.3). On top of that, the collaboration (4.3) between local and regional actors from disaster and water management 
authorities was enhanced. As a result of the collaborative capacity, the pilot manager observed an increase of trust (2.1) and improved communication about diverse FRMS. In addition, the pilot results showed improvements in preparedness (2.2) due to the actions taken. For example, farmers and other inhabitants are better informed about FRM and evacuation planning; flood risk maps at the local level are improved, and these will be used by the German state agency to support emergency planning decisions. The pilot project actions and outcomes are publicly accessible on paper and online (database, reports, flyers). This evidence base (2.5) can be used to learn from this pilot project and replicate it.

The interview with the pilot project manager revealed two capacities that were identified as 'lacking capacities for upscaling of the pilot project' (Table 5, indicated with - in column 'before'). The first one is the lack of entrepreneurial leadership because the leading authority of this pilot project has no formal responsibilities in FRM. Moreover, none of the other organizations involved have shown the initiative to take on responsibilities (4.2) regarding upscaling. The second lacking capacity is insufficient human (5.2) and financial (5.3) resources to update the developed pilot project outcomes when needed by the responsible authorities.

\subsection{Perceived Importance of Adaptive Capacities in Diversifying FRMS}

Three TFG focused on a different type of strategy to diversify the current FRMS, and each TFG selected five adaptive capacities that were evaluated as having the highest relevance for implementing these strategies. TFG1 focused on mitigation, TFG2 on preparedness, and TFG3 on emergency response. Table 5 presents an overview of the capacities that were linked to specific strategies.

The TFG1 (mitigation) focused on spatial zoning in flood prone areas to mitigate flood risk. Visionary long-term planning (4.1) was highlighted as having a high relevance. All pilot projects in FRAMES face long term challenges considering flood risk and other climate related issues. The TFG stressed that sharing information (3.1) about future projects between spatial planners and water managers is needed. Stakeholders perceived that the attention for long term goals is hampered by short term gain, and often, economic benefits on the short term prevail. Authority by law via procedures (5.1) and financial resources (5.3) were seen as important resources to arrange mitigation measures. In addition, they stressed the need for a variety of stakeholders (1.2) who provide a diversity of solutions (1.3).

TFG2 (preparedness) looked into flood preparedness by integrating emergency response planning in flood risk management. The group indicated that available human resources (5.2) are key adaptive capacities. There is a need for specialized staff that has the expertise to perform an impact assessment of flooding to aid preparedness and emergency response. Moreover, equity (6.2) is considered important in flood preparedness. Different societal groups have different needs in case of emergency, for example, less self-reliant (elderly, disabled) people depend on the assistance of authorities. This focus group also highlighted that emergency response could be supported by spatial planning measures, for instance, by building public shelters and safe evacuation roads. A diversity of actors (1.2) responsible for spatial planning and crisis management should collaborate (4.3) and share information (3.1) about their current policies and projects.

TFG3 (community resilience) focused in more detail on empowering communities to take action for local flood mitigation and response measures. The TFG emphasized it is important to encourage collaboration (4.3) and build trust (2.1) between responsible authorities and communities. Stronger collaboration capacity contributes to higher availability volunteers (5.2) in emergency preparedness. The capacity to provide relevant stakeholders with access to information (3.1) about mitigation and preparedness measures for communities appears to be an important issue. Raising awareness about the measures that communities can take by themselves fosters social capital (3.3).

\section{Discussion}

This paper aimed to identify the adaptive capacities that support the learning process in pilot projects to achieve a diversification of FRMS. Through questionnaires, focus groups, and interviews, we 
focused on the adaptive capacities that were lacking, employed and developed before, during, and after two pilot projects in the Netherlands and Germany. The results showed that in both pilot projects, the current FRMS leans traditionally on flood protection, with flood preparedness as a secondary pillar. Flood mitigation, but especially recovery strategies, were hardly present. The learning process in both pilot projects focused on strengthening flood preparedness and mitigation, for instance, by involving new stakeholders, sharing knowledge, reviewing contingency plans, and by providing information to citizens to increase knowledge and awareness.

We found three adaptive capacities that were stressed as important for developing more diversified FRMS and that were also lacking before but had developed as a result of the pilot projects. First, a greater 'diversity of solutions' was regarded as important, especially for developing flood mitigation strategies but not for flood preparedness and community resilience. The reason for this is that flood mitigation is currently underdeveloped and requires a balanced mix of cost-effective spatial planning actions. Finding cost-effective spatial planning measures is difficult since flood defences act as a 'front door' which make any investments in the area behind this front door redundant [48,49]. In the current frame of FRM, clear added benefits first need to be identified to gain political support for these investments, which seems difficult. Increased opportunities for integrating spatial planning in FRMS, therefore, requires reframing of current FRM policy and practice. In the Netherlands, such reframing has partly taken place with the adoption of the multi-layered safety concept (protection, spatial planning, crisis management) in FRM policy [50]. However, because the basic question 'are we doing what we do right?' (single-loop learning) has not changed to 'are we doing the right things?' (double-loop learning). Pilot projects have not succeeded in putting more diversified FRMS into practice $[16,48]$. For instance, there is currently little urgency to consider the meaning of a wider set of challenges originating from long term processes such as soil subsidence and sea level rise [51]. Since such challenges are not yet fully incorporated into the current FRMS, also at the level of pilot projects they are hardly considered. Reframing the problems and goals of FRM, therefore, requires the inclusion of a 'variety of perspectives over problems/needs' beyond FRM. The processes that steer this type of fundamental reframing require learning and governance capacities, which were not prioritized as important capacities in the pilot projects due to the incremental improvements (single-loop learning) that were aimed for.

Second, to create room for autonomous change, authorities and communities require greater access to information. Although this may sound obvious, the challenge is in making the right information accessible for the different stakeholder groups. Information preferences may differ substantially between actors in terms of information type, detail, and ways of receiving information (e.g., channel, format), for instance, a step-by-step checklist for farmers to prepare themselves and their livestock (Wesermarsch) and how entrepreneurs can protect their businesses (Alblasserwaard-Vijfheerenlanden) in case of flooding. Making the information on emergency planning available for the actors resulted in enhanced mutual understanding of interests, actions, and information needs.

Third, type of leadership was regarded as an important antecedent of diversifying FRMS. Actors agreed that collaborative leadership, encouraging the collaboration among actors, is currently needed to further develop preparedness and community resilience. The literature supports that collaborative networks are essential for performing adaptive management [52,53]. Alignment across sectoral boundaries is key in governance arrangements for adapting to climate change [54], which is also observed in both cases. Boundary spanning interactions, including cherishing boundaries for clear allocation of responsibilities [55], is required for collective action in diversifying FRMS. Since mitigation strategies are underdeveloped and complex, visionary leadership seemed more important for developing cost-effective spatial planning strategies. These strategies were employed during the pilot projects; however, the capacity to develop 'long term goals and strategies' did not result from the pilot projects. This aligns with their focus on incremental improvements.

Furthermore, the adaptive capacity dimension 'resources' received some importance ratings for diversifying FRMS. Law, procedures, and policy development, as well as financial resources, 
were regarded as important for developing mitigation strategies. Human resources, such as knowledge, expertise, and availability of volunteers, were regarded as important for developing preparedness and community resilience. However, during the pilot projects, none of these capacities were developed, which can be seen as a risk for further uptake of the outcomes of the pilot projects [16].

Additionally, two capacity dimensions hardly received importance ratings. First, within the 'learning capacity' dimension only, trust was regarded of some importance for building community resilience. This is remarkable because the interviews with pilot managers did show that learning capacities were employed and improved as a result of the pilot projects. The reason that learning was not identified as an important capacity may be explained because, as stated previously, the pilot projects rather focused on single-loop learning (incremental improvements of established routines) instead of double-loop learning (reframing of the FRMS) or triple-loop learning (transformation of FRMS). This is also supported by the pilot managers ambitions of diversifying the FRMS through the pilot projects (i.e., small incremental improvements were expected in mitigation and preparedness). This aligns with planning literature, which emphasizes that planning practices are more adaptive (adjust to changing circumstances) and incremental (gradual changes) than often assumed by scholars proposing 'new' planning approaches [56,57]. The interviews in our study showed that stakeholders learning capacities improved as a result of the pilot projects. Second, none of the capacities related to the dimension 'governance' emerged from the interviews, and governance was hardly regarded as an important antecedent for mitigation, preparedness, and community resilience. Governance may have gained little attention because most of the governance dimensions are already well institutionalized in the current arrangements of FRMS and, therefore, little action is needed to improve governance capacities in the current FRMS. Again, because current FRMS are well developed and institutionalized, improving weak links in the current governance regime is challenging. For instance, in a review of Dutch water governance, the OECD has pointed to a lack of awareness and preparedness among citizens and the large distance between water institutions and the general public [58]. Since society has a high level of trust in FRM, there is little urgency to bridge this gap, neither by the institutions nor by members of the general public. As a result, governance capacities become a passive part of FRM and fall short in gaining public support, responding to (implicit) information needs in society and taking responsibility for providing information about preparedness and response strategies. The lack of importance ratings for governance shows that there was little awareness for this underlying mechanism, likely because the pilot projects did not fully enter the process of double or triple-loop learning. In addition to more urgency [51], more research is also needed about the role of pilot projects in transitions processes. The pilot projects studied in this paper appeared to be examples of incremental change in the diversification of FRM. Considering wicked problems like sea level rise, these pilot projects can be considered as small wins [59]. Taking the contextual dynamics of experiments into account, the studied pilot project matched best with a seedbed lens [60]. The protective environment of the Interreg project FRAMES creates an environment to develop new FRM actions and learn from these. The propelling mechanism framework by Termeer and Dewulf [59] is relevant for future research to evaluate the transformation potential of various small wins. Recent expectations about sea level rise [51] can result in a change of the contextual dynamics of flood resilience pilot projects, in which battleground experiments [60] could become more relevant.

The Governance Capacity Framework (GCF) developed by Koop et al. [61] and applied by Brockhoff et al. [62] has many similarities with the ACW framework applied in this paper (see [62] for a comparison of both frameworks). The main difference between the GCF paper [62] and this paper is in the application aim. We have applied the ACW to assess the capacity development of practitioners in pilot projects, while the GCF aims to assess the governance capacity of society to solve specific challenges [61,62]. This results in differences in the applied methodology. In this paper, we have combined the ACW with Triple-loop Learning and applied this as a qualitative approach without scoring the adaptive capacities. With case narratives and focus groups, we have aimed to gain insight into the development of adaptive capacities by pilot projects over time and identification of key 
capacities for diversified FRM. In the GCF approach, Brockhoff et al. [62] scored the current governance capacity of cities and prescribed what steps involved practitioners need to take. The combination of both methods can be complementary in future research by combining scores to assess the current status and development of governance capacity. The indicator scoring of capacities is valuable for comparing scores of multiple cases. The qualitative approach, as applied in this paper, provides a more in-depth insight into the development of adaptive capacities in the context of specific actions for flood resilience.

\section{Conclusions}

In this study, an analytical framework was proposed combining the ACW and Triple-loop Learning to assess capacity development in pilot projects. The combination of these two approaches is a unique outcome of this paper. It acknowledges the development of adaptive capacities as a result of pilot projects and enables to link this with three types of learning. The findings contribute to theories about niche-regime interactions [20] and policy transfer via pilot projects [63]. The ACW within the framework was used as a qualitative approach without scoring the adaptive capacities [22]. The narratives allowed to pinpoint the development and interdependencies between adaptive capacities over time [22] in the phases (before, during, and after) of the pilot projects. Therefore, this analytical framework is practical to assess the development of capacities of stakeholders in pilot projects that aim to diversify FRMS. Likewise, it also identifies lacking capacities that are needed to ensure successful pilots and uptake in policy.

Since the proposed framework is the product of ongoing research, much room for improvement exists. Here, we mention a few avenues needing improvement. First, the framework misses clear guidance to evaluate the success of pilots and upscaling of pilots in the policy regime. By assessing pilot goals and outcomes more explicitly, the evaluation process can be improved. In particular, we regard the 'pilot paradox' [16] as a valuable approach because it defines the conditions underlying this process. Interestingly, the pilot paradox argues that the same conditions that make pilots successful often hamper their uptake in policy. Propelling mechanisms can help to assess the transformation potential of pilot projects as small wins in the domain of climate change [59]. Second, the methods of identifying adaptive capacities can be improved by incorporating multi-item rating scales to increase the reliability of measurements. This is a common approach in questionnaire research and provides a strong asset for further validation of the framework in future studies. Lastly, in order to get a better understanding of the capacity development in the pilot projects, it is necessary to consider different actors' perspectives. Therefore, it is recommended to conduct interviews with a variety of stakeholders of the pilot projects. This can strengthen the framework and application in future studies.

To conclude, this study has shown that the analytical framework is valuable for assessing pilot projects and learning about capacity development in their transition towards diversified FRMS. This methodology is a unique outcome of the FRAMES project, and its applicability to this study contributes to the existing literature about diversification of FRMS.

Author Contributions: Conceptualization: F.S.C., J.-M.B., M.B. and T.T.; data curation: F.S.C., J.-M.B., M.B. and T.T.; formal analysis: F.S.C., J.-M.B., M.B. and T.T.; investigation F.S.C., J.-M.B., M.B. and T.T.; methodology: F.S.C., J.-M.B., M.B. and T.T.; supervision: F.S.C., J.-M.B., M.B. and T.T.; writing-original draft preparation: F.S.C., J.-M.B., M.B. and T.T.; writing - review and editing: F.S.C., J.-M.B., M.B. and T.T.

Funding: This research was funded as part of FRAMES [19], an Interreg project supported by the North Sea Programme of the European Regional Development Fund of the European Union.

Acknowledgments: We want to give thanks to the knowledge institutes (Ghent University, University of Oldenburg, Jade University of Applied Sciences) for their contribution in developing the interview guideline. Moreover, special thanks to the pilot managers to provide valuable input and reviews from their pilots. Additionally, we want to thank all FRAMES project partners for their participation and input through the questionnaires and focus groups discussions.

Conflicts of Interest: The authors declare no conflict of interest. 


\section{Appendix A Selection of Cases, Based on Intended FRM Actions in Pilot Projects}

Table A1 below provides an overview of the pilot projects in FRAMES and their intended actions considering diversification of flood risk management strategies (FRMS). All pilot projects, actions, and implementation processes are more detailed described on www.frameswiki.eu.

The selection of the Alblasserwaard and the Wesermarsch pilots was based, firstly, on that the idea that traditional flood management relies mainly on flood defence with hard infrastructure. Selection of the two cases for this paper was based on the intended integration of Mitigation (via spatial planning) and Preparedness (awareness raising and evacuation planning) (see Table A1). In addition to the two selected cases, the Sloegebied pilot project also intended to focus on the same aspects, but this pilot project just started when we started with the analysis for this paper.

Table A1. Flood risk management actions implemented in FRAMES all pilot projects.

\begin{tabular}{|c|c|c|c|c|c|c|c|}
\hline \multirow[b]{2}{*}{ Pilot Projects } & \multicolumn{7}{|c|}{ Flood Risk Management Actions } \\
\hline & $\begin{array}{c}\text { Mitigation } \\
\text { via Spatial } \\
\text { Planning }\end{array}$ & $\begin{array}{l}\text { Preparation } \\
\text { (Awareness, } \\
\text { Evacuation } \\
\text { Planning) }\end{array}$ & $\begin{array}{c}\text { Natural } \\
\text { Flood } \\
\text { Man. }\end{array}$ & $\begin{array}{c}\text { Critical } \\
\text { Infra-Structure }\end{array}$ & Recovery & $\begin{array}{l}\text { Adaptive } \\
\text { Planning }\end{array}$ & $\begin{array}{c}\text { Community } \\
\text { Resilience }\end{array}$ \\
\hline \multicolumn{8}{|l|}{ 1. Alblasserwaard (NL) } \\
\hline \multicolumn{8}{|l|}{ 2. Flood proof electricity } \\
\hline \multicolumn{8}{|l|}{ 3. Reimerswaal (NL) } \\
\hline \multicolumn{8}{|l|}{ 4. Sloegebied (NL) } \\
\hline \multicolumn{8}{|l|}{ 5. Wesermarsch (DE) } \\
\hline \multicolumn{8}{|l|}{ 6. Ninove (BE) } \\
\hline \multicolumn{8}{|l|}{ 7. Denderleeuw (BE) } \\
\hline \multicolumn{8}{|l|}{ 8. Geraardsbergen (BE) } \\
\hline \multicolumn{8}{|l|}{ 9. Kent (UK) } \\
\hline \multicolumn{8}{|l|}{ 10. Medway (UK) } \\
\hline \multicolumn{8}{|l|}{ 11. Southwell (UK) } \\
\hline \multicolumn{8}{|l|}{ 12. Lustrum Beck (UK) } \\
\hline \multicolumn{8}{|l|}{ 13. Butt Green Shield (UK) } \\
\hline \multicolumn{8}{|l|}{ 14. Roskilde (DK) } \\
\hline \multicolumn{8}{|l|}{ 15. Assens (DK) } \\
\hline 16. Vejle (DK) & & & & & & & \\
\hline
\end{tabular}

Light grey colour represents the diversified FRM actions implemented in each pilot project while dark grey colour shows the FRM actions' resemblance between the selected pilot projects for this study.

\section{Appendix B Monitoring Survey (FRAMES)}

Baseline measurement

Pilot: ....

Important:

We kindly ask the pilot manager to complete this questionnaire in consultation with relevant experts/stakeholders in the pilot/region. The pilot manager can send this questionnaire and ask these experts/stakeholders to complete (certain) questions, or ask them to review answers. Per pilot we would like to have 1 questionnaire returned.

Who contributed to completing this questionnaire? Table A2 provides the organisations and the function of the stakeholders who filled the questionnaire for both pilots, Alblasserwaard and Wesermarsch. 
Table A2. Stakeholders who filled the questionnaires for Alblasserwaard (left) and Wesermarsch (right) pilot projects.

\begin{tabular}{|c|c|c|c|c|c|}
\hline & Organization & Function & & Function & Function \\
\hline 1 & $\begin{array}{l}\text { Province of } \\
\text { Zuid-Holland }\end{array}$ & $\begin{array}{c}\text { Pilot } \\
\text { manager/Policy } \\
\text { advisor }\end{array}$ & 1 & Jade University & $\begin{array}{l}\text { Pilot manager/full } \\
\text { professor }\end{array}$ \\
\hline 2 & Rijkswaterstaat & Policy advisor & 2 & Jade University & Researcher \\
\hline 3 & $\begin{array}{l}\text { Regio Alblasserwaard } \\
\text { en Vijfheerenlanden }\end{array}$ & Policy advisor & 3 & $\begin{array}{l}\text { Landkreis } \\
\text { Wesermarsch } \\
\text { Wesermarsch }\end{array}$ & $\begin{array}{c}\text { Head of Crisis } \\
\text { Management at the } \\
\text { County }\end{array}$ \\
\hline 4 & & Policy advisor & 4 & $\begin{array}{c}\text { Wesermarsch, Küste } \\
\text { and Raum }\end{array}$ & $\begin{array}{c}\text { Consultant in Coastal } \\
\text { Management }\end{array}$ \\
\hline 5 & $\begin{array}{l}\text { Noordelijke } \\
\text { Drechtsteden }\end{array}$ & & 5 & $\begin{array}{l}\text { Drinking Water } \\
\text { Company OOWV }\end{array}$ & $\begin{array}{c}\text { Spatial Planning } \\
\text { Manager }\end{array}$ \\
\hline 6 & & & 6 & $\begin{array}{l}\text { Drinking Water } \\
\text { Company OOWV }\end{array}$ & $\begin{array}{c}\text { Asset, Strategic } \\
\text { Planning Manager }\end{array}$ \\
\hline 7 & & & 7 & $\begin{array}{l}\text { Drinking Water } \\
\text { Company OOWV }\end{array}$ & $\begin{array}{c}\text { Consultant } \\
\text { Innovation Networks }\end{array}$ \\
\hline 8 & & & 8 & & \\
\hline 9 & & & 9 & & \\
\hline 10 & & & 10 & & \\
\hline
\end{tabular}

\section{Short Explanation}

FRAMES [19] is about improving flood resilience by taking different types of actions. A common and well-known typology in flood risk management is the disaster management cycle, as shown in the diagram below. This survey first focuses on the flood resilience of areas by considering the five elements of the Flood Risk Management cycle (Figure A1): pro-action (1), protection (2), mitigation (3), preparation (4) and recovery (5). Hereafter, a few questions will be asked with regard to the flood resilience of communities and authorities.

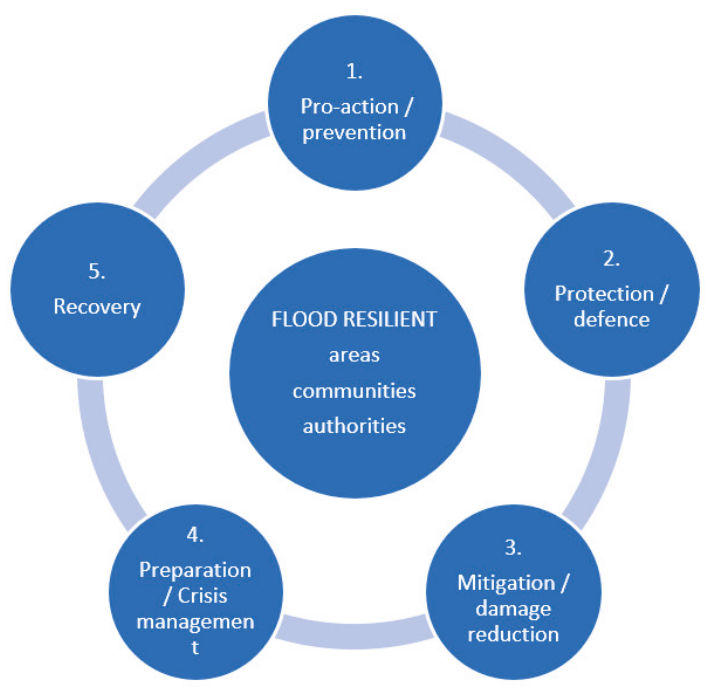

Figure A1. Flood Risk Management cycle. 


\section{Appendix B.1 Diversification of FRMS:}

\section{Appendix B.1.1 Pro-Action/Prevention}

Negative consequences of flooding can be avoided by pro-active spatial planning or land use policies ('keeping people away from water'), aimed at building only outside areas that are prone to flooding.

To what extent is pro-action/prevention currently a strong characteristic of the pilot area?

\begin{tabular}{cccccccccc}
\hline Not at All & & & & & & & & & To a Great Extent \\
\hline 1 & 2 & 3 & 4 & 5 & 6 & 7 & 8 & 9 & 10 \\
\hline
\end{tabular}

Please shortly explain your answer:

Appendix B.1.2 Flood Protection/Defence

Keeping water away from people by (combinations of) hard infrastructural works (dykes, dams, etc.) or softer (nature based) solutions (dunes, retention in nature areas, etc.).

To what extent is flood protection/defence currently a strong characteristic of the pilot area?

\begin{tabular}{cccccccccc}
\hline Not at All & & & & & & & & To a Great Extent \\
\hline 1 & 2 & 3 & 4 & 5 & 6 & 7 & 8 & 9 & 10 \\
\hline
\end{tabular}

Please shortly explain your answer:

Appendix B.1.3 Flood Risk Mitigation

Consequences of floods can be mitigated by a smart design of the flood-prone area including spatial orders, constructing flood compartments, or (regulations for) flood-proof building.

To what extent is flood risk mitigation a strong characteristic of the pilot area?

\begin{tabular}{cccccccccccc}
\hline \multicolumn{1}{c}{ Not at all } & 1 & 1 & & & To a great extent \\
\hline Currently & 1 & 2 & 3 & 4 & 5 & 6 & 7 & 8 & 9 & 10 \\
Expectation after FRAMES & 1 & 2 & 3 & 4 & 5 & 6 & 7 & 8 & 9 & 10 \\
\hline
\end{tabular}

What will be done in FRAMES with regard to flood risk mitigation, that improves the

1. physical resilience in the pilot area?

2. capacities of local organisations/institutions in the pilot area?

3. capacities of local communities (citizens, businesses) in the pilot area?

Appendix B.1.4 Flood Preparation

Consequences of floods can be mitigated by preparing for adequate response to a flood event. Measures include flood warning systems, disaster management and evacuation/rescue plans, and managing a flood when it occurs by taking last call emergency measures (e.g., sand bags).

To what extent is flood preparation a strong characteristic of the pilot area?

\begin{tabular}{cccccccccccc}
\hline \multicolumn{1}{c}{ Not at all } & \multicolumn{1}{c}{ To great extent } \\
\hline Currently & 1 & 2 & 3 & 4 & 5 & 6 & 7 & 8 & 9 & 10 \\
Expectation after FRAMES & 1 & 2 & 3 & 4 & 5 & 6 & 7 & 8 & 9 & 10 \\
\hline
\end{tabular}

What will be done in FRAMES with regard to flood preparation, that improves the

1. physical resilience in the pilot area? 
2. capacities of local organisations/institutions in the pilot area?

3. capacities of local communities (citizens, businesses) in the pilot area?

Appendix B.1.5 Flood Recovery

Facilitates a good and fast recovery after a flood event. Includes plans for draining/pumping away flood water and restoring safety and security, plans for reconstruction or rebuilding critical infrastructure, damage compensation/insurance systems, return of evacuated communities and social-psychological support.

To what extent is flood recovery a strong characteristic of the pilot area?

\begin{tabular}{cccccccccccc}
\hline \multicolumn{1}{c}{ Not at all } & 1 & 1 & & To a great extent \\
\hline Currently & 1 & 2 & 3 & 4 & 5 & 6 & 7 & 8 & 9 & 10 \\
Expectation after FRAMES & 1 & 2 & 3 & 4 & 5 & 6 & 7 & 8 & 9 & 10 \\
\hline
\end{tabular}

What will be done in FRAMES with regard to flood recovery, that improves the

1. physical resilience in the pilot area?

2. capacities of local organisations/institutions in the pilot area?

3. capacities of local communities (citizens, businesses) in the pilot area?

Appendix B.2 Resilience of Authorities and Communities

Appendix B.2.1 Flood Resilience of Authorities

Please name the organisations/stakeholders that will be involved in your pilot:

\begin{tabular}{cc}
\hline & Organization \\
\hline 1 & \\
2 & \\
3 & \\
4 & \\
5 & \\
6 & \\
7 & \\
8 & \\
9 & \\
10 & \\
\hline
\end{tabular}

In general, to what extent is flood risk mitigation embedded in policy and practice of these organisations, in your opinion?

\begin{tabular}{cccccccccccc}
\hline \multicolumn{1}{c}{ Not at all } & \multicolumn{1}{c}{ To a great extent } \\
\hline Currently & 1 & 2 & 3 & 4 & 5 & 6 & 7 & 8 & 9 & 10 \\
Expectation after FRAMES & 1 & 2 & 3 & 4 & 5 & 6 & 7 & 8 & 9 & 10 \\
\hline
\end{tabular}

Please shortly explain your answer:

In general, to what extent is flood preparation embedded in policy and practice of these organisations, in your opinion?

\begin{tabular}{cccccccccccc}
\hline \multicolumn{1}{c}{ Not at all } & 1 & 1 & & & To a great extent \\
\hline Currently & 1 & 2 & 3 & 4 & 5 & 6 & 7 & 8 & 9 & 10 \\
Expectation after FRAMES & 1 & 2 & 3 & 4 & 5 & 6 & 7 & 8 & 9 & 10 \\
\hline
\end{tabular}


Please shortly explain your answer:

In general, to what extent is flood recovery embedded in policy and practice of these organisations, in your opinion?

\begin{tabular}{ccccccccccccc}
\hline \multicolumn{1}{c}{ Not at all } & 1 & 1 & & & To a great extent \\
\hline Currently & 1 & 2 & 3 & 4 & 5 & 6 & 7 & 8 & 9 & 10 \\
Expectation after FRAMES & 1 & 2 & 3 & 4 & 5 & 6 & 7 & 8 & 9 & 10 \\
\hline
\end{tabular}

Please shortly explain your answer:

Appendix B.2.2 Flood Resilience of Local Communities

Please name the communities (e.g., neighbourhoods, municipalities) that will be involved in/informed about your pilot(s), and how many citizens they consist of:

\begin{tabular}{ccc}
\hline & Community & Number of Citizens (Approximately) \\
\hline 1 & \\
2 & \\
3 & \\
4 & \\
5 & \\
6 & \\
7 & \\
8 & \\
9 & \\
10 & \\
\hline
\end{tabular}

In general, to what extent is flood risk mitigation embedded in the behaviour of these communities, in your opinion?

\begin{tabular}{cccccccccccc}
\hline \multicolumn{1}{c}{ Not at all } & 1 & 1 & & & & & To a great extent \\
\hline Currently & 1 & 2 & 3 & 4 & 5 & 6 & 7 & 8 & 9 & 10 \\
Expectation after FRAMES & 1 & 2 & 3 & 4 & 5 & 6 & 7 & 8 & 9 & 10 \\
\hline
\end{tabular}

Please shortly explain your answer:

In general, to what extent is flood preparation embedded in the behaviour of these communities, in your opinion?

\begin{tabular}{cccccccccccc}
\hline \multicolumn{1}{c}{ Not at all } & 1 & 1 & & & & To a great extent \\
\hline Currently & 1 & 2 & 3 & 4 & 5 & 6 & 7 & 8 & 9 & 10 \\
Expectation after FRAMES & 1 & 2 & 3 & 4 & 5 & 6 & 7 & 8 & 9 & 10 \\
\hline
\end{tabular}

Please shortly explain your answer:

In general, to what extent is flood recovery embedded in the behaviour of these communities, in your opinion?

\begin{tabular}{ccccccccccccc}
\hline \multicolumn{1}{c}{ Not at all } & 1 & \multicolumn{1}{c}{ To a great extent } \\
\hline Currently & 1 & 2 & 3 & 4 & 5 & 6 & 7 & 8 & 9 & 10 \\
Expectation after FRAMES & 1 & 2 & 3 & 4 & 5 & 6 & 7 & 8 & 9 & 10 \\
\hline
\end{tabular}

Please shortly explain your answer: 


\section{Appendix C Interview Guideline}

The interview guideline was developed between December 2018 and January 2019 by 7 project partners from the knowledge institutes: 4 from HZ Delta Academy, 1 from Oldenburg University and 2 from Ghent University.

General information

Pilot area:

Name of the pilot manager:

Organization:

Interviewers:

Date:

Objective:

This interview consists of 14 semi-structured questions to facilitate/guide an open discussion with the pilot coordinators/managers about the implementation process of the MLS approach in the pilot area and the impact/influence of the expected outcomes in the pilot region. This input will be used for the development of the FRAMES Decision Support System and resilience toolkit. The bullet lists relevant aspects to follow and bring into the discussion if they are mentioned by the pilot manager.

Introductory questions:

1. Which were/are the most relevant flood risk management measures taken in the pilot area and in the pilot region (before FRAMES?)?

2. How did you get involved in setting up this pilot and what was your main motivation?

Key questions:

3. Main goals/MLS: What are the main goal(s) in the pilot in relation to the MLS layers (protection/prevention/preparation/recovery)?

$\checkmark \quad$ Specify if the goal(s) is/are for short/medium/long term $(<5 / 5-25 />25$ years $)$

$\checkmark \quad$ Reason of the pilot, was it completely new compared to the region's FRM approach?

4. Pilot process and decision making: Throughout the implementation process of MLS, which were/are

$\checkmark \quad$ Follow up steps towards new/improved strategies in FRM

$\checkmark \quad$ Tools/methods used to perform and monitor these steps/decisions

$\checkmark \quad$ Current and missing actors (level, sector)

$\checkmark \quad$ Tools/methods to involved and keep actors engaged (special attention of local communities)

5. Interaction of layers/hierarchy of layers: Have you encountered any interaction of activities between several layers of MLS? If yes, how have you coordinated activities when they take place on different layers? Could you give any examples?

6. Struggles/hurdles: Which were/are the main struggles that you have faced in implementing and reaching the goal(s) in relation to the MLS approach? What would you never do again? How have you overcome these struggles?

$\checkmark \quad$ Drivers/barriers of change: stakeholders, time, resources, uncertainties of climate change, power

7. Accomplishments: What did it go well? Would you do again the same thing? If not, what would you change?

8. (Expected) Outcomes: Which are the outcomes or expected outcomes of implementing the MLS in the pilot area and in the pilot region? 
$\checkmark \quad$ Concrete outputs/products (new or not?)

$\checkmark \quad$ Share information/communicate outcomes

9. Embedding/upscaling of MLS approach. Based on the pilot (expected) outcomes, what are the potential/opportunities to embed/upscale the MLS approach in the region after FRAMES? For example, community resilience, spatial planning/infrastructure, FRM policies/strategies.

10. Role of pilot coordinator: How do you see your role as pilot manager in facilitating the implementation of the MLS approach during the pilot project and embedding/upscaling the project outcomes afterwards?

11. Role of key actors: How do you see the role of the key actors in facilitating the implementation of the MLS approach during the pilot project and embedding/upscaling the project outcomes afterwards?

12. What do you think will be the main drivers/barriers for the embedding/upscaling of the expected outcomes after FRAMES?

13. What is needed to make use of these drivers and to overcome these barriers?

Ending questions:

14. Do you recommend to talk with the key actors that will have a role in enabling/facilitating the implementation of MLS approach further, after FRAMES, at regional/national level?

15. Do you have any comments related to this interview? (additional questions or ideas).

Thanks so much for your time and contribution in this interview

\section{Appendix D Transnational Focus Groups (TFG)}

Table A3 lists the 12 FRM actions derived from the 15 pilot projects of FRAMES.

Table A3. List of FRM actions, derived from pilot activities.

\begin{tabular}{cl}
\hline No & \multicolumn{1}{c}{ Flood Resilience Actions in Pilot Project } \\
\hline 1 & Improving zoning of developments in flood prone areas* \\
\hline 2 & $\begin{array}{l}\text { Reducing surface flood risk from extreme rainfall via increasing storage capacity in private and } \\
\text { public space }\end{array}$ \\
\hline 3 & Lowering flood risk for communities via nature based solutions upstream \\
\hline 4 & $\begin{array}{l}\text { 4a Realizing a flood proof critical infrastructure } \\
\text { 4b Limit cascade-effects of critical infrastructure failure }\end{array}$ \\
\hline 5 & Integrate emergency response planning in flood risk management (and vice versa) ${ }^{*}$ \\
\hline 6 & Improve strategies for preventive evacuation \\
\hline 7 & Develop alternative evacuation strategies (safe haven, shelters, vertical evacuation) \\
\hline 9 & Raising awareness for flood resilience measures \\
\hline 10 & $\begin{array}{l}\text { Involving communities in flood resilience measures } \\
\text { 10b Empower communities to take action for local flood resilience measures }{ }^{*}\end{array}$ \\
\hline 11 & Support local authorities and communities in adaptive planning for flood resilience \\
\hline 12 & $\begin{array}{l}\text { Apply adaptive planning to look for tipping points in flood risk management strategies and to } \\
\text { explore synergetic combinations of strategies }\end{array}$ \\
\hline
\end{tabular}

* Actions used during the TFGs discussions.

The total number of 31 project partners participated during of the 3 TFGs held on 27th March 2019 in Oldenburg: 12 from The Netherlands (3/HZ Delta Academy, 4/Province of Zeeland, 3/Province of 
South Holland, 1/Rijkswaterstaat and 1/Reeleaf); 8 from Germany (2/Jade UAS, 3/Oldenburg University, 1/Küste \& Raum Consultancy, 1/Oldenburg-East-Frisian Water Board and 1/Jade HS-citizens science-); 1 from Denmark (1/Danish Coastal Authority); 3 from Belgium (1/Ghent University, 2/Provincie Oost-Vlaanderen); and 7 from UK (1/Kent County Council, 2/National Flood Forum, 1/Trent River Trust, 2/South East River Trust and 1/Tees Rivers Trust).

\section{References}

1. IPCC. Global Warming of $1.5^{\circ} \mathrm{C}$. An IPCC Special Report on the Impacts of Global Warming of $1.5^{\circ} \mathrm{C}$ Above Pre-Industrial Levels and Related Global Greenhouse Gas Emission Pathways, in the Context of Strengthening the Global Response to the Threat of Climate Change; IPCC: Geneve, Switzerland, 2018.

2. Aerts, J.C.J.H.; Botzen, W.; van der Ven, A.; Krywkow, J.; Werners, S. Dealing with uncertainty in flood management through diversification. Ecol. Soc. 2008, 13, 41. [CrossRef]

3. Hegger, D.L.T.; Driessen, P.P.J.; Wiering, M.; Van Rijswick, H.F.M.W.; Kundzewicz, Z.W.; Matczak, P.; Crabbé, A.; Raadgever, G.T.; Bakker, M.H.N.; Priest, S.J.; et al. Toward more flood resilience: Is a diversification of flood risk management strategies the way forward? Ecol. Soc. 2016, 21. [CrossRef]

4. Dieperink, C.; Hegger, D.L.T.; Bakker, M.H.N.; Kundzewicz, Z.W.; Green, C.; Driessen, P.P.J. Recurrent Governance Challenges in the Implementation and Alignment of Flood Risk Management Strategies: A Review. Water Resour. Manag. 2016, 30, 4467-4481. [CrossRef]

5. Driessen, P.P.J.; Hegger, D.L.T.; Bakker, M.H.N.; van Rijswick, H.F.M.W.; Kundzewicz, Z.W. Toward more resilient flood risk governance. Ecol. Soc. 2016, 21, 53. [CrossRef]

6. Berkhout, F.; Hertin, J.; Gann, D.M. Learning to adapt: Organisational adaptation to climate change impacts. Clim. Chang. 2006, 78, 135-156. [CrossRef]

7. Folke, C.; Hahn, T.; Olsson, P.; Norberg, J. Adaptive governance of social-ecological systems. Annu. Rev. Environ. Resour. 2005, 30, 441-473. [CrossRef]

8. Bodin, Ö.; Crona, B.; Ernstson, H. Social networks in natural resource management: What is there to learn from a structural perspective? Ecol. Soc. 2006, 11, r2. [CrossRef]

9. Lebel, L.; Anderies, J.M.; Campbell, B.; Folke, C.; Hatfield-Dodds, S.; Hughes, T.P.; Wilson, J. Governance and the capacity to manage resilience in regional social-ecological systems. Ecol. Soc. 2006, 11, 19. [CrossRef]

10. Bodin, Ö.; Crona, B.I. The role of social networks in natural resource governance: What relational patterns make a difference? Glob. Environ. Chang. 2009, 19, 366-374. [CrossRef]

11. Mortreux, C.; Barnett, J. Adaptive capacity: exploring the research frontier. WIREs Clim. Chang. 2017, 8, e467. [CrossRef]

12. Adger, W.N.; Vincent, K. Uncertainty in adaptive capacity. Comptes Rendus Geosci. 2005, 337, 399-410. [CrossRef]

13. Hegger, D.L.T.; Driessen, P.P.J.; Dieperink, C.; Wiering, M.; Raadgever, G.T.T.; van Rijswick, H.F.M.W. Assessing stability and dynamics in flood risk governance: An empirically illustrated research approach. Water Resour. Manag. 2014, 28, 4127-4142. [CrossRef]

14. Pahl-Wostl, C.; Craps, M.; Dewulf, A.; Mostert, E.; Tabara, D.; Taillieu, T. Social learning and water resources management. Ecol. Soc. 2007, 12, 1-19. [CrossRef]

15. Klijn, E.H.; Koppenjan, J. Governance Networks in the Public Sector. In Governance Networks in the Public Sector; Routledge: London, UK; New York, NY, USA, 2016; pp. 16-33.

16. Van Buuren, A.; Vreugdenhil, H.S.I.; Van Popering Verkerk, J.; Ellen, G.J; Van Leeuwen, C.; Breman, B. The pilot paradox. In Innovating Climate Governance. Moving Beyond Experiments; Cambridge University Press: Cambridge, UK, 2018; pp. 145-165.

17. Van Popering-Verkerk, J.; van Buuren, A. Developing collaborative capacity in pilot projects: Lessons from three Dutch flood risk management experiments. J. Clean. Prod. 2017, 169, 225-233. [CrossRef]

18. Driessen, P.P.J.; Hegger, D.L.T.; Kundzewicz, Z.W.; van Rijswick, H.F.M.W.; Crabbé, A.; Larrue, C.; Matczak, P.; Pettersson, M.; Priest, S.; Suykens, C.; et al. Governance strategies for improving flood resilience in the face of climate change. Water 2018, 10, 1595. [CrossRef]

19. Flood Resilient Areas by Multi-LayEr Safety. Available online: https://northsearegion.eu/frames/ (accessed on 14 October 2019). 
20. Hans de Haan, J.; Rotmans, J. Patterns in transitions: Understanding complex chains of change. Technol. Forecast. Soc. Chang. 2011, 78, 90-102. [CrossRef]

21. Hegger, D.L.T.; Van Vliet, J.; Van Vliet, B.J.M. Niche management and its contribution to regime change: The case of innovation in sanitation. Technol. Anal. Strateg. Manag. 2007, 19, 729-746. [CrossRef]

22. Gupta, J.; Termeer, C.; Klostermann, J.; Meijerink, S.; van den Brink, M.; Jong, P.; Nooteboom, S.; Bergsma, E. The Adaptive Capacity Wheel: A method to assess the inherent characteristics of institutions to enable the adaptive capacity of society. Environ. Sci. Policy 2010, 13, 459-471. [CrossRef]

23. Pahl-Wostl, C. A conceptual framework for analysing adaptive capacity and multi-level learning processes in resource governance regimes. Glob. Environ. Chang. 2009. [CrossRef]

24. Munaretto, S.; Klostermann, J.E.M. Assessing adaptive capacity of institutions to climate change: A comparative case study of the Dutch Wadden Sea and the Venice Lagoon. Clim. Law 2011, 2, 219-250. [CrossRef]

25. Hurlbert, M.; Gupta, J. The adaptive capacity of institutions in Canada, Argentina, and Chile to droughts and floods. Reg. Environ. Chang. 2017, 17, 865-877. [CrossRef]

26. Schneider, F.; Bonriposi, M.; Graefe, O.; Herweg, K.; Homewood, C.; Huss, M.; Kauzlaric, M.; Liniger, H.; Rey, E.; Reynard, E.; et al. Assessing the sustainability of water governance systems: The sustainability wheel. J. Environ. Plan. Manag. 2015, 58, 1577-1600. [CrossRef]

27. Grecksch, K. Adaptive capacity and regional water governance in north-western Germany. Water Policy 2013, 15, 794-815. [CrossRef]

28. Bergsma, E.; Gupta, J.; Jong, P. Does individual responsibility increase the adaptive capacity of society? The case of local water management in the Netherlands. Resour. Conserv. Recycl. 2012, 64, 13-22. [CrossRef]

29. Reed, M.S.; Evely, A.C.; Cundill, G.; Fazey, I.; Glass, J.; Laing, A.; Newig, J.; Parrish, B.; Prell, C.; Raymond, C.; et al. What is social learning? Ecol. Soc. 2010, 15, r1. [CrossRef]

30. IPCC. Managing the Risks of Extreme Events and Disasters to Advance Climate Change Adaptation; IPCC: Cambridge, UK; New York, NY, USA, 2012.

31. Argyris, C.; Schön, D. Organizational Learning II: Theory, Method, and Practice; Addison-Wesley: Boston, MA, USA, 1996.

32. Armitage, D.; Marschke, M.; Plummer, R. Adaptive co-management and the paradox of learning. Glob. Environ. Chang. 2008, 18, 86-98. [CrossRef]

33. Blackmore, C.; van Bommel, S.; de Bruin, A.; de Vries, J.; Westberg, L.; Powell, N.; Foster, N.; Collins, K.; Roggero, P.P.; Seddaiu, G. Learning for transformation of water governance: reflections on design from the climate change adaptation and water governance (CADWAGO) project. Water 2016, 8, 510. [CrossRef]

34. Johannessen, Å.; Gerger Swartling, Å.; Wamsler, C.; Andersson, K.; Arran, J.T.; Hernández Vivas, D.I.; Stenström, T.A. Transforming urban water governance through social (triple-loop) learning. Environ. Policy Gov. 2019, 29, 144-154. [CrossRef]

35. Haasnoot, M.; Kwakkel, J.H.; Walker, W.E.; ter Maat, J. Dynamic adaptive policy pathways: A method for crafting robust decisions for a deeply uncertain world. Glob. Environ. Chang. 2013, 23, 485-498. [CrossRef]

36. Buijs, J.-M.; Boelens, L.; Bormann, H.; Restemeyer, B.; Terpstra, T.; Van Der Voorn, T. Adaptive planning for flood resilient areas: dealing with complexity in decision-making about multilayered flood risk management. In Proceedings of the 16th Meeting: Adaptive Planning for Spatial Transformation, Groningen, The Netherlands, 23-25 May 2018; p. 23. Available online: https://www.projectenportfolio.nl/images/archive/ e/ea/20180906092418\%2120180430_Paper_Aesop_FRAMES.pdf (accessed on 27 September 2019).

37. Van Herk, S.; Zevenbergen, C.; Gersonius, B.; Waals, H.; Kelder, E. Process design and management for integrated flood risk management: Exploring the multi-layer safety approach for Dordrecht, The Netherlands. J. Water Clim. Chang. 2014, 5, 100-115. [CrossRef]

38. LAWA. Empfehlungen zur Aufstellung von Hochwassergefahrenkarten und Hochwasserrisikokarten; The German Federal/State Working Group on Water (in German Bund/Länderarbeitsgemeinschaft Wasser, LAWA) Saxon State Ministry of Environment and Agriculture: Dresden, Germany, 2010.

39. Deltacommissie. Deltabeslissing Waterveiligheid; Ministry of Infrastructure and the Environment Ministry of Economic Affairs (in Dutch, Ministerie van Infrastructuur en Milieu Ministerie van Economische Zaken): Hague, The Netherlands, 2014.

40. Heintz, M.D.; Hagemeier-Klose, M.; Wagner, K. Towards a risk governance culture in flood policy-findings from the implementation of the "floods directive" in Germany. Water 2012, 4, 135-156. [CrossRef] 
41. Ahlhorn, F.; Bormann, H. Entwicklungsmöglichkeiten des Hochwasserschutzes im Küstenraum-Risiko oder Sicherheit? Wasser Und Abfall 2015, 17, 26-30. [CrossRef]

42. Ahlhorn, F.; Kebschull, J.; Bormann, H. Risikowahrnehmung und informations- bedarfe der bevölkerung über die auswirkungen des klimawandels auf hochwasser und sturmfluten. Wasser Und Abfall 2018, 20, 44-51. [CrossRef]

43. Matczak, P.; Wiering, M.; Lewandowski, J.; Schellenberger, T.; Trémorin, J.-B.; Crabbé, A.; Ganzevoort, W.; Kaufmann, M.; Larrue, C.; Liefferink, D.; et al. Comparing Flood Risk Governance in Six European Countries: Strategies, Arrangements and Institutional Dynamics; STAR-FLOOD Consortium: Utrecht, The Netherlands, 2016.

44. Bubeck, P.; Kreibich, H.; Penning-Rowsell, E.C.; Botzen, W.J.W.; de Moel, H.; Klijn, F. Explaining differences in flood management approaches in Europe and in the USA-a comparative analysis. J. Flood Risk Manag. 2017, 10, 436-445. [CrossRef]

45. Fereday, J.; Muir-Cochrane, E. Demonstrating Rigor Using Thematic Analysis: A Hybrid Approach of Inductive and Deductive Coding and Theme Development. Int. J. Qual. Methods 2006, 5, 80-92. [CrossRef]

46. Greenhalgh, T.; Russell, J.; Swinglehurst, D. Narrative methods in quality improvement research. Qual. Saf. Heal. Care 2005, 14, 443-449. [CrossRef]

47. Bormann, H.; Ahlhorn, F.; Klenke, T. Climate Proof Areas-Anpassung von Wassermanagement und Küstenschutz in der Wesermarsch an den Klimawandel. In Sicherung von Dämmen, Deichen und Stauanlagen. Handbuch für Theorie und Praxis; Vol. IV-2012; Herrmann, R.A., Jensen, J., Eds.; Siegen, Universitätsverlag: Siegen, Germany, 2013; pp. 137-153.

48. Linde, A.H.; Gudde, T.; Steenstra, M.K.; Hkv, B.K.; Twynstra, S.M.G.A. Analyse Slimme Combinaties; Delta Commissioner: Hague, The Netherlands, 2018; Available online: https://www.projectenportfolio.nl/images/ archive/e/ea/20180906092418\%2120180430_Paper_Aesop_FRAMES.pdf (accessed on 27 September 2019).

49. Van Berchum, E.C.; Mobley, W.; Jonkman, S.N.; Timmermans, J.S.; Kwakkel, J.H.; Brody, S.D. Evaluation of flood risk reduction strategies through combinations of interventions. J. Flood Risk Manag. 2018, 12, 18. [CrossRef]

50. Ministry of Transport, Public Works and Water Management. National Water Plan 2009-2015; Ministry of Transport, Public Works and Water Management: Hague, The Netherlands, 2009.

51. Haasnoot, M.; Mosselman, E.; Sloff, K.; Huismans, Y.; Mens, M.; Ter Maat, K.; Weiler, O.; Bouwer, L.; Diermanse, F.; Kwadijk, J.; et al. Mogelijke Gevolgen Van Versnelde Zeespiegelstijging Voor Het Deltaprogramma; Deltares: Delft, The Netherlands, 2018; Available online: https:/www.deltares.nl/app/uploads/2018/08/ Deltares_Mogelijke-gevolgen-van-versnelde-zeespiegelstijging-voor-het-Deltaprogramma.pdf (accessed on 27 September 2019).

52. Kallis, G.; Kiparsky, M.; Norgaard, R. Collaborative governance and adaptive management: Lessons from California's CALFED Water Program. Environ. Sci. Policy 2009, 12, 631-643. [CrossRef]

53. Huitema, D.; Mostert, E.; Egas, W.; Moellenkamp, S.; Pahl-Wostl, C.; Yalcin, R. Adaptive water governance: Assessing the institutional prescriptions of adaptive (co-)management from a governance perspective and defining a research agenda. Ecol. Soc. 2009, 14, 26. [CrossRef]

54. Termeer, K.; Huitema, D.; Mees, H.; Meijerink, S.; van Rijswick, M.; Dewulf, A. Governance Arrangements for the Adaptation to Climate Change. In The Oxford Research Encyclopedia of Climate Science; Oxford University Press: Oxford, UK, 2016; p. 31. ISBN 9780190228620.

55. Mees, H. Local governments in the driving seat? A comparative analysis of public and private responsibilities for adaptation to climate change in European and North-American cities. J. Environ. Policy Plan. 2017, 19, 374-390. [CrossRef]

56. Van Karnenbeek, L.; Janssen-Jansen, L. Playing by the rules? Analysing incremental urban developments. Land Use Policy 2018, 72, 402-407. [CrossRef]

57. Lindblom, C.E. The science of muddling through. Public Adm. Rev. 1959, 19, 79-88. [CrossRef]

58. OECD. Water Governance in the Netherlands: Fit for the Future? OECD Studies on Water; OECD Publishing: Paris, France, 2014.

59. Termeer, C.J.A.M.; Dewulf, A. A small wins framework to overcome the evaluation paradox of governing wicked problems. Policy Soc. 2019, 38, 298-314. [CrossRef]

60. Torrens, J.; Schot, J.; Raven, R.; Johnstone, P. Seedbeds, harbours, and battlegrounds: On the origins of favourable environments for urban experimentation with sustainability. Environ. Innov. Soc. Transit. 2019, 31, 211-232. [CrossRef] 
61. Koop, S.H.A.; Koetsier, L.; Doornhof, A.; Reinstra, O.; Van Leeuwen, C.J.; Brouwer, S.; Dieperink, C.; Driessen, P.P.J. Assessing the Governance Capacity of Cities to Address Challenges of Water, Waste, and Climate Change. Water Resour. Manag. 2017, 31, 3427-3443. [CrossRef]

62. Brockhoff, R.C.; Koop, S.H.A.; Snel, K.A. Pluvial Flooding in Utrecht: On ItsWay to a Flood-Proof City. Water 2019, 11, 1501. [CrossRef]

63. Ilgen, S.; Sengers, F.; Wardekker, A. City-To-City Learning for Urban Resilience: The Case of Water Squares in Rotterdam and Mexico City. Water 2019, 11, 983. [CrossRef]

(C) 2019 by the authors. Licensee MDPI, Basel, Switzerland. This article is an open access article distributed under the terms and conditions of the Creative Commons Attribution (CC BY) license (http://creativecommons.org/licenses/by/4.0/). 


\title{
Reducing Hydro-Meteorological Risk by Nature-Based Solutions: What Do We Know about People's Perceptions?
}

\author{
Sungju Han ${ }^{1,2, *}$ and Christian Kuhlicke ${ }^{1,2,3}$ \\ 1 Department of Urban and Environmental Sociology, UFZ-Helmholtz Centre for Environmental Research, \\ Permoserstraße 15, 04318 Leipzig, Germany; Christian.Kuhlicke@ufz.de \\ 2 Institute for Environmental Sciences and Geography, University of Potsdam, 14468 Potsdam-Golm, Germany \\ 3 German Centre for Integrative Biodiversity Research (iDiv) Halle-Jena-Leipzig, Deutscher Platz 5e, \\ 04103 Leipzig, Germany \\ * Correspondence: sungju.han@ufz.de
}

Received: 16 October 2019; Accepted: 5 December 2019; Published: 10 December 2019

\begin{abstract}
Nature-based solutions (NBS) have recently received attention due to their potential ability to sustainably reduce hydro-meteorological risks, providing co-benefits for both ecosystems and affected people. Therefore, pioneering research has dedicated efforts to optimize the design of NBS, to evaluate their wider co-benefits and to understand promoting and/or hampering governance conditions for the uptake of NBS. In this article, we aim to complement this research by conducting a comprehensive literature review of factors shaping people's perceptions of NBS as a means to reduce hydro-meteorological risks. Based on 102 studies, we identified six topics shaping the current discussion in this field of research: (1) valuation of the co-benefits (including those related to ecosystems and society); (2) evaluation of risk reduction efficacy; (3) stakeholder participation; (4) socio-economic and location-specific conditions; (5) environmental attitude, and (6) uncertainty. Our analysis reveals that concerned empirical insights are diverse and even contradictory, they vary in the depth of the insights generated and are often not comparable for a lack of a sound theoretical-methodological grounding. We, therefore, propose a conceptual model outlining avenues for future research by indicating potential inter-linkages between constructs underlying perceptions of NBS to hydro-meteorological risks.
\end{abstract}

Keywords: disaster risk reduction; climate change adaptation; river restoration; green infrastructure; ecosystem services; acceptability; attitudes; co-benefits; preferences; participation

\section{Introduction}

An increase in natural hazards caused by meteorological and climate events such as floods, landslides, and hurricanes has been observed worldwide in recent decades [1]. When these hazards are coupled with societal vulnerabilities [2,3], it creates a higher chance of disasters, which can cause not only serious economic loss but also loss of lives [4]. Moreover, the likelihood of these hazards could become even higher in the future because of changes in precipitation and temperature patterns associated with ongoing global climate change [5,6]. Next to climate change, alterations of land-use also play a decisive role in potentially increasing hydro-meteorological risk [7-9]. Rural areas have been converted into urban landscapes, resulting in more deforested or drained areas vulnerable to erosion $[10,11]$ as well as an increased number of assets, infrastructure, and people exposed to hydro-meteorological hazards [12-14].

In response to this phenomenon, nature-based solutions (NBS) have recently received considerable attention $[15,16]$. They are positioned as an alternative to conventional technical solutions that have so 
far dominated the management of hydro-metrological risks [17]. In contrast to traditional management measures, NBS are inspired by or copied from natural processes. NBS help to address multiple societal challenges and pursue more than one single objective (i.e., reduce hydro-meteorological risks); rather, they aim to generate multiple co-benefits for both ecosystems and humans $[18,19]$. Therefore, great efforts are currently being undertaken to establish pioneering projects that aim to design and implement NBS as well as systematically evaluate the wider co-benefits of NBS. Although some expected co-benefits are not tangible [20] and need long-term observation strategies to evaluate them [21], it is anticipated that the documentation of the wider effects of NBS will help stakeholders to better understand the potential positive impacts of NBS and eventually lead to increased uptake [22]. In addition to the evaluation of co-benefits, there is also an emerging debate focusing on actors, institutions, and their interactions in order to identify governance conditions that support or hinder NBS [23-25].

In this article, we aim to complement recent research that evaluates the co-benefits of NBS and the wider governance context. Although the importance of NBS and their effective implementation has been recognized [26-28], a comprehensive analysis of factors shaping perceptions of NBS as a means to reduce hydro-meteorological risks is still lacking. It is generally acknowledged that negative perceptions of NBS can be a decisive barrier to the uptake of NBS. Decision-makers might be uncertain with respect to the effects of NBS as well as with respect to procedural aspects related to their planning, implementation, and maintenance [28]. Similarly, perceptions of NBS can be shaped by cognitive barriers, such as unawareness or fear, discouraging stakeholders from considering the realization of NBS [29]. Moreover, the few existing studies that focus on NBS as a means to reduce hydro-meteorological risks highlight conflicting views. On the one hand, some studies imply that NBS are perceived positively as they not only help to reduce risks, but can also result in co-benefits [30,31]. On the other hand, studies suggest that exposed residents prefer technical solutions over NBS as the latter are perceived as less effective in reducing risks [32,33].

In addition, we aim to advance the discussion on perceptions of hydro-meteorological risks. Within the social sciences, the term 'risk perception' has a long tradition [34]. It refers to the process of collecting, selecting, and interpreting signals about uncertain impacts of events, activities, or technologies $[35,36]$. In recent years, a behavioral turn has occurred in this field of research, focusing on perceptions of risks and factors shaping individual adaptive behavior [37]. Relevant factors that have been identified include: experience of flood damage [38-40], personal risk perception [38,41], fear of flooding in the future [42,43], and coping appraisal (including self-efficacy and response/outcome efficacy) $[38,41]$. Some studies have also identified that individual adaptive behavior is positively influenced by perceived social norms [44,45], local connectedness [46] and perceived incentives for adaptive behavior [45]. What is lacking in this strand of research is how perceptions of measures to reduce future risks interact with both perceptions of risk as well as adaptive behavior. By means of this literature review, we aim to lay the basis for future research endeavors that tackle the above-mentioned relationships.

Against this background, this review paper aims to provide a systematic analysis of state-of-the-art research considering people's perceptions of NBS in the context of hydro-meteorological risks. By perceiving NBS as a means to reduce hydro-meteorological risks, we refer predominantly to how people perceive the co-benefits of NBS as well as the perceived efficacy of NBS to reduce risks.

The paper is structured as follows: Section 2 provides an overview of key terminology including NBS and relevant neighboring concepts, Section 3 lays out the methodology underlying the review process, Section 4 presents the main findings, Section 5 follows with a discussion, and Section 6 concludes with some overarching remarks.

\section{Key Definitions and NBS as an Overarching Concept}

In this section, we provide a short synoptic overview of NBS and their differences and similarities to related concepts, such as ecosystem-based adaptation/risk reduction or green infrastructure. 
Incorporating neighboring terms is relevant, not only because NBS is a relatively new concept but also because it is vaguely defined [47]; this section also helps to further specify the definition of NBS underlying this literature review (see Section 3).

The scope of NBS, and how they differ from similar concepts, is a matter of ongoing debate [23,48]. Nesshover et al. [23], for instance, have identified six neighboring concepts: (1) ecological engineering/catchment systems engineering, (2) green/blue infrastructure, (3) ecosystem approach, (4) ecosystem-based adaptation/mitigation, (5) ecosystem service approach/framework, and (6) natural capital. Each of these concepts is based on different definitions (also for each of the terms), pursues different objectives and can have potentially different relations to the NBS concept. In our view, there are two different viewpoints on NBS that can be identified: While some argue that NBS should be understood as an inclusive umbrella term that spans various neighboring concepts, others argue that NBS is a concept that is distinct from other established concepts. To further illustrate both views, a close look at two common definitions of NBS is helpful.

Since 2013, the European Commission (EC) has conceptualized NBS within the spectrum of ecosystem-based approaches 'as a way to address societal challenges with solutions that are inspired and supported by nature, which are cost-effective, simultaneously provide environmental, social, and economic benefits and help build resilience.' [49]. The International Union for Conversation of Nature (IUCN) provides a similar, but slightly different definition: NBS are understood as "actions to protect, sustainably manage and restore natural and modified ecosystems that address societal challenges effectively and adaptively, simultaneously providing human well-being and biodiversity benefits" [50]. Both definitions are directed towards addressing societal challenges (e.g., risk reduction) and highlight the decisive role of ecosystem processes that are framed as a means to provide multiple co-benefits to ecosystems and society. The IUCN definition, however, clearly features the relevance of protecting, sustainably managing, and ideally restoring ecosystems that have been modified by anthropogenic use. On the contrary, the EU definition is less strict with respect to the protection/restoration of ecosystems; it rather highlights how nature might support addressing societal challenges [25].

Applying both definitions to the subject of this literature review, differences in the means of reducing hydro-meteorological risks become apparent. Whereas conventional measures to reduce hydro-meteorological risks frame 'nature' as an external entity that triggers hazards, both definitions highlight the importance of re-introducing nature as a solution to benefit both ecosystem and humans [18,51]. In this respect, both definitions focus on NBS to tackle the societal challenge of reducing risks by fostering resilience through consciously using the capacity of nature $[25,33,52]$. However, these definitions propose different means to reduce risks. On the one hand, the EC definition implies that 'ecosystem-based' solutions are not the sole way of reducing risks-NBS can also include engineered hybrid solutions, meaning a mix of green and gray solutions $[53,54]$. The stance of the EC also clearly differs from that of the IUCN in terms of cost-effectiveness of the solution: the EC places the importance of cost-effectiveness at the same level as the multiple benefits in diverse systems and resilience that NBS can bring. On the other hand, the IUCN definition has a different emphasis: if NBS are utilized to reduce hydro-meteorological risks, they should also protect and restore affected ecosystems. In this regard, the IUCN definition has a clear focus on protecting or restoring ecosystems, such as river/ecological restoration and ecological engineering.

Likewise, various allegedly neighboring terms have shown some similarities and differences in comparison with the definitions provided by EC and IUCN. Table 1 illustrates some of the most relevant neighboring terms including ecosystem-based adaptation, river restoration/ecological engineering, and green infrastructure that are of relevance with respect to reducing hydro-meteorological risks. While the concept of ecosystem-based adaptation is quite similar to NBS, as it also points towards promoting multiple co-benefits apart from environmental benefits, its scope is more limited compared to that of NBS as it focuses primarily on reducing the consequences of climate change. Concepts related to river restoration/ecological engineering emphasize the relevance of re-naturalizing ecological elements so that riverine ecosystems develop the capacity to regenerate themselves. In that sense they 
are close to the IUCN definition. However, publications for restoration have increased in past decades, not only focusing on classical ecological theories but also rendering 'nature' as an objective for human use [55], embracing utilitarian concerns that align more closely with the EC definition [48]. In other words, restoration works should meet the needs of humans and, to do so, the delivery of the ecosystem should be maximized. Last, green infrastructure is a concept that originally emerged in urban contexts, whereas it meanwhile has also been adopted in rural contexts [56]. A major difference lies in the focus provided by the definition to solve a pressing societal problem: Whereas NBS emphasize a variety of actions to be taken, green infrastructure points towards solutions that can be provided by 'infrastructure'.

In the light of the previous discussion and being aware of similarities, differences, and the underlying vagueness in NBS concepts [23,47,50], we are not pursuing a narrow definition of NBS [48]. Rather, our analysis is inclusive of various neighboring terms (see Section 3). In line with the definition provided by the EC, the solutions should be clearly directed towards a societal challenge (in this case disaster risk reduction and climate change adaptation), the means to achieve this objective should be inspired and supported by ecosystems and they should provide wider co-benefits for society and/or ecosystems. 


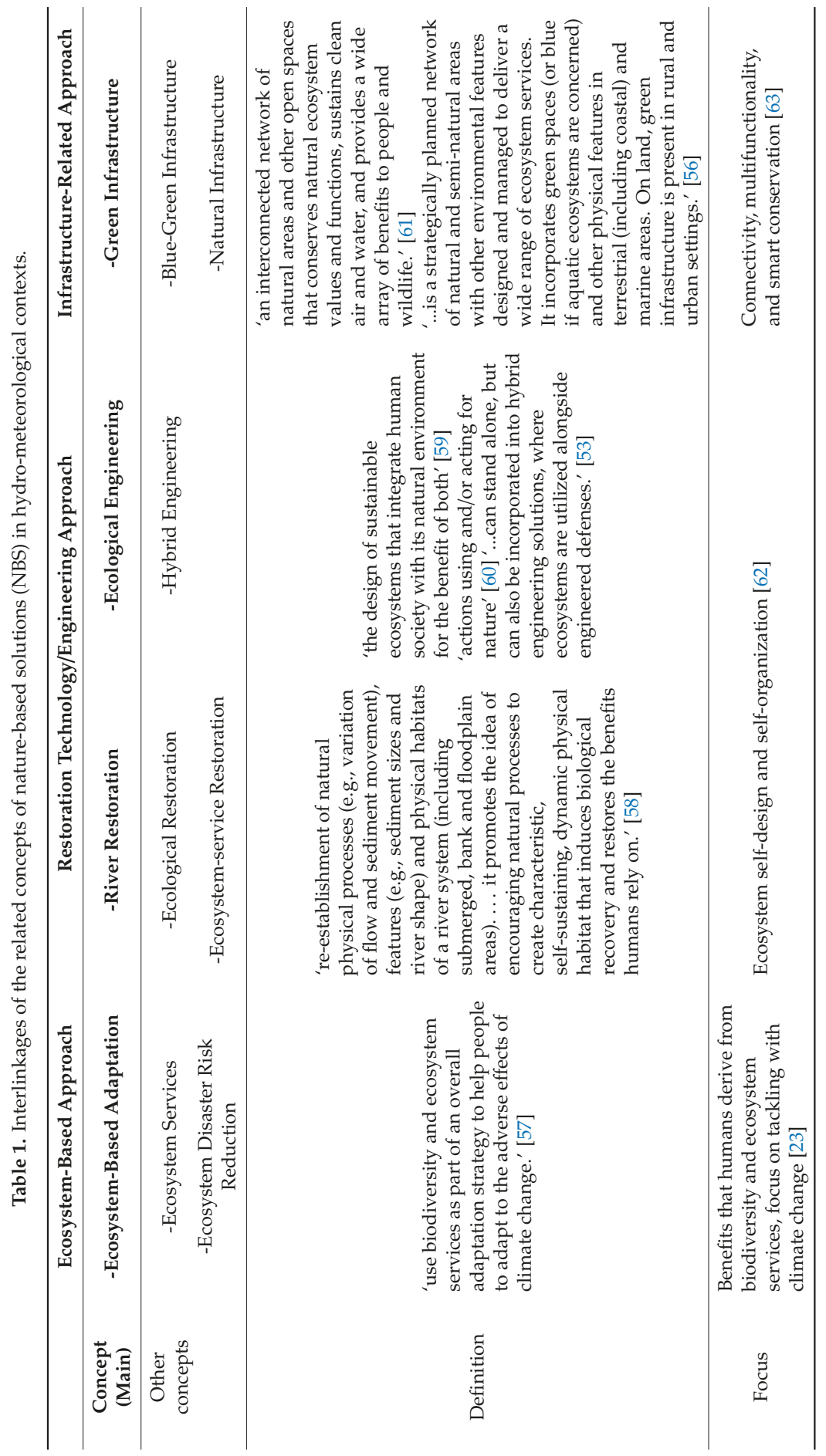




\section{Methods}

We conducted a systematic literature review using the Web of Science database by following the PRISMA guidelines. Web of Science provides an advanced research query tool that guarantees effective and proper coverage [64]. We used a structured query with keywords from three categories to extract the literature from the aforementioned database. This included NBS and relevant neighboring terms, different hydro-meteorological hazards as well as key themes we considered as relevant for a better understanding of how people perceive NBS. We based our search in the Web of Science on the Topic Search, which includes title, abstract, author keywords, and Keywords Plus (assigned by Web of Science). Table 2 summarizes the searched terms and an overview of how we conducted the search.

Table 2. Keywords for the literature survey.

\begin{tabular}{|c|c|c|}
\hline NBS and Related Concepts & Hydro-Meteorological Hazards & Key Themes \\
\hline $\begin{array}{ll}\text { - } & \text { Nature-based Solution } \\
\text { - } & \text { Ecosystem-based solution/management } \\
\text { /adaptation/mitigation/approach/framework } \\
\text { - } & \text { Ecological engineering } \\
\text { - } & \text { Catchment System Engineering } \\
\text { - } & \text { Ecological Restoration } \\
\text { - } & \text { Green Infrastructure } \\
\text { - } & \text { Natural Infrastructure } \\
\text { - } & \text { Eco-hydrological solution/management } \\
\text { - } & \text { /adaptation/mitigation/engineering } \\
\text { - } & \text { Ndaptation service } \\
\text { - } & \text { River Restoration } \\
\end{array}$ & $\begin{array}{ll}\text { - } & \text { Pluvial Risk/Hazard } \\
\text { - } & \text { Coastal Risk/Hazard } \\
\text { - } & \text { Heteorological Risk/Hazard } \\
\text { - } & \text { Flood Risk/Hazard } \\
\text { - } & \text { Climate Change Risk/Hazard } \\
\text { - } & \text { Disaster Risk/Hazard } \\
\text { - } & \text { Natural Risk/Hazard } \\
\text { - } & \text { Environmental Risk/Hazard }\end{array}$ & $\begin{array}{ll}\text { - } & \text { Perception } \\
\text { - } & \text { Awareness } \\
\text { - } & \text { Participation } \\
\text { - } & \text { Stakeholder Involvement } \\
\text { - } & \text { Governance } \\
\text { - } & \text { Vulnerability } \\
\text { - } & \text { Trust } \\
\text { - } & \text { Planning } \\
\text { - } & \text { Policy } \\
\text { - } & \text { Acceptance } \\
\text { - } & \text { Cognition } \\
\text { - } & \text { Preference } \\
\end{array}$ \\
\hline \multicolumn{3}{|c|}{ Search Terms } \\
\hline $\begin{array}{l}\text { "Nature based solution*" OR ("Eco*system*" } \\
\text { NEAR (solution OR management OR adaptation } \\
\text { OR mitigation OR Approach OR Framework)) } \\
\text { OR "Ecolog* Engineer" OR "Catchment System } \\
\text { Engineer*" OR "Ecolog* Restor" OR "Green } \\
\text { Infrastructur" OR "Natur*Infrastructur" OR } \\
\text { ("Eco*hydro*" NEAR (solution OR management } \\
\text { OR adaptation OR mitigation OR engineer)) OR } \\
\text { "Adapt*service*" OR "Natural Capital" OR } \\
\text { "River Restoration" }\end{array}$ & $\begin{array}{l}\text { AND } \\
\text { (pluv* OR coast* OR * meteo* OR } \\
\text { hydro* OR flood* OR climate } \\
\text { Change OR disaster OR natural } \\
\text { OR environmental) AND (risk OR } \\
\text { hazard) }\end{array}$ & $\begin{array}{l}\text { AND } \\
\left(\text { perce }^{*}\right) \text { OR }\left(\text { aware }^{*}\right) \text { OR } \\
\text { (resilien }^{*} \text { OR }\left(\text { participat }^{*}\right) \text { OR } \\
\text { (stakeholder involv*) OR } \\
\text { (governance) OR (vulnerab*) } \\
\text { OR (trust) OR (planning) OR } \\
\left.\text { (policy) OR (accept }{ }^{*}\right) \text { OR } \\
\left({ }^{*} \text { cognit }^{*}\right) \text { OR }\left(\text { prefer }^{*}\right)\end{array}$ \\
\hline
\end{tabular}

The search elicited 1834 entries. All entries were scanned by having a closer look at the title, abstract, and keywords in order to exclude entries of no relevance for the aim of this study. We only considered papers that included at least one search term within each of three categories (i.e., neighboring terms, hydro-meteorological hazards, and key themes). Articles that did not focus on the reduction of hydro-meteorological risks, such as forest fire, landslide, volcanic risk, etc. were eliminated. After this screening process, 110 papers were left for full-text assessment for its eligibility. These 110 papers were fully read in order to identify papers that have no direct relation to the topic of this paper. Through this process, eight papers were excluded again, resulting in a final database of 102 papers.

With this database, we drew an overview which includes: the types of conceptual terms underlying the studies (e.g., NBS, green infrastructure, restoration, etc.); countries where the study was conducted (if the study has more than one site, all sites mentioned were counted); year of publication; type of analysis followed in each of the papers (e.g., review study, original empirical research), and key topics underlying the studies in order to better understand the factors shaping the perceptions of NBS as a means to reduce hydro-meteorological risks (see Section 4 for the results). During this step, it became apparent that the majority of papers $(N=71)$ were too generic and lacked methodological rigorousness in order to generate robust evidence on factors shaping perceptions of NBS as a means to reduce hydro-meteorological risks. In this regard, we decided to identify the papers that were based on a 
robust methodology and which presented empirical evidence in order to pursue an in-depth analysis. As a result, we chose 31 field studies for the in-depth analysis. The flow chart that shows the whole analytical reviewing process can be found in Figure 1 .

The authors acknowledged the inherent limitations of the methodology. The online research of the peer-reviewed papers using keywords does not provide an exhaustive survey, lacking other essential documents such as gray literature or project reports. However, with the concise and detailed keywords, the authors tried to include the relevant articles as much as possible. To minimize such errors, the result was also double-checked by both authors to raise the credibility of the analysis. By doing so, this review provided readers insight into the scholarly work on the perceptions of NBS with a social science perspective.

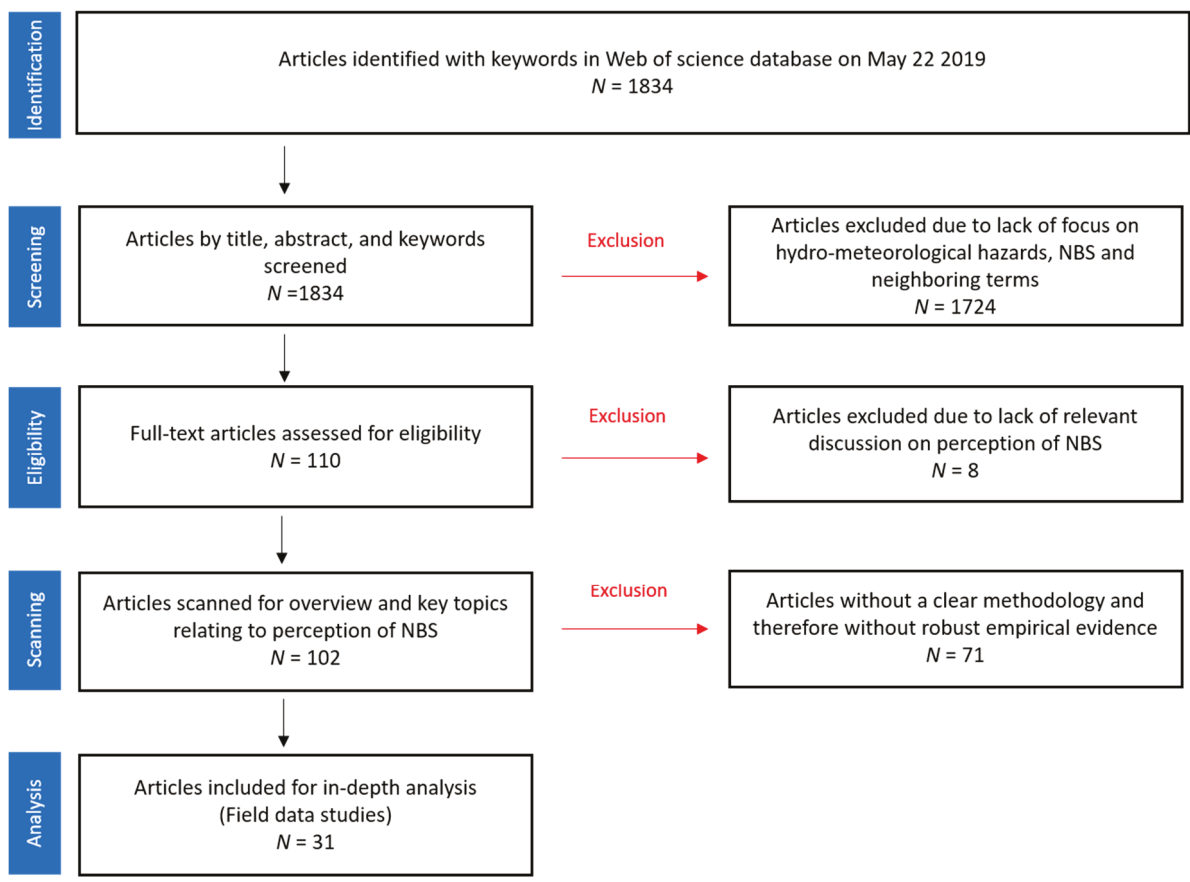

Figure 1. Flow chart of the underlying review process.

\section{Result}

In this section, we present the findings of the review as follows. First, the background information of 102 relevant articles is outlined, such as publication trends, usage of conceptual terms, and geographical location of papers. Second, we identify the core topics that construct perceptions of NBS in hydro-meteorological contexts. Last, the result of in-depth analysis investigating the evidence of the aforementioned topics in 31 field data studies is presented by each topic.

\subsection{Overview of the Relevant Articles}

All 102 papers were published between January 2000 and May 2019. Although papers focusing on 'ecosystem-based' and 'green infrastructure' were already being published in the 1980s and early 1990 s $[65,66]$, they did not focus on the hazards and key topics relevant for this review. As Figure 2 indicates, the number of publications has increased over time. Not only has the absolute number of selected publications increased, but also the normalized value of numbers of the selected papers shows 
an increase in more recent years compared to the normalized value of papers with the topic of flood risk in general. The keywords for the general flood research included the topics we outlined in the 'hydro-meteorological hazard' column in Table 2. The escalation of normalized values in the selected publications indicates that the increase in the number of selected papers did not correlate with an overall increase in general flood risk research, but rather seemed to be related to a greater focus on NBS and neighboring concepts.

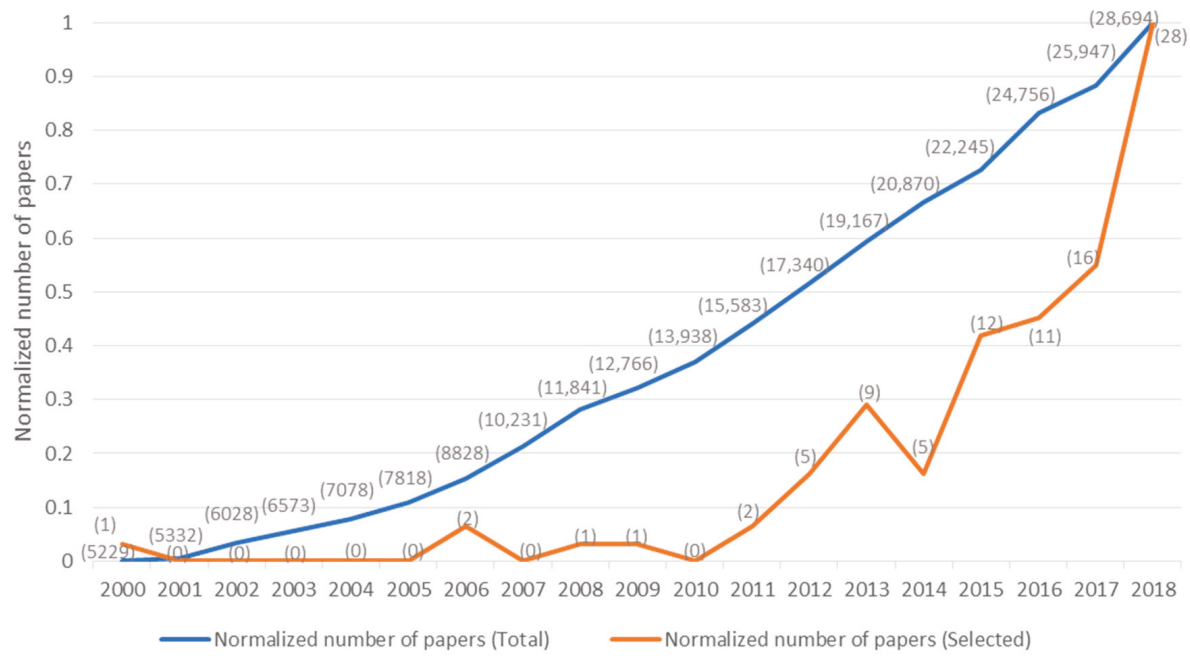

Figure 2. Normalized number of articles comparing the selected papers $(n=102)$ with all flood-related publications between 2000 and 2018 in Web of Science (see Table 2; hazard context).

In a next step, we classified whether the papers focused on NBS or neighboring concepts (Table 3). The broad concepts that represent the sum of sub-concepts are stated in bold. The term 'ecosystem-based' was most widely used in the papers we selected $(n=31,30 \%)$, followed by 'green infrastructure' $(n=24,24 \%)$ and 'restoration' ( $n=21,21 \%)$. NBS was used in 14 papers (14\%), and noticeably all of them were published after 2016 reflecting the recent history of the term. Three papers used the term 'natural infrastructure' or 'nature-based infrastructure.' Besides, nine papers labeled as 'Etc.' adopted specific contextual terms such as hybrid engineering, multi-functional urban watercourses, de-culverting, etc. 
Table 3. The list of full concepts in broad conceptual categories.

\begin{tabular}{|c|c|c|}
\hline Concepts & Number of Papers & Percent \\
\hline Ecosystem-based & 31 & $30 \%$ \\
\hline Eco-Disaster Risk Reduction & 4 & $4 \%$ \\
\hline Ecosystem Approach & 1 & $1 \%$ \\
\hline Ecosystem Services & 4 & $4 \%$ \\
\hline Ecosystem-based Adaptation & 13 & $13 \%$ \\
\hline Ecosystem-based Approach & 1 & $1 \%$ \\
\hline Ecosystem-based DRR & 2 & $2 \%$ \\
\hline Ecosystem-based Management & 5 & $5 \%$ \\
\hline Ecosystem-based Solution & 1 & $1 \%$ \\
\hline Green Infrastructure & 24 & $23 \%$ \\
\hline Blue-Green Infrastructure & 3 & $3 \%$ \\
\hline Green Infrastructure & 20 & $20 \%$ \\
\hline Urban Green Infrastructure & 1 & $1 \%$ \\
\hline Restoration & 21 & $21 \%$ \\
\hline Ecological Restoration & 2 & $2 \%$ \\
\hline Ecosystem Restoration & 1 & $1 \%$ \\
\hline Ecosystem Services Restoration & 1 & $1 \%$ \\
\hline Restoration & 2 & $2 \%$ \\
\hline River Restoration & 14 & $14 \%$ \\
\hline Stream Restoration & 1 & $1 \%$ \\
\hline Nature-based solution & 14 & $30 \%$ \\
\hline Etc. & 9 & $9 \%$ \\
\hline Conservation & 1 & $1 \%$ \\
\hline Flood Control Infrastructure & 1 & $1 \%$ \\
\hline Hybrid Engineering & 2 & $2 \%$ \\
\hline Integrated Catchment Management & 1 & $1 \%$ \\
\hline Multi-functional Urban Watercourses & 1 & $1 \%$ \\
\hline Planned Retreat & 1 & $1 \%$ \\
\hline River Corridor Management & 1 & $1 \%$ \\
\hline River Engineering, de-culverting & 1 & $1 \%$ \\
\hline Natural Infrastructure & 3 & $3 \%$ \\
\hline Natural and Nature-based Infrastructure & 1 & $1 \%$ \\
\hline Natural Infrastructure & 1 & $1 \%$ \\
\hline Nature-based Infrastructure & 1 & $1 \%$ \\
\hline Total & 102 & $100 \%$ \\
\hline
\end{tabular}

Our analysis revealed that the term 'restoration' was gradually substituted by other emerging terms such as NBS, 'ecosystem-based' and 'green infrastructure' (Figure 3). 


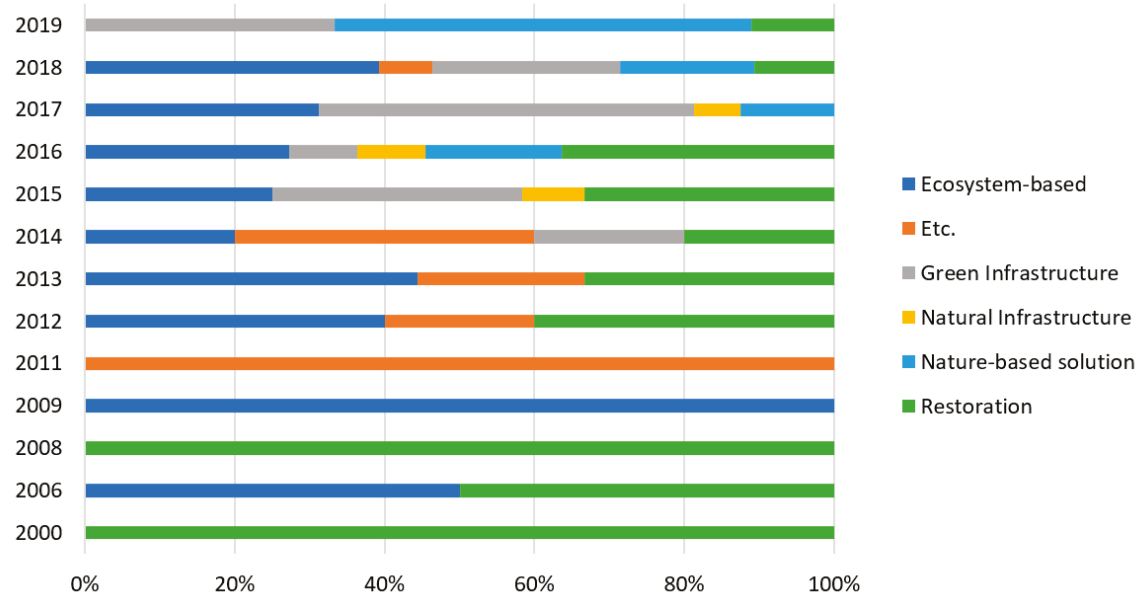

Figure 3. Use of the dominant terms in each paper by publication year.

With 34 papers, most studies were conducted in the European context (32\%), followed by 19 papers in North America (18\%) and 13 in Asia constituting 12\% (Table 4).

Table 4. Number of papers by continent.

\begin{tabular}{ccc}
\hline Continent & \# of Papers & Percent \\
\hline Europe & 34 & $32 \%$ \\
North America & 19 & $18 \%$ \\
Asia & 13 & $12 \%$ \\
Africa & 4 & $4 \%$ \\
South America & 4 & $4 \%$ \\
Oceania & 3 & $3 \%$ \\
Global & 28 & $27 \%$ \\
\hline Total & $105^{1}$ & $100 \%$ \\
\hline
\end{tabular}

${ }^{1}$ When the research was conducted at more than one site, all sites were counted. Therefore, total number of papers did not conform to the total number of reviewed papers $(N=102)$.

Within the sample of this study, studies pursuing an 'ecosystem-based' approach were most frequent in Asia. The terms 'NBS' and 'green infrastructure' were most commonly applied in Europe and in North America (particularly in the US) the term 'restoration' was used most often. Interestingly, 'green infrastructure' was used relatively evenly among all three continents (Figure 4). 


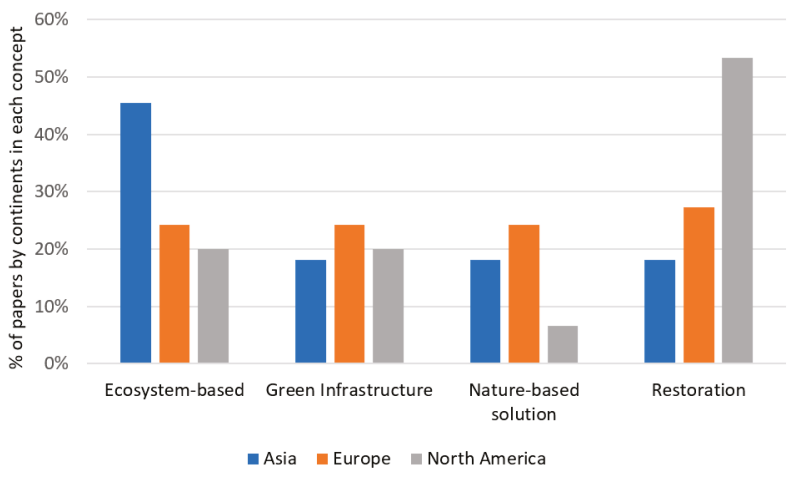

Figure 4. Use of the terms by three major continents.

\subsection{Core Topics}

There are six core topics with respect to perceptions of NBS as a means to reduce hydro-meteorological risks we could identify by scanning 102 relevant papers: (1) valuation of co-benefits (including the valuation of benefits related to ecosystems and society), (2) evaluation of risk reduction efficacy, (3) stakeholder participation, (4) socio-economic and location-specific conditions, (5) environmental attitude, and (6) uncertainty. Table 5 provides an overview of the key features that are dealt with in the single topics.

Table 5. Core topics for perceptions of NBS.

\begin{tabular}{lc}
\hline \multicolumn{1}{c}{ Topics } & Key References \\
\hline (1) Valuation of co-benefits & \\
- Valuation of benefits for ecosystem & {$[30,67-70]$} \\
- Valuation of societal or other benefits & {$[20,30,31,71-75]$} \\
(2) Evaluation of risk reduction efficacy & \\
- Relevance of the physical presence and visibility of measures & {$[20,30,31,72,73,76-78]$} \\
- Expectation towards the successful realization of NBS & {$[30,71,79]$} \\
(3) Stakeholder participation & \\
- Role of communication between stakeholders & {$[31,71,80-83]$} \\
- Role of trust between stakeholders & {$[84-86]$} \\
- Role of trust in institutions & {$[87]$} \\
(4) Socio-economic and location-specific condition & {$[75,88]$} \\
- Individual economic conditions & {$[33,74,89,90]$} \\
- Educational level & {$[30,91-94]$} \\
- Location-specific conditions & {$[84,88]$} \\
- Environmental justice and equity & \\
(5) Environmental Attitude & {$[74,91,93]$} \\
- Stewardship of nature & {$[21,53,77,95,96]$} \\
(6) Uncertainty & {$[30,53,84,91,94,97-99]$} \\
- Time lag for observing benefits & {$[21,100]$} \\
- Lack of data and knowledge & \\
- Uncertain conditions upon human-nature interactions &
\end{tabular}

\subsection{In-Depth Analysis Based on Empirical Evidence for Core Topics}

The in-depth analysis was based on six key topics derived from the scanning process of the 31 field data studies. The investigation process allowed us to grasp what kind of empirical evidences are presented with respect to the six key topics.

The analysis first revealed that 21 out of 31 papers $(68 \%)$ did not show any explicit theories. Three papers used utility theory, along with contingent valuation and choice modeling as a methodology 
to scrutinize people's preferences. Another three papers were based on grounded theory, which is rather a methodological for gathering and analyzing data based inductive reasoning. In addition, we found that the following theories were utilized by one paper each: the theory of sustainability transition, the theory of adaptive co-management, human ecology and interdisciplinary theories of governance, socio-ecological systems, infrastructure studies, and multilevel politics. Last, we identified some papers that, while not explicitly engaged with a theory, showed a slight inclination towards certain theories such as protection motivation theory and environmental justice. In the following subsections, we analyzed how empirical studies illustrate and operationalize six key topics and the underlying relationships between the constructs.

\subsubsection{Valuation of Co-Benefits}

One of the most prominent topics in the reviewed literature, represented in 15 papers, addresses how people value and perceive the co-benefits of NBS and related concepts. The assessment, evaluation and demonstration of the wider benefits of NBS is currently a prominent topic in research on NBS and emphasizes the funding of Horizon 2020 calls [101]. Compared to conventional, technical, and/or engineering-based solutions, NBS are expected to deliver wider benefits, including various 'ecosystem services' they provide to society [85]. Therefore, studies have explored how people value ecosystem services and how this influences their perceptions of NBS. All reviewed studies are based on surveys, interviews and workshops. The following methods were adopted: content analysis [30,102], statistical analysis [74,103], contingent valuation as a form of willingness to pay [85], and multi-criteria decision analysis (MCDA) paired with multi-attribute utility theory and choice experiment [67].

Studies focusing on the individual valuation of co-benefits focused predominantly on aesthetical $[20,31,87,102,104]$ and recreational aspects $[30,71,87,105]$. Both co-benefits seem to have a positive influence on people's perception of NBS, although in some studies aesthetical aspects were found to be perceived as of lower relevance compared to other co-benefits [31,104].

Other studies explored attitudes towards NBS compared to more established technical-engineering based measures to reduce risks. Findings indicate that people support NBS and that they prefer NBS if they also positively value wider social and natural co-benefits, such as aesthetical, recreational, economic, and nature-related aspects $[31,103,106]$.

Studies have also explored how interaction with NBS shape individual perceptions of NBS. People who directly interact with NBS report higher awareness of both the potential positive effects of NBS and of risks compared to people with lower degrees of interaction, such as tourists [74], users compared to non-users [75], or NBS sites that are less accessible [71].

\subsubsection{Evaluation of Risk Reduction Efficacy}

The perceived efficacy of NBS is another prominent topic in the literature we reviewed $(n=9)$. As NBS are often replacing or complementing more established technical, engineering-based risk reduction measures, many studies take a comparative perspective by, at least implicitly, comparing the efficacy of established measures with NBS.

NBS and related approaches are often perceived by people as being less effective than traditional protection schemes. This pattern was found in the management of coastal hazards [30] and urban flooding (e.g., removal of culverts) $[79,102,105,106]$. We can only speculate about the reasons for this pattern: Some authors suggest that the immediate physical presence and visibility of technical measures are interpreted by individuals as a demonstration of progress and problem-solving attitudes by responsible governmental bodies [32], and may also contribute to an increased feeling of protection $[30,106]$. Other studies point to the underlying threat appraisal. People who perceive a high threat of future typhoons and monsoon events also report higher trust in technical solutions than in NBS [79]. Similarly, the ambivalent role of pioneering projects is touched upon: if preceding NBS projects were not well planned and implemented and turned out to be ineffective, this can undermine people's trust in their effectiveness [79]. 
We found one study stating that respondents of a survey reported that flood risk was reduced and that this reduction was attributable to the successful realization of NBS [71]. Another study suggested that the framing of NBS as a means to enhance the safety of a place could positively influence the perceived efficacy of NBS [87]. At the same time, one study showed that lower levels of perceived efficacy of NBS do not affect the support of people. Wong-Parodi and Klima [103] found out that people support and prefer green infrastructure over gray, even though they think that current engineer-based infrastructure secures them more effectively.

\subsubsection{Stakeholder Participation}

Stakeholder participation has received attention as one of the essential elements in risk management processes and NBS implementation. It is crucial to respect the right of stakeholders, including those affected by NBS for hydro-meteorological risk reduction purpose, to be involved in decision-making processes and to facilitate effective solutions for societal problems [107].

The willingness of stakeholders to take part in the realization of NBS can be explained in multiple ways, including from a supportive attitude towards NBS, or from strong resistance to the realization of NBS.

Although participation was touched upon in 12 of the empirical studies we reviewed, it was not usually their main focus. Nevertheless, we found several cases that prove that participation can stimulate people to be aware of ongoing local problems and needs $[32,106]$. This can result in improved stakeholder coordination to realize projects [108]. In addition, participation can embrace the diversity of the affected community in the design and planning process, promoting local buy-in of solutions [31]. In this regard, effective communication among stakeholders is considered key to innovation and dynamism in NBS projects [32,71], which can be a driving force to sustainable project implementation [20].

A few other studies insist that trust influences stakeholder participation and involvement. Trust between stakeholders facilitates the exchange of information and strengthen relationships [32]. By doing so, it enhances stakeholder's acceptance of vulnerability to project implementation $[84,86]$ and can ease conflicts of interest between actors [85]. In addition, participation can also increase ownership among local communities of the realization of NBS projects [84]. Furthermore, trust in responsible organizations and institutions (as exemplified in the Room for River Program in the Netherlands and people's trust in Dutch safety standards) brings more support for new solutions [87]. When involved communities have a strong attachment to a proposed project site, extra care for the building of trust is needed [87].

Lastly, the studies also found that wider stakeholder participation can contribute to mainstreaming NBS while fulfilling the project's ecological aim [109]. In order to foster more participation and satisfaction of stakeholders, the implementation scheme, including the purpose and technique of the project, should be described to them in advance of its implementation [110]. Likewise, a realistic implementation scheme, including information about long-term benefits or time lags in a project's successful delivery, should be shared between stakeholders to prevent frustration [71].

\subsubsection{Socio-Economic and Location-Specific Conditions}

Numerous other papers $(n=10)$ have reported socio-economic and location-specific conditions related to people's perceptions of NBS. However, the reviewed papers provided inconsistent findings; they showed heterogeneous results that are largely shaped by the respective context.

In contrast with a study that indicated that different socio-economic conditions do not affect perceptions of green measures [88], other papers show evidence for such a correlation. For example, Sheng et al. [110] found that household income and the amount of government subsidy received for owned pasture area correlated with the positive support of a restoration project. However, Brouwer et al. [75] found that this correlation is not universal but only occurs for lower-income households depending on the respective national context. Furthermore, educational level seems to have a clear 
positive effect on perceptions of NBS [74,111]. This observation can be linked with the finding that a lack of knowledge/understanding of NBS affects people's supportive attitudes $[30,89,90]$.

Other studies found that a preference for NBS can be location-specific $[30,103]$. On the one hand, the location associated with the personal experiences of a hazard influences perceptions of NBS [30]. This is particularly true for negative experiences, which may impede NBS support [111]. On the other hand, socio-cultural aspects seem to influence the preference of the local communities with respect to NBS. In detail, it can differ depending on how much people are attached to the project location [87] and the local history regarding mitigation measures [30].

\subsubsection{Environmental Attitude}

A few studies $(n=2)$ have found evidence that the environmental attitude of stakeholders shapes their attitude towards NBS. For instance, people who reported higher degrees of stewardship to nature or, otherwise stated, those who put a higher value on feeling responsible for the conservation of nature, preferred NBS over more conventional flood management approaches [93]. Another study interpreted a preference for NBS as evidence of altruistic behavior: though individuals did not receive any personal benefit, they still preferred NBS for the sake of 'the level of environmental quality provided' and 'the act of giving' [67].

\subsubsection{Uncertainty}

A considerable number of papers, which we scanned previously for the core topics, mentioned uncertainty in NBS implementation. This was attributed to lack of long-term data and the complexity inherent in nature (i.e., 'surprise', given by the variability of nature as a baseline) and human-nature interactions, which depend on physical, ecological, and socio-economic conditions (see Table 5). However, these arguments are backed up by merely two empirical studies. First, uncertain aspects of project implementation are seen to play a role in raising local concerns about safety. It relates to the individual perception of risk efficacy of NBS, and the idea that unstable features of nature threaten local people [105]. Second, a survey-based study revealed that a lack of knowledge and understanding was a barrier to gaining support from local authorities and public [89].

\section{Discussion}

This review has thematically focused on documenting state-of-the-art factors that shape perceptions of NBS by means of reducing hydro-meteorological risks. Departing from a rather broad understanding of NBS that is grounded in the definitions of NBS provided by the EC and IUCN, we also included neighboring terms in this review to ensure broad thematic coverage.

Based on 102 studies, we identified six topics shaping the current discussion in this field of research. The empirical insights concerning these topics are not only diverse but also sometimes even contradictory, and they also vary in the depth of the insights generated. Most pronounced are studies focusing on affected people's perceptions of the co-benefits and efficacy of NBS.

Concerning perceptions of co-benefits, the results are relatively consistent: Studies suggest that if co-benefits are valued positively, NBS are also perceived positively, particularly if people have direct access to NBS and interact with these solutions relatively often. However, the studies we reviewed focused only on co-benefits related to recreational and aesthetical aspects of NBS - other aspects such as health, wellbeing, cultural values, and economic development have not yet been considered.

As for the perceived efficacy of NBS, findings are rather mixed. While NBS are often perceived as less effective than more established and technical risk reduction measures, we know very little about the underlying reasons for this tendency. Next to the immediate physical presence of technical measures, the relation between perceived efficacy of NBS and threat appraisal seems relevant: if threat appraisal is high, trust in NBS seems to be lower. However, few available studies explore this connection more thoroughly. Some studies indicate that trust in NBS efficacy can increase over time if exposed residents realize that NBS can reduce the risk of hydro-meteorological events. 
Regarding socio-economic and location-specific conditions, findings are also mixed: While some studies suggest no correlation between socio-economic statuses of households and their perception of NBS, other studies highlight a correlation. We assume that contextual factors play a decisive role here. This is at least suggested by the cross-country studies conducted by Brouwer et al. [75], which imply that different spatial, socio-economic-demographic, cultural, and institutional settings may correlate with a different perception of NBS.

Very few studies have focused on how people's environmental attitudes shape their perceptions of NBS. It was shown that people who report higher degrees of stewardship to nature prefer NBS over more conventional flood management approaches $[67,93]$.

The role of uncertainty is also seldom explored. High uncertainty concerning the realization of NBS projects may undermine people's feelings of safety, furthermore, a lack of knowledge about the effects of NBS may also be a barrier for the support for NBS.

Finally, findings on stakeholder participation are rather limited. We found that participation can stimulate people's awareness of ongoing local problems and needs, and can, therefore, result in improved stakeholder coordination to realize projects. Stakeholder perceptions of NBS also seem to be positively influenced when effectively informed about the realization of NBS. Studies also found that wider stakeholder participation can contribute to the mainstreaming of NBS and can help fulfill the wider ecological objectives of NBS projects.

The field of research in this review is still emerging. Among the papers we reviewed, very few focus explicitly on NBS to reduce hydro-meteorological risks and how they are perceived. The majority focuses on other topics, though they do touch upon the core topics of this paper. The studies we identified as most relevant for this paper (i.e., defined by an explicated methodology aiming at generating evidence) also underline that this research field is still developing. Most of the papers did not explicate their underlying theories. This hampers the comparability of empirical insights. For instance, in other related fields of research (e.g., what motivates individual adaptive behavior) where at least basic theoretical aspects are shared (e.g., protection motivation theory), a comparison of empirical studies has become possible eventually by allowing the conduction of statistically grounded meta-analyses [112]. However, this is barely possible in for the reviewed studies, most of which collect empirical data and insights without grounding them in a theoretical framework.

As an implication of the previously identified gap, there are hardly any studies that systematically frame the inter-linkages between the different constructs we previously outlined. Based on the review, however, it is possible to outline some basal inter-linkages that require further exploration in future studies (see Figure 5). We also believe that this generic model has the potential to be applied in other hazard contexts such as a landslide and earthquake, which can be investigated more in-depth in future studies.

More specifically, we expect that interacting constructs, particularly the valuation of efficacy and co-benefits of NBS, could influence people's perception of NBS. We also consider it likely that other variables might moderate these interactions. First, people's threat appraisal could moderate the impact of evaluation of risk reduction efficacy on perceptions of NBS. If people feel threatened by the consequences of hydro-meteorological risks, they may have lower levels of trust in the effectiveness of NBS to reduce risk. This lack of trust could outweigh positive attitudes towards the co-benefits of NBS, and result in negative attitudes towards NBS. However, it is likely that people's threat appraisal not only relates to primary hydro-meteorological risks but also to potential secondary risks related to NBS. People may believe that the replacement of technical measures with NBS will increase hydro-meteorological risk for their property [113], or that NBS may cause new risks such as invasive organic species or rising groundwater levels [54]. Second, we also expect that people's environmental attitudes and the likelihood of their direct use of, or interaction with, NBS could moderate their perception of co-benefits. If people have a strong pro-environmental attitude, this might positively reinforce the impact of their valuation of the NBS co-benefits. Perceived NBS co-benefits also might then outweigh concern about the efficacy of NBS, resulting in more positive attitudes towards NBS. 
Likewise, if affected people are more likely to benefit from or interact with NBS due to spatial proximity, etc., this might positively moderate the valuation of co-benefits. However, at this stage, we can only speculate about these construct interactions.

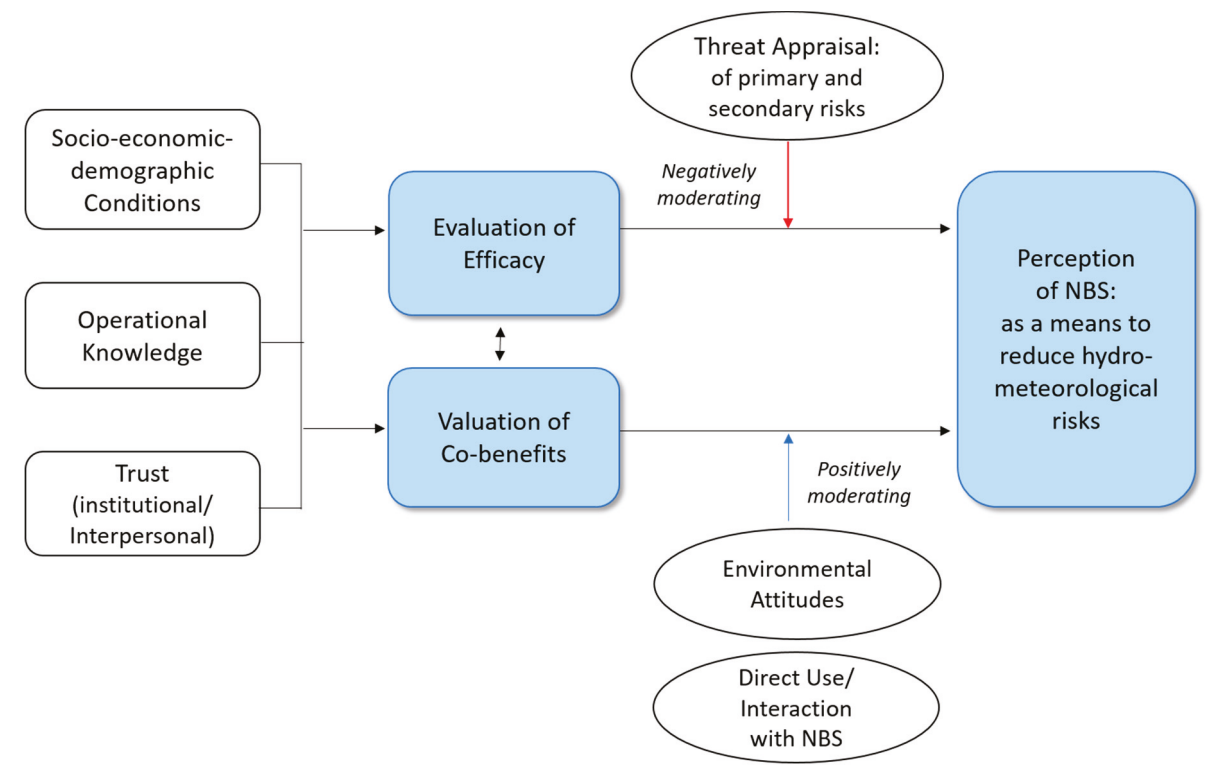

Figure 5. A generic model for the potential interplay of key constructs underlying perceptions of NBS as a means to reduce hydro-meteorological risks.

Furthermore, we assume that an individual's valuation of NBS co-benefits and efficacy might be influenced by their socio-economic-demographic conditions and NBS knowledge (for instance, knowledge about the effects of NBS and realistic implementation scheme), possibly obtained from prior experiences or other informational sources. Based on our literature review, we could only conjecture about the role of people's socio-economic-demographic situation and point towards contextual factors. In addition, it is assumed that both intrapersonal (i.e., between stakeholders) and institutional (i.e., in responsible organizations and institutions) trust shape the valuation of NBS co-benefits and efficacy. We also surmise that participation may play a role in stimulating these factors and, ultimately, positively influence the valuation of efficacy and co-benefits.

While we believe that a more structured and theoretically grounded approach to the assessment of people's perception of NBS is necessary, we also consider that greater attention needs to be paid to what counts as NBS. In this study, we reviewed a considerable number of publications that focused on different concepts, such as ecosystem-based adaptation, restoration, and green infrastructure. As the concept of NBS implies, at least in its more inclusive definition, all 'solutions' are comparable as long as they are directed towards addressing societal challenges, provide co-benefits and are inspired or supported by ecosystems. Focusing on how people perceive NBS, however, it is debatable that a small-scale hybrid NBS, implemented in an urban context, is comparable to a large-scale river restoration project at the catchment scale, the latter of which not only influences people's livelihoods but also profoundly transforms an entire landscape. In addition, environmental attitudes were distinctively scrutinized in publications focusing on restoration, while the perceived co-benefit was explored more systematically in literature dealing with NBS and green infrastructure literature. Such differences, both for NBS and thematic emphases, need to be accounted for more carefully in future research. 
We, therefore, propose that future research should reflect these different NBS by using a more conscious sampling strategy, at least for the quantitative standardized surveys-this would contribute a better understanding of how different NBS perceptions are shaped. The typology proposed by Eggermont et al. [54] can offer some instructive insights on how to operationalize such a sampling procedure. They argue that NBS approaches can be broadly classified into three types along a gradient of the level and intensity of engineering applied. Type 1 NBS approaches involve no or minimal intervention in ecosystems, type 2 measures are aimed at establishing sustainable and multifunctional ecosystems, and type 3 NBS approaches imply a profound transformation of ecosystems possibly even resulting in new ecosystems. Based on our review, we assume that these fundamental differences in NBS setup would have a great impact on people's attitudes towards them. Therefore, such differences should be reflected in the selection of case studies for empirical research.

\section{Conclusions}

We believe that more social science research, based on rigorous methodologies and grounded in social science theories, is needed to complement the currently dominant approach that focuses on the quantitative evaluation of NBS co-benefits. As this review has indicated, our knowledge about perceptions of NBS as a means to reduce hydro-meteorological risks is still hampered by profound gaps in knowledge. With this article, we have outlined some avenues for future research.

Our results show that the current knowledge of concepts surrounding perceptions of NBS is not always consistent. While perceived co-benefits show a relatively strong positive impact on the people's perceptions of NBS, other factors such as perceived efficacy of NBS and individual socio-economic-demographic conditions show conflicting results. We concluded that the scale of each NBS project (e.g., large-scale river restoration compared with small scale installation of green infrastructure) and the level of engineering used can contribute to the discrepancies in perceptions of NBS shown in the empirical studies. Therefore, we propose that future empirical studies regarding perceptions of NBS should conduct a careful sampling of different NBS and be cognizant of comparing NBS projects. We also found that some essential variables, such as environmental attitudes and uncertainty, have been overlooked in the empirical research. Finally, our model for the potential interplay of key constructs underlying perceptions of NBS shows the possible relationships between constructs and emphasizes the need for a theoretical framework. Such frameworks encompass fragmented knowledge and generate meaningful insights to help raise people's supportive attitudes towards NBS.

Author Contributions: Conceptualization, S.H. and C.K.; methodology, S.H. and C.K.; validation, S.H. and C.K.; investigation, S.H. and C.K.; writing-original draft preparation, S.H.; writing-review and editing, C.K.; visualization, S.H.; supervision, C.K.

Funding: C.K. received funding from the European Union's Horizon 2020 research and innovation program under grant agreement No. 776866.

Acknowledgments: S.H. would like to express her gratitude for the research support from German Academic Exchange Service (DAAD).

Conflicts of Interest: The authors declare no conflict of interest.

\section{References}

1. Wu, H.; Huang, M.; Tang, Q.; Kirschbaum, D.B.; Ward, P. Hydrometeorological hazards: Monitoring, forecasting, risk assessment, and socioeconomic responses. Adv. Meteorol. 2016, 3. [CrossRef]

2. Blaikie, P.; Cannon, T.; Davis, I.; Wisner, B. At Risk: Natural Hazards, People's Vulnerability, and Disaster; Routledge: London, UK; New York, NY, USA, 1994.

3. Watts, M.J.; Bohle, H.G. The space of vulnerability: The causal structure of hunger and famine. Prog. Hum. Geogr. 1993, 17, 43-67. [CrossRef]

4. Kundzewicz, Z.W.; Jania, J.A. Extreme hydro-meteorological events and their impacts. From the global down to the regional scale. Geogr. Pol. 2007, 80, 9-23. 
5. Hirabayashi, Y.; Mahendran, R.; Koirala, S.; Konoshima, L.; Yamazaki, D.; Watanabe, S.; Kim, H.; Kanae, S. Global flood risk under climate change. Nat. Clim. Chang. 2013, 3, 816. [CrossRef]

6. Milly, P.C.D.; Betancourt, J.; Falkenmark, M.; Hirsch, R.M.; Kundzewicz, Z.W.; Lettenmaier, D.P.; Stouffer, R.J. Stationarity is dead: Whither water management? Science 2008, 319, 573-574. [CrossRef] [PubMed]

7. Thieken, A.H.; Cammerer, H.; Dobler, C.; Lammel, J.; Schöberl, F. Estimating changes in flood risks and benefits of non-structural adaptation strategies-A case study from Tyrol, Austria. Mitig. Adapt. Strateg. Glob. Chang. 2016, 21, 343-376. [CrossRef]

8. Field, C.B.; Barros, V.; Stocker, T.F.; Dahe, Q. Managing the Risks of Extreme Events and Disasters to Advance Climate Change Adaptation: Special Report of the Intergovernmental Panel on Climate Change; Cambridge University Press: Cambridge, UK, 2012.

9. Hooijer, A.; Klijn, F.; Pedroli, G.B.M.; Van Os, A.G. Towards sustainable flood risk management in the Rhine and Meuse river basins: Synopsis of the findings of IRMA-SPONGE. River Res. Appl. 2004, 20, 343-357. [CrossRef]

10. Rogger, M.; Agnoletti, M.; Alaoui, A.; Bathurst, J.C.; Bodner, G.; Borga, M.; Chaplot, V.; Gallart, F.; Glatzel, G.; Hall, J.; et al. Land use change impacts on floods at the catchment scale: Challenges and opportunities for future research. Water Resour. Res. 2017, 53, 5209-5219. [CrossRef]

11. Seto, K.C.; Fragkias, M.; Güneralp, B.; Reilly, M.K.J.P.O. A meta-analysis of global urban land expansion. PLoS One 2011, 6, e23777. [CrossRef]

12. Beckers, A.; Dewals, B.; Erpicum, S.; Dujardin, S.; Detrembleur, S.; Teller, J.; Pirotton, M.; Archambeau, P. Contribution of land use changes to future flood damage along the river Meuse in the Walloon region. Nat. Hazards Earth Syst. Sci. 2013, 13, 2301-2318. [CrossRef]

13. Hall, J.W.; Sayers, P.B.; Walkden, M.J.; Panzeri, M. Impacts of climate change on coastal flood risk in England and Wales: 2030-2100. Philos. Trans. R. Soc. A Math. Phys. Eng. Sci. 2006, 364, 1027-1049. [CrossRef] [PubMed]

14. Barredo, J.I. Normalised flood losses in Europe: 1970-2006. Nat. Hazards Earth Syst. Sci. 2009, 9, 97-104. [CrossRef]

15. Accastello, C.; Blanc, S.; Brun, F. A framework for the integration of nature-based solutions into environmental risk management strategies. Sustainability 2019, 11, 489. [CrossRef]

16. Kabisch, N.; Korn, H.; Stadler, J.; Bonn, A. (Eds.) Nature-Based Solutions to Climate Change Adaptation in Urban Areas: Linkages between Science, Policy and Practice; Springer: Cham, Switzerland, 2017.

17. Bubeck, P.; Kreibich, H.; Penning-Rowsell, E.C.; Botzen, W.J.W.; de Moel, H.; Klijn, F. Explaining differences in flood management approaches in Europe and in the USA-A comparative analysis. J. Flood Risk Manag. 2017, 10, 436-445. [CrossRef]

18. Mitsch, W.J.; Jørgensen, S.E. Ecological engineering: A field whose time has come. Ecol. Eng. 2003, 20,363-377. [CrossRef]

19. Fernandes, J.P.A.; Guiomar, N. Environmental ethics: Driving factors beneath behavior, discourse and decision-making. J. Agric. Environ. Ethics 2016, 29, 507-540. [CrossRef]

20. Barthelemy, C.; Armani, G. A comparison of social processes at three sites of the French Rhone River subjected to ecological restoration. Freshw. Biol. 2015, 60, 1208-1220. [CrossRef]

21. Doswald, N.; Munroe, R.; Roe, D.; Giuliani, A.; Castelli, I.; Stephens, J.; Moller, I.; Spencer, T.; Vira, B.; Reid, H. Effectiveness of ecosystem-based approaches for adaptation: Review of the evidence-base. Clim. Dev. 2014, 6, 185-201. [CrossRef]

22. Collentine, D.; Futter, M.N. Realising the potential of natural water retention measures in catchment flood management: Trade-offs and matching interests. J. Flood Risk Manag. 2018, 11, 76-84. [CrossRef]

23. Nesshover, C.; Assmuth, T.; Irvine, K.N.; Rusch, G.M.; Waylen, K.A.; Delbaere, B.; Haase, D.; Jones-Walters, L.; Keune, H.; Kovacs, E.; et al. The science, policy and practice of nature-based solutions: An interdisciplinary perspective. Sci. Total Environ. 2017, 579, 1215-1227. [CrossRef]

24. Raymond, C.M.; Frantzeskaki, N.; Kabisch, N.; Berry, P.; Breil, M.; Nita, M.R.; Geneletti, D.; Calfapietra, C. A framework for assessing and implementing the co-benefits of nature-based solutions in urban areas. Environ. Sci. Policy 2017, 77, 15-24. [CrossRef]

25. Albert, C.; Schroter, B.; Haase, D.; Brillinger, M.; Henze, J.; Herrmann, S.; Gottwald, S.; Guerrero, P.; Nicolas, C.; Matzdorf, B. Addressing societal challenges through nature-based solutions: How can landscape planning and governance research contribute? Landsc. Urban Plan. 2019, 182, 12-21. [CrossRef] 
26. Brink, E.; Aalders, T.; Adam, D.; Feller, R.; Henselek, Y.; Hoffmann, A.; Ibe, K.; Matthey-Doret, A.; Meyer, M.; Negrut, N.L.; et al. Cascades of green: A review of ecosystem-based adaptation in urban areas. Glob. Environ. Chang. 2016, 36, 111-123. [CrossRef]

27. van Wesenbeeck, B.; IJff, S.; Jongman, B.; Balog, S.; Kaupa, S.; Bosche, L.; Lange, G.; Holm-Nielsen, N.; Nieboer, H.; Taishi, Y. Implementing nature based flood protection: principles and implementation guidance (English); World Bank Group: Washington, DC, USA, 2017.

28. Kabisch, N.; Frantzeskaki, N.; Pauleit, S.; Naumann, S.; Davis, M.; Artmann, M.; Haase, D.; Knapp, S.; Korn, H.; Stadler, J.; et al. Nature-based solutions to climate change mitigation and adaptation in urban areas: Perspectives on indicators, knowledge gaps, barriers, and opportunities for action. Ecol. Soc. 2016, 21, 39. [CrossRef]

29. Dhakal, K.P.; Chevalier, L.R. Managing urban stormwater for urban sustainability: Barriers and policy solutions for green infrastructure application. J. Environ. Manag. 2017, 203, 171-181. [CrossRef] [PubMed]

30. Gray, J.D.E.; O'Neill, K.; Qiu, Z.Y. Coastal residents' perceptions of the function of and relationship between engineered and natural infrastructure for coastal hazard mitigation. Ocean Coast. Manag. 2017, 146, 144-156. [CrossRef]

31. Loos, J.R.; Rogers, S.H. Understanding stakeholder preferences for flood adaptation alternatives with natural capital implications. Ecol. Soc. 2016, 21. [CrossRef]

32. Ardaya, A.B.; Evers, M.; Ribbe, L. What influences disaster risk perception? Intervention measures, flood and landslide risk perception of the population living in flood risk areas in Rio de Janeiro state, Brazil. Int. J. Disaster Risk Reduct. 2017, 25, 227-237. [CrossRef]

33. Short, C.; Clarke, L.; Carnelli, F.; Uttley, C.; Smith, B. Capturing the multiple benefits associated with nature-based solutions: Lessons from a natural flood management project in the Cotswolds, UK. Land Degrad. Dev. 2019, 30, 241-252. [CrossRef]

34. Slovic, P. Perception of risk. Science 1987, 236, 280-285. [CrossRef]

35. Renn, O. Concepts of risk: A classification. In Social Theories of Risk; Krimsky, S., Golding, D., Eds.; Praeger: Westport, CT, USA; London, UK, 1992; pp. 53-79.

36. Renn, O. Three decades of risk research: Accomplishments and new challenges. J. Risk Res. 1998, 1, 49-71. [CrossRef]

37. Wachinger, G.; Renn, O.; Begg, C.; Kuhlicke, C. The risk perception paradox-implications for governance and communication of natural hazards. Risk Anal. 2013, 33, 1049-1065. [CrossRef] [PubMed]

38. Grothmann, T.; Reusswig, F. People at risk of flooding: Why some residents take precautionary action while others do not. Nat. Hazards 2006, 38, 101-120. [CrossRef]

39. Zaalberg, R.; Midden, C.; Meijnders, A.; McCalley, T. Prevention, adaptation, and threat denial: Flooding experiences in The Netherlands. Risk Anal. 2009, 29, 1759-1778. [CrossRef] [PubMed]

40. Harvatt, J.; Petts, J.; Chilvers, J. Understanding householder responses to natural hazards: Flooding and sea-level rise comparisons. J. Risk Res. 2011, 14, 63-83. [CrossRef]

41. Terpstra, T.; Lindell, M.K. Citizens' perceptions of flood hazard adjustments: An application of the protective action decision model. Environ. Behav. 2013, 45, 993-1018. [CrossRef]

42. Harries, T. The anticipated emotional consequences of adaptive behaviour-Impacts on the take-up of household flood-protection measures. Environ. Plan. A Econ. Space 2012, 44, 649-668. [CrossRef]

43. Terpstra, T. Emotions, trust, and perceived risk: Affective and cognitive routes to flood preparedness behavior. Risk Anal. 2011, 31, 1658-1675. [CrossRef]

44. Lo, A.Y. The role of social norms in climate adaptation: Mediating risk perception and flood insurance purchase. Glob. Environ. Chang. 2013, 23, 1249-1257. [CrossRef]

45. Poussin, J.K.; Botzen, W.J.W.; Aerts, J.C.J.H. Factors of Influence on flood damage mitigation behavior by households. Environ. Sci. Policy 2014, 40, 69-77. [CrossRef]

46. Kim, Y.-C.; Kang, J. Communication, neighbourhood belonging and household hurricane preparedness. Disasters 2010, 34, 470-488. [CrossRef] [PubMed]

47. Albert, C.; Spangenberg, J.H.; Schröter, B. Nature-based solutions: Criteria. Nature 2017, 543, 315. [CrossRef] [PubMed] 
48. Pauleit, S.; Zölch, T.; Hansen, R.; Randrup, T.B.; Konijnendijk van den Bosch, C. Nature-based solutions and climate change-Four shades of green. In Nature-Based Solutions to Climate Change Adaptation in Urban Areas: Linkages between Science, Policy and Practice; Kabisch, N., Korn, H., Stadler, J., Bonn, A., Eds.; Springer International Publishing: Cham, Switzerland, 2017; pp. 29-49. [CrossRef]

49. Faivre, N.; Fritz, M.; Freitas, T.; de Boissezon, B.; Vandewoestijne, S. Nature-Based Solutions in the EU: Innovating with nature to address social, economic and environmental challenges. Environ. Res. 2017, 159, 509-518. [CrossRef] [PubMed]

50. Cohen-Shacham, E.; Walters, G.; Janzen, C.; Maginnis, S.J.I. Nature-Based Solutions to Address Global Societal Challenges; IUCN: Gland, Switzerland, 2016; Volume 97.

51. Fernandes, J.P.; Guiomar, N. Nature-based solutions: The need to increase the knowledge on their potentialities and limits. Land Degrad. Dev. 2018, 29, 1925-1939. [CrossRef]

52. Kronenberg, J.; Bergier, T.; Maliszewska, K. The challenge of innovation diffusion: Nature-based solutions in Poland. In Nature-Based Solutions to Climate Change Adaptation in Urban Areas; Springer: Cham, Switzerland, 2017; pp. 291-305.

53. Spalding, M.D.; McIvor, A.L.; Beck, M.W.; Koch, E.W.; Moller, I.; Reed, D.J.; Rubinoff, P.; Spencer, T.; Tolhurst, T.J.; Wamsley, T.V.; et al. Coastal ecosystems: A critical element of risk reduction. Conserv. Lett. 2013, 7, 293-301. [CrossRef]

54. Eggermont, H.; Balian, E.; Azevedo, J.M.N.; Beumer, V.; Brodin, T.; Claudet, J.; Fady, B.; Grube, M.; Keune, H.; Lamarque, P.; et al. Nature-based solutions: New influence for environmental management and research in Europe. GAIA 2015, 24, 243-248. [CrossRef]

55. Palmer, M.A.; Hondula, K.L.; Koch, B.J. Ecological restoration of streams and rivers: Shifting strategies and shifting goals. Annu. Rev. Ecol. Evol. Syst. 2014, 45, 247-269. [CrossRef]

56. European Commission. Green Infrastructure (Gi)_Enhancing Europe's Natural Capital; European Commission: Brussels, Belgium, 2013.

57. Convention on Biological Diversity. Connecting Biodiversity and Climate Change Mitigation and Adaptation: Key Messages from the Report of the Second Ad Hoc Technical Expert Group on Biodiversity and Climate Chang; Secretariat of the Convention on Biological Diversity: Montreal, QC, Canada, 2009.

58. Addy, S.; Cooksley, S.; Dodd, N.; Waylen, K.; Stockan, J.; Byg, A.; Holstead, K. River Restoration and Biodiversity; IUCN: Gland, Switzerland, 2016.

59. Mitsch, W.J.; Jørgensen, S.E. Ecological Engineering: An Introduction to Ecotechnology; John Wiley\&Sons, Inc.: New York, NY, USA, 1989.

60. Rey, F.; Cécillon, L.; Cordonnier, T.; Jaunatre, R.; Loucougaray, G. Integrating ecological engineering and ecological intensification from management practices to ecosystem services into a generic framework: A review. Agron. Sustain. Dev. 2015, 35, 1335-1345. [CrossRef]

61. Benedict, M.A.; McMahon, E.T. Green Infrastructure: Linking Landscapes and Communities; Island Press: Washington, DC, USA, 2012.

62. Fath, B.D. Encyclopedia of Ecology; Elsevier: Amsterdam, The Netherlands, 2018.

63. Agency, E.E. Green Infrastructure and Territorial Cohesion: The Concept of Green Infrastructure and Its Integration into Policies Using Monitoring Systems; Publications Office of the European Union: Brussels, Belgium, 2011.

64. Bramer, W.M.; Rethlefsen, M.L.; Kleijnen, J.; Franco, O.H. Optimal database combinations for literature searches in systematic reviews: A prospective exploratory study. Syst. Rev. 2017, 6, 245. [CrossRef]

65. Long, R.D.; Charles, A.; Stephenson, R.L. Key principles of marine ecosystem-based management. Mar. Policy 2015, 57, 53-60. [CrossRef]

66. Mell, I.C. Green infrastructure: Reflections on past, present and future praxis. Landsc. Res. 2017, 42, $135-145$. [CrossRef]

67. Drake, B.; Smart, J.C.R.; Termansen, M.; Hubacek, K. Public preferences for production of local and global ecosystem services. Reg. Environ. Chang. 2013, 13, 649-659. [CrossRef]

68. Hammersley, M.A.; Scott, C.; Gimblett, R. Evolving conceptions of the role of large dams in social-ecological resilience. Ecol. Soc. 2018, 23. [CrossRef]

69. Jones, S.; Somper, C. The role of green infrastructure in climate change adaptation in London. Geogr. J. 2014, 180, 191-196. [CrossRef]

70. Cousins, J.J. Remaking stormwater as a resource: Technology, law, and citizenship. Wiley Interdiscip. Rev. Water 2018, 5, e1300. [CrossRef] 
71. Tunstall, S.M.; Penning-Rowsell, E.C.; Tapsell, S.M.; Eden, S.E. River restoration: Public attitudes and expectations. J. Chart. Inst. Water Environ. Manag. 2000, 14, 363-370. [CrossRef]

72. Matthews, T.; Lo, A.Y.; Byrne, J.A. Reconceptualizing green infrastructure for climate change adaptation: Barriers to adoption and drivers for uptake by spatial planners. Landsc. Urban Plan. 2015, 138, 155-163. [CrossRef]

73. Gumiero, B.; Mant, J.; Hein, T.; Elso, J.; Boz, B. Linking the restoration of rivers and riparian zones/wetlands in Europe: Sharing knowledge through case studies. Ecol. Eng. 2013, 56, 36-50. [CrossRef]

74. Duan, J.Y.; Wang, Y.F.; Fan, C.; Xia, B.C.; de Groot, R. Perception of urban environmental risks and the effects of urban green infrastructures (UGIs) on human well-being in four public green spaces of Guangzhou, China. Environ. Manag. 2018, 62, 500-517. [CrossRef]

75. Brouwer, R.; Bliem, M.; Getzner, M.; Kerekes, S.; Milton, S.; Palarie, T.; Szerenyi, Z.; Vadineanue, A.; Wagtendonk, A. Valuation and transferability of the non-market benefits of river restoration in the Danube river basin using a choice experiment. Ecol. Eng. 2016, 87, 20-29. [CrossRef]

76. Matthews, J.; Van der Velde, G.; Collas, F.P.L.; De Hoop, L.; Koopman, K.R.; Hendriks, A.J.; Leuven, R. Inconsistencies in the risk classification of alien species and implications for risk assessment in the European Union. Ecosphere 2017, 8, e01832. [CrossRef]

77. Sutton-Grier, A.E.; Wowk, K.; Bamford, H. Future of our coasts: The potential for natural and hybrid infrastructure to enhance the resilience of our coastal communities, economies and ecosystems. Environ. Sci. Policy 2015, 51, 137-148. [CrossRef]

78. Mazzorana, B.; Nardini, A.; Comiti, F.; Vignoli, G.; Cook, E.; Ulloa, H.; Iroume, A. Toward participatory decision-making in river corridor management: Two case studies from the European Alps. J. Environ. Plan. Manag. 2018, 61, 1250-1270. [CrossRef]

79. Chou, R.J. The problems of watercourse redevelopment Disseminating new knowledge about flood risk perception in Taiwan's densely populated, typhoon-affected urban areas. Int. Dev. Plan. Rev. 2012, 34, 241-267. [CrossRef]

80. Brink, E.; Wamsler, C. Collaborative Governance for climate change adaptation: Mapping citizen-municipality interactions. Environ. Policy Gov. 2018, 28, 82-97. [CrossRef]

81. Jones, H.P.; Hole, D.G.; Zavaleta, E.S. Harnessing nature to help people adapt to climate change. Nat. Clim. Chang. 2012, 2, 504. [CrossRef]

82. Biggs, D.; Abel, N.; Knight, A.T.; Leitch, A.; Langston, A.; Ban, N.C. The implementation crisis in conservation planning: Could "mental models" help? Conserv. Lett. 2011, 4, 169-183. [CrossRef]

83. Denjean, B.; Altamirano, M.A.; Graveline, N.; Giordano, R.; van der Keur, P.; Moncoulon, D.; Weinberg, J.; Costa, M.M.; Kozinc, Z.; Mulligan, M.; et al. Natural Assurance Scheme: A level playing field framework for Green-Grey infrastructure development. Environ. Res. 2017, 159, 24-38. [CrossRef]

84. Dalimunthe, S.A. Who manages space? Eco-DRR and the local community. Sustainability 2018, $10,1705$. [CrossRef]

85. Reynaud, A.; Lanzanova, D.; Liquete, C.; Grizzetti, B. Going green? Ex-post valuation of a multipurpose water infrastructure in Northern Italy. Ecosyst. Serv. 2017, 27, 70-81. [CrossRef]

86. Metcalf, E.C.; Mohr, J.J.; Yung, L.; Metcalf, P.; Craig, D. The role of trust in restoration success: Public engagement and temporal and spatial scale in a complex social-ecological system. Restor. Ecol. 2015, 23, 315-324. [CrossRef]

87. Verbrugge, L.; van den Born, R. The role of place attachment in public perceptions of a re-landscaping intervention in the river Waal (The Netherlands). Landsc. Urban Plan. 2018, 177, 241-250. [CrossRef]

88. Ambrey, C.; Byrne, J.; Matthews, T.; Davison, A.; Portanger, C.; Lo, A. Cultivating climate justice: Green infrastructure and suburban disadvantage in Australia. Appl. Geogr. 2017, 89, 52-60. [CrossRef]

89. O'Donnell, E.C.; Lamond, J.E.; Thorne, C.R. Recognising barriers to implementation of Blue-Green Infrastructure: A Newcastle case study. Urban Water J. 2017, 14, 964-971. [CrossRef]

90. Chin, A.; Daniels, M.D.; Urban, M.A.; Piegay, H.; Gregory, K.J.; Bigler, W.; Butt, A.Z.; Grable, J.L.; Gregory, S.V.; Lafrenz, M.; et al. Perceptions of wood in rivers and challenges for stream restoration in the United States. Environ. Manag. 2008, 41, 893-903. [CrossRef]

91. Thorne, C.R.; Lawson, E.C.; Ozawa, C.; Hamlin, S.L.; Smith, L.A. Overcoming uncertainty and barriers to adoption of Blue-Green Infrastructure for urban flood risk management. J. Flood Risk Manag. 2018, 11, S960-S972. [CrossRef] 
92. Laura, M.M.; Adriana, M.K.; Cecilia, B.; La Ludmila, M.; Di Cecilia, P.Y.; Gabriela, P.; Jose, B. Ecological status of a patagonian mountain river: Usefulness of environmental and biotic metrics for rehabilitation assessment. Environ. Manag. 2016, 57, 1166-1187. [CrossRef]

93. de Groot, M. Exploring the relationship between public environmental ethics and river flood policies in western Europe. J. Environ. Manag. 2012, 93, 1-9. [CrossRef]

94. Nalau, J.; Becken, S.; Mackey, B. Ecosystem-based Adaptation: A review of the constraints. Environ. Sci. Policy 2018, 89, 357-364. [CrossRef]

95. McVittie, A.; Cole, L.; Wreford, A.; Sgobbi, A.; Yordi, B. Ecosystem-based solutions for disaster risk reduction: Lessons from European applications of ecosystem-based adaptation measures. Int. J. Disaster Risk Reduct. 2018, 32, 42-54. [CrossRef]

96. Meyer, A. Intertemporal valuation of river restoration. Environ. Resour. Econ. 2013, 54, 41-61. [CrossRef]

97. Carter, J.G.; Handley, J.; Butlin, T.; Gill, S. Adapting cities to climate change-exploring the flood risk management role of green infrastructure landscapes. J. Environ. Plan. Manag. 2017, 61, 1535-1552. [CrossRef]

98. Buhl-Mortensen, L.; Galparsoro, I.; Fernandez, T.V.; Johnson, K.; D’Anna, G.; Badalamenti, F.; Garofalo, G.; Carlstrom, J.; Piwowarczyk, J.; Rabaut, M.; et al. Maritime ecosystem-based management in practice: Lessons learned from the application of a generic spatial planning framework in Europe. Mar. Policy 2017, 75, 174-186. [CrossRef]

99. Triyanti, A.; Chu, E. A survey of governance approaches to ecosystem-based disaster risk reduction: Current gaps and future directions. Int. J. Disaster Risk Reduct. 2018, 32, 11-21. [CrossRef]

100. Liao, K.H. From flood control to flood adaptation: A case study on the Lower Green River Valley and the City of Kent in King County, Washington. Nat. Hazards 2014, 71, 723-750. [CrossRef]

101. Bauduceau, N.; Berry, P.; Cecchi, C.; Elmqvist, T.; Fernandez, M.; Hartig, T.; Krull, W.; Mayerhofer, E.; Sandra, N.; Noring, L. Towards an EU Research and Innovation Policy Agenda for Nature-Based Solutions $\mathcal{E}$ Re-Naturing Cities: Final Report of the Horizon 2020 Expert Group on'Nature-Based Solutions and Re-Naturing Cities'; Publications Office of the European Union: Bruxelles, Belgium, 2015. [CrossRef]

102. Chou, R.J. Exploring the quasi-naturalistic landscaping design of a taiwanese culverted urban stream. Landsc. Res. 2013, 38, 347-367. [CrossRef]

103. Wong-Parodi, G.; Klima, K. Preparing for local adaptation: A study of community understanding and support. Clim. Chang. 2017, 145, 413-429. [CrossRef]

104. Ruiz-Villanueva, V.; Diez-Herrero, A.; Garcia, J.A.; Ollero, A.; Piegay, H.; Stoffel, M. Does the public's negative perception towards wood in rivers relate to recent impact of flooding experiencing? Sci. Total Environ. 2018, 635, 294-307. [CrossRef]

105. Chou, R.J. Achieving successful river restoration in dense urban areas: Lessons from Taiwan. Sustainability 2016, 8, 1159. [CrossRef]

106. Martinez-Juarez, P.; Chiabai, A.; Suarez, C.; Quiroga, S. Insights on urban and periurban adaptation strategies based on stakeholders' perceptions on hard and soft responses to climate change. Sustainability 2019, 11, 647. [CrossRef]

107. van Ham, C.; Klimmek, H. Partnerships for nature-based solutions in urban areas-Showcasing successful examples. In Nature-Based Solutions to Climate Change Adaptation in Urban Areas: Linkages between Science, Policy and Practice; Kabisch, N., Korn, H., Stadler, J., Bonn, A., Eds.; Springer International Publishing: Cham, Switzerland, 2017; pp. 275-289. [CrossRef]

108. Pinto, P.J.; Kondolf, G.M.; Wong, P.L.R. Adapting to sea level rise: Emerging governance issues in the San Francisco Bay Region. Environ. Sci. Policy 2018, 90, 28-37. [CrossRef]

109. Wamsler, C. Mainstreaming ecosystem-based adaptation: Transformation toward sustainability in urban governance and planning. Ecol. Soc. 2015, 20. [CrossRef]

110. Sheng, W.P.; Zhen, L.; Xiao, Y.; Hu, Y.F. Ecological and socioeconomic effects of ecological restoration in Chins's Three Rivers Source Region. Sci. Total Environ. 2019, 650, 2307-2313. [CrossRef] [PubMed]

111. O'Donnell, E.C.; Lamond, J.E.; Thorne, C.R. Learning and Action Alliance framework to facilitate stakeholder collaboration and social learning in urban flood risk management. Environ. Sci. Policy 2018, 80, 1-8. [CrossRef] 
112. Bamberg, S.; Masson, T.; Brewitt, K.; Nemetschek, N. Threat, coping and flood prevention-A meta-analysis. J. Environ. Psychol. 2017, 54, 116-126. [CrossRef]

113. Jørgensen, D.; Renöfält, B. Damned if you do, dammed if you don't: Debates on dam removal in the Swedish media. Ecol. Soc. 2013, 18, 1-9. [CrossRef]

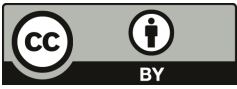

(C) 2019 by the authors. Licensee MDPI, Basel, Switzerland. This article is an open access article distributed under the terms and conditions of the Creative Commons Attribution (CC BY) license (http://creativecommons.org/licenses/by/4.0/). 

Article

\title{
What Can We Learn from Planning Instruments in Flood Prevention? Comparative Illustration to Highlight the Challenges of Governance in Europe
}

\author{
Mathilde Gralepois \\ Department of Planning and Environment, Engineering School, University of Tours, \\ 35 allée Ferdinand de Lesseps, 37200 Tours, France; mathilde.gralepois@univ-tours.fr; Tel.: +33-247-361-461
}

Received: 5 May 2020; Accepted: 22 June 2020; Published: 26 June 2020

\begin{abstract}
Studying the selection of planning instruments in flood prevention can be critical to gain a better understanding of governance. This choice is underestimated in the flood management literature. This paper fills a knowledge gap in flood management governance by examining the rationales for the choice of instruments. The study is grounded on a comparative illustration of planning instruments in flood prevention in three European countries: England, France and the Netherlands. Flood prevention through spatial planning is a specific example, as the implementation of the Floods Directive has reactivated the role of spatial planning in urban agglomerations. The choice of instruments is never neutral. In the field of flood management, alignment among strategies is supposed to lead to resilience. Instruments should be aligned and coherent. Is that the case? The article explains the challenges of governance configured by a conflict between the spatial planning policy steered by local authorities and the risk prevention policy led by national authorities. This model is further complicated by the tension between the preference for legal, technical or scientific instruments, and the difference in professional culture between planning and prevention. The selection of instrument shows that if their conflicts are exacerbated to debates on variables or parameters, it is because there is no political agreement on the balance between development and security.
\end{abstract}

Keywords: flood prevention; policy instruments; spatial planning; governance; resilience

\section{Introduction}

Since the 1960s, flood management has been dominated by hazard assessment, defense strategy and infrastructural measures, as if human societies could indefinitely control nature [1,2]. In the 1990s, extreme hydrological events occurred in the River Rhine (1993, 1995), in the Mediterranean region (1994), and in Central Europe (1997) [3]. After this flood-rich decade in Europe, policymakers have also focused attention on flood prevention and crisis management [4,5]. More precisely, flood management policy now tends to diversify its strategies in Europe [6]. Despite political and institutional efforts of diversification, flood risks persist, and disasters cause increased damage. Since 2000, floods in Europe have caused at least 700 deaths, and $€ 25$ billion in insured economic losses [7]. This trend is not decreasing. Several studies and reports underline that global warming increases the frequency of river floods in Europe [8-10].

During the 2000s, flood risk management at the European level extended the scope of interests in flood governance $[2,11]$. The consequences of natural disasters are considered as management failures, not only flood hazards [12]. The difference is radical: flood management shifts from controlling nature to adapting to uncertainty: "Risk is typically viewed as something that can be described in statistical terms, while uncertainty is viewed as something that applies to situations in which potential outcomes and causal forces are not fully understood" [13]. 
Flood management is not a question of reduction or mitigation, but a challenge of adaptation and transformation. This challenge is not only a question of improving parameters, factors and models but of integrating the uncertainty associated with each input variable [14]. Rather than necessarily being a barrier, uncertainty is an opportunity to reconsider risk governance and to better handle floods [15].

The literature on flood governance argues for a diversification of flood management strategies, first to respect the objective of the Floods Directive [16], but more broadly to promote the implementation of resilience [17]. Five types of flood risk strategies can be cited: action on probability of flooding (Flood Defense); on the potential consequences of flooding (Flood Prevention, Flood Mitigation, Flood Preparation) and on recovery after a flood has struck (Flood Recovery) [2]. Beyond the objectives for the diversification of the different policy strategies, coordination and alignment of these strategies is a prerequisite [18]. This comprehensive approach is difficult to implement concretely in flood governance in Europe. The literature explains how path dependence on institutional routines, traditional political arrangements or traditional technical choices are barriers to more resilient and adaptive governance $[1,11,19]$. Nevertheless, there is no radical change in European public policy, national levels or local implementation. To take a step forward, flood governance literature explores precise issues, such as coordination mechanisms [20] and science-policy interfaces [21]. This paper believes that those precise inputs are likely to contain general insights and should be pursued. It is argued in this paper that policy instruments are underestimated in flood governance literature [22], for example, in the selection of instruments of spatial planning in flood prevention.

Flood prevention can be described as an attempt to avoid the negative consequences of flooding mainly by means of proactive spatial planning ("keeping people away from water"). It aims at building away from areas prone to flooding by applying rules banning construction, expropriation or, more often, measures to adapt buildings to flooding. Public information could also be cited in flood prevention instruments, but there is not much evidence to measure their efficacy because few policy dynamics are observed in the information instruments [22-24]. By contrast, the production of planning instruments is dynamic in Europe. The implementation of the Floods Directive reactivates the role of spatial control instruments, especially in concentrated urban settlements. Growing urbanization brings about major challenges regarding aggravating flood risk. It reduces the capacity of cities to resist and to adapt to floods by reducing the capacity for infiltration, evaporation and absorption, as well as increasing the concentration of populations, activities, services and networks. This both increases the likelihood of flooding and the vulnerability of urban contexts [5,25-28]. In addition, flood regimes are fostered by other human activities such as intensive agriculture, deforestation or motorized traffic [29,30], especially in the context of climate change [8].

The paper aims to address the lack of knowledge, both for practitioners and academics, on the use and limits of planning instruments for flood prevention from a European perspective. It fills a vacuum in risk management by firstly examining the rationales for the selection of planning instruments, which today is critical to gain a better understanding of governance. The following section considers the conceptual insights of policy instruments for a better understanding of flood governance. Then, a third section provides an overview of the empirical dataset used to draw the comparative illustration between England, France and the Netherlands. Results on what the place of planning instruments in flood prevention reveals for a better understanding of flood governance in the context of urban resilience are presented in the fourth section. The final section draws conclusions and reflects on future directions.

\section{Conceptual Insights of the Choice of Instruments for Flood Governance}

This paper proceeds from the observation that there is a lack of studies on the specific role of instruments in flood governance. Although there have been studies on the complex interactions between urban planning and flood prevention, there has been no study of instruments. 


\subsection{The Role of the Choice of Instruments in Governance Studies}

The paper studies the planning of policy instruments for flood prevention in European cities. If flood management is composed of several strategies, each strategy is implemented through instruments. These instruments matter. A strategy can be defined as a combination of the measures and the resources necessary to implement them. Instruments stand as a means of application, involving a certain use of resources and techniques to attain a set of goals within the framework of a specific strategy [31]. Put differently, instrumentation is "the set of problems posed by the choice and the use of instruments (techniques, methods of operation, devices ... ) that allow governmental policies to be made material and operational" [32] (p. 4). Policy scholars agree that the selection of instruments is never neutral. Indeed, among the number of instruments available in the public policy toolkit, there is room for choice [33,34]. This choice reveals modes of governance. However simple it might be, instruments are key to understanding trends in governance $[31,35,36]$. The parameters, justifications and applicability of an instrument are not secondary issues. Depending on its own structure and logic, every instrument constitutes a condensed form of power in governance.

Although research on policy instruments has been prolific in recent years [37], it has received little attention in the field of flood management [22,38]. Our goal is to offer an overview of governance trends in flood prevention in Europe through the role of planning instruments. The paper starts with a conceptual framework inspired both by the instrument analysis of Le Galès and Lascoumes [32] and the governance modes from Howlett [31].

Lascoumes and Le Galès analyze policy instruments through a multidimensional typology, highlighting the links between instruments, legitimacy and political relations. Policy instruments reveal types of public policy outcomes "in [their] meaning [and] in the cognitive and normative framework" [32] (p. 16). Policy instrumentation reflects specific governance choices and the ways in which they evolve. Elaborating on Hood's reference work [33], Lascoumes and Le Galès identify five types of instrument:

- Regulatory instruments: traditional coercive tools of state interventionism based on legal forms;

- Economic instruments: also based on legal dimensions, their peculiar feature is to resort to monetary techniques in a way either to redistribute resources or to redirect them;

- Incentives: in a critical context of bureaucracy, the rigidity of legislative and regulatory rules, these agreements coupled with sets of incentives have become a general injunction;

- De facto standards: made by governmental actors to organize power relations within civil society, they frame methods or conditions of production for services;

- Communication and information-based instruments: part of what is generally referred to as the "open" or "grassroot" democracy and participative public.

This typology is useful for describing public policies, and especially for studying the role of the state, its political relations and its types of legitimacy. As public authorities are central actors in flood management, especially in prevention strategy, the typology has a concrete application. Nevertheless, an earlier study on flood management instruments [22] reveals that "soft instruments", such as best practices, incentives or communication, have not really permeated European flood management. More generally, the three last categories overlapped, as few examples already exist. Somehow, it underlines the lack of co-production in flood management and the need for adjustments within civil society [24].

Working on instruments, Howlett proposes a table of modes of governance [31]. Public policies are a multi-level and nested process. The choices of policy instrument are "all about constrained efforts to match goals and expectations both within and across categories of policy elements" [31] (p. 74). The calibration of instruments is tricky because it requires achieving several goals, in multiple policy levels, at the same time. Flood management is, in Europe, a fairly long-term and stable governance arrangement [2], grounded in modern liberal-democratic states. His typology is pragmatic, giving concrete examples of instruments. Howlett's typology offers four different modes of governance with 
which to study the choice of instruments and explains how it reveals governance. As in Lascoumes and Le Galès' typology, Howlett identifies a "Legal Governance" and a "Market Governance".

Next, Howlett makes room for a corporatist mode of governance, which fits with the expertise and technocratic pattern of public instruments in flood prevention, such as plans, maps or models. He then merges the different trends of non-mandatory but competitive instruments, such as standards, best prices or charts, in a "network pattern". I propose to merge the two typologies in one table (Table 1).

Table 1. From the choice of instruments to the legitimacy of governance.

\begin{tabular}{|c|c|c|c|c|}
\hline $\begin{array}{l}\text { Implementation } \\
\text { Preference }\end{array}$ & $\begin{array}{c}\text { Type of } \\
\text { Instruments }\end{array}$ & $\begin{array}{c}\text { Mode of } \\
\text { Governance }\end{array}$ & Governance Aim & Type of Legitimacy \\
\hline $\begin{array}{l}\text { Legal system: } \\
\text { legislative and } \\
\text { regulatory } \\
\text { preference }\end{array}$ & $\begin{array}{l}\text { Legislation, rule, } \\
\text { law, regulation. }\end{array}$ & Legal governance. & $\begin{array}{l}\text { Legitimacy and } \\
\text { compliance through the } \\
\text { promotion of law } \\
\text { and order. }\end{array}$ & $\begin{array}{l}\text { Imposition of a general } \\
\text { interest by mandated } \\
\text { elected representatives. }\end{array}$ \\
\hline $\begin{array}{l}\text { Expertise system: } \\
\text { macro-level } \\
\text { bargaining }\end{array}$ & $\begin{array}{c}\text { Model, map, plan, } \\
\text { scheme, } \\
\text { framework. }\end{array}$ & $\begin{array}{l}\text { Corporatist } \\
\text { governance. }\end{array}$ & $\begin{array}{l}\text { Controlled and balanced } \\
\text { socio-economic } \\
\text { development through the } \\
\text { management of major } \\
\text { organized social actors. }\end{array}$ & $\begin{array}{c}\text { Justification by } \\
\text { socio-technical } \\
\text { expertise from a } \\
\text { top-down perspective. }\end{array}$ \\
\hline $\begin{array}{c}\text { Market system: } \\
\text { economic and fiscal } \\
\text { preference }\end{array}$ & $\begin{array}{l}\text { Contracts, } \\
\text { Subsidies, tax } \\
\text { incentives, } \\
\text { penalties. }\end{array}$ & $\begin{array}{c}\text { Market } \\
\text { Governance. }\end{array}$ & $\begin{array}{l}\text { Resource/cost efficiency } \\
\text { and control through the } \\
\text { promotion of competition. }\end{array}$ & $\begin{array}{c}\text { Benefit to the } \\
\text { community through } \\
\text { social and economic } \\
\text { efficiency. }\end{array}$ \\
\hline
\end{tabular}

Modified from Howlett [31] with some inputs from Lascoumes and Le Galès [32].

This table helped to guide the analysis of the paper, to explain the distribution of instruments, and to categorize and capture the evolution of flood governance.

\subsection{Crossing Urban Planning and Flood Prevention through Instruments}

European cities were considered as secure and resistant to floods. In the 1990s-2010s, dramatic and recurrent floods in cities in the United Kingdom, the Czech Republic, Bulgaria, Hungary, France, Romania and Spain constantly highlighted the emergency of the situation. Policymakers, as well as the general public, witnessed the vulnerability of cities and the need to prioritize proactive spatial planning. Prevention strategy in flood management mostly revolves around spatial planning. Its main objective is to influence the location of concrete activities as well as future spatial and economic developments. The main objective is to regulate urbanization by banning construction in flood-prone areas and allowing development under conditions elsewhere (upper-elevation, choice of building, materials).

Yet cities are specifically vulnerable to floods, as they are densely populated, with large numbers of activities, services and networks, with a limited capacity for discharge and absorption. They also experience continuous geographic and demographic urban development [39]. During the first step of the Floods Directive implementation, countries have identified cities as areas most at risk from significant flooding [40]. The Floods Directive requires EU Member States to implement flood maps and prevention plans for spatial planning decisions [7]. More than ten years after the Floods Directive was implemented, cities are still not adapted to flood risks [41].

Connecting planning, especially urban planning, and flood prevention received attention in the 2000s [42-48]. Analyzing the literature on urban planning and flood prevention reveals several obstacles in governance. During the years after World War II in Europe, urban planning overwhelmingly neglected the integration of flood prevention in cities. Urbanization has continued in flood prone areas. Even where flood land-use controls existed, they were underestimated, incomplete and depreciated in the face of the challenges of urban development [45-47]. In 2007, the Floods Directive required states 
not only to formalize extreme flood scenarios, but to enter into the arena of spatial planning. It is difficult to coordinate the governances of water management and urban planning [44,49]. There are few incentives to develop a sense of risk-reduction "ownership" among urban planners. First, planners do not perceive risk management as part of their remit $[49,50]$. Secondly, significant differences can be observed in terms of historical and educational backgrounds between disaster-prevention and planning officials [51]. Spatial planning is supposed to be interactive and comprehensive [52]. Flood prevention is commonly implemented via expert-based hydraulic engineering of urban structures $[1,11,53]$ including canalization of streams, construction of floodwater retention basins and diking.

While the governance literature studying urban planning and flood prevention highlights the divergences between priorities, interests, experiences, cultures or beliefs, the role of instruments is not analyzed. Moreover, separate studies focus on single countries, such as the United Kingdom [46,47], the Netherlands [52] or France [42,43,54,55]. This paper fills a knowledge gap with a comparative illustration of planning instruments in flood prevention strategy in different European countries: England, France and the Netherlands. In the field of flood management in Europe, alignment among strategies and coordination between scales (geographical, spatial, institutional) promotes urban resilience $[6,18]$. This paper looks at whether the selection of spatial planning instrument is aligned, coherent and convergent in flood prevention.

\section{Methods}

To address the question, the author examines the rationales for the selection of planning instruments in flood prevention. I proceed in three steps.

First, searching through national and international academic databases which cross-reference planning and risk management is an important starting point, especially given that the literature is not extensive. A total of 94 publications concerned with spatial planning in flood management were analyzed, mainly in peer-reviewed journals and book chapters from international scientific databases (Springer, Science Direct, Google Scholar, Wiley, Elsevier), as well as grey literature, such as expertise and public authority reports. These references are selected for their precise accuracy on the subject. They provide an updated and critical knowledge framework that effectively serves as a theoretical background.

Next, the empirical data were retrieved from two European research reports, as well as their minutes, briefs and notes: STARFLOOD and TRANSADAPT. These two research projects focused specifically on flood governance, although neither the intersections between risk and planning, nor the role of instruments, were central to the results. However, the quality of the data produced, and the diversity of the investigations carried out, enable the collection of a large quantity of data to be processed henceforth. I look at general insights from European flood prevention strategy as well as the specific role played by planning instruments. Concerning reports from the STARFLOOD database, the empirical data is based on country reports available to the public via the project reports of England [56], the Netherlands [57] and France [58]. Each country report is based on 50 interviews per country on average. Concerning reports from the TRANSADAPT database, between 20 and 30 interviews with national, regional and local stakeholders and citizens as well as practitioner workshops were organized in each country between May 2015 and March 2016. Data is collected in country reports for France [59], the Netherlands [60], and in a final comparative analysis [61]. In both reports, each interview was recorded and transcribed verbatim. Additionally, an analysis of the institutional context of hazard and risk management systems in each country was conducted, including an analysis of relevant policy documents. It built a substantial database including observations, policy and legal document analyses in which the issue of instruments was not fully studied. The qualitative data thus produced makes it possible to have access to the actors' representations of their interests and strategies, as well as the idea they have of those of other actors. By comparing these data with the results of the literature, I can analyze the choice of instruments, beyond their supposed neutrality. 
Finally, three European countries were studied to draw a comparative illustration of urban planning instruments and evolution in flood prevention: England, France and the Netherlands, taking concrete examples from national and local instruments. "Comparative illustration" means that the document does not lead to a systematic term-by-term comparison. It draws insights from similarities and differences in the way each country used planning instruments to cope with flood prevention. The three countries present concrete differences in terms of their legal system, institutional structure, political traditions or administrative routines. But they are all rooted in the same cultural space of Northern Europe. Thus, this common social and societal context allows for a comparison.

\section{Comparative Illustration of Planning Instruments in Flood Prevention to Highlight Governance Challenges in Europe}

Analyses of the instruments used to face floods brings new understandings of flood prevention. Policy instrumentation may relate to the fact that actors find it easier to agree on methods than on objectives. While instruments are often seen as secondary administrative techniques, they have a huge potential to better understand governance choices.

\subsection{England: The Legal Governance through Regulatory Instruments Remains Inadequate}

In England, spatial planning instruments are organized with hierarchical articulations from national to local authorities. The National Planning Policy Framework sets out guidelines from the Ministry of Housing, Communities and Local Government on how flood risks should be incorporated into the overall planning system, with provisions regarding climate change. The National Planning Policy Framework provides top-down governance with the type of production, agenda, plan-making process and conditions of participation for Local Planning Authorities. Despite their prospective and strategic status, Local Plans have to incorporate national recommendations. Included in Development Plans, Local Plans provide specific allocations of land for different purposes. Local Plans are put into practice by Local Planning Authorities. They identify where, and how many, homes, buildings, businesses, shops, local infrastructures or networks should be located in respect of environment, sensitive landscapes, climate adaptation or flood prevention. Guidance for Local Plans have recently been incorporated into the guide on Plan-making (March 2019). "In addition to the statutory requirement to take the Framework into account in the preparation of Local Plans, there is a statutory duty on local planning authorities to include policies" [62]: Local Plans are documents with both strategic (objectives) and non-strategic (operational) policies. They should illustrate geographically the policies in the plan. Based on the Local Plans, Local Planning Authorities are responsible for "deciding whether a proposed development should be allowed to go ahead" through Land Planning Permissions [63]. Concretely, planning authorities have concern for flood prevention and mitigation. They bear the responsibility of assessing risks at the local level while ensuring that flooding is taken into account.

If building developments are planned in flood-prone areas, local authorities have a statutory requirement to consult the Environment Agency. To obtain a Land Planning Permission, any land developer is required to conduct a Flood Risk Assessment according to the rules set out in the Local Plans. This should contain the estimated flood level for the development, details of your flood resistance or resilience plans and any supporting plans and drawings [64]. A specific instrument of the English system is called the sequential test. "The sequential test compares your proposed site with other available sites to show which one has the lowest flood risk" [64]. Developers have to prove that they cannot build their project somewhere else. This mechanism aims at reducing developments in floodplains.

In sum, English planning instruments in flood prevention are implemented through a full legal system. Here, legitimacy is supposedly conferred by the common interest but is in fact a matter of socio-technical expertise imposed from on high. 
At first, flood prevention was a matter of local bodies taking their lead from state doctrine. Nowadays, there is a trend towards managing floods at local scales (local authorities, communities) but still from a legal perspective [21,56]. The rules for spatial planning, such as Land Planning Permission, are supported by scientific hydraulic models and represented though geographic information mapping systems. The relations between planning and flood management are complex [45]. Flood management concerns are incorporated in planning systems and the legal strength of flood management has been reinforced during the 2000s [48]. However, this legal governance through regulatory instruments remains unsatisfactory if one considers the theoretical results and practical successes of citizen involvement $[24,65,66]$. Here, at the end, the selection of instruments remains unsatisfactory because spatial planning seems to be an intangible priority, whatever the conditions of environment, risk or uncertainty. Various options to veto developments are rarely used. Governance is supposed to be pyramidal from national recommendations to local permits, but Local Planning authorities are still permissive [48]. When national flood recommendations are not mandatory, they are ignored [47]. In a central mode of governance based entirely on legal instruments, Local Planning Authorities oppose other legal instruments stemming from public transport, social housing or energy policies to defend their own development interests. Beyond the legal system, there is no global agreement on the balance between development and prevention. This is evidenced by the fact that flood risk management is rarely a political issue in the sense that it is not addressed in political debates, in the media or in electoral campaigns outside specific natural crisis times $[67,68]$.

\subsection{France: Towards Resolving Controversies over Instruments through the Transfer of Competences?}

In France, there is also a history of separation between spatial planning and flood management, coupled with a historical opposition between national and local authorities [69]. Dating back to the nineteenth century, flood prevention originated with the idea of floodplain preservation. The first flood planning laws were introduced in 1935. As of today, French flood prevention systems have diverged: the spatial planning system is led by local authorities, and risk prevention by the state. Concerning the planning system, land development is ruled by Spatial Strategic Plans (Schémas de Cohérence Territorial) as well as Local Urban Plans (Plan Local d'Urbanisme). The Local Urban Plan is enforceable against all private and public persons who want to build in this sector. Indeed, the Local Urban Plan is the more binding regulation. Concretely, building permits (Permis de Construire) are examined through the Local Urban Plan and then accepted or refused by local authorities on the basis of the French planning system, decentralized since the 1980s. To integrate flood prevention, one instrument is supposed to link the planning and flood management systems: the Flood Risk Prevention Plan (Plan de Prévention des Risques d'Inondation). Introduced in 1995, the Flood Risk Prevention Plan reinforces the state's responsibility in the flood management domain and the legitimacy of flood maps based on hydraulic models. It plays a key role in spatial planning, as part of a broader planning culture dominated by an engineered approach and legal restrictions on construction in risk areas [70-72]. Legally, the Flood Risk Prevention Plan is not a planning document, but a public easement adopted by the national authority that must be respected by all the building permits. The planning competencies of the local authorities are de facto restricted. For decades, the Flood Risk Prevention Plan has been a matter or a symbol of conflict, between land development and flood prevention, between the legitimacy of national or local authorities. The Flood Risk Prevention Plan is interpreted as a way for the central government to maintain control over both local authorities and the spatial planning decision process. Recently, changes have occurred: the transfer of competences of some flood prevention duties to local authorities. Justified by the Floods Directive implementation, but most probably to find a way out of decades of conflicts over Flood Risk Prevention Plans, a new competence for the management of aquatic environments and flood prevention (GEMAPI: Gestion des Milieux Aquatiques et Prévention des Inondations) was implemented in 2018. It allows local authorities to develop both their political legitimacy and their technical capacity [73]. 
In short, controversies over flood risk prevention in local plans highlight conflicts in governance. For some local authorities responsible for land development, unbuildable flood-prone areas represent a breaking point for their urban expansion programs, even more so when these local authorities have little free space left and experience a strong real-estate pressure. Their only way to continue building, and ensure economic development, is to tackle the issue of flood risk through the Flood Risk Prevention Plan. The flooding issue is a way for local powers to show their disapproval of central government trespassing on their own areas of competence and to progressively usurp their role in flood governance $[25,74,75]$. If the transfer of the legal instrument from national to local authorities can be seen as an opportunity to affirm themselves local governance, the new regulation GEMAPI represents an additional burden that will impact on already weak resources [68,76].

\subsection{Netherlands: When Instruments are Mandatory but Non-Binding}

In the Netherlands, "water" is considered the twenty-first-century challenge of spatial planning. More than $90 \%$ of the Dutch population lived in urbanized areas in 2018. If most of the residents are protected by the dike-rings system, 35\% of all the inhabitants live in flood-prone area [77]. Many studies underline the need to strengthen the integration of land-use planning and flood risk prevention [52,78,79]. Strategic spatial development plans (structuurvisies) and legally binding spatial zoning plans (bestemmingsplannen) have to feature flood reduction provisions. They include specific bans or restrictions applicable to building work, as well as relevant expropriations or re-allocations. However, the rules are less embedded in spatial planning legislation than in England or France. Dutch flood prevention in spatial planning relies on two agreement-based incentives. Designed as bridging mechanisms, the Water Assessment (watertoets) is a formal advisory construction mechanism used to facilitate the integration of spatial planning and water management. Local planning authorities need to consult regional water authorities—which belong to Dutch water management-during the process of drafting spatial plans. The Water Assessment is mandatory to ensure that local plans fit the national criteria [80] but non-binding [81]. The watertoets practical implementation is described as ineffective for the prevention of inappropriate urban development or to support flood-proofing [78]. For example, the checks take place when the plans have been made, mostly almost finished. Other issues, such as economic growth, mobility, environmental quality, are prioritized.

Studies have shown that the lack of inclusion of risk prevention in urban planning offends flood managers because they prioritize the issue of safety and prevention over that of development $[45,52,68]$. Nevertheless, we must also side with the planners. Sometimes, the local authorities are obliged to follow old practices and traditional models, even if scientific developments have proven those practices and models inadequate. Instead of improving the flood prevention plan by considering urban development, how can flood prevention measures be integrated into planning instruments [82]? In brief, just as in England and France, legal instruments predominate. Furthermore, the Netherlands has a global strategy of diversification of flood management strategies through the concept of multi-layered safety [21,57]. The country makes a more diversified use of flood prevention instruments, especially via the Water Assessment, which is a pillar of the flood prevention system. Even though it helps to make flood management in spatial planning mainstream, this incentive-based instrument does not in practice systematically prevent constructions in flood-prone areas [80].

Considering the different modes of governance categorized by Howlett (Howlett 2009) and Lascoumes and Le Galès [32], flood prevention in planning is characterized by a classic pattern, rather resistant to change, of public actors, by hierarchical power relationships, whether from the national to the local level, or from the public authorities to civil society, and, finally, by compartmentalized public policies. Even if these observations have recently been acknowledged [11,52,83], the article draws new significant conclusions.

First, flood prevention in urban planning is largely based on legal instruments. England and France display particularly hierarchical legal structures in the field of flood prevention. 
The Netherlands, even if it is not optimal, is diversified with incentive-based instruments. Governance is historically based on legislative preference, legitimated by the democratic representation of mandated representatives in public authorities. Nevertheless, the study of the instruments demonstrates that legal legitimacy is based more on a system of socio-technical expertise in a top-down perspective than on general interest.

Secondly, the comparative illustration of the policy instruments in three European countries confirms the solid role of hierarchical governance. Flood management has a long tradition of central governance: all water-related issues are described by Wiering and Crabbé as "hegemony of the state" [84] (p. 99). However, in the three countries, there is a shift toward devolving responsibilities to lower governments and the market [82]. When local authorities have flood prevention instruments, they are not binding and completely controlled by national authorities.

Thirdly, public policies in spatial planning and flood prevention are still working in parallel rather than together. They are not sufficiently complementary or interacting. There are many obstacles to future "Flood Risk Management Planning" [52]. There is currently no common practice concerning the introduction of flooding into development [82]. The next section examines how another step forward can be accomplished. For the time being, until the selection of instruments is adapted to the challenges of interdisciplinarity, neither policies nor governance can be integrated and resilient.

\section{Discussion and Conclusion. A Step towards Integration of Flood Prevention and Spatial Planning by Looking at the Choice of Policy Instruments}

Returning to the flood resilience literature, the case study analysis confirms that European governance face three challenges: adaptation, diversification and participation. First, flood governance requires a serious shift from resistance to adaptation of both physical and socio-economic systems [6,85]. In the three countries examined, protection remains a founding principle. The "stickiness" of the flood defense strategy can be explained by path dependency factors, especially with regard to instruments based on old practices and traditional models from national policies. However, when the position of resistance is shifting, changes are defined as part of a multi-layered and adaptive strategy rather than as a real change in nature [1]. Thus, the study of the power struggles between risk management and planning instruments shows that urban planners do not consider planning instruments to be a driving force in flood management. They consider that floods are controlled by protective measures elsewhere, such as in the Netherlands. Secondly, the diversification of several flood management strategies should be developed with multi-level coordination mechanisms in order to avoid unintended fragmentation effects $[20,83]$. Beyond the discourse on the alignment of strategies or the coherence of instruments, the case studies show that coordination between instruments must be anticipated at the early stages. Bringing together instruments developed separately, such as Risk Prevention Plans in France, takes decades of conflict before solutions are identified [86]. Thirdly, more bottom-up initiatives and powers for local authorities, inhabitants, communities and local business have to emerge to encourage collaborative public decisions and open public debate $[24,61,65]$. While there are mechanisms for debate on strategic orientations, citizen participation in the development of public policy instruments remains absent. In France, England and to a lesser extent in the Netherlands, the development and selection of instruments remains the hierarchical prerogative of experts. There are incentives to promote property adaptation in France and England. Also, in the Netherlands, local community forums help local policy practitioners and citizens to discuss and cooperate on measures to store rainwater on private grounds [24]. Nevertheless, these marginal points do not fully deal with planning instruments in flood risk areas. They provide resources to reduce the vulnerability of existing houses or they are part of a mitigation strategy concerning/aimed at rainwater management more than flood management.

The results of the case studies and the approach to instruments from a social science perspective provide new perspectives, both in literature and in practice. To address these three issues (adaptation, 
diversification and participation) and because they are interconnected, the literature on flood governance could focus on two possible entry points.

The first possibility allows for an instrument-based approach by tackling the place of legal flood maps. The second approach is more general but offers the possibility of actor-centered or representation-centered approaches: it concerns the dilemma between development and flood prevention.

The first entry point, the implementation of the Floods Directive [16], promotes the application of legal maps to flood prevention [87]. Using a hydrologic-hydraulic approach and geographic information systems (GIS), flood maps have a statutory role in Local Plans [88,89]. As for the Flood Risk Prevention Plan in France, the use of planning instruments in flood prevention emphasizes that maps are not only geographical representations and indications, but an act of legal zoning to limit expansion and densification of construction. As socio-technical objects, flood maps are negotiated. Flood maps are subject to negotiation because the different methods lead to a completely different ranking of degrees of flood risk depending on the importance of the parameters $[14,15,90]$. Even with precise factors and data, it is impossible to draw definite conclusions on flood levels, magnitude, severity or probability [90]. Uncertainty is inherent in risk and allows—even requires—discussion, negotiation and selection. In France and England, the controversies are about procedures, scientific parameters, scales, even the "thickness of the line" that delineates the risk of flooding, and therefore the areas where you may or may not be able to build $[70,71,74,88,89]$. The negotiation of flood maps illustrates two trends in governance: the evolution of legitimacy and the evolution between professional cultures. The first trend, the negotiation of flood maps, shows the evolution of legitimacy between national and local authorities. The study of decision processes on flood maps illustrates the conflicts between the legitimacy of expertise and legal legitimacy. Until the 1980s, the national authorities in Europe possessed an unquestioned resource: expertise on flooding, i.e., the hazard assessment, the definition of the hydraulic model, the choice of scenarios and the return periods. With the weakening of the states in the 1990s due to the contradictory movements of internationalization and devolution, the legitimacy of central governments regarding expertise-based instruments has been challenged. Local authorities are contesting the scientific and technical resources to frame flood maps. Controversies over instruments have concrete implications for land development if local authorities are not implicated early on, especially for powerful European cities that have more resources than national authorities. Sometimes, for example, local authorities have access to more precise data, are more easily adapted in the new research developments or they can pay for alternative experts' reports to recalculate the scale of the flood map $[74,88]$. To deal with the local authorities' complaints, national authorities are focusing more narrowly on a strict application of legal and organizational rules (agenda, choices in the decision-making process, conditions of participation, etc.). It is a vicious circle, which could be broken by opening up the discussion to public participation and debate [65,91,92]. Nevertheless, several actors are little studied, especially private expertise actors. Governance literature lacks the analysis of private consulting bodies, working more and more for national and local authorities. Secondly, the negotiation of flood maps shows the evolution of governance between planning and flood management professional cultures. Governance is characterized by a double path: the spatial planning system led by local authorities, and the risk prevention system driven by the state. Hartmann and Driessen explain that water managers no longer defend the idea of "lines of defense" as a strict delimitation between an area at risk of flooding and one that is not [52]. This is despite their different backgrounds; planning has a holistic and multi-disciplinary approach and flood management is more specific and sectional [44]. If the boundaries are shifting, the study of instruments shows that planning and flood management are still two separate domains [82]. The recent merging of national-level institutions of water and spatial planning, such as in France [67] and the Netherlands [82], does not appear to be sufficient. For planners, flood management is seen as an overestimation of danger that could be solved technically to continue development when there is a low magnitude or low probability risk of flooding. Urban planners valorize the role of resilient urban planning measures, 
such as upper-elevation, but without a comprehensive view of the potential indirect effects on flooding. Meanwhile, risk managers underestimate or misunderstand urban development opportunities [93]. In a central mode of governance based entirely on legal instruments, the way forward is to consider flooding from the point of view of urban design where planners propose local solutions that respect the general national rules. National authorities accept them-or not-and local authorities take legal responsibility for the project.

The second entry point, the recurrence and increase of damage caused by urban floods, is increasingly drawing attention to the links between development and prevention. A step forward can be taken in understanding governance issues better if literature looks specifically at the selection of instruments. This paper aims to boost debate on how planning and prevention could benefit from two-way interaction both by integrating flood planning into building, but also by changing the way building considers flooding. The objectives of spatial planning should be driven by public interest concerning environment and security, but the actual process of planning is a matter for legal experts, taking into account economic inputs. Legal, technical and scientific controversies underline that there is no overall agreement on the balance between development and prevention. Similarly, there is no political agreement between national and local authorities, between public authorities and civil society, between development and security perspectives. A complete comparative analysis of the selection of instruments in prevention, defense, mitigation, preparation and insurance strategies might examine in detail each of the following: the range of available options for prevention and the decisions made; the setting of agendas regarding instruments; and the implementation of measures, their evaluation and resulting modification.

Funding: This research received no external funding.

Acknowledgments: The paper was proofread by Anthony Cummins and re-read by Brynhild Drain-Brule.

Conflicts of Interest: The authors declare no conflict of interest.

\section{References}

1. Gralepois, M.; Larrue, C.; Wiering, M.; Crabbé, A.; Tapsell, S.; Mees, H.; Ek, K.; Szwed, M. Is flood defense changing in nature? Shifts in the flood defense strategy in six European countries. Ecol. Soc. 2016, 21. [CrossRef]

2. Hegger, D.; Driessen, P.; Dieperink, C.; Wiering, M.; Raadgever, T.; van Rijswick, H. Assessing Stability and Dynamics in Flood Risk Governance. Water Resour. Manag. 2014, 28, 4127-4142. [CrossRef]

3. Kundzewicz, Z.; Pińskwar, I.; Brakenridge, R. Large floods in Europe, 1985-2009. Hydrol. Sci. J. 2013, 58, 1-7. [CrossRef]

4. Piatyszek, E.; Ayral, P.-A.; Gralepois, M. Local Crisis Management-The Communal Safety Plan: Challenges and Obstacles to Operationality. In Floods; Vinet, F., Ed.; Elsevier: Amsterdam, The Netherlands, 2017; pp. 241-258.

5. Scarwell, H.-J.; Laganier, R. Risque D'inondation et Aménagement Durable des Territoires; Presses Universitaires du Septentrion: Villeneuve d'Ascq, France, 2017; ISBN 978-2-7574-1892-5.

6. Hegger, D.; Driessen, P.; Wiering, M.; van Rijswick, H.; Kundzewicz, Z.W.; Matczak, P.; Crabbé, A.; Raadgever, G.T.; Bakker, M.H.N.; Priest, S.J.; et al. Toward more flood resilience: Is a diversification of flood risk management strategies the way forward? Ecol. Soc. 2016, 21, 52-71. [CrossRef]

7. European Environmental Agency. Mapping the Impacts of Natural Hazards and Technological Accidents in Europe; Technical Report No. 13/2010; European Environmental Agency: Copenhagen, Denmark, 2010.

8. Alfieri, L.; Burek, P.; Feyen, L.; Forzieri, G. Global warming increases the frequency of river floods in Europe. Hydrol. Earth Syst. Sci. 2015, 19, 2247-2260. [CrossRef]

9. Kundzewicz, Z.; Pińskwar, I.; Brakenridge, R. Changes in river flood hazard in Europe: A review. Hydrol. Res. 2018, 49, 294-302. [CrossRef]

10. European Environmental Agency River Floods: What Is the Trend in River Floods across Europe? Available online: https://www.eea.europa.eu/data-and-maps/indicators/river-floods-3/.-1 (accessed on 14 April 2020). 
11. Liefferink, D.; Wiering, M.; Crabbé, A.; Hegger, D. Explaining stability and change. Comparing flood risk governance in Belgium, France, the Netherlands, and Poland. J. Flood Risk Manag. 2018, 11, 281-290. [CrossRef]

12. November, V. Recalcitrance of risks: A management failure? In Proceedings of the Society for Social Studies of Science (4S) Conference, The University of Tokyo, Tokyo, Japan, 25-29 August 2010.

13. Miller, R.; Lessard, D.R. Evolving Strategy: Risk Management and the Shaping of Mega-Projects. In Decision Making on Mega Projects, Cost Benefit Analysis, Planning and Innovation; Edward Elgar Publishing: Cheltenham, UK, 2008.

14. Dimitriadis, P.; Tegos, A.; Oikonomou, A.; Pagana, V.; Koukouvinos, A.; Mamassis, N.; Koutsoyiannis, D.; Efstratiadis, A. Comparative evaluation of 1D and quasi-2D hydraulic models based on benchmark and real-world applications for uncertainty assessment in flood mapping. J. Hydrol. 2016, 534, 478-492. [CrossRef]

15. Teng, J.; Jakeman, A.J.; Vaze, J.; Croke, B.F.W.; Dutta, D.; Kim, S. Flood inundation modelling: A review of methods, recent advances and uncertainty analysis. Environ. Model. Softw. 2017, 90, 201-216. [CrossRef]

16. European Commission. Directive of the European Parliament and of the Council of 23 October 2007 on the assessment and management of flood risks (2007/60/EC). Off. J. Eur. Communities L 2007, 288, 27-34.

17. Hegger, D.; Driessen, P.; Bakker, M. A View on More Resilient Flood Risk Governance: Key Conclusions of the STAR-FLOOD Project; STAR-FLOOD Consortium: Utrecht, The Netherlands, 2016.

18. Dieperink, C.; Hegger, D.; Bakker, M.; Kundzewicz, Z.; Green, C.; Driessen, P. Recurrent Governance Challenges in the Implementation and Alignment of Flood Risk Management Strategies: A Review. Water Resour. Manag. 2016, 30, 4467-4481. [CrossRef]

19. Wiering, M.; Kaufmann, M.; Mees, H.; Schellenberger, T.; Ganzevoort, W.; Hegger, D.L.T.; Larrue, C.; Matczak, P. Varieties of flood risk governance in Europe: How do countries respond to driving forces and what explains institutional change? Glob. Environ. Chang. 2017, 44, 15-26. [CrossRef]

20. Dieperink, C.; Mees, H.; Priest, S.; Ek, K.; Bruzzone, S.; Larrue, C.; Matczak, P. Managing urban flood resilience as a multilevel governance challenge: An analysis of required multilevel coordination mechanisms. Ecol. Soc. 2018, 23. [CrossRef]

21. Hegger, D.; Alexander, M.; Raadgever, T.; Priest, S.; Bruzzone, S. Shaping flood risk governance through science-policy interfaces: Insights from England, France and the Netherlands. Environ. Sci. Policy 2020, 106, 157-165. [CrossRef]

22. Gralepois, M. Instruments for Strategies to Face Floods through Prevention, Mitigation, and Preparation in Europe. In Facing Hydrometeorological Extreme Events; La Jeunesse, I., Larrue, C., Eds.; John Wiley \& Sons, Ltd.: Chichester, UK, 2019; pp. 71-97, ISBN 978-1-119-38356-7.

23. Douvinet, J.; Pallares, R.; Genre-Grandpierre, C.; Gralepois, M.; Rode, S.; Servain-Courant, S. L'information sur les risques majeurs à l'échelle communale. Occurrence et facteurs explicatifs du DICRIM, un outil préventif sous-utilisé. Cybergeo Eur. J. Geogr. 2013, 658. [CrossRef]

24. Mees, H.; Alexander, M.; Gralepois, M.; Matczak, P.; Mees, H. Typologies of citizen co-production in flood risk governance. Environ. Sci. Policy 2018, 89, 330-339. [CrossRef]

25. Beucher, S.; Rode, S. L'aménagement des territoires face au risque d'inondation: Regards croisés sur la Loire moyenne et le Val-de-Marne. Mappemonde 2009, 94, 19.

26. Beucher, S.; Reghezza-Zitt, M. Gérer le risque dans une métropole: Le système français face à l'inondation dans l'agglomération parisienne. EUE 2008, 2, 1-10. [CrossRef]

27. Chaline, C.; Dubois-Maury, J. Les Risques Urbains; Armand Colin: Paris, France, 2002.

28. November, V. Risques naturels et croissance urbaine: Réflexion théorique sur la nature et le rôle du risque dans l'espace urbain. Rev. Géog. Alp. 1994, 82, 113-123. [CrossRef]

29. IPPC. Global Warming of $1.5^{\circ} \mathrm{C}$. Available online: https://www.ipcc.ch/sr15/ (accessed on 14 April 2020).

30. Kundzewicz, Z. Changes in Flood Risk in Europe; IAHS Special Edition; CRC Press: Boca Raton, FL, USA, 2019; ISBN 1-136-22546-3.

31. Howlett, M. Governance modes, policy regimes and operational plans: A multi-level nested model of policy instrument choice and policy design. Policy Sci. 2009, 42, 73-89. [CrossRef]

32. Lascoumes, P.; Le Galès, P. Introduction: Understanding public policy through its instruments-From the nature of instruments to the sociology of public policy instrumentation. Governance 2007, 20, 1-21. [CrossRef]

33. Hood, C. The Tools of Government; Springer: New York, NY, USA, 1983; ISBN 0-333-34395-6. 
34. Lascoumes, P.; Le Galès, P. L'action Publique Saisie par ses Instruments; Presses de Sciences Po: Paris, France, 2004.

35. Howlett, M. Managing the "hollow state": Procedural policy instruments and modern governance. Can. Pub. Admin. 2000, 43, 412-431. [CrossRef]

36. Howlett, M. Designing Public Policies: Principles and Instruments; Routledge: Abingdon-on-Thames, UK, 2019; ISBN 1-351-86675-3.

37. Halpern, C.; Lascoumes, P.; Le Galès, P. L'instrumentation de L'action Publique: Controverses, Résistances, Effets; Presses de Sciences Po: Paris, France, 2014; ISBN 2-7246-1458-5.

38. Filatova, T. Market-based instruments for flood risk management: A review of theory, practice and perspectives for climate adaptation policy. Environ. Sci. Policy 2014, 37, 227-242. [CrossRef]

39. Andjelkovic, I. Guidelines on Non-Structural Measures in Urban Flood Management; Technical Documents in Hydrology; UNESCO: Paris, France, 2001; p. 89.

40. Santato, S. The European Floods Directive and Opportunities offered by Land Use Planning; Climate Service Center: Hamburg, Germany, 2013; p. 79.

41. European Environmental Agency. Urban Adaptation to Climate Change in Europe, Transforming Cities in a Changing Climate; EEA Report No 12/2016; European Environmental Agency: Copenhagen, Denmark, 2016.

42. Gralepois, M.; Dournel, S.; Sajaloli, B.; Servain, S.; Serrano, J. Tant va la ville à l'eau. L'intégration du risque d'inondation aux décisions politiques et administratives d'aménagement urbain des agglomérations ligériennes. Revue Nord 2011. Hors série.

43. Guevara Viquez, S.; Rode, S.; Gralepois, M. Le changement radical et silencieux de paradigme sur le développement urbain face aux risques naturels. Métropoles 2017, 20, 176.

44. Hartmann, T.; Juepner, R. The flood risk management plan between spatial planning and water engineering. J. Flood Risk Manag. 2017, 10, 143-144. [CrossRef]

45. Howe, J.; White, I. Like a Fish Out of Water: The Relationship between Planning and Flood Risk Management in the UK. Plan. Pract. Res. 2004, 19, 415-425. [CrossRef]

46. Penning-Rowsell, E. Flooding and planning: Conflict and confusion. Town Ctry. Plan. 2001, 70, 108-110.

47. White, I.; Howe, J. Flooding and the Role of Planning in England and Wales: A Critical Review. J. Environ. Plan. Manag. 2002, 45, 735-745. [CrossRef]

48. White, I.; Richards, J. Planning policy and flood risk: The translation of national guidance into local policy. Plan. Pract. Res. 2007, 22, 513-534. [CrossRef]

49. Gralepois, M.; Guevara, S. L'adaptation aux risques d'inondation façonnée par les métiers de la ville. Tensions à l'échelle du projet d'aménagement. Développement Durable Territoires 2015, 6. [CrossRef]

50. Hartmann, T.; Tejo, S. Implementing the European flood risk management plan. J. Environ. Plan. Manag. 2016, 59, 360-377. [CrossRef]

51. Wamsler, C. Mainstreaming Risk Reduction in Urban Planning and Housing: A Challenge for International Aid Organisations. Disasters 2006, 30, 151-177. [CrossRef] [PubMed]

52. Hartmann, T.; Driessen, P. The flood risk management plan: Towards spatial water governance. J. Flood Risk Manag. 2017, 10, 145-154. [CrossRef]

53. Handmer, J. Improving flood warnings in Europe: A research and policy agenda. Global Environmental Change Part B. Environ. Hazards 2001, 3, 19-28. [CrossRef]

54. Rode, S. La prévention du risque d'inondation, facteur de recomposition urbaine? L'Information Géographique 2008, 72, 6-26. [CrossRef]

55. Rode, S. Le chêne ou le roseau: Quelles stratégies de gestion du risque d'inondation en France? Cybergeo 2012, document 603. [CrossRef]

56. Alexander, M.; Priest, S.J.; Micou, P.; Tapsell, S.M.; Green, C.H.; Parker, D.J.; Homewood, S. Analysing and Evaluating Flood Risk Governance in England-Enhancing Societal Resilience through Comprehensive and Aligned Flood Risk Governance Arrangements; Middlesex University: London, UK, 2016.

57. Kaufmann, M.; van Doorn-Hoekveld, W.J.; Gilissen, H.K.; Van Rijswick, M. Analysing and Evaluating Flood Risk Governance in the Netherlands: Drowning in Safety; STARFLOOD Consortium: Utrecht, The Netherlands, 2016; ISBN 94-91933-11-6.

58. Larrue, C.; Bruzzone, S.; Lévy, L.; Gralepois, M.; Schellenberger, T.; Trémorin, J.-B.; Fournier, M.; Manson, C.; Thuillier, T. Analysing and Evaluating Flood Risk Governance in France: From State Policy to Local Strategies. Country Report: France; CITERES: Tours, France, 2016. 
59. Gatien-Tournat, A.; Gralepois, M.; Fournier, M.; Bonnefond, M.; Servain, S. The French Country Report: Societal Transformation and Adaptation Necessary to Manage Dynamics in Flood Hazard and Risk Mitigation; JPI Climate Funding: Tours, France, 2016.

60. Mees, H.; Uittenbroek, C.J. The Dutch Country Report-Societal Transformation and Adaptation Necessary to Manage Dynamics in Flood Hazard and Risk Mitigation; JPI Climate Funding: Utrehct, The Netherlands, 2016.

61. Thaler, T.; Attems, M.-S.; Bonnefond, M.; Clarke, D.; Gatien-Tournat, A.; Gralepois, M.; Fournier, M.; Murphy, C.; Rauter, M.; Papathoma-Köhle, M. Drivers and barriers of adaptation initiatives-How societal transformation affects natural hazard management and risk mitigation in Europe. Sci. Total Environ. 2019, 650, 1073-1082. [CrossRef]

62. Ministry of Housing, Communities \& Local Government Plan-Making. Guidance on Plan-Making. Available online: https://www.gov.uk/guidance/plan-making (accessed on 14 April 2020).

63. Planning Portal Planning Permission. Available online: https://www.planningportal.co.uk/info/200127/ planning/102/about_the_planning_system/4 (accessed on 14 April 2020).

64. Department for Environment, Food \& Rural Affairs, E.A. Flood Risk Assessment: Standing Advice. Available online: https://www.gov.uk/guidance/flood-risk-assessment-standing-advice (accessed on 14 April 2020).

65. Mees, H.; Uittenbroek, C.; Hegger, D.; Driessen, P. From citizen participation to government participation: An exploration of the roles of local governments in community initiatives for climate change adaptation in the Netherlands. Environ. Sci. Policy 2019, 29, 198-208. [CrossRef]

66. Klein, J.; Araos, M.; Karimo, A.; Heikkinen, M.; Ylä-Anttila, T.; Juhola, S. The role of the private sector and citizens in urban climate change adaptation: Evidence from a global assessment of large cities. Glob. Environ. Chang. 2018, 53, 127-136. [CrossRef]

67. Gralepois, M. Face aux Risques D'inondation. Entre Prévention et Négociation; Rue d'Ulm Éditions: Paris, France, 2012; ISBN 2-7288-0478-8.

68. Gralepois, M. Les Risques Collectifs Dans les Agglomérations Françaises à Travers le Parcours Des Agents Administratifs Locaux. Ph.D. Thesis, Université Paris-Est, Paris, France, November 2008.

69. Barraqué, B. The common property issue in flood control through land use in France. J. Flood Risk Manag. 2017, 10, 182-194. [CrossRef]

70. Martinais, E. La cartographie au service de l'action publique. EspacesTemps.net 2007, Travaux, 8.

71. Bourhis, J.-P.L. Du savoir cartographique au pouvoir bureaucratique. Les cartes des zones inondables dans la politique des risques (1970-2000). Geneses 2007, 68, 75-96. [CrossRef]

72. Pigeon, P. Les Plans de Prévention des Risques (PPR): Essai d'interprétation géographique. Géocarrefour 2007, 82, 27-34. [CrossRef]

73. Fournier, M.; Larrue, C.; Schellenberger, T. Changes in flood risk governance in France: A David and Goliath story? J. Flood Risk Manag. 2018, 11, 261-270. [CrossRef]

74. Gralepois, M. Négociation et controverse des périmètres de prévention des risques. In Habiter les Territoires à Risques; November, V., Penelas, M., Viot, P., Eds.; Presse Universitaire de Lausanne: Lausanne, Suisse, 2011; pp. 121-140.

75. Tricot, A.; Labussière, O. Les difficultés d'application des plans de prévention en France: Lorsque le territoire façonne le risque. Cah. Geogr. Que. 2009, 53, 119-134. [CrossRef]

76. Bruzzone, S.; Levy, L.; Fournier, M. When the risk becomes opportunity: Flooding as possibility for urban agglomerations to affirm themselves in local governance. 2015.

77. de Moel, H.; Aerts, J.C.J.H. Effect of uncertainty in land use, damage models and inundation depth on flood damage estimates. Nat. Hazards 2011, 58, 407-425. [CrossRef]

78. Kaufmann, M.; Priest, S.J.; Leroy, P. The undebated issue of justice: Silent discourses in Dutch flood risk management. Reg. Environ. Chang. 2018, 18, 325-337. [CrossRef]

79. van Ruiten, L.J.; Hartmann, T. The spatial turn and the scenario approach in flood risk management-Implementing the European Floods Directive in the Netherlands. AIMS Environ. Sci. 2016, 3, 697. [CrossRef] 
80. Steenstra, M.; Kwadijk, F. Evaluatie Watertoets 2010: Rapportage Fase 1: Recapitulatie en Inventarisatie Relevante Nieuwe Ontwikkelingen; Association of Dutch Provinces (IPO), Association of Dutch Municipalities (VNG), Association of Dutch Water Authorities (UvW), Ministry of Infrastructure and Environment, Ministry of Economy; Ministry of Economic Affairs, Agriculture and Innovation; Rijkswaterstaat: Utrecht, The Netherlands, 2010.

81. Van Rijswick, M.; van Rijswick, H.; Havekes, H.J. European and Dutch Water Law; UWA Publishing: Perth, Australia, 2012; ISBN 90-8952-107-0.

82. Hooimeijer, F.; Tummers, L. Integrating subsurface management into spatial planning in the Netherlands, Sweden and Flanders. Proc. Inst. Civ. Eng. Urban Des. Plan. 2017, 170, 161-172. [CrossRef]

83. Driessen, P.; Hegger, D.; Kundzewicz, Z.; Van Rijswick, H.; Crabbé, A.; Larrue, C.; Matczak, P.; Pettersson, M.; Priest, S.; Suykens, C.; et al. Governance Strategies for Improving Flood Resilience in the Face of Climate Change. Water 2018, 10, 1595. [CrossRef]

84. Leroy, P.; Arts, B. Institutional Dynamics in Environmental Governance; Springer: New York, NY, USA, 2006; ISBN 978-1-4020-5079-4.

85. de Bruijn, K. Resilience and flood risk management. Water Policy 2004, 6, 53-66. [CrossRef]

86. Rode, S.; Langumier, J. Vive la règle pour le projet! L'articulation de la règle et du projet au service de la résilience urbaine à l'inondation. In Adaptation, Résilience, Réversibilité, Transition: De Nouveaux Enjeux Pour le Projet? Scarwell, H.-J., Ed.; Peter Lang: Bern, Germany, 2019.

87. Raadgever, T.; Hegger, D. Flood Risk Management Strategies and Governance; Springer: New York, NY, USA, 2018; ISBN 978-3-319-67698-2.

88. Porter, J.; Demeritt, D. Flood-Risk Management, Mapping, and Planning: The Institutional Politics of Decision Support in England. Environ. Plan A 2012, 44, 2359-2378. [CrossRef]

89. Vojtek, M.; Vojteková, J. Flood maps and their potential role in local spatial planning: A case study from Slovakia. Water Policy 2018, 20, 1042-1058. [CrossRef]

90. Pappenberger, F.; Beven, K.J.; Ratto, M.; Matgen, P. Multi-method global sensitivity analysis of flood inundation models. Adv. Water Resour. 2008, 31, 1-14. [CrossRef]

91. Hegger, D.; Mees, H.; Driessen, P.; Runhaar, H.A. The Roles of Residents in Climate Adaptation: A systematic review in the case of the Netherlands. Environ. Policy Gov. 2017, 27, 336-350. [CrossRef]

92. Klein, J.; Juhola, S.; Landauer, M. Local authorities and the engagement of private actors in climate change adaptation. Environ. Plan. C Politics Space 2017, 35, 1055-1074. [CrossRef]

93. Rode, S.; Gralepois, M. Towards an Urban Design Adapted to Flood Risks? In Floods: Volume 2-Risk Management; Vinet, F., Ed.; Elsevier: Amsterdam, The Netherlands, 2017; pp. 365-380, ISBN 978-0-08-102384-6.

(C) 2020 by the author. Licensee MDPI, Basel, Switzerland. This article is an open access article distributed under the terms and conditions of the Creative Commons Attribution (CC BY) license (http://creativecommons.org/licenses/by/4.0/). 

MDPI

St. Alban-Anlage 66

4052 Basel

Switzerland

Tel. +41 616837734

Fax +41 613028918

www.mdpi.com

Water Editorial Office

E-mail: water@mdpi.com www.mdpi.com/journal/water

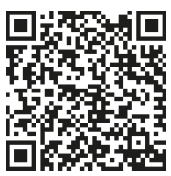



MDPI

St. Alban-Anlage 66

4052 Basel

Switzerland

Tel: +41 616837734

Fax: +41 613028918 